\title{
TÓPICOS EM \\ CIÊNCIAS DA SAÚDE
}

VOLUME VII

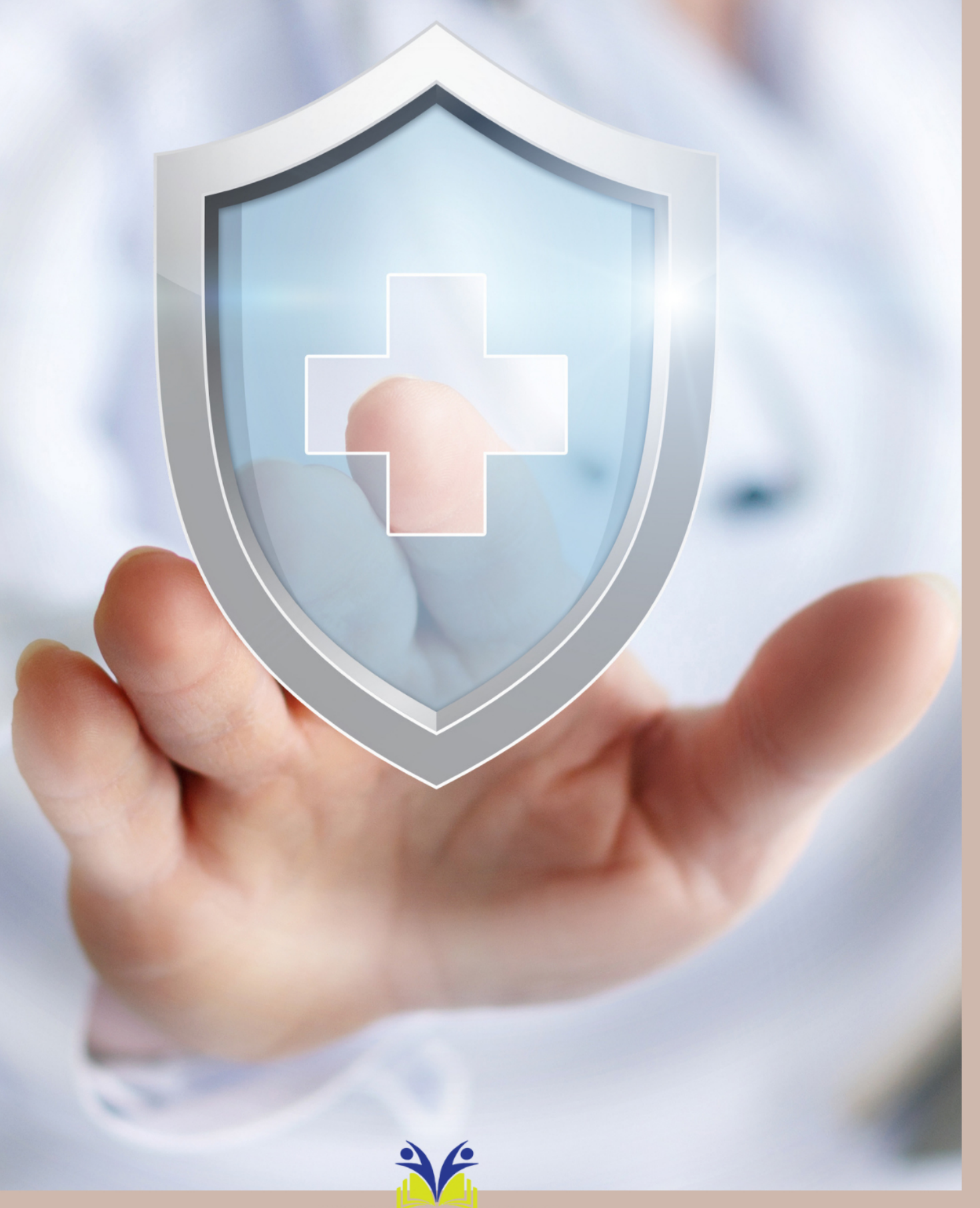


Frederico Celestino Barbosa

Tópicos em ciências da saúde

$7^{\mathrm{a}} \mathrm{ed}$.

Piracanjuba-GO

Editora Conhecimento Livre

Piracanjuba-GO 
$7^{\mathrm{a}} \mathrm{ed}$

\title{
Dados Internacionais de Catalogação na Publicação (CIP)
}

\author{
Barbosa, Frederico Celestino \\ B238T Tópicos em ciências da saúde \\ / Frederico Celestino Barbosa. - Piracanjuba-GO
}

Editora Conhecimento Livre, 2021

$$
259 \text { f.: il }
$$

DOI: $10.37423 / 2021$.edcl 353

ISBN: 978-65-89955-97-9

Modo de acesso: World Wide Web

Incluir Bibliografia

1. equipe-multidisciplinar 2. prevenção 3. tratamento 4. cuidados I. Barbosa, Frederico Celestino II.

Título

CDU: 613

https://doi.org/10.37423/2021.edc1353

O conteúdo dos artigos e sua correção ortográfica são de responsabilidade exclusiva dos seus respectivos autores. 


\title{
EDITORA CONHECIMENTO LIVRE
}

\section{Corpo Editorial}

\author{
Dr. João Luís Ribeiro Ulhôa \\ Dra. Eyde Cristianne Saraiva-Bonatto \\ Dr. Anderson Reis de Sousa \\ MSc. Frederico Celestino Barbosa \\ MSc. Carlos Eduardo de Oliveira Gontijo
}

$\underline{\text { MSc. Plínio Ferreira Pires }}$

Editora Conhecimento Livre

Piracanjuba-GO 


\section{SUMÁRIO}

CAPÍTULO 1

INSUFICIÊNCIA VALVAR AÓRTICA E SUA PROPEDÊUTICA

Pedro Victor de Arruda Armelin

Daniela Boscoli da Sllva Noma Boigues

DOI 10.37423/211004814

CAPÍTULO 2

BENEFÍCIOS DA AURICULOTERAPIA EM PACIENTES COM DORES CRÔNICAS

Fabrício Vieira Cavalcante

Márcia Regina Pinez Mendes

Paula Darliny da Silva Ferreira

DOI 10.37423/211004817

CAPÍTULO 3

UM ESTUDO SOBRE FIBROMIALGIA E OS BENEFÍCIOS DA ATIVIDADE FÍSICA ORIENTADA POR PROFISSIONAL DE EDUCAÇÃO FÍSICA

Weigler Serafim Azarias

Luis Eduardo Moraes Sinésio

DOI 10.37423/211004820

CAPÍTULO 4

AVALIAÇÃO DA COBERTURA VACINAL DE CRIANÇAS MENORES DE 5 ANOS NO HAITI 2016-2018

Cirina Bayard

Olbichoo Lexius

Maria de Nazaré de Souza Ribeiro

Edinilza Ribeiro dos Santos

Gianne Zupelari dos Santos Melo

DOI 10.37423/211004852

CAPÍTULO 5 66

VULNERABILIDADE DAS ISTS EM ADULTOS JOVENS NO BRASIL: PERFIL E SEXUALIDADE.

Kamyla Chicarolli da Cunha

Priscila Moraes Henrique Paiva

DOI 10.37423/211004881 
A INFLUÊNCIA DA LIRAGLUTIDA NOS RECEPTOR GLP-1 DURANTE O PROCESSO DE

EMAGRECIMENTO

Raquel Araújo de Carvalho

Valdemiro Freitas Neto

Rômulo Diego Marinho Siqueira

Paula Simplicio Viana de Carvalho

Clara Simplício Viana de Carvalho

Yuri Nascimento Fróes

Flaviana Manuella Froés Abreu Pavão

João Jorge Jinkings Pavão Filho

Darlan Ferreira da Silva

Maria Raimunda Chagas Da Silva

DOI 10.37423/211004889

CAPÍTULO 7

CORONAVÍRUS

Pedro Victor de Arruda Armelin

DOI 10.37423/211004898

CAPÍTULO 8

A PERCEPÇÃO DO ENFERMEIRO FRENTE A EUTANÁSIA

Ciliana Antero Guimarães da Silva

Gabriel Henrique Carvalho Dionizio

Sarah do Couto Barbosa

DOI 10.37423/211004902

CAPÍTULO 9

DIVULGAÇÃO CIENTÍFICA E INCLUSÃO SOCIAL ATRAVÉS DE SITES ACESSÍVEIS: NOVOS CENÁRIOS EM VELHOS PROBLEMAS

Luciana Fernandes Rêgo

Neuza Rejane Wille Lima

DOI 10.37423/211004904

CAPÍTULO 10

PRINCIPAIS CAUSAS DE INFERTILIDADE FEMININA E OS BENEFÍCIOS DOS MÉTODOS DE CRIOPRESERVAÇÃO: UMA REVISÃO BIBLIOGRÁFICA

Gabriela Eugênio de Aguiar

Maria Clara Borges Nani

Giulia Maria de Castro Bani

Thiago Franco Nasser

DOI 10.37423/211004906 
SINDROME DE RAPUNZEL: TRICOBEZOAR GASTRODUODENAL GIGANTE ANA ANGELICA DE ARAUJO MEDEIROS

ALIANDRO WILLY DUARTE MAGALHAES

DOI 10.37423/211004918

CAPÍTULO 12

DIABETES MELLITUS E COMPORTAMENTO ALIMENTAR: OS RISCOS E IMPACTOS DE UM

TRATAMENTO PAUTADO NUMA ALIMENTAÇÃO RESTRITIVA

Camila Maria Mont'Alverne Frota

Kaline Sádie Sauaia Alves

Ananda da Silva Araujo Nascimento

Eduarda Gomes Bogéa

Júlio César da Costa Machado

DOI 10.37423/211004927

CAPÍTULO 13

VIVÊNCIA DE IDOSOS EM INSTITUIÇÃO DE LONGA PERMANÊNCIA EM JOÃO PESSOA - PB:

RELATO DE EXPERIÊNCIA

Matheus de Sousa Carvalho

Laís Clark de Carvalho Barbosa

Letícia Diniz Aranda

Vívian Maria Vieira Moura de Holanda

DOI 10.37423/211004928

CAPÍTULO 14

PREVENÇAO DO CANCER CERVICO UTERINO; FATORES PARA NAO REALIZAÇAO

ALIANDRO WILLY DUARTE MAGALHAES

ANA ANGELICA DE ARAUJO MEDEIROS

DOI 10.37423/211004933

CAPÍTULO 15

EXÉRESE DE DISPLASIA CEMENTO-ÓSSEA PERIAPICAL ASSOCIADA À APICECTOMIA E ENXERTIA COM PLASMA RICO EM FIBRINA (PRF) - RELATO DE CASO

Alexia Cristina da Cruz Gatti

Laís Santos do Nascimento

Caroline Águeda Corrêa

Bruno Augusto Benevenuto de Andrade

Fabiano Luiz Heggendorn

DOI 10.37423/211004946 
UNIDADES HEMOTERÁPICAS E HEMOCENTROS DO SUL DE MINAS GERAIS: IMPACTOS DA PANDEMIA DA COVID-19 NOS ESTOQUES DE BOLSAS DE SANGUE E GESTÃO DOS

SERVIÇOS

Ana Cláudia de Oliveira Silva

Roberta Ribeiro de Carvalho

Amilton Marques

DOI 10.37423/211104956

CAPÍTULO 17

AVALIAÇÃO DO GRAU DE CONHECIMENTO EM ALUNAS DE ÂMBITO UNIVERSITÁRIO

SOBRE A CANDIDÍASE VULVOVAGINAL

Milena Oliveira

Ana Clara Mendes

Hadassa Cristhina de Azevedo dos Santos

DOI 10.37423/211104957

CAPÍTULO 18

CONHECIMENTO, EXPECTATIVAS E PREFERÊNCIAS DOS HOMENS SOBRE O CÂNCER DE PRÓSTATA E O TOQUE RETAL

Geraldo de Azevedo Souza

Matheus de Azevedo Souza

José Fernandes Neto

Victor de Azevedo Souza

Lucas Praxedes Barreto

DOI 10.37423/211104969 


\section{Capítulo 1}

\section{doi $10.37423 / 211004814$}

\section{INSUFICIÊNCIA VALVAR AÓRTICA E SUA PROPEDÊUTICA}

Pedro Victor de Arruda Armelin

Daniela Boscoli da SIlva Noma Boigues

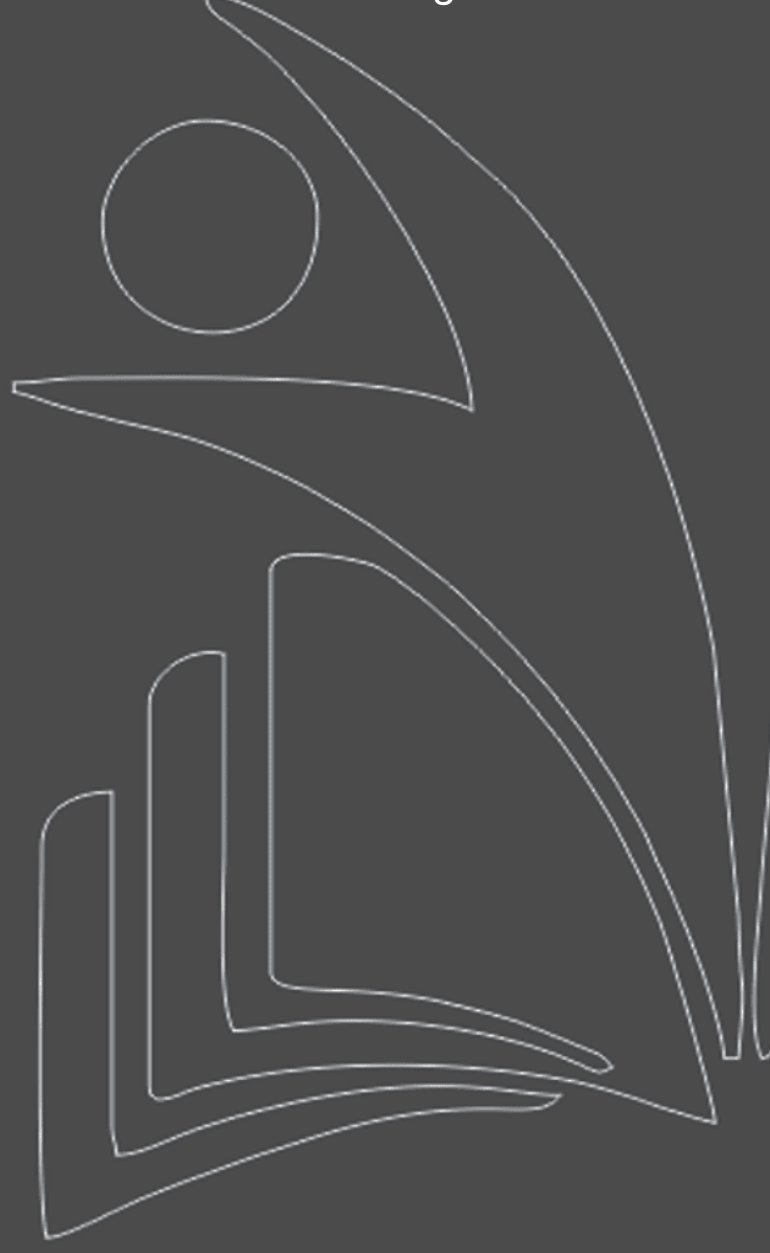

Universidade do Oeste Paulista - UNOESTE. Campus Presidente Prudente SP

Universidade do Oeste Paulista - UNOESTE. Campus Presidente Prydente SP

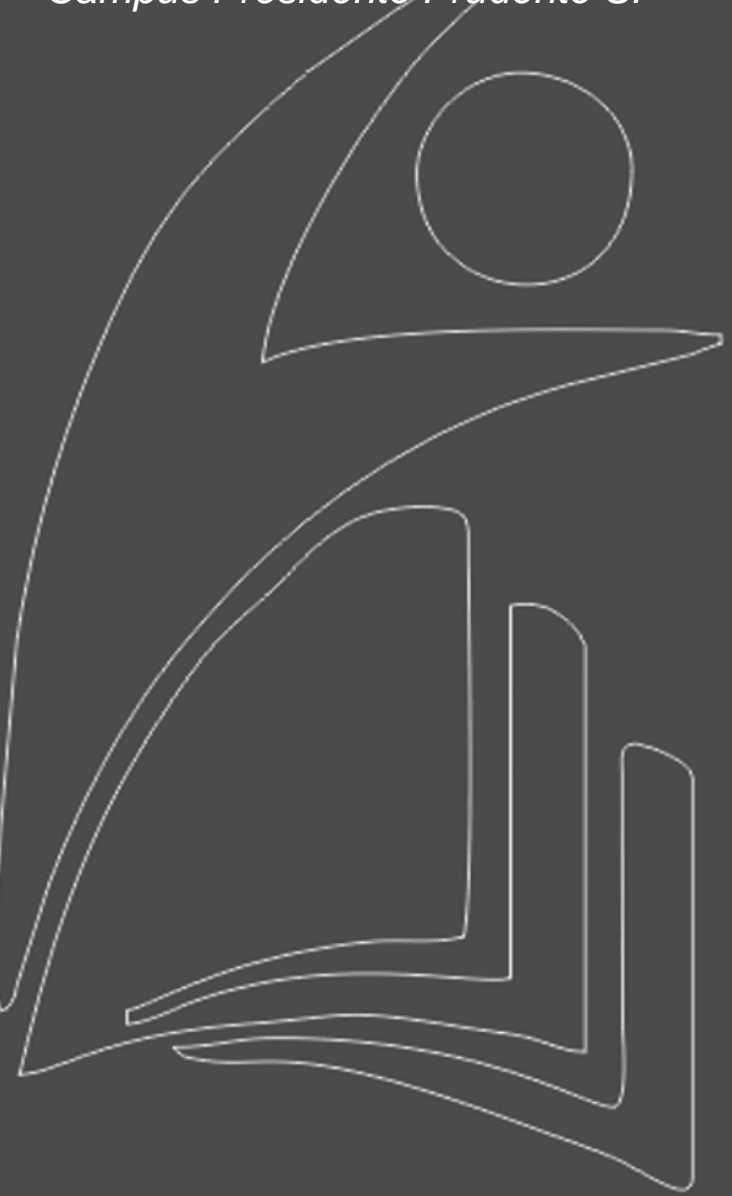




\section{Insuficiência Valvar Aórtica}

A válvula aórtica é responsável pelo controle do fluxo sanguíneo que sai do coração quando ele realiza o movimento de sístole e diástole. Dessa maneira, um coração saudável consegue manter um bom fluxo sanguíneo na artéria durante a contração e relaxamento do ventrículo. Ao contrário disso, a insuficiência valvar aórtica representa um problema na válvula aórtica que a faz fechar parcialmente, possibilitando a volta do fluxo sanguíneo para o ventrículo esquerdo e assim, gerando uma sobrecarga de volume que com o tempo, pode trazer sérios riscos para o coração. ${ }^{(1,2)}$ Dados epidemiológicos sobre a patologia não são tão conhecidos na literatura, mas de acordo com alguns estudos de coorte realizados por Framingham Heart Study pode-se dizer que a doença é mais comum no sexo masculino e se agrava de acordo com a idade do paciente. ${ }^{(2)}$

Tal patologia pode ser causada por vários fatores, dentre eles estão a febre reumática, endocardite infecciosa e sífilis/espondilite anquilosante. Quando a valvopatia é causada por febre reumática, devese atentar a fibrose causada pelo processo cicatricial da doença. O diagnóstico pode ser feito por exame físico através dos sintomas apresentados pelo paciente, porém como a doença pode ser assintomática, é viável fazer uso de exames mais específicos como eletrocardiograma, radiografia ou tomografia de tórax, ecocardiograma, ressonância magnética, e em alguns casos, estudos hemodinâmicos para verificar a elevação da pressão de enchimento e regurgitação aórtica. 0 tratamento da doença é cirúrgico e consiste em cirurgia de troca valvar ou implante valvar transcateter. ${ }^{(3)}$

\section{RELATO DE CASO}

O caso em questão trata- se de um paciente do sexo masculino com 62 anos de idade que apresenta insuficiência valvar aórtica. Portanto, esse paciente deverá passar por 4 exames físicos para ser avaliado sinais e sintomas possíveis apresentados pela doença. São eles, somatoscopia, exame de cabeça e pescoço, exame do aparelho cardiovascular e exame do aparelho respiratório. Somatoscopia

A ectoscopia ou somatoscopia é um exame feito a partir de uma análise geral do paciente, isto é, o médico se baseia nos sintomas apresentados, o estado nutricional do paciente, a forma em que ele se apresenta na consulta e condições de higiene para suspeitar de determinada patologia, ou seja, é uma avaliação subjetiva que leva em consideração a experiência clínica do médico. ${ }^{(4)}$

De acordo com o que foi exposto, o exame de somatoscopia do paciente analisado com insuficiência valvar aórtica, podemos esperar, de uma forma geral, diversos sintomas como por exemplo dispnéia ( 


\section{Insuficiência Valvar Aórtica}

ocorre por aumento da pressão diastólica final secundária à sobrecarga de volume sanguíneo no ventrículo esquerdo, e consequente congestão venocapilar pulmonar), ortopneia, diaforese, dor anginosa (ocorre pela redução da reserva miocárdica), dispneia paroxística noturna (ocorre pela regurgitação valvar decorrente da bradicardia durante o sono), sopro aórtico, sinais periféricos como alteração da pressão sistólica e diastólica, alteração da pulsação de várias partes do corpo, edema (pés, pernas e abdome), entre outros. Vale ressaltar que a sintomatologia pode ser variada e que o paciente pode ir desde a uma fase assintomática, quanto ter sintomas de síncopes frequentes. $(3,4)$

\section{EXAME DA CABEÇA E PESCOÇO}

O exame da cabeça e do pescoço consiste em avaliar de uma maneira geral a cabeça, pescoço, glândulas salivares, gânglios linfáticos, tireóide e os demais vasos do pescoço do paciente. De forma separada, na cabeça é examinado o crânio, cabelo, face, pele, seios da face, olhos e regiões orbitárias, nariz, orelha, boca, faringe, orofaringe, língua, lábios e a cavidade oral. Já no pescoço, o exame consiste em avaliar o estado da pele e tecido celular subcutâneo, bem como a forma, posição e mobilidade do pescoço. Nessa parte também é feita uma avaliação das glândulas salivares e dos vasos linfáticos assim como da traquéia e tireóide. ${ }^{(3)}$ Os sintomas esperados nessa etapa do exame do paciente são sinal de musset (balanço da cabeça para frente a cada batimento cardíaco), sinal de Felleti (balanço da cabeça para trás a cada batimento cardíaco), sinal de Roch-Landolfi ( pulsação das pupilas - miose na sístole e midríase na diástole), sinal de Becker (pulsação visível da arteríola da retina), sinal de Bozzolo ( pulsação dos vasos da mucosa nasal), sinal de Friedrich-Müller (vibração sistólica da úvula), sinal de Huchard ( pulsação das amígdalas), sinal de Minervini (pulsação da base da língua), sinal de Mercklen (pulsação da ponta da língua), sinal de Lighthouse (hiperemia intermitente da face), sinal de Rosenbach (pulso hepático sistólico), e sinal de Gerhard ( pulso esplênico sistólico). ${ }^{(1,3,4,5)}$

\section{EXAME DO APARELHO CARDIOVASCULAR}

Após realizar os exames de somatoscopia, cabeça e pescoço, será feito o exame cardiovascular do paciente, que consiste em avaliar os focos precordiais do coração ( foco aórtico, foco pulmonar, foco tricúspide, foco aórtico acessório e foco mitral), a caixa torácica , o pulso jugular e arterial, e o coração na forma de palpação e ausculta com o auxílio de um estetoscópio (para identificar possíveis anormalidades, desdobramentos ou presença de sopros). ${ }^{(4)}$

O ciclo cardíaco do coração é representado pela sua fase de sístole e diástole. Na fase de contração do coração (sístole) ocorre a chamada contração isovolumétrica e a ejeção sanguínea, e durante essas 


\section{Insuficiência Valvar Aórtica}

fases ocorrem o aumento da pressão sanguínea nos ventrículos e o surgimento das bulhas B1 (válvulas atrioventriculares - bicúspide e tricúspide) e B2 (válvulas pulmonar e aórtica), que representa os sons das válvulas cardíacas no momento em que se fecham para não haver retorno do sangue ejetado para fora do coração. Já na fase de relaxamento isovolumétrica (diástole) , a pressão nos átrios se encontra maior que a pressão dos ventrículos (pressão baixa).Mas por conta do retorno venoso e diferença de pressão, o sangue que chega nos átrios passa direto para os ventrículos, gerando um aumento de volume, caracterizando o enchimento ventricular. ${ }^{(4)}$

Na insuficiência valvar aórtica a ausculta cardíaca da bulha do paciente depende da causa da doença, isto é, se a patologia for causada por algum trauma ou doença da raiz da aorta, a ausculta da bulha B2 pode estar normal ou aumentada, no entanto, caso a causa da regurgitação aórtica for causada por doença valvar, o som se apresenta diminuído ou até mesmo ausente. Se durante o procedimento da ausculta for perceptível a bulha B3, significa que o paciente possui uma sobrecarga de volume no ventrículo esquerdo, promovendo sua dilatação, o que é característico da insuficiência valvar aórtica. ${ }^{(1)}$

Além disso, também são utilizadas técnicas como o "hand grip" e manobras específicas (Rivero Carvallo, Muller, Valsava) para analisar especificamente a pressão aórtica, retorno venoso, sopros, bulhas e outras questões do coração. ${ }^{(4,5)}$ Os sopros são perceptíveis em um paciente com insuficiência aórtica, o sopro diastólico representa uma deficiência valvar durante a fase de relaxamento, e pode tanto o sopro protodiastólico quanto o sopro mesodiastólico e holodiastólico. Os sopros são melhores auscultados no foco aórtico quando o paciente encontra-se na posição sentado, inclinado para frente e expirando. ${ }^{(1)}$

Sendo assim, nesse exame podemos esperar que o paciente tenha alterações no pulso arterial ( quando a insuficiência aórtica é considerada leve, o pulso arterial do paciente encontra-se normal, no entanto, de acordo com a severidade da doença o pulso arterial se torna mais agudo e ascendente podendo gerar uma síncope.) - pulso em martelo d’agua (alteração na amplitude), dança das artérias (pulsação com alto débito), taquicardia, ictus deslocado e coração aumentado de tamanho na palpação, também podem ser encontrados três sopros durante a ausculta, são eles o sopro diastólico aspirativo e decrescente, sopro mesossistólico aórtico (pelo volume sistólico aumentado) e sopro de Austin Flint (resultante do deslocamento da cúspide mitral anterior pelo sangue regurgitado). Além disso, podem ser encontrados sintomas do sinal de Quincke ( pulsação capilar no leito ungueal), sinal de Traube (ausculta de som sistólico e diastólico na artéria femoral), sinal de Duroziez (sopro arterial 


\section{Insuficiência Valvar Aórtica}

femoral sistólico e diastólico quando essa artéria é parcialmente comprimida), sinal de Musset (balanço da cabeça para frente a cada batimento cardíaco) e sinal de Friedrich-Müller ( vibração sistólica da úvula). ${ }^{(1,3,4,5,6)}$

\section{EXAME DO APARELHO RESPIRATÓRIO}

Na última seção do exame físico, o paciente será submetido ao exame do aparelho respiratório, que consiste em analisar o paciente de forma estática (examinação física - tórax, cicatrizes, erupções cutâneas, presença/ausência de ginecomastia, gânglios hipertrofiados ) e dinâmica (examinação dos movimentos respiratórios para detectar possíveis anormalidades). ${ }^{(4)}$ Para isso são utilizadas técnicas de palpação, ausculta e percussão, que contribuem para achados clínicos como possíveis sopros. ${ }^{(4,5,6)}$ Então, de acordo com a patologia da insuficiência valvar aórtica e com as técnicas utilizadas nessa seção do exame, podem ser encontrados sintomas como dispnéia, ortopneia, dor anginosa, edema próximo ao abdome, presença de alterações no timbre de sopros protodiastólicos. $(1,4,5,6)$

Após submeter o paciente às quatro seções do exame físico, e analisar a anamnese juntamente com a história clínica e idade do mesmo, pode-se abordar que as causas patológicas da insuficiência valvar aórtica são muitas, e como já descrito, existem diferentes gravidades para a doença. Sendo assim, o médico pode pedir exames específicos como eletrocardiograma (aponta sobrecarga do ventrículo esquerdo), radiografia do tórax (aponta sinais de dilatação ou ectasia da aorta e ventrículo esquerdo ) e/ou ecocardiograma (demonstra a estrutura e o funcionamento do coração) para confirmar o diagnóstico. ${ }^{(3,7)}$ No entanto, de uma maneira geral, são exemplos de causas que podem levar o paciente a desenvolver a doença: defeito congênito da válvula bicúspide, endocardite infecciosa, febre reumática , algum possível trauma na região do coração (trauma cardíaco ou na região torácica), sífilis, espondilite anquilosante, artrite reumatóide, degeneração mixomatosa, hipertensão arterial sistêmica, dissecção da aorta ascendente, síndrome de marfan (pela degeneração media cística), osteogênese imperfeita, síndrome de Ehlers-Danlos, síndrome de Reiter, estenose subaórtica , aortite, artrite reativa, anormalidade de folhetos valvares induzidos por drogas, acromegalia, ectasia aórtica e até doença intestinal inflamatória. ${ }^{(1,3,4)}$

\section{CONSIDERAÇÕES FINAIS}

Diante de tudo o que foi exposto, e das pesquisas realizada sobre a insuficiência valvar aórtica, é de suma importância abordar o aprendizado adquirido na atividade. Isso porque, o paciente de 62 anos do sexo masculino, mesmo que fictício , passou por quatro seções de exames físicos, e ainda que a 


\section{Insuficiência Valvar Aórtica}

doença possa ser considerada assintomática na fase leve, foi abordado uma lista de causas que geram a patologia, bem como os sintomas esperados na somatoscopia, exames da cabeça e do pescoço, exame cardiovascular e exame do aparelho respiratório. Portanto, durante as quatro seções, foi adquirido experiências do que deve ser feito durante a prática clínica e de como deve ser realizado cada exame, juntamente com quais locais do corpo devem ser examinados para obter presença ou ausência de determinados sintomas, bem como conhecimento de técnicas e manobras cruciais para a realização de cada etapa do exame físico. 


\section{REFERÊNCIAS BIBLIOGRÁFICAS}

(1) Tosetto AD, Dutra CZ, Guaragna JC. Insuficiência aórtica. Acta méd.(Porto Alegre). 2015:7.

(2) Boucher CA, Friedlich AL, Buckley MJ. Capítulo 20-Regurgitação Aórtica. Disponível em < https://www.bibliomed.com.br/bibliomed/books/livro11/cap/cap20.htm >

(3) Tarasoutchi F, Montera MW, Ramos AI, Sampaio RO, Rosa VE, Accorsi TA, Santis AD, Fernandes JR, Pires LJ, Spina GS, Vieira ML. Atualização das Diretrizes Brasileiras de Valvopatias-2020. Arquivos Brasileiros de Cardiologia. 2020 Oct;115(4):720-75.

(4) Rocco JR, editor. Semiologia médica. Elsevier Brasil; 2011 May 9.

(5) Benseñor IM, Atta JA, Martins M de A. Semiologia clinica. 2002 ;

(6) Bates B, Hoekelman RA, Bickley LS. Propedêutica médica. México: Harla; 1992.

(7) Alsidawi S. Avaliação da Insuficiência Valvar Aórtica por Ecocardiografia: Conceitos Básicos e Novos. Arquivos Brasileiros de Cardiologia. 2020 Aug;115(2):261-2. 


\section{Capítulo 2}

\section{doi $10.37423 / 211004817$}

\section{BENEFÍCIOS DA AURICULOTERAPIA EM PACIENTES COM DORES CRÔNICAS}

Fabrício Vieira Cavalcante

Márcia Regina Pinez Mendes

Paula Darliny da Silva Fèreira

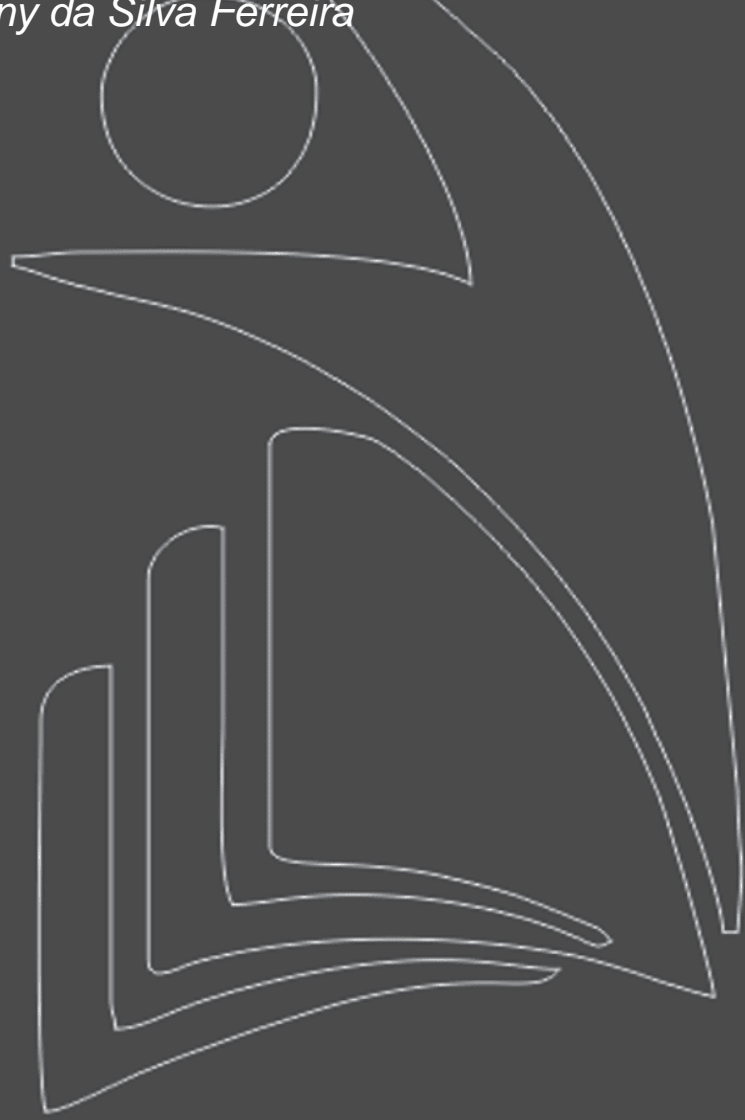

Universidade de Brasília

Universidad Internacional/beroamericana

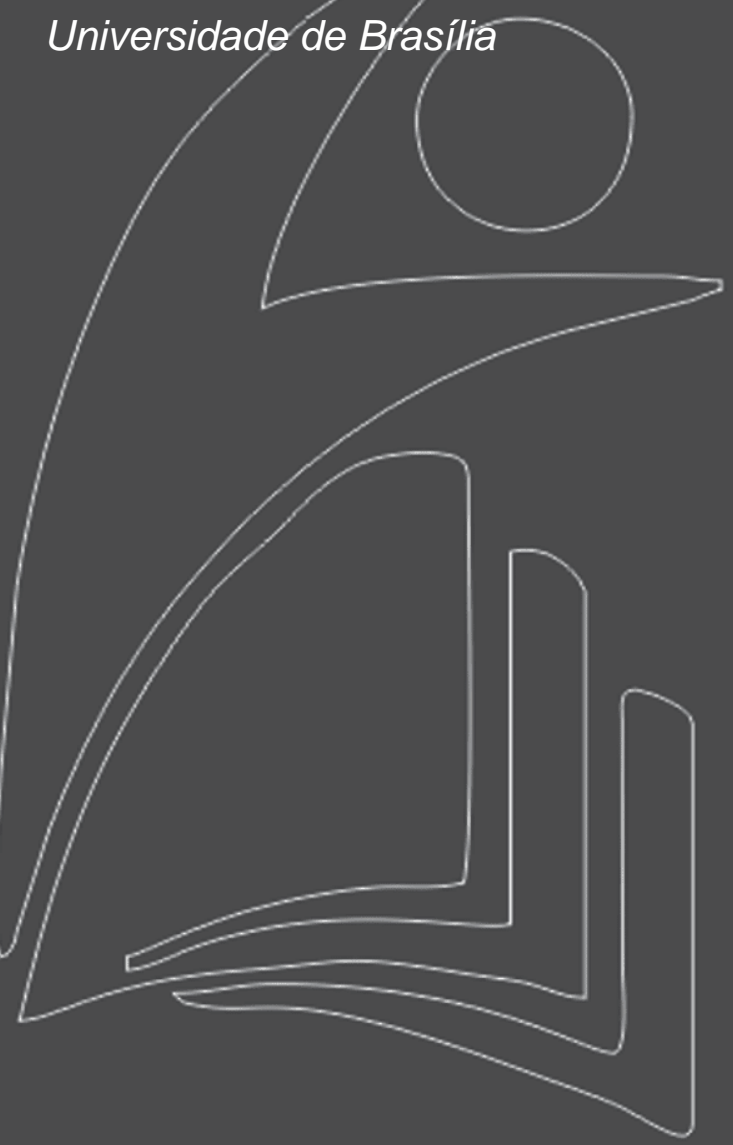




\section{Benefícios Da Auriculoterapia Em Pacientes Com Dores Crônicas}

Resumo: As Práticas Integrativas e Complementares (PICs) compreendem um conjunto de técnicas não-farmacológicas, onde vários recursos terapêuticos estão inseridos dentro da chamada Medicina Tradicional Chinesa (MTC). A acupuntura é considerada um desses recursos, que permite o estímulo preciso de locais anatômicos espalhados por todo o corpo através da inserção de agulhas, sementes, prata, ouro, dentre outros materiais. Esses materiais funcionam como pivôs para intermediar o fluxo energético, pois a obstrução desses fluxos, prejudicam a correta circulação sanguínea, resultando no aparecimento de pontos doloros. A acupuntura tem sido indicada para a prevenção de agravos em doenças, bem como para a manutenção e recuperação da saúde, podendo fazer uso dos acupontos do pavilhão auricular, sendo então conhecida como auriculoterapia ou auriculopuntura. Sabe-se que esse pavilhão auricular possui uma relação direta com os órgãos internos, estando conectado ao sistema nervoso, onde o estímulo dessas zonas energéticas localizadas na região da orelha pode promover a sensação de analgesia da dor, devido a liberação de neurotransmissores e outras substâncias. A auriculoterapia é recomendada para os mais diversos tipos de patologias, com mais de 200 enfermidades descritas como passíveis desse tipo de tratamento, incluindo as mais diversas dores agudas ou crônicas, podendo ainda potencializar os resultados na recuperação de doenças, quando realizada em conjunto a outros tratamentos. Quando as dores do indivíduo são crônicas, os sintomas tendem a se acumular com o tempo, causando sofrimento ao portador, podendo acarretar em consequências biopsicossociais, e chegando até mesmo a afastar o indivíduo de suas atividades rotineiras. Nesse sentido, esse estudo propõe uma busca na literatura atual que apontem evidências científicas dos benefícios do tratamento de auriculoterapia em pacientes que sofrem com dores crônicas, utilizando-se como base o método de revisão integrativa da literatura.

Palavras-chave: Acupuntura. Pavilhão auricular. Saúde. Medicina Tradicional Chinesa. Equílibrio Energético. 


\section{INTRODUÇÃO}

A acupuntura é uma tecnologia de intervenção em saúde que faz parte dos recursos terapêuticos da medicina tradicional chinesa (MTC), permitindo o estímulo preciso de locais anatômicos espalhados por todo o corpo, por meio da inserção de agulhas metálicas filiformes (BRASIL, 2018). Essa técnica tem sido indicada para a prevenção de agravos em doenças, bem como para a manutenção e recuperação da saúde (BRASIL, 2012).

A Medicina Tradicional Chinesa baseia-se na filosofia taoísta sobre as composições energéticas, onde o indivíduo é visto como parte integrante do universo (DA SILVA, 1997). Segundo essa filosofia, o ser é constituído por um conjunto de energias provenientes do céu e da terra que fluem por todo o indivíduo, devendo estar em constante equilíbrio, sendo o TAO o equilíbrio perfeito entre essas duas forças opostas conectadas (WEN, 1989; DA SILVA, 1997). Nesse sentido, o corpo humano é a acomodação de espíritos chamados Shen (estrutura mental), onde cada órgão do corpo é alojado por um determinado espírito, e as doenças seriam resultados da invasão de energias perversas (DULCETTI $J R, 2001)$.

O reequilíbrio e a manutenção dessas energias devem ser feitos através da aplicação de finas agulhas em pontos específicos, que funcionam como pivôs para intermediar o fluxo energético do celestial e terrestre (Yang/Yin), que o Homem recebe do meio (DULCETTI JR, 2001). Nesse sentido, o organismo humano é considerado um sistema integrado, único e independente (CHONGHUO, 1993), onde a saúde do indivíduo dependerá da harmonia vibratória, que quando fora de equilíbrio, deverá ser analisado e reequilibrado, sendo o homem quem deverá administrar seu próprio organismo em relação à saúde e a doença (CORDEIRO \& CORDEIRO, 2001).

As Práticas Integrativas e Complementares (PICs) compreendem um conjunto de técnicas nãofarmacológicas, como a Medicina Tradicional Chinesa (MTC), Homeopatia, Plantas medicinais/ fitoterapia, Termalismo social/crenoterapia, Arteterapia, Biodança, Meditação, Musicoterapia, Reiki, Quiropraxia, dentre outras modalidades (BRASIL, 2017). A busca por tratamentos alternativos e tradicionais, como a MTC, Medicina Ayurvedica, Homeopatia, terapias corporais e energéticas, vem aumentando mais a cada dia. Considerando esse cenário, a Organização Mundial da Saúde (OMS) lançou um texto que fala sobre a "Estratégia da OMS sobre a Medicina Tradicional", visando promover uma utilização segura e eficaz destas técnicas, através da regulamentação de produtos, práticas e profissionais (WHO, 2013). No Brasil, o Ministério da Saúde incorporou no Sistema Único de Saúde (SUS), a Política Nacional de Práticas Integrativas e Complementares (PNPICS) - Portaria Nº 971, com 
o intuito de padronizar experiências e garantir a integralidade e acessibilidade nos centros de referência destas atividades (BRASIL, 2006; BRASIL, 2017). Nos anos posteriores, a PNPICS sofreu novas alterações, com a adição de novas práticas por meio das portarias $\mathrm{N}^{\circ}-849$ e $\mathrm{N}^{\circ}-702$ (BRASIL, 2017; BRASIL, 2018).

Dentre as técnicas da MTC, a acupuntura pode ainda fazer o uso terapêutico do pavilhão auricular, sendo popularmente conhecida como auriculoterapia ou auriculopuntura. Há relatos históricos que apontam o interesse de diferentes civilizações antigas pelo órgão de audição, em especial os chineses, que de acordo com escrituras antigas, acreditavam que a orelha era um órgão isolado que mantinha estreita relação com todo o corpo humano (NEVES, 2009). A auriculoterapia trata-se de uma técnica terapêutica que promove a regulação psíquico-orgânica do indivíduo por meio do estímulo de pontos neurorreativos localizados na orelha, com a aplicação de esferas de aço, agulhas, sementes de mostardas, ouro, prata ou plástico (BRASIL, 2018). O estímulo dessas zonas energéticas por meio da acupuntura, podem promover a sensação de analgesia da dor, devido a liberação de neurotransmissores e outras substâncias no organismo, pois o pavilhão auricular está conectado ao sistema nervoso, sendo desencadeadas cascatas neuroendócrinas como resposta ao estímulo, que promovem então o reequilíbrio energético do órgão afetado (REGO, 2011; BRASIL, 2019).

O pavilhão auricular possui uma relação com os órgãos, sendo conhecido como o palácio do rim, que tem sua porta de entrada através do ouvido, onde ambos apresentam forma anatômica similar. Quando algum meridiano é obstruído prejudicando a correta circulação sanguínea, a energia perde seu fluxo, aparecendo pontos dolorosos na orelha como uma reação reflexa (NEVES, 2009). Esses pontos representam todo o corpo, onde cada ponto representa um órgão ou estrutura do corpo humano que atua de maneira simples e ampla (TOLENTINO, 2016). A auriculoterapia é recomendada para os mais diversos tipos de patologias, sendo descritas mais de 200 enfermidades passíveis desse tipo de tratamento, tais como: cefaléias, ansiedade, insônia, depressão, dispepsias, e as mais diversas dores agudas ou crônicas, podendo ainda potencializar o tratamento de doenças quando realizada em conjunto a outros tratamentos (SOUZA, 2010; KUREBAYASHI et al., 2017).

São inúmeros os casos em que a acupuntura e auriculoterapia podem ser indicadas, com destaque para as doenças crônicas e incapacitantes que podem provocar muita dor e incômodo aos seus portadores, interferindo diretamente na sua qualidade de vida (BRASIL, 2008). A dor é subjetiva, sendo interpretada de maneira única para cada indivíduo, a partir de suas próprias experiências, podendo ou não ter um sintoma físico (BRASIL,2008). Quando as dores do indivíduo são crônicas, resultam do 


\section{Benefícios Da Auriculoterapia Em Pacientes Com Dores Crônicas}

acumulo desse sintoma no decorrer do tempo, causando sofrimento ao portador, podendo acarretar em consequências biopsicossociais, chegando até mesmo a afastar o indivíduo de suas atividades rotineiras (BAKER et al., 2010; OLIVEIRA et al., 2013). Alguns estudos demonstram a eficiência da auriculoterapia para a diminuição desse sofrimento nos pacientes, como Tolentino (2016), que demonstrou significativo declínio da dor em indivíduos tratados com auriculopuntura, independente do material utilizado (agulha ou semente). Kurebayashi (2017) também relata os benefícios desse tratamento na redução da dor, através do uso de agulhas. E Martins (2017) realizou um estudo, onde constatou uma redução de 70\% nas dores crônicas após sessão de acupuntura, através de escala analógica.

É importante ressaltar, que a utilização das práticas integrativas complementares para os mais diversos tratamentos, tornam o paciente corresponsável pelo seu processo de melhora, podendo por exemplo, reduzir significativamente a medicação ao longo do tratamento convencional do paciente, reduzindo também qualquer efeito colateral que possa ser desencadeado por ela (MARTINS, 2017).

Haja vista, que o presente trabalho justifica-se pela escassez de informações sobre o uso da auriculoterapia em dores crônicas como estratégia de analgesia e melhoria da qualidade de vida. Com isso, o presente trabalho tem como objetivo descrever as evidências científicas sobre os benefícios e utilização da auriculoterapia para o tratamento de pacientes com patologias crônicas, utilizando-se como base a revisão integrativa da literatura.

\section{REFERÊNCIAL TEÓRICO}

\subsection{CONCEITO E HISTÓRICO DA MEDICINA TRADICIONAL CHINESA E ACUPUNTURA}

\subsubsection{MEDICINA TRADICIONAL CHINESA}

A Medicina Tradicional Chinesa (MTC), visa o equilíbrio energético na interação entre o homem e a natureza, tendo como principal foco o perfeito funcionamento entre os fatores internos e externos para lidar com as agressões que o corpo humano vai sofrendo no decorrer da sua vida (WEN, 1985). A MTC tem base na filosofia taoísta, sendo o Tao o equilíbrio entre duas forças opostas conectadas, uma dualidade perfeita entre a energia celestial (QI cósmico) e terrestre (QI telúrico), o Yang (QI cósmico) com o Yin (QI telúrico) (WEN, 1985; DA SILVA, 1997).

Segundo essa filosofia, o indivíduo é constituído por um conjunto de energias provenientes do céu e da terra que fluem por todo o seu corpo, devendo estar em constante equilíbrio, onde as doenças 


\section{Benefícios Da Auriculoterapia Em Pacientes Com Dores Crônicas}

seriam resultados da invasão de energias perversas (WEN, 1989; DA SILVA, 1997; DULCETTI JR, 2001). A principal característica do Tao é a sua natureza de constante mudança, onde todos os acontecimentos apresentam um padrão cíclico de expansão e contração, sendo essas manifestações geradas pela interação dinâmica dessas duas forças polarizadas (DA SILVA, 1997).

A MTC tem seus primeiros registros datados de 5000 a.C. com informações codificadas muitas vezes em forma de poesias, músicas, imagens e em livros antigos. Esses registros apesar de expressos em diferentes conceitos, implicam sempre em uma mudança do estilo de vida, ressaltando a necessidade do papel fundamental de prevenção (ABE, 2006).

Além do taoísmo, a MTC também tem o budismo e o confucionismo como pilares filosóficos, sendo as doenças consideradas como caminhos para contribuir com uma transformação pessoal. Na MTC as doenças não são consideradas fatos isolados, mas sim integrantes de um processo geral, ressaltando a necessidade de mudanças de hábitos e costumes do indivíduo, que de alguma forma possa ter contribuído para o seu adoecimento (ABE, 2006).

Muitas das técnicas da MTC foram modernizadas, novos equipamentos foram incorporados para realizar diagnósticos e tratamentos, métodos foram desenvolvidos e inserido nas técnicas antigas, sendo a MTC fortemente difundida na medicina ocidental para os mais diversos tratamentos em doenças, possibilitando que os profissionais tenham uma visão mais abrangente e com maior número de ferramentas visando a saúde integral do indivíduo (ABE, 2006).

\subsubsection{ACUPUNTURA}

O surgimento da acupuntura é atribuído aos primórdios da civilização chinesa, sendo considerada a origem da acupuntura também o início da civilização e da cultura chinesa (NEVES, 2009). A acupuntura trata-se de uma técnica da MTC praticada há mais de quatro milênios, cujo o termo é originário do latim acus e pungere, que significa puncionar agulhas. Essa técnica terapêutica visa o tratamento de enfermidades através do estímulo de pontos específicos do corpo (acupontos), por meio da inserção de agulhas, sendo posteriormente incorporada à medicina em outros países orientais e ocidentais (JAGGAR, 1992; SCHOEN, 1993; SUSMANN, 2000).

A acupuntura é considerada uma das principais vertentes da MTC, sendo um dos recursos mais procurados por usuários no mundo todo. Essa alta procura é influenciada principalmente pelos avanços nas pesquisas científicas da área, legislação profissional, e a estruturação do seu ensino nos mais diversos países (SILVÉRIO-LOPES \& SEROISKA, 2013). 
A acupuntura conhecida como sistêmica no Brasil, remete a acupuntura clássica chinesa, sendo considerada um dos pilares principais dentro da MTC, na qual agulhas filiformes são inseridas em pontos específicos do corpo. Para o diagnostico energético pode-se utilizar o pulso, língua, palpação, dentre outros, sendo possível também o uso de recursos complementares como a moxabustão, ventoterapia, sangrias, etc. Os chineses denominam de método de Zhen Jiu a moxabustão, que significa basicamente agulha e fogo. Nesse sentido, é utilizado um recurso térmico além da agulha, para estimular os acupontos, consistindo na combustão de uma pequena quantidade de pó de Artemísia vulgaris ou sinensis (DA SILVA, 1997).

\subsubsection{AURICULOTERAPIA}

A auriculoterapia é uma técnica da Medicina Tradicional Chinesa que se utiliza de pontos específicos da orelha para tratar o desequilíbrio energético em todo o corpo (NEVES, 2009). Historicamente, relata-se o interesse pelo pavilhão auricular por distintas civilizações antigas, a exemplo dos egípcios que acalmavam algumas dores por meio da estimulação de pontos da orelha, algumas tribos indígenas que perfuravam a orelha de seus guerreiros em pontos específicos para estimular sua bravura e agressividade, ou os piratas que usavam brincos de ouro no sentido de aguçar a visão. Entretanto, foi na China em que se teve início o tratamento de acupuntura sistêmica por intermédio do uso terapêutico do pavilhão auricular, sendo estabelecida a relação entre a orelha e os demais órgãos e regiões do corpo (NEVES, 2009).

A orelha possui um formato ovoide, que remete à figura de um rim ou um embrião, apresentando uma morfologia rica em sulcos e minências, onde cada estrutura e relevo representa uma região especifica do corpo (NEVES, 2009). Essa relação da orelha com a figura de um feto na posição invertida foi estabelecida pelo médico francês Paul Nogier, que também cunhou o termo "auriculoterapia". Paul iniciou os seus estudos na área da auriculoterapia após receber em seu consultório uma paciente que afirmava ter sido curada de suas dores ciáticas depois de receber tratamento de cauterização num ponto de sua orelha por uma curandeira (NOGIER, 1969; NEVES, 2009; NOGIER, 2010). Suas pesquisas prosseguiram na área tendo como base os pontos auriculares chineses, onde ele determinou mais de 40 pontos auriculares e sua correspondência com órgãos e sistemas do corpo humano, produzindo o primeiro mapa auricular, onde suas cartografias ficaram conhecidas como Auriculoterapia Francesa (NOGIER, 1969; NEVES, 2009; ROUXEVILLE \& MÉAS; 2011) 


\section{Benefícios Da Auriculoterapia Em Pacientes Com Dores Crônicas}

Os estudos de Nogier serviram também de base para o desenvolvimento da Auriculoterapia na China, impulsionando novos estudos e descobertas. Com a intensificação das pesquisas na área e o surgimento de novas publicações, a orelha foi sendo mapeada e utilizada como meio de diagnóstico e tratamento para diversas doenças (NEVES, 2009).

De modo geral, a auriculoterapia se baseia num conjunto de mapas anatômicos sobrepostos a orelha, que utiliza de um ponto específico do mapa proposto para afetar um órgão macroscópico através da estimulação com materiais que podem ser: agulhas, semente de Vaccaria, sementes de mostarda, sondas ou dedos (acupressão), ou até mesmo unidades elétricas como laser (GARY et al, 2010).

\subsubsection{DORES CRÔNICAS E AURICULOTERAPIA}

Segundo a Organização Mundial da Saúde, a definição de qualidade de vida seria "a percepção do indivíduo de sua posição na vida, no contexto da cultura e sistema de valores nos quais ele vive, e em relação aos seus objetivos, expectativas, padrões e preocupações" (THE WHOQOL GROUP, 1994). Nesse sentido, a Dor é um sintoma de alerta comumente percebido num processo de enfermidade, que apresenta impacto negativo na vida do indivíduo acometido. Normalmente o portador da dor tende a buscar alternativas para aliviar esses sintomas, onde a acupuntura e auriculoterapia são descritas como técnicas de efeito analgésico (BRASIL, 2008).

Quando as dores em um indivíduo são consideradas crônicas, são resultantes do acumulo desse sintoma no tempo, causando muito sofrimento ao portador (BAKER et al., 2010; OLIVEIRA et al., 2013). A dor crônica pode provocar impactos negativos na vida de seu portador em vários aspectos: físico, psicológico e social, na qual esses impactos podem resultar em incertezas, medos, preocupações e sensação de incapacidade pelo indivíduo, onde a persistência desse quadro de sofrimento compromete diretamente sua saúde e qualidade de vida (BATES et al., 1993; YENG \& TEIXEIRA, 2004; KRELING et al., 2006; SZUMITA \& SZUMITA, 2010).

Quando o quadro de dor persiste, a atenção deve ser voltada para ajudar o paciente a ajustar-se à incapacidade resultante e aos efeitos adversos de fármacos, que quando usados excessivamente de maneira prolongada, podem provocar a diminuição da produção de endorfinas pelo organismo (bloqueadores de dor), aumentando assim, a percepção do quadro álgico (WELLS et al., 1994; TURK, 1996; FERREIRA et al., 2008). Nesse sentido, compreender como cada paciente interpreta o impacto do quadro de dor crônica na sua vida constitui-se uma ferramenta fundamental para a efetividade do tratamento proposto pela equipe multi ou interdisciplinar (LODUCA et al., 2014). 


\section{Benefícios Da Auriculoterapia Em Pacientes Com Dores Crônicas}

Ao longo das últimas duas décadas, o exercício da acupuntura se tornou cada vez mais rotineira, onde foram observados resultados surpreendentes no uso da auriculoterapia em situações envolvendo dor (SILVÉRIO-LOPES \& SEROISKA, 2013). O estímulo das zonas energéticas por meio da acupuntura, podem promover essa sensação de analgesia da dor, devido a alta taxa de liberação de neurotransmissores e outras substâncias no organismo, onde cascatas neuroendócrinas são desencadeadas como resposta ao estímulo (BRASIL, 2019; REGO, 2011).

\section{MÉTODO}

Esta é uma revisão integrativa da literatura, uma das técnicas utilizadas nas Práticas Baseadas em Evidências, que possibilita a incorporação de novas descobertas na prática clínica (MENDES et al., 2008). Assim, a revisão integrativa pode ser utilizada como uma estratégia para gerar conhecimento em diversas áreas da saúde, por possibilitar a inclusão de diversas metodologias e por ser capaz de ajudar pesquisadores a sintetizar a literatura teórica e empírica sobre um tema específico (WHITTEMORE \& KNAFL, 2005). As etapas de elaboração da revisão seguiram a seguinte ordem: 1formulação do tema e elaboração da pergunta norteadora; 2- resgate das publicações nas bases de dados selecionadas; 3- síntese e análise das informações evidenciadas nos estudos; 4- análise dos estudos escolhidos; 5- apresentação dos resultados; e 6 - análise crítica dos achados (SOUZA et al., 2010).

A estratégia PICO (P - population; I - intervention; C - comparison; O - outcomes) (SHUSTER, 2011), guiou a elaboração da pergunta norteadora: "Quais são os benefícios da auriculoterapia no tratamento da dor crônica?"

As buscas foram realizadas nas bases de dados SciELO (Scientific Eletronic Library Online) e Google Acadêmico, mediante os descritores auriculoterapia (Auriculotherapy) e doença crônica (Chronic Disease) de acordo como a terminologia em saúde DeCS, (Descritores em Ciências da Saúde) da Biblioteca Virtual em Saúde. Para sistematizar as buscas foram utilizados os operadores booleanos com o seguinte esquema: (auriculotherapy AND Chronic Disease) e com o descritor de maneira isolada (auriculotherapy) na SciELO.

O percurso metodológico se deu pela análise dos títulos, resumos e palavras-chave, sendo adotado como critério de inclusão: artigos sobre auriculoterapia e diminuição da dor crônica, artigo sobre reabilitação funcional utilizando-se a auriculoterapia, estudos realizados com seres humanos adultos de 18 anos ou mais e estudos publicados nos últimos dez anos. Não foram incluídos na pesquisa 


\section{Benefícios Da Auriculoterapia Em Pacientes Com Dores Crônicas}

trabalhos de dissertações ou teses acadêmicas, artigos replicados em mais de uma base de dados e artigos não relacionados com o assunto proposto.

Assim, este estudo investiga e apresenta as evidências cientificas em Fisioterapia e auriculoterapia em paciente com dor crônica que possam direcionar os profissionais fisioterapeutas na prática clínica.

Figura 1 - Fluxograma do resgate dos artigos nas bases de dados Google Acadêmico e SCIELO.

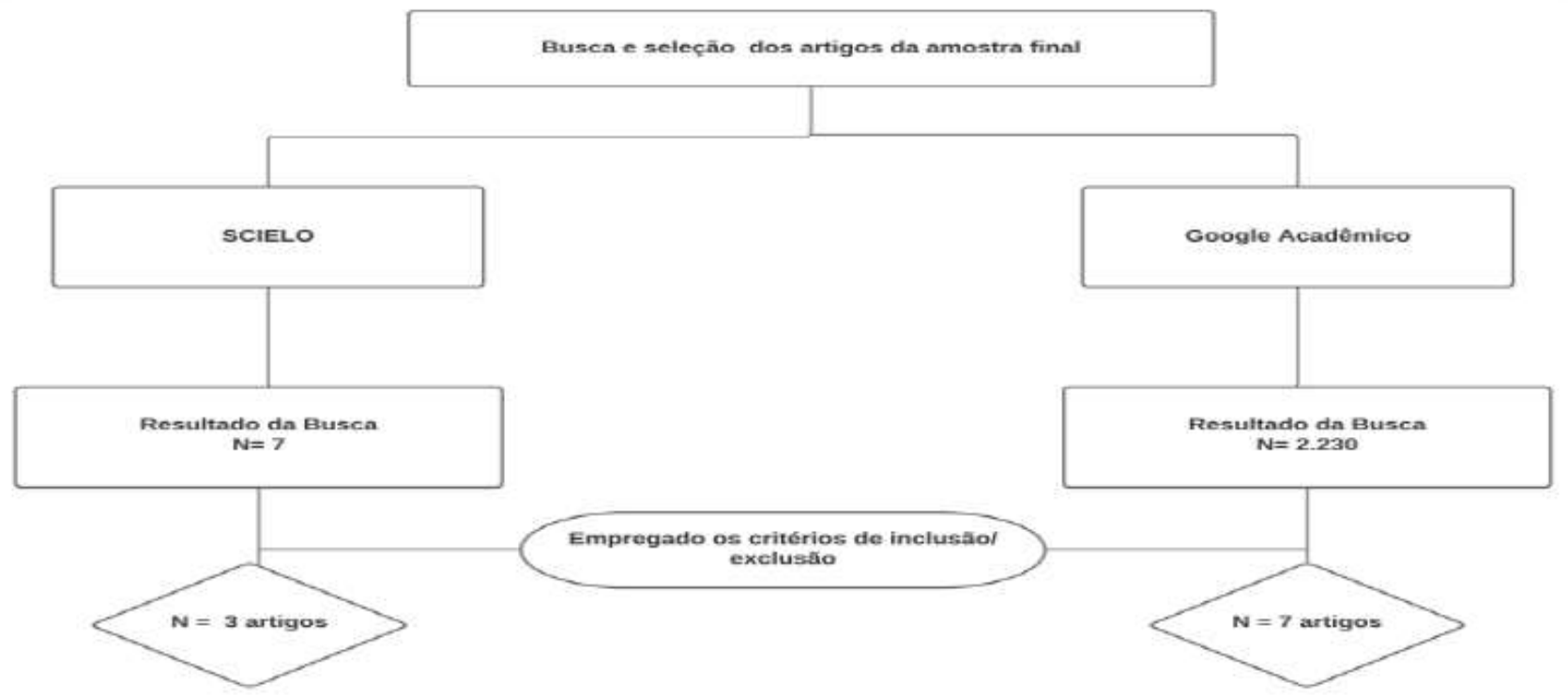

4. RESULTADOS 


\section{Benefícios Da Auriculoterapia Em Pacientes Com Dores Crônicas}

Quadro 1. Descrição dos estudos selecionados

\begin{tabular}{|c|c|c|c|c|c|c|}
\hline Autor/Ano & $\begin{array}{l}\text { Tipo de } \\
\text { estudo }\end{array}$ & $\begin{array}{l}\text { Classificação } \\
\text { Qualis/área de } \\
\text { avaliação }\end{array}$ & Amostra & Intervenções & $\begin{array}{l}\text { Variáveis } \\
\text { avaliadas }\end{array}$ & Principais Resultados \\
\hline $\begin{array}{l}\text { MORAIS et } \\
\text { al., 2021 }\end{array}$ & $\begin{array}{l}\text { Revisão } \\
\text { Integrativa }\end{array}$ & $\begin{array}{c}\mathrm{B} 1 \\
\text { (Interdisciplinar) }\end{array}$ & $\begin{array}{c}14 \text { artigos } \\
\text { selecionados }\end{array}$ & $\begin{array}{l}\text { Sementes de } \\
\text { Colza; esferas de } \\
\text { cristais; agulhas } \\
\text { semipermanentes } \\
\text { e exercícios } \\
\text { físicos; } \\
\text { auriculoterapia e } \\
\text { agulhamento a } \\
\text { seco; esferas } \\
\text { magnéticas e } \\
\text { auriculoterapia. }\end{array}$ & $\begin{array}{l}\text { Dor crônica e } \\
\text { melhora do } \\
\text { sono; }\end{array}$ & $\begin{array}{l}\text { Observou-se redução } \\
\text { da dor crônica entre a } \\
\text { primeira e a última } \\
\text { aplicação da } \\
\text { auriculoterapia, dentre } \\
\text { as intervenções } \\
\text { analisadas a técnica de } \\
\text { eletroacupuntura } \\
\text { apresentou resultados } \\
\text { significantes (p<0,05) } \\
\text { para alivio da dor } \\
\text { crônica, quando } \\
\text { comparado com a } \\
\text { aplicação de agulhas } \\
\text { semipermanentes. }\end{array}$ \\
\hline $\begin{array}{l}\text { GARNER et } \\
\text { al., } 2018\end{array}$ & $\begin{array}{c}\text { Estudo } \\
\text { Clínico } \\
\text { Randomizado }\end{array}$ & $\begin{array}{c}\text { B2 } \\
\text { (Interdisciplinar) }\end{array}$ & $\begin{array}{c}45 \\
\text { participantes }\end{array}$ & $\begin{array}{l}\text { GI: Acupuntura } \\
\text { Auricular } \\
\text { GC: Cuidados } \\
\text { Habituais }\end{array}$ & $\begin{array}{l}\text { Validade da } \\
\text { acupuntura } \\
\text { auricular } \\
\text { estratégia no } \\
\text { tratamento da } \\
\text { dor e insônia; }\end{array}$ & $\begin{array}{l}\text { Teve-se efeitos } \\
\text { positivos no tratamento } \\
\text { da dor crônica e } \\
\text { melhora da insonnia } \\
\text { com o uso da } \\
\text { acupuntura auricular. } \\
\text { Foi empregado o } \\
\text { protocolo de } \\
\text { acupuntura auricular } \\
\text { que teve efeitos } \\
\text { positivos no grupo } \\
\text { intervenção para dor e } \\
\text { insônia quando } \\
\text { comparado com o } \\
\text { grupo controle. }\end{array}$ \\
\hline $\begin{array}{c}\text { SUEN } ~ \\
2014\end{array}$ & $\begin{array}{c}\text { Estudo Caso- } \\
\text { Controle }\end{array}$ & $\begin{array}{c}\text { B2 } \\
\text { (Interdisciplinar) }\end{array}$ & $\begin{array}{c}\text { GI: } 50 \\
\text { participantes } \\
\text { GC: } 50 \\
\text { participantes }\end{array}$ & $\begin{array}{c}\text { Pacientes da } \\
\text { unidade cardíaca } \\
\text { de um hospital } \\
\text { regional de Hong } \\
\text { Kong. }\end{array}$ & $\begin{array}{c}\text { Medição de } \\
\text { resistência } \\
\text { elétrica da } \\
\text { pele e teste } \\
\text { de } \\
\text { sensibilidade } \\
\text { e sua relação } \\
\text { com doenças } \\
\text { crônicas; }\end{array}$ & $\begin{array}{l}\text { O estudo evidência a } \\
\text { significância entre os } \\
\text { pontos de tensão da } \\
\text { auriculoterapia em } \\
\text { pacientes com dor } \\
\text { crônica quando } \\
\text { comparado com o } \\
\text { grupo controle. } \\
\text { Também evidenciou } \\
\text { um aumento da } \\
\text { sensibilidade na zona } \\
\text { cardíaca. }\end{array}$ \\
\hline
\end{tabular}

Legenda: GI: Grupo de Intervenção; GC: Grupo Controle;

Fonte: Elaboração própria 


\section{Benefícios Da Auriculoterapia Em Pacientes Com Dores Crônicas}

\begin{tabular}{|c|c|c|c|c|c|c|}
\hline Autor/Ano & $\begin{array}{l}\text { Tipo de } \\
\text { estudo }\end{array}$ & $\begin{array}{l}\text { Classificação } \\
\text { Qualis/área de } \\
\text { avaliaçâo }\end{array}$ & Amostra & Intervenções & $\begin{array}{l}\text { Variáveis } \\
\text { avaliadas }\end{array}$ & $\begin{array}{l}\text { Principais } \\
\text { Resultados }\end{array}$ \\
\hline $\begin{array}{c}\text { YEH et al., } \\
2014\end{array}$ & $\begin{array}{l}\text { Revisão } \\
\text { Sistemática } \\
\text { e meta- } \\
\text { análise }\end{array}$ & $\begin{array}{c}\text { A2 } \\
\text { (Interdisciplinar) }\end{array}$ & $\begin{array}{l}22 \text { estudos } \\
\text { clínicos } \\
\text { randomizados }\end{array}$ & $\begin{array}{c}\text { Sem } \\
\text { intervenção }\end{array}$ & $\begin{array}{l}\text { Efeito da } \\
\text { auriculoterapia } \\
\text { no alivio da dor } \\
\text { crônica }\end{array}$ & $\begin{array}{lr}\text { O estudo evidenciou } \\
\text { uma redução } \\
\text { significativa da dor } \\
\text { crônica com a } \\
\text { aplicação } & \text { da } \\
\text { auriculoterapia } \\
\text { quando comparado } \\
\text { com o grupo } \\
\text { controle. }\end{array}$ \\
\hline $\begin{array}{c}\text { ZHAO et al., } \\
2015\end{array}$ & $\begin{array}{l}\text { Revisão } \\
\text { Sistemática }\end{array}$ & $\begin{array}{c}\mathrm{C} \\
\text { (Interdisciplinar) }\end{array}$ & $\begin{array}{l}5.728 \text { artigos } \\
\text { selecionados }\end{array}$ & $\begin{array}{c}\text { Sem } \\
\text { intervenção }\end{array}$ & $\begin{array}{l}\text { Terapia } \\
\text { auricular } \\
\text { diminuição da } \\
\text { dor }\end{array}$ & $\begin{array}{l}\text { Evidenciou que a } \\
\text { Terapia Auricular é } \\
\text { promissora para o } \\
\text { alivio da dor crônica, } \\
\text { principalmente para } \\
\text { dor lombar crônica e } \\
\text { cefaleia. }\end{array}$ \\
\hline $\begin{array}{c}\text { VIEIRA et al., } \\
2018\end{array}$ & $\begin{array}{c}\text { Revisão } \\
\text { Sistemática }\end{array}$ & $\begin{array}{c}\text { C } \\
\text { (Interdisciplinar) }\end{array}$ & $\begin{array}{c}14 \text { artigos } \\
\text { selecionados }\end{array}$ & $\begin{array}{c}\text { Sem } \\
\text { intervenção }\end{array}$ & $\begin{array}{l}\text { Eficácia da } \\
\text { auriculoterapia }\end{array}$ & $\begin{array}{lr}\text { Está revisão } \\
\text { sistemática } \\
\text { evidenciou efeitos } \\
\text { positivos } \\
\text { auriculoterapia como } \\
\text { uma terapia de } \\
\text { diminuição da dor, no } \\
\text { entanto, reporta a } \\
\text { importância de } \\
\text { associar a técnica } \\
\text { com outros } \\
\text { tratamentos. }\end{array}$ \\
\hline $\begin{array}{c}\text { ASHER et al., } \\
2010\end{array}$ & $\begin{array}{l}\text { Revisão } \\
\text { Sistemática }\end{array}$ & $\begin{array}{c}\text { B1 } \\
\text { (Interdisciplinar) }\end{array}$ & $\begin{array}{c}17 \text { artigos } \\
\text { selecionados }\end{array}$ & $\begin{array}{c}\text { Sem } \\
\text { intervenção }\end{array}$ & $\begin{array}{l}\text { Avaliação da } \\
\text { auriculoterapia } \\
\text { para controle da } \\
\text { dor }\end{array}$ & $\begin{array}{l}\text { O estudo reporta que } \\
\text { a utilização da } \\
\text { auriculoterapia gera a } \\
\text { diminuição da } \\
\text { ingestão de } \\
\text { analgésicos, diminui } \\
\text { a dor em doenças } \\
\text { agudas e crônicas. }\end{array}$ \\
\hline
\end{tabular}

Legenda: GI: Grupo de Intervenção; GC: Grupo Controle;

Fonte: Elaboração Própria 


\section{Benefícios Da Auriculoterapia Em Pacientes Com Dores Crônicas}

\begin{tabular}{|c|c|c|c|c|c|c|}
\hline Autor/Ano & Tipo de estudo & $\begin{array}{l}\text { Classificação } \\
\text { Qualis/área de } \\
\text { avaliação }\end{array}$ & Amostra & Intervenções & $\begin{array}{l}\text { Variáveis } \\
\text { avaliadas }\end{array}$ & $\begin{array}{l}\text { Principais } \\
\text { Resultados }\end{array}$ \\
\hline $\begin{array}{l}\text { GRACA et } \\
\text { al., } 2020\end{array}$ & $\begin{array}{c}\text { Estudo } \\
\text { experimental }\end{array}$ & $\begin{array}{c}\text { B2 } \\
\text { (Interdisciplinar) }\end{array}$ & 18 participantes & $\begin{array}{l}\text { GI: Tratado com } \\
\text { auriculoterapia } \\
\text { GC: Não tratado }\end{array}$ & $\begin{array}{lr}\begin{array}{l}\text { Dor } \\
\text { numérica de dor), } \\
\text { ansiedade }\end{array} \\
\text { (Inventário de } \\
\text { Ansiedade Traço- } \\
\text { Estado) }\end{array}$ & 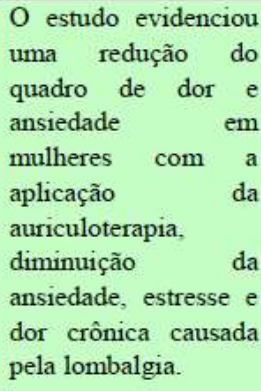 \\
\hline $\begin{array}{l}\text { MANFROI et } \\
\text { al., } 2019\end{array}$ & $\begin{array}{c}\text { Estudo } \\
\text { Qualitativo }\end{array}$ & $\begin{array}{c}\text { B2 } \\
\text { (Interdisciplinar) }\end{array}$ & 15 participantes & Sem intervenção & $\begin{array}{l}\text { "Caracterização do } \\
\text { grupo investigado e } \\
\text { dinâmica dos } \\
\text { encontros", "O } \\
\text { grupo como } \\
\text { potencial de cura"e } \\
\text { "Lian Gong/Qi } \\
\text { Gong como uma } \\
\text { possibilidade de } \\
\text { olhar para a dor" }\end{array}$ & $\begin{array}{l}\text { E reportado que a } \\
\text { melhora da dor por } \\
\text { meio da } \\
\text { auriculoterapia tem } \\
\text { uma relação com o } \\
\text { estado de espirito do } \\
\text { indivíduo frente ao } \\
\text { local onde ele está } \\
\text { sendo tratado e a } \\
\text { abordagem utilizada. } \\
\text { Os autores trazem } \\
\text { como conceito de } \\
\text { reconhecimento da } \\
\text { dorospressupostos de } \\
\text { Lian Gong e a } \\
\text { necessidade do } \\
\text { paciente enxergar a } \\
\text { intensidade da sua } \\
\text { própria dor. }\end{array}$ \\
\hline $\begin{array}{l}\text { LING-LING } \\
\text { et al., (2006) }\end{array}$ & $\begin{array}{c}\text { Ensaio Clínico } \\
\text { Randomizado } \\
\text { controlado }\end{array}$ & $\begin{array}{c}\text { B2 } \\
\text { (Interdisciplinar) }\end{array}$ & $\begin{array}{l}80 \text { participantes } \\
\text { com lombalgia }\end{array}$ & $\begin{array}{l}\text { GI: Recebeu como } \\
\text { tratamento a } \\
\text { auriculoterapia. } \\
\text { GC: Não recebeu } \\
\text { esse tratamento }\end{array}$ & $\begin{array}{l}\text { Intensidade da dor } \\
\text { e controle postural }\end{array}$ & $\begin{array}{l}\text { O estudo mostra que a } \\
\text { intensidade da dor } \\
\text { diminuiu em ambos } \\
\text { os grupos (GI e GC), } \\
\text { mas que o GI teve } \\
\text { essa diminuição da } \\
\text { dor de maneira mais } \\
\text { rápida e duradoura } \\
\text { quando comparado } \\
\text { com o outro grupo. } \\
\text { Não foi encontrado } \\
\text { nenhuma associação } \\
\text { entre o uso da } \\
\text { auriculoterapia e o } \\
\text { controle postural dos } \\
\text { pacientes com } \\
\text { lombalgia. }\end{array}$ \\
\hline
\end{tabular}

Legenda: GI: Grupo de Intervenção; GC: Grupo Controle;

Fonte: Elaboração Própria 


\section{DISCUSSÃO}

As análises dos artigos evidenciam que a auriculoterapia é uma técnica eficaz para redução da dor crônica e apresenta boa aceitação pelos indivíduos. Esses achados são essenciais para a assistência em saúde, visto que a auriculoterapia configura-se como um recurso terapêutico de fácil aplicação e com quase nenhum efeito colateral, o que lhe proporciona o manuseio nas estratégias de proteção dos agravos e promoção da saúde (MOURA et al, 2018). Os seus efeitos não se restringem apenas a diminuição da dor, como visto na revisão sistemática de Chen et al., (2007) em que de 1-120 dias a eficácia da acupuntura auricular foi estatística e clinicamente melhor do que a dos controles (risco relativo: 1,32-3,83; IC 95\%: 1,05-6,66; $p<0,05$ ) com base em medidas subjetivas e objetivas do sono.

Atualmente são utilizados protocolos de acupuntura auricular padrão, que é reportado na literatura como efetivo para a redução significativa na intensidade da dor. Essa diminuição sintomática vai de encontro a meta-análise de Asher et al., (2010), que reportou melhores resultados da auriculoterapia em comparação ao uso de pílulas de placebo, acupuntura simulada ou tratamento usual para resolução da dor aguda e crônica. São amplas as variações de intervenções com acupuntura (por exemplo; locais de acupuntura auricular, estimulação a laser, acupressão e locais para pontos sham), no qual essas medidas são resultados de anos de experiências na administração de acupuntura por especialistas. Ou seja, a diminuição da intensidade da dor proporcionada pela auriculoterapia pode promover a saúde e a melhoria da qualidade de vida, promovendo a reabilitação para o desenvolvimento de atividades cotidianas, bem como melhora da qualidade do sono (MOURA et al., 2018).

Nesse sentido, o presente trabalho reportou que a auriculoterapia quando associada com outras terapias, potencializa seus resultados para a diminuição da dor. Esse achado vai de encontro ao estudo de Sator-Katzenschlager et al., (2003) no qual mostraram que a utilização de corrente elétrica nos pontos auriculares aumenta a eficácia da analgesia no local, pois de acordo com a intensidade da estimulação elétrica, são liberados diferentes tipos de endorfinas. Corroborando com isso, um estudo realizado em Minas Gerais, reportou que o uso da auriculoterapia por meio de agulhas semipermanentes teve eficácia na redução da dor crônica na região da coluna vertebral, auxiliando também na melhora clínica da incapacidade física, permitindo assim um melhor desenvolvimento nas atividades cotidianas (MOURA et al., 2019).

É importante ressaltar que as agulhas semipermanentes quando comparadas com as sementes, não precisam ser estimuladas de modo manual, o que produz uma estimulação contínua nas inervações 


\section{Benefícios Da Auriculoterapia Em Pacientes Com Dores Crônicas}

da região auricular até serem completamente removidas. No entanto, a aceitabilidade das sementes e esferas metálicas são melhores, pois o desconforto é mínimo, sendo necessária a participação dos pacientes na estimulação dos pontos, podendo esse ser um fator limitante para às pesquisas científicas (DE CASTRO MOURA et al., 2015).

A auriculoterapia também pode ser utilizada para inspeção e avaliação da orelha dentro do processo de anamnese do paciente, o que a torna base do diagnóstico do ouvido, que por meio da palpação e condutância elétrica da pele de áreas relevantes do ouvido, permite a identificação de distúrbios em outras partes do corpo. Portanto, com base nessa ideia, quando uma doença ou distúrbio está presente, alguns acupontos auriculares relacionados mostram uma resistência maior ou menor em comparação com os pontos auriculares de referência próximos (COLBERT et al., 2011).

De acordo com Juan Muñoz-Ortego et al., (2016), a acupuntura sistêmica é frequentemente usada no tratamento da dor, como no tratamento de tensão provocadas por dores de cabeça e enxaquecas, osteoartrite, dor lombar, entorses de tornozelo, bem como dor de garganta. Esse estudo também indica as terapias de acupuntura na área de neurologia, no entanto é necessário um maior aprofundamento metodológico envolvendo acupuntura sistêmica e auriculoterapia para esclarecer sua utilidade (MUÑOZ-ORTEGO et al., 2016).

Somando a isso, a auriculoterapia dentro do Sistema Único de Saúde encontra-se no espectro das terapias complementares aprovadas pela Portaria no 971/2006 que criou a Política Nacional de Práticas Integrativas e Complementares (PNPIC) (BRASIL, 2006). Nos anos de 2017 e 2018, a PNPIC ampliou o rol de sistemas complexos e recursos terapêuticos reconhecidos, com possibilidade de oferta no SUS: arteterapia, ayurveda, biodança, dança circular, meditação, musicoterapia, naturopatia, osteopatia, quiropraxia, reflexoterapia, reiki, shantala, terapia comunitária integrativa, yoga, aromaterapia, apiterapia, bioenergética, constelação familiar, cromoterapia, geoterapia, hipnoterapia, imposição de mãos, ozonioterapia e terapia de florais, além das já elencadas pela política em 2006: Medicina Tradicional Chinesa/acupuntura, homeopatia, plantas medicinais e fitoterapia, medicina antroposófica e termalismo-crenoterapia. A ampliação se deu num contexto político conturbado, com repercussões favoráveis e contrárias por parte de diferentes segmentos de interesse (TESSER et al.,2018).

Dentre o rol de terapias oferecidas pela PNPIC, a acupuntura encontra-se inserida nas terapias vibracionais, no toque terapêutico e nas essências florais. A acupuntura pode ser conceituada como um tratamento que envolve a inserção de agulhas em locais da pele conhecidos como acupontos, que 


\section{Benefícios Da Auriculoterapia Em Pacientes Com Dores Crônicas}

são pontos energéticos que fornecem energia ao corpo, formando canais chamados de meridianos, que correspondem à estimulação de pontos até à região corpórea específica a ser estimulada, como articulações e ramificações nervosas específicas para controle da dor (VIEIRA et al., 2018).

Hipóteses são levantadas sobre a magnitude da aplicação das terapias complementares e aderência pelos profissionais de saúde, em especial os da atenção primária, aumentando consideravelmente a demanda por essas práticas (BEN-ARYE et al., 2008). No entanto, o desconhecimento dos profissionais da saúde sobre as terapias complementares pode ser responsável por conceitos equivocados, o que pode gerar dificuldades na relação médico-paciente e com colegas praticantes dessas especialidades (FRANCO \& PECCI, 2002).

Assim sendo, as práticas complementares em sua maioria, como a auriculoterapia, buscam o reequilíbrio global (aspectos biopsicossociais) e não somente o tratamento sintomático. Dessa forma, acabam exigindo uma maior participação do indivíduo em seu próprio tratamento, com uma maior disponibilidade de tempo para o autocuidado, sendo os resultados muitas vezes não tão imediatos (NOGALES-GAETE, 2004).

\section{CONSIDERAÇÕES FINAIS}

As Práticas Integrativas Complementares (PICs) visam dar assistência ao indivíduo nos aspectos biopsicossocial com ênfase na: promoção da saúde e prevenção dos agravos, considerando o paciente como um ser holístico. Essas práticas visam o equilíbrio energético no processo saúde-doença, contribuindo assim para uma melhora na qualidade de vida do indivíduo. Observam-se na literatura mundial poucos relatos do uso de instrumentos projetivos nos estudos psicológicos sobre avaliação e tratamento de dores crônicas, e os resultados encontrados na análise evidenciaram a dificuldade de se generalizar as informações, ou seja, reforçam a importância do estudo dos determinantes sociais da saúde.

Conclui-se nesse estudo, que a auriculoterapia é uma técnica bastante eficaz na redução de dores crônicas, sendo bem aceita pelos pacientes, configurando-se assim, como um recurso terapêutico fácil e prático, com quase nenhum efeito colateral. Os estudos mostram que essa técnica ajuda no combate de diversas patologias, dentre elas: insônia, doenças mentais, diminuição de crises de ansiedade e dentre outras. A acupuntura de modo geral tem proporcionado grandes benefícios para saúde humana ao longo dos anos, sendo uma alternativa para prevenção, tratamento e o bem-estar do paciente. 


\section{Benefícios Da Auriculoterapia Em Pacientes Com Dores Crônicas}

A utilização de agulhas semipermanentes na auriculoterapia descarta a necessidade da estimulação manual dos acupontos pelo paciente, sendo evidenciada uma maior eficácia no tratamento quando comparada as sementes e esferas metálicas. Entretanto, vale ressaltar que as sementes e esferas ainda possuem uma maior aceitabilidade por parte dos pacientes, por serem menos desconfortável durante o tratamento.

De um modo geral, a auriculoterapia, bem como outras técnicas das PICs exigem uma co-participação do indivíduo em seu próprio tratamento, ressaltando a necessidade de um maior autocuidado, sendo os resultados acumulativos com o tempo. Sugere-se estudos de intervenção na área, visto que as PICs ainda estão em processo de evidenciação cientifica. 


\section{REFERÊNCIAS}

ABE, Gislaine Cristina. Medicina Tradicional Chinesa (MTC). Revista Neurociências, v. 14, p. 80-85, 2006.

ASHER, Gary N. et al. Auriculotherapy for pain management: a systematic review and meta-analysis of randomized controlled trials. The Journal of Alternative and Complementary Medicine, v. 16, n. 10, p. 1097-1108, 2010.

ASHER, Gary N. et al. Auriculotherapy for pain management: a systematic review and meta-analysis of randomized controlled trials. The Journal of Alternative and Complementary Medicine, v. 16, n. 10, p. 1097-1108, 2010. BATES, Maryann S.; EDWARDS, W. Thomas;

ANDERSON, Karen O. Ethnocultural influences on variation in chronic pain perception. Pain, v. 52, n. 1, p. 101-112, 1993.

BAKER, M. et al. Pain proposal: improving the current and future management of chronic pain. A European consensus report. 2010.

BEN-ARYE, Eran et al. Attitudes toward integration of complementary and alternative medicine in primary care: perspectives of patients, physicians and complementary practitioners. Patient education and counseling, v. 70, n. 3, p. 395-402, 2008. BRASIL. Ministério da Saúde. Departamento de Atenção Básica. Política Nacional de Práticas Integrativas e Complementares no SUS. Brasília, DF 2006. BRASIL. Ministério da Saúde. Glossário temático: práticas integrativas e complementares em saúde [Internet]. Brasília: Ministério da Saúde; 2018 [acesso em: 26 set. 2019]. Disponível em: https://portalarquivos2.saude.gov.br/images/pdf/2018/marco/12/glossario-tematico.pdf

BRASIL. Ministério da Saúde. Glossário temático: práticas integrativas e complementares em saúde [Internet]. Brasília: Ministério da Saúde; 2018 [acesso em: 26 set. 2019]. Disponível em: https://portalarquivos2.saude.gov.br/images/pdf/2018/marco/12/glossario-tematico.pdf

BRASIL. Ministério da Saúde. Política nacional de práticas integrativas e complementares no SUS: atitude de ampliação de acesso. 2a. ed. [Internet]. Brasília: Ministério da Saúde; 2015 [acesso em 26 set. 2019]. Disponível em:

https://bvsms.saude.gov.br/bvs/publicacoes/politica_nacional_praticas_integrativas_com plementares_2ed.pdf 1

BRASIL. Ministério da Saúde. Secretaria de Atenção à Saúde. Departamento de Atenção Básica. Política Nacional de Práticas Integrativas e Complementares no SUS - PNPIC-SUS / Ministério da Saúde, Secretaria de Atenção à Saúde, Departamento de Atenção Básica. - Brasília : Ministério da Saúde, 2006. 92 p. Disponível em http://bvsms.saude.gov.br/bvs/publicacoes/pnpic.pdf Acesso em novembro de 2015

BRASIL. Ministério da Saúde. Secretaria de Atenção à Saúde. Protocolo Clínico e Diretrizes Terapêuticas: Dor crônica. Portaria SAS/MS no 1.083, de 02 de outubro de 2012 [acesso em: 26 set. 2019]. Disponível em: http://conitec.gov.br/images/Protocolos/DorCronica.pd

BRASIL. Portaria GM/MS no 702, de 21 de março de 2018. 
BRASIL. Portaria GM/MS no 849, de 27 de março de 2017. CHEN, Hai Yong et al. Auricular acupuncture treatment for insomnia: a systematic review. The Journal of Alternative and Complementary Medicine, v. 13, n. 6, p. 669-676, 2007.

CHONGHUO, T. Tratado de medicina chinesa. São Paulo: Roca, 1993.

COLBERT, Agatha P. et al. Electrodermal activity at acupoints: literature review and recommendations for reporting clinical trials. Journal of Acupuncture and Meridian Studies, v. 4, n. 1, p. 5-13, 2011.

CORDEIRO, A. T. \& CORDEIRO, R. C. Acupuntura Elementos Básicos. 3a ed. São Paulo: Polis, 143 p. 2001. DA SILVA, Alexander Raspa. Fundamentos da Medicina Tradicional Chinesa. 1997.

DE CASTRO MOURA, Caroline et al. Auriculoterapia efeito sobre a ansiedade. Revista Cubana de Enfermería, v. 30, n. 2, 2015.

DOS SANTOS, Raquel Silva; SULIANO, Lirane Carneiro. Auriculoterapia como Recurso Complementar na Alteração Inespecífica da Pele. Rev Bras Terap e Saúde, 4(2):1-5, 2014.

DULCETTI JR, O. Pequeno tratado de Acupuntura tradicional chinesa. São Paulo: Andrei, 257 p.2001.

FERREIRA, Karine Azevedo São Leão; DE SIQUEIRA, Silvia Regina Dowgan T.; TEIXEIRA, Manoel Jacobsen. Atendidos em centro multidisciplinar de dor. Cad. Saude colet, v. 16, n. 3, p. 449-470, 2008.

FRANCO, Jorge A.; PECCI, Cristina. La relación médico-paciente, la medicina científica y las terapias alternativas. Medicina (Buenos Aires), v. 62, p. 111-118, 2002.

GARNER, Betty K. et al. Auricular acupuncture for chronic pain and insomnia: a randomized clinical trial. Medical acupuncture, v. 30, n. 5, p. 262-272, 2018.

GRACA, Bianca Carvalho da et al. Use of auriculotherapy to control of low back pain, anxiety and stress of professionals of the correctional system. BrJP, São Paulo , v. 3, n. 2, p. 142-146, Mar. 2020.

JAGGAR, D. History and basic introduction to veterinary acupuncture. Problems in Veterinary Medicine, v. 4, n. 1, p. 1-11, 1992.

KRELING, Maria Clara Giorio Dutra; CRUZ, Diná de Almeira Lopes Monteiro da; PIMENTA, Cibele Andrucioli de Mattos. Prevalence of chronic pain in adult workers. Revista brasileira de enfermagem, v. 59, n. 4, p. 509-513, 2006.

KUREBAYASHI, Leonice Fumiko Sato et al. Auriculoterapia para redução de ansiedade e dor em profissionais de enfermagem: ensaio clínico randomizado. Revista Latino-Americana de Enfermagem, v. 25, 2017.

LODUCA, Adrianna et al. Retrato de dores crônicas: percepção da dor através do olhar dos sofredores. Revista Dor, v. 15, n. 1, p. 30-35, 2014.

MARTINS, Eveliny Silva. Efeitos da acupuntura no tratamento de dor lombar em gestantes. 2017.

MENDES, Karina Dal Sasso; SILVEIRA, Renata Cristina de Campos Pereira; GALVÃO, Cristina Maria. Revisão integrativa: método de pesquisa para a incorporação de evidências na saúde e na enfermagem. Texto \& contexto-enfermagem, v. 17, n. 4, p. 758-764, 2008. 


\section{Benefícios Da Auriculoterapia Em Pacientes Com Dores Crônicas}

MORAIS, Bruna Xavier et al. Auriculoterapia e redução da dor musculoesquelética crônica: revisão integrative. Rev. Bras. Enferm., Brasília, v. 73, supl. 6, e20190394, 2020.

MOURA, Caroline de Castro et al. Action of ear acupuncture in people with chronic pain in the spinal column: a randomized clinical trial. Revista latino-americana de enfermagem, v. 26, 2018.

MOURA, Caroline de Castro et al. Effects of auricular acupuncture on chronic pain in people with back musculoskeletal disorders: a randomized clinical trial. Revista da Escola de Enfermagem da USP, v. 53, 2019.

MUÑOZ-ORTEGO, Juan et al. Medical indications for acupuncture: systematic review. Medicina Clínica (English Edition), v. 147, n. 6, p. 250-256, 2016.

NEVES, Marcos Lisboa. Manual prático de auriculoterapia. Porto Alegre: Ed. Do Autor, 2009.

NOGALES-GAETE, Jorge. Medicina alternativa y complementaria. Revista chilena de neuro-psiquiatría, v. 42, n. 4, p. 243-250, 2004.

NOGIER, P. Traite d'Auriculotherapie. Maisonneuve-Moulin les Metz (France). 1972. Treatise of Auriculotherapy, 1969. NOGIER, Paul François Marie;

NOGIER, Raphaël. L'homme dans l'oreille. Sauramps médical, 2010.

OLIVEIRA, Welington Saraiva de; MORAES, Niele; SANTOS, Fania Cristina. Vitamina D e dor crônica em idosos. Rev. dor, São Paulo, v. 14, n. 3, p. 223-225, set.2013 . Disponível em $<$ http://www.scielo.br/scielo.php?script=sci_arttext\&pid=S1806-

00132013000300015\&lng=pt\&nrm=iso >. acessos em 31 maio 2018. http://dx.doi.org/10.1590/S180600132013000300015.

REGO PBL. Auriculoterapia no Tratamento da Insônia em Adultos: Revisão bibliográfica. São Paulo, 2011. Disponível em:

https://www.posgraduacaoredentor.com.br/ hide/path_img/conteudo_542b166ba3dee.p df Acesso em: 19/05/2016.

ROUXEVILLE, Yves; MÉAS, Yunsan. Panorama de l'auriculothérapie et de l'auriculomédecine. Springer, 2011.

SATOR-KATZENSCHLAGER, Sabine M. et al. Electrical stimulation of auricular acupuncture points is more effective than conventional manual auricular acupuncture in chronic cervical pain: a pilot study. Anesthesia \& Analgesia, v. 97, n. 5, p. 1469-1473, 2003.

SHUSTER, Jonathan J. Cochrane handbook for systematic reviews for interventions, Version 5.1. 0, published 3/2011. Julian PT Higgins and Sally Green, Editors. 2011.

SILVA, Roberta de Paiva et al. Contribuciones de la auriculoterapia al cese del tabaquismo: estudio piloto. Revista da Escola de Enfermagem da USP, v. 48, n. 5, p. 883-890, 2014.

SILVÉRIO-LOPES, Sandra; SEROISKA, Mariângela Adriane. Auriculoterapia para analgesia. Analgesia por acupuntura. Curitiba (PR): Omnipax, p. 1-22, 2013. 


\section{Benefícios Da Auriculoterapia Em Pacientes Com Dores Crônicas}

SOUZA, Marcela Tavares de; SILVA, Michelly Dias da; CARVALHO, Rachel de. Revisão integrativa: o que é e como fazer. Einstein (São Paulo), São Paulo , v. 8, n. 1, p. 102-106, Mar. 2010.

SCHOEN, A. M. Introduction to veterinary acupunture: Scientific basic and clinical aplications. ANNUAL CONVENTION OF THE AMERICAN ASSOCIATION OF EQUINE PRACTIONERS, 39, 1993. California. Proceeding... California, 1993. p.39.

SUSMANN, D. Acupuntura, Teoria y Práctica. 13aㅡ ed. Buenos Aires: Kier, 2000.

SUEN, Lorna Kwai-Ping; YEH, Chao Hsing. Auricular diagnosis in chronic illnesses. Medical Acupuncture, v. 26, n. 2, p. 125-129, 2014.

SZUMITA, Richard P.; SZUMITA, Paul M.; JUST, Nancy. Understanding and managing patients with chronic pain. Oral and Maxillofacial Surgery Clinics, v. 22, n. 4, p. 481-494, 2010.

TESSER, Charles Dalcanale; SOUSA, Islandia Maria Carvalho de; NASCIMENTO, Marilene Cabral do. Práticas integrativas e complementares na atenção primária à saúde brasileira. Saúde em debate, v. 42, p. 174-188, 2018.

TOLENTINO, Flora. Efeito de um tratamento com auriculoterapia na dor, funcionalidade e mobilidade de adultos com dor lombar crônica. 2016.

THE WHOQOL GROUP. Development of the WHOQOL: rationale and current status. Monograph on Quality of Life Assessment: cross-cultural issues - 2. International Journal of Mental Health, 23(3):2456; 1994.

TURK DC. Biopsychosocial perspective on chronic pain. In: Gatchel RJ, Turk DC, (editors). Psychological approaches to pain management: a practitioner's handbook. New York: Guilfold; 3-32p, 1996.

VIEIRA, Andreia et al. Does auriculotherapy have therapeutic effectiveness? An overview of systematic reviews. Complementary therapies in clinical practice, v. 33, p. 61-70, 2018.

WELLS, Chris; NOWN, Graham; HOWARD, Jane. In Pain? A Self-Help Guide for Chronic Pain Sufferers. Physiotherapy, v. 80, n. 12, p. 871, 1994.

WEN, T.S.Acupuntura Clássica Chinesa. São Paulo: Culttrix,225 -226 p.1985.

WHITTEMORE, Robin; KNAFL, Katheleen. The integrative review: updated methodology. Journal of Advanced Nursing, v.52, n.5 p.546-553,2005.

YENG, Lin Tchia; TEIXEIRA, Manoel Jacobsen. Tratamento Multidisciplinar dos doentes com dor crônica. Prática Hospitalar, v.35, p.21-24,2004.

ZHAO, Hong-Jia et al. Auricular Therapy for Chronic pain management in adults: A synthesis of evidence. Complementary therapies in clinical practice, v.21, n.2 p.68-78,2015. 


\section{Capítulo 3}

\section{UM ESTUDO SOBRE FIBROMIALGIA E OS BENEFÍCIOS DA ATIVIDADE FÍSICA ORIENTADA POR PROFISSIONAL DE EDUCAÇÃO FÍSICA}

Weigler Serafim Azarias

Luis Eduardo Moraes Sinésio

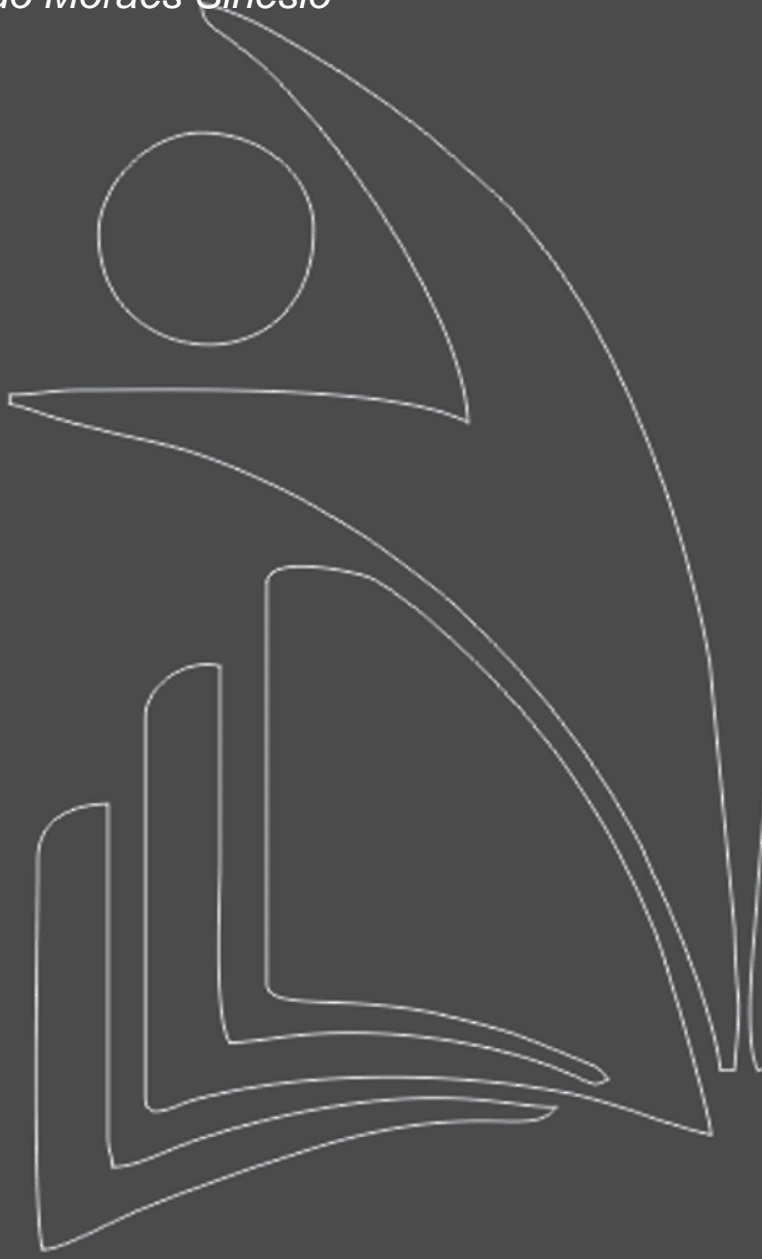

CENTRO UNIVERSITÁRIO UNIGRAN EAD

Instituto Federal de Educação, ciência e Tecnologia de MS 
Resumo: Estudos na área da saúde e mais especificamente da fibromialgia, tem demonstrado o agravamento desta doença principalmente em mulheres. O objetivo geral deste estudo foi analisar as causas e consequências da fibromialgia e a intervenção do profissional de educação física com a prescrição de atividades físicas orientadas. A partir da revisão literária, aspectos clínicos e fisiológicos foram identificados na possibilidade de compreensão dessa doença, e de que forma a pratica de atividades físicas podem melhorar significativamente as condições de vida desses pacientes. Como procedimento metodológico, foi realizado um estudo de natureza exploratória, descritiva e com análises de revisão da literatura acerca. A questão norteadora foi: Qual a contribuição da atividade física por meio da intervenção de um profissional de educação física no combate a fibromialgia? Os resultados do estudo evidenciaram que a fibromialgia é uma doença decorrente de alguns fatores de ordem genética, sendo ainda um problema de saúde pública, desta maneira propõe-se que alguns exercícios sejam desenvolvidos no sentido de estimular a estrutura anátomo fisiológica dos sistemas orgânicos, a adoção de um estilo de vida ativo, bem como uma alimentação adequada que podem amenizar as dores causadas pelas fortes contrações musculares decorrentes das crises, e com as atividades físicas o aumento na capacidade funcional de suportar essas dores.

Palavras-chave: Fibromialgia, atividade física e profissional de educação física. 


\section{INTRODUÇÃO}

Vivenciamos na sociedade contemporânea diversas problemática na área da saúde: vírus, doenças, síndromes entre outros. No campo das políticas públicas, a proliferação das doenças tem se agravado e a sociedade tem sofrido as consequências desses desarranjos do meio ambiente.

Levando em consideração a evolução dos estudos na área da saúde, e em consenso com o campo da ciência podemos afirmar a eficácia da prática de atividades físicas regulares, bem como dos exercícios físicos em combinação com o tratamento adequado, contribuem de forma significativa para a manutenção e profilaxia de doenças decorrentes desses acometimentos.

Nesse contexto de comorbidades, a fibromialgia tem afetado, sobretudo a saúde das mulheres de modo geral, comprometendo de forma significativa a qualidade de vida e a sua condição de saúde.

Nesse sentido, este estudo tem como objetivo investigar e analisar a fibromialgia (FM) e qual a sua relação com a atividade física que é considerada pelos estudiosos uma síndrome dolorosa crônica, que ainda tem sua etiologia desconhecida, e que é uma síndrome mais aparente em mulheres. A FM pode se manifestar em qualquer sistema do nosso corpo, porém, é mais frequente no musculoesquelético, localizando-se em sítios anatômicos, denominados tender points.

A questão norteadora do estudo se delineou a partir da seguinte problematização: Qual é a contribuição da atividade física orientada por um profissional de educação física, no que tange respeito ao combate da fibromialgia?

Este trabalho trouxe informações favoráveis de como a atividade física, pode estar vinculada a um processo benéfico de recuperação, ou seja, no tratamento da síndrome. Para isso, o objetivo específico a ser alcançado será demonstrar que através dos alongamentos e exercícios, haverá benefícios e redução dos efeitos causados pela fibromialgia.

Pelo fato de não se ter uma real origem da FM, consideram-na uma síndrome somatória, associada frequentemente a distúrbios do sono, fadiga, cefaleia crônica e distúrbios psíquicos e entre outros. Pelo fato de ser uma síndrome somatória, fica ainda mais complicado seus estudos, no entanto, algumas recentes pesquisas apontam a FM como um distúrbio no processamento dos estímulos sensoriais, ocasionando hipersensibilidade, especialmente dolorosa. Consequentemente, o profissional de educação física seria de extrema importância podendo orientar diversos tipos de exercícios que seriam benéficos para esse tipo público. 
O tratamento da FM utiliza-se de medicamentos associados com atividades físicas e orientação de alongamentos. Os principais medicamentos utilizados para a terapia são os analgésicos, mio relaxantes, anti-inflamatórios não-esteroidais, antidepressivos e os benzodiazepínicos, que provocam calma e sedação.

A prática de exercícios físicos aeróbicos apresenta as melhores evidencias científicas na melhoria da dor, bem-estar geral, função física, sensibilidade nos tender points e sintomas.

O indivíduo que possui a FM, antes de iniciar qualquer atividade física, deve passar por uma anamnese minuciosa, sabendo-se que a dor é o principal sintoma da síndrome, utiliza-se de outros instrumentos como avaliação: escalas de mapas de dor, questionário McGill de dor, considerado um dos melhores instrumentos para avaliação de dores em geral, e dolorimetria medida pelo algômetro.

Segundo o Colégio Americano de Medicina do Esporte, a prática de atividade física aeróbica é caracterizada por três a cinco vezes por semana com intensidade 55 e 65 a 90\% da frequência cardíaca máxima, ou 40 e 50 a $90 \%$ do consumo de $\mathrm{Vo}^{2}$ max e duração de 20 a 60 minutos.

Em 1992, a Organização Mundial da Saúde (OMS) incluiu a Fm na International Statistical Classification of Diseases and Related Health Problems (ICD 10) ${ }^{2}$. Nesse documento, recomenda-se que as ferramentas de pesquisas, de uma forma padronizada, sejam baseadas nos critérios do Colégio Americano de Reumatologia, lembrado que, para se ter um valor diagnóstico positivo são avaliados de 11 ou mais entre 18 tender points, segundo pesquisas feitas pelo próprio colégio. Porém, um paciente pode apresentar menos de 11 pontos dolorosos no momento do exame, então leva-se em consideração a presença de outros sintomas, como dor ou dolorimento difuso sem causa aparente, rigidez matinal generalizada, e o sono não-restaurador, que é a sensação de dormir e não descansar.

\section{2- REFERENCIAL TEÓRICO}

Neste item do referencial teórico, buscamos descrever processos de análise histórica sobre a fibromialgia e os seus acometimentos em relação à inatividade física e consequentemente os benefícios para as pessoas que possuem essa doença. Nesse sentido procuramos organizar um roteiro de escrita no sentido de melhor organizar as ideias referentes ao tema.

O trabalho a seguir, visa descrever as possíveis causas e tratamentos conhecidos de uma síndrome chamada de Fibromialgia, cuja sua real origem, ainda desconhecida, mas que seus sintomas podem ser gerados por vários outros distúrbios. Importantes profissionais como Pollock, profissional de 
Educação Física, Mauro Vaisberg e Marco T. de Mello, ambos da área de Medicina, contribuíram para os estudos dessa síndrome, pautando a importância da atividade física como tratamento fundamental. Com os avanços dos estudos sobre os fatores que favorecem a saúde através atividades físicas, observamos que essa tem se tornado uma prática cada vez mais comum na vida da população. Com inúmeros benefícios para uma qualidade de vida melhor, o exercício físico é recomendado de forma geral para maioria da população, incluindo os portadores de FM. Tais práticas contribuiriam para esse grupo como uma forma de tratamento contra a dor e o estresse. Esse fator é benéfico tanto para saúde física como para saúde mental, visto que, além de regular os níveis de hormônio também traz o alivio psicológico.

\title{
2.1- QUADRO CLÍNICO - FISIOPATOLOGIA
}

A fibromialgia tem sido objeto de estudos e pesquisas na área no sentido de compreender quais os motivos que provocam essa doença e de que forma podemos combate-la, nesse sentido:

\begin{abstract}
A Fibromialgia tem sido apontada como uma das desordens reumatológicas mais constantes no mundo, em países como Espanha, Bangladesh, Brasil e México, a síndrome encontra-se em quarto lugar. "Na assistência médica geral, pode representar cerca de $7 \%$ de todas as queixas", variando de região e metodologia utilizada, pode apresentar dados dominantes de 0,66\%a 10,5\%, na população adulta os dados mais aceitos giram em torno $2 \%$, aumentando para $3,4 \%$ nas mulheres e ainda mais para algo em torno de $5 \%$ na população de meia-idade. Na população brasileira os dados são em torno de 2,5\% em adultos, 3,4\% meia-idade e 5,5\% em idosos. (POLLOCK, 2013 p.508).
\end{abstract}

Nesse sentido, podemos observar que a FM ainda tem sua real origem desconhecida, mas caracterizase por dores musculares difusas, que podem se manifestar em movimento, mas que piora por períodos inativos do indivíduo. Pelo fato de ainda não ter uma real origem da FM, alguns a consideram como uma síndrome de somatização, pois os seus sintomas se confundem com a depressão maior e a síndrome da fadiga crônica. Porém, com o avanço nos estudos e um crescimento de conhecimento, contribuiu para sua caracterização de síndrome de dor crônica, provocando um distúrbio no processamento dos estímulos sensoriais pelo sistema nervoso, ocasionando uma hipersensibilidade, especialmente dolorosa.

Segundo (POLLOCK, 2013, p.508), os achados mais relevantes apontam para os neurotransmissores relacionados à dor, tanto inibitórios quanto excitatórios. Substâncias como aminas biogênicas, serotoninas e norepinefrinas estão reduzidas em portadores da FM, e substância P (neurotransmissor excitatório à dor) estão em maior número de concentração no fluído cerebrospinal. Essas alterações 
de substâncias poderiam justificar também outros sintomas da FM, como distúrbios no sono e de humor.

A serotonina é um neurotransmissor que exerce sua função no cérebro, promovendo comunicações entre as células nervosas, porém, também pode ser encontrada nas plaquetas do sangue e no sistema digestivo. Ela tem como função de regulação, sendo assim, responsável pelo sono, humor, apetite, ritmo cardíaco, temperatura corporal. Quando encontrada em baixa concentração, pode causar mau humor, dificuldade para dormir, ansiedade e até mesmo a depressão.(ZANIN,2021)

A substância $P$, que é encontrada em maior quantidade em pacientes com $F M$, é um neurotransmissor responsável por transmitir impulsos de dor para o cérebro e para a medula espinhal, produzir um impulso nervoso para dilatar os vasos sanguíneos e fazer com que os fluídos e proteínas das células migrem para fora das células.

Indivíduos fibromialgicos apresentam em seu corpo os chamados de tender points, pode-se achar de 11 até 18 sítios de dor em um indivíduo, porém, vale ressaltar que para uma perspectiva puramente clínica, um paciente pode apresentar com menos de 11 pontos dolorosos. Outros distúrbios também pode aparecem como sintomas: fadiga, sono não-restaurador ( 60 a 90\% dos casos), cefaleia tensional, que é uma dor de cabeça coma sensação de uma faixa abertando-a ( 25 a 58\% dos casos), síndrome do cólon e da bexiga irritáveis(33 a 34\% dos casos) e sintomas como depressão, alteração de humor, ansiedade, traumas (como lesão em "chicote"), infecções como hepatite C e B, HIV, e doença de Lyme, cirurgias, doenças autoimunes, etc. (POLLOCK, 2013. p.509)

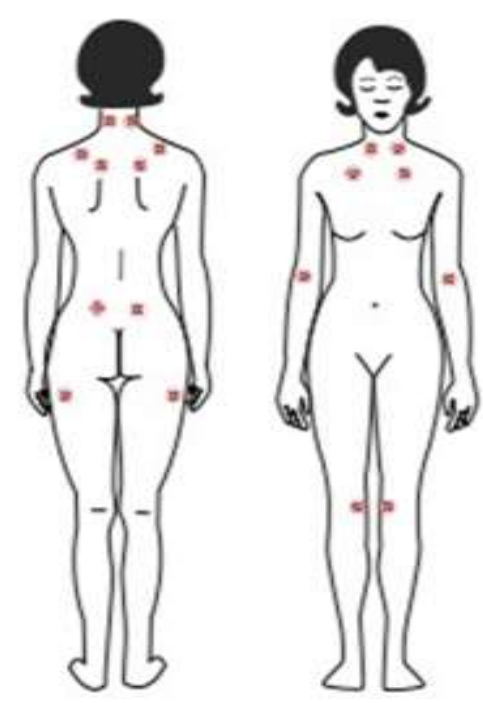


A OMS (Organização Mundial da Saúde ) incluiu a FM, em 1992, na International Statistical Classification of Diseases and Related Health Problems (ICD 10), nesse documento sugere que os padrões de pesquisam sejam adotados pelos critérios do Colégio Americano de Reumatologia.

\section{2- TRATAMENTO COM MEDICAMENTOS/AVALIAÇÃO}

Segundo Pollock (2013), por ainda não se ter uma origem exata e considera-la uma síndrome somatória, alguns medicamentos como antidepressivos tricíclicos e seus derivados, os inibidores de recaptação da serotonina e neropinefrina, são as drogas mais usadas no tratamento da FM, obtendose assim, uma melhora na dor, fadiga, sono, estado depressivo e qualidade de vida. $\mathrm{O}$ tramadol, um analgésico muito utilizado no tratamento, mostrou resultados positivos também, mas seu uso é bem restrito em períodos de dor intensa, por conta de suas contraindicações, efeitos colaterais, como a tolerância e a dependência. Relaxantes musculares também são utilizados no tratamento, entre eles, a ciclobenzaprina tem destaque especial, pois sua estrutura e ação são semelhantes aos antidepressivos tricíclicos e juntamente com a ação de mio relaxante em nível de medula espinhal. Os anti-inflamatórios não foram comprovados cientificamente, por isso não são recomendados para tratamento.

Profissionais da saúde que atendem fibromiálgicos utilizam algumas ferramentas padronizadas para conseguir o histórico de dados do indivíduo, pois permite comparar os impactos do tratamento com outras doenças e a sua evolução do tratamento. Tendo a dor como principal efeito da FM, vários são os instrumentos para avalia-la, como: escalas a mapas de dor, questionário McGill de dor e dolorimetria medida pelo algômetro. Alguns instrumentos específicos avaliam a qualidade de vida, como por exemplo o FIQ ( fibromialgia impact questionnaire), " é um instrumento específico que avalia o impacto na qualidade de vida" desenvolvido por Burckhardt et al. , tem sido muito utilizado. A ansiedade é avaliada pelo inventário de ansiedade traço-estado (IDATE), a depressão, assim como a ansiedade, são sintomas considerados secundários frequentemente severos.

Para Pollock (2013, p.511), a depressão pode ser avaliada pela escala de Beck. Os instrumentos utilizados para se avaliar o sono são o post sleep inventory (PSI) sugerido por Webb e o índice de qualidade de sono de Pittsburgh, desenvolvido por Buysses.

Várias técnicas são utilizadas visando à identificação de como o organismo reage no momento da crise da fibromialgia. 


\section{3- A PRÁTICA DE ATIVIDADE FÍSICA/ ASPECTOS PROFILÁTICOS E INTERVENÇÕES NECESSÁRIAS DO PROFISSIONAL DE EDUCAÇÃO FÍSICA}

Com o objetivo de evitar a introdução de doenças numa população, controlar e/ou evitar o surgimento de novos casos de doenças que já existem e reduzir os efeitos da doença, quando já não é possível evitá-la, verificamos a indispensabilidade da prevenção, e o exercício físico é uma das ações específicas. Essa prática vem sendo utilizada por vários anos como parte do tratamento, como é descrita no livro Exercício na Saúde e na Doença, (VAISBERG \& MARCO T. DE MELLO, 2010, p. 269) descreve que "O uso cauteloso do exercício físico é fundamental para a melhora dos pacientes portadores de fibromialgia", ou seja, deve-se saber quando iniciar o tratamento com exercícios físicos, caso contrário poderá não ter um resultado positivo. A FM, por ser discreta, com relação a morbidade e mortalidade, gera nos indivíduos uma incapacidade não somente emocional quanto física também.

Segundo Vaisberg, (2010, p. 269), quando iniciar o tratamento com atividade física, junto com um profissional capacitado, o indivíduo poderá descrever como está se sentindo, ou seja, uma auto avaliação da dor, caso esse sintoma esteja controlado ou tolerável, pois não poderá ser iniciado a atividade física com a musculatura contraída, isso comprometerá o tratamento e possivelmente a desistência do paciente.

A Sociedade Brasileira de Reumatologia ressalta a importância da prescrição da atividade física como parte do tratamento, "Todo individuo acometido pela fibromialgia obrigatoriamente deve praticar alguma modalidade de atividade física. Em geral o paciente tem a liberdade de escolher aquela na qual se ajusta melhor"

\section{1- A ATUAÇÃO DO PROFISSIONAL DE EDUCAÇÃO FÍSICA: ASPECTOS DE INTERVENÇÃO}

O profissional de Educação Física tem um papel fundamental na sociedade, pois atua diretamente nos campos de tratamento e prevenção de doenças, assim também, podendo fazer parte de uma equipe de multiprofissionais dentro e fora de ambientes hospitalares através do NASF (Núcleo Ampliado de Saúde da Família e Atenção Básica). Criado em 2008 pelo Ministério da Saúde com o foco em apoiar e fortalecer a Atenção Básica no Brasil, aumentando os benefícios de saúde nas redes de serviços. (MINISTÉRIO DA SAÚDE, 2008).

Para Ferreira (2016), no ano de 2008: 
[...] o ministério da saúde cria os (NASF), cujo objetivo é ampliar e melhorar o conjunto de ações oferecidas a população por meio da Estratégia Saúde da família (ESF). Os NASFS são formados por equipes multiprofissionais, incluindo nesse rol algumas profissões da área da saúde que não estavam contempladas na equipe mínima da ESF (FERREIRA, 2016 p.50)

Esse programa permite que os profissionais tenham uma relação e discussão clínica dos casos, podendo assim analisar qual a melhor forma de tratamento para a doença em questão, e também formularem em conjunto projetos terapêuticos para melhoraram sua intervenção no espaço e na saúde da população. A normatização que regulamenta o NASF, bem como a participação dos profissionais de educação física, está organizada na portaria no 2488/2011 e na portaria 3124/2012.

No documento está expresso que:

Podem compor os NASF as seguintes ocupações (conforme código Brasileiro de ocupações- $\quad \mathrm{CBO}$ ): Médico acupunturista; assistente social; profissional/professor de educação física; farmacêutico, fisioterapeuta, fonoaudiólogo; médico ginecologista/obstetra; médico homeopata;; nutricionista; médico pediatra;picólogo;médico psiquiatra;médico do trabalho; médico veterinário; profissional com formação em arte e educação (arte educador); profissional de saúde sanitarista (aquele profissional com graduação na área da saúde e com pós graduação em saúde pública ou saúde coletiva; profissional graduado em saúde pública ou saúde coletiva. (FERREIRA, 2016. p.51-52)

O Profissional de Educação Física estará apto a prescrever exercícios orientados e específicos para cada indivíduo e sua comorbidade estando devidamente formado em bacharelado e legalmente cadastrado no CREF, desta maneira ele estará protegido pela Classificação de Ocupações (CBO), sob o código 2241-40, assim, sendo Profissional da Educação Física na saúde. A nova definição foi inserida no sistema em 17 de fevereiro de 2020, e com ela os profissionais tem maior autenticidade dentro das redes de serviço do Sistema Único de Saúde (SUS), garantindo assim o desenvolvimento de suas atividades de forma remunerada. (CONFEF, PROFISSIONAL DE EDUCAÇÃO FÍSICA NA SAÚDE ESTA NA $\mathrm{CBO})$.

A prática de atividade física orientada, em específico, para portadores de fibromialgia é um grande obstáculo para o indivíduo, a sensibilidade à dor é a maior característica dessa patologia e a atuação do profissional de Educação Física é fundamental, pois as chances da desistência da atividade física pelo indivíduo nos primeiros meses de tratamento são grandes. Todas as modalidades de atividades físicas são recomendadas para melhorarem a qualidade de vida para fibromialgicos, feitas de forma lenda, gradativa e individual, gerando assim a diminuição da intensidade das dores e melhorando a qualidade do sono 
Segundo Gonçalves (2019), traz duas teorias explicativas sobre os efeitos benéficos da atividade física, uma é a elevação dos níveis de endorfina e serotonina, pois estes se encontram em níveis baixos em indivíduos com fibromialgia, e a segunda teoria é que o aumento da temperatura corpórea causa um efeito tranquilizante, ajudando para dor crônica e aguda, sendo de curto em longo prazo variando de indivíduo.

O atual cenário que a sociedade global vem vivenciando teve como consequência uma procura maior por exercícios físicos, tanto em academias, espaços ao ar livre ou dentro de casa, isso porque foram feitos estudos científicos comprovando os benefícios da atividade física. Realizadas de forma regular, a atividade física melhora a função dos macrófagos ao estimular nosso sistema imunológico, além de favorecer a ativação e recirculação dos elementos do sistema imunológico, como imunoglobinas, citocinas anti-inflamatórias, neutrófilos, células NK, células T citotóxicas e B imaturos, articulando o sistema imunológico. (NIGRO et al, 2020; DIXIT, 2020, SILVEIRA et al., 2021).

A pratica de atividade física orientada por profissionais vai muito além de questões estéticas, sua atuação como promotores de saúde e agentes fundamentais no tratamento de doenças tem grande valor na sociedade, atuando na linha de frente no combate e tratamento de diversas doenças juntamente com outros profissionais de outras áreas.

\section{2- EXERCÍCIOS RECOMENDADOS PARA O COMBATE A FIBROMIALGIA: POSSIBILIDADES DE MELHORIA DAS CONDIÇÕES DE SAÚDE.}

Estudos realizador pelo Colégio Americanos de Medicina do Esporte, relatado no livro de Pollock, Fisiologia Clínica de Exercício, relata que:

[...] .os exercícios aeróbicos, para indivíduos acometidos por essa síndrome, são caracterizados por três e cinco vezes na semana, com intensidade entre 55 e 65 a 90\% da frequência cardíaca máxima, ou 40 e 50 a 90\% do consumo de oxigênio de reserva (VO2) e duração de 20 a 60 minutos. (POLLOCK, 2013, p 511)

Esses estudos realizados pelo colégio assinalaram que os exercícios aeróbicos têm mostrado os melhores resultados em ambos os sintomas, como a melhoria da dor, sensibilidade nos tender points e no bem-estar geral. Esses estudos utilizaram também das práticas de fortalecimentos muscular e alongamento, algumas vezes utilizou-se programas aquáticos e de relaxamento. 
Os exercícios aeróbicos são mais citados porque liberam e aumentam os níveis de endorfina, serotonina e cortisol e também melhoram a qualidade de sono e a redução dos níveis de estresse. A FM está ligada diretamente à sensibilidade do indivíduo diante a um estímulo doloroso, e apresentase nos músculos esqueléticos. Pelo fato de não existir uma causa exata do surgimento da FM, muitas vezes o seu tratamento é feito de modo errado, ocasionando para o indivíduo uma piora dos sintomas. Por, ainda, não existir uma cura, o objetivo do tratamento é o controle dos sintomas, como a depressão. Seguindo a linha de tratamento, os exercícios físicos contribuem na melhora do humor e na maioria dos sintomas.

A FM causa grande impacto na qualidade de vida dos indivíduos, esses impactos envolvem fatores familiares, profissionais, pessoais e sociais. A qualidade de vida é impactada conforme a intensidade da dor, a fadiga e a diminuição da capacidade funcional. (SCIELO, REVISTA BRASILEIRA DE REUMATOLOGIA, FIBROMIALGIA, 2011).

A serotonina é um neurotransmissor que atua no cérebro, sua função é estabelecer comunicação entre células nervosas. Esta molécula é produzida por um aminoácido chamado triptofano.

Segundo Zanin (2021), a serotonina tem importante função, como atuar regulando o humor, sono, apetite, ritmo cardíaco, temperatura corporal, sensibilidade e funções cognitivas. A serotonina quando se encontra em níveis baixos pode causar mau humor, dificuldade de dormir, ansiedade e até mesmo a depressão.

As melhores formas de aumentar os níveis de serotonina na corrente sanguínea é consumir alimentos ricos em triptofano, praticar atividades físicas, e em casos mais graves, apelar-se para uso de medicamentos.(ZANIN, 2021 )

A endorfina é um neuro-hormônio produzido pela glândula hipófise, encontrada no cérebro. Ela impede o estresse e a irritação, colaborando para a sensação de satisfação e felicidade. Umas das funções da endorfina é reduzir o estado de tensão do corpo, ela também combate questões emocionais, como ansiedade e depressão.

A prática de atividade física aumenta os níveis de endorfina no organismo, pelos eu efeito analgésico, a endorfina leva ao alivio de tensões musculares e o controle da dor, que é característica predominante em pessoas com FM. 
E ainda o cortisol, produzido pelas glândulas suprarrenais, localizada acima dos rins, o cortisol ajuda o organismo no controle do estresse, reduz inflamações, auxilia para o funcionamento do sistema imune e ajuda a manter os níveis de açúcar no sangue constante, assim como a pressão arterial.

Os níveis de cortisol variam durante o decorrer do dia, pois estão relacionados à atividade diária e à serotonina. O cortisol quando encontrado em baixo nível pode causar sintomas como depressão, cansaço ou fraqueza e outros problemas também. Se estiver em níveis altos pode originar sintomas como perda de massa muscular, ganho de peso ou diminuição da testosterona.

\subsection{1- EXERCÍCIOS COM ALONGAMENTO E COM PESO}

O alongamento deverá ser prescrito como parte importante no tratamento, já que, como consequência de FM, os indivíduos acabam limitando seus movimentos, causando uma atrofia muscular, sendo necessária a recuperação do comprimento funcional, amplitude e correção postural. Apesar de poucos estudos evidenciarem cientificamente, estudos feitos recentes, ptencializam os exercícios de flexibilidade.

Valencia et al. comparam o efeito de um programa de cinesioterapia com exercícios gerais de mobilidade e alongamento com a técnica de alongamento global de Mezières. Os autores observaram efeitos positivos na dor, na flexibilidade e nos sintomas da FM em ambos os grupos após o tratamento que, no entanto, perde-se no decorrer do seguimento. (Pollock, 2013, p. 512)

Segundo (Pollock, 2013, p. 511 e 512), as recomendações feitas pelo Colégio Americano de Medicina do Esporte, os exercícios com peso deveram ser realizados, pelo menos, series de 8 a 10 repetições e de 2 a 3 vezes por semana. "Apesar de vários estudos apontarem diminuição em torno de 20 a $40 \%$ de força e endurance musculares, revisões sistemáticas recentes relatam pobre literatura sobre os efeitos desses exercícios na FM". Alguns indícios concretos apontam positividade na melhora de força muscular, qualidade de vida, e na percepção da dor. Outros aspectos positivos da associação dos treinos aeróbicos e treinos com peso é a melhoria da fadiga, ganho de força geral.

Definições feitas pelo Colégio Americano de Medicina do Esporte, "os exercícios de alongamento têm o objetivo de aumentar a amplitude de movimento, sustentando uma posição de médio desconforto.

" Ele destaca que essa posição de desconforto seja assegurada por tempo de 30 segundos, entre duas a três vezes na semana. 


\subsection{2- EXERCÍCIOS EM AMBIENTE AQUÁTICO E O PILATES}

Apesar de não de ser dados literários sobre a duração, intensidade e frequência dos exercícios em ambiente aquático, Jetoft et al. observavam, juntamente com exercícios de alongamento, aeróbico e fortalecimento muscular, em duas condições de água, uma dessas condições a piscina é aquecida a 34ํC e em solo. Porém, reavaliações recentes, concluíram que as atividades físicas em ambientes aquáticos tiveram resultados satisfatórios no tratamento da FM. "Em geral, as sessões têm duração de 60 minutos, três vezes por semana, e ma intensidade de 60 a $80 \%$ da frequência cardíaca máxima. " Ainda são pouco as evidencias que beneficiam a hidroterapia, assim como, há uma insuficiência metodológica e pequenos estudos.

Segundo (CRUZ, 2013), O pilates, é uma modalidade que consciente em controle de flexibilidade e amplitude de movimento, sendo um grande aliado à reeducação postural. O pilates é muito procurado, principalmente por quem necessita de uma correção postural ou outra particularidade especial, como vem sendo nos casos de portadores de FM

Conforme (BORGES, 2011), o pilates consiste em uma série de exercícios que priorizam o fortalecimento do core, que são os músculos abdominais, lombares, glúteos e oblíquos, a postura, coordenação da respiração com o movimento, unindo métodos técnicos asiáticos e orientais

\section{4- FIBROMIALGIA NA PANDEMIA}

O Presidente da Associação Brasileira de Reumatologia José Roberto Provenza ressalta que as pessoas com doenças reumáticas e outras enfermidades crônicas tem alto risco de desenvolver a Covid-19 com um quadro grave e com o tratamento sem interrupções. Os cuidados com a imunidade atualmente são extremamente importantes e como os fibromiálgicos já possuem seu sistema imunológico prejudicado, isso faz com que eles fiquem mais vulnerável ao novo corona vírus.

O profissional da Educação Física tem papel fundamental nesse momento, pois ele pode prescrever uma rotina de atividades físicas para aqueles que estão em casa, ajudando assim o sistema imunológico e o alivio do estresse vivido diariamente por todo mundo e não só pra quem tem a FM.

\section{5- METODOLOGIA}

Este é um trabalho de características descritiva, exploratória e bibliográfica, produzido através da livraria eletrônica da Scielo, da obra de Pollock, Fisiologia Clínica do Exercício, publicada em 2013, Exercícios na Saúde e na Doença de Marco T. de Mello e Mauro Vaisberg e também pela Sociedade 
Brasileira de Fibromialgia. Em sua produção foram empregadas palavras-chaves como "fibromialgia" e "revisão".

Como forma de atender aos objetivos da pesquisa, foi necessária a leitura minuciosa e detalhada sobre a temática da fibromialgia, bem como os estudos que se aproximam analisar essa doença. A partir das leituras realizadas fizemos um levantamento da produção e dialogamos com o referencial teórico do estudo. Na perspectiva de organizarmos melhor o estudo, procuramos durante o processo de leitura e escrita do artigo, aprofundar em alguns pontos ao qual consideramos relevantes sobre a fibromialgia e suas consequências para a saúde da população, bem como qual seria a contribuição do profissional de educação física na prevenção e intervenção, num processo de melhorias das condições de vida e saúde dos considerados acometidos pela doença.

Também foi feito uma busca em outros sites de pesquisa, porém foram constatados dados insuficientes e até mesmo saturados para serem agregados nesse trabalho, levando somente em consideração os dados obtidos como mais clareza a respeito do objeto de pesquisa, ou seja, as possíveis causas, tratamento medicamentoso e a relação do Profissional da Educação Física como papel fundamental positivo no tratamento da FM.

\section{6- CONSIDERAÇÕES FINAIS}

Apesar dos estudos realizados, ainda não se constatou uma origem exata da FM, considerando suas causas desconhecidas, mas tento como principal sintoma a dor, levando o indivíduo a ter problemas, não somente físicos, mas também psíquicos, comprometendo sua qualidade de vida.

O tratamento para os portadores da síndrome tem que ser supervisionado por uma equipe multidisciplinar, pois envolve tratamento medicamentoso acompanhado de atividades físicas, como exercícios aeróbicos, exercícios com peso, alongamento, pilates e em ambientes aquáticos. De todo modo, a fibromialgia necessita de vários estudos que busquem esclarecer sua origem, porém, há a conclusão de que os exercícios físicos terapêuticos são de suma importância para o indivíduo fibromialgico.

Sendo assim, desta maneira torna-se fundamental a intervenção do profissional de educação física no momento em que surgir o diagnóstico, o sujeito acometido por essa doença precisará de um acompanhamento de equipes multiprofissionais da área, e a atividade física deverá parte desse tratamento com exercícios orientados e prescritos em função da individualidade de cada um dos pacientes. 
Considerando também o novo cenário global que estamos vivendo, a prática de atividade física tornou-se um aliado importantíssimo para o combate ao novo coronavírus COVID-19, pois os benefícios de uma rotina de exercícios físicos se tornam a primeira linha de defesa, já que nosso sistema imunológico é fortificado e assim, mesmo que contraindo o vírus, pode ser que sintamos seus efeitos de forma reduzida, porém, vale ressaltar que o novo coronavírus pode ser fatal para quem possuir algum tipo de comorbidade. 


\section{7- REFERÊNCIAS}

BRITO, CONFESSOR et al. Medicina: os benefícios da prática de atividade física no combate à covid-19: uma revisão de literatura integrativa. 10.22533/at.ed.59621140515. São Paulo, 2019. Disponível em:<https://www.atenaeditora.com.br/post-artigo/52143> Acesso em 03/06/2021.

CRUZ, MARQUES et al. Benefícios do método pilates nos sintomas da fibromialgia. FAIPE, v. 8, n. 1, p. 49-59, jan./jun. 2018. Disponível em:

<https://revistafaipe.com.br/index.php/RFAIPE/article/view/99/87 > Acesso em 03/06/2021.

FERREIRA, JOEL SARAIVA O percurso da saúde pública no Brasil: do empirismo à promoção da saúde. Campo Grande-MS, Ed. UFMS, 2016

GUILHARDI, J. H. Sobre Comportamento e Cognição (Vol. 18). Expondo a Variabilidade. (2006). Disponível em: <https://www.researchgate.net/profile/Daniel_Matos3/publication/342747917_18__Guilhardi_J_H_2006_Sobre_Comportamento_e_Cognicao_Vol_18_Expondo_a_Variabilidade/links/ 5f049e04a6fdcc4ca4533de0/18-Guilhardi-J-H-2006-Sobre-Comportamento-e-Cognicao-Vol-18Expondo-a-Variabilidade.pdf\#page=238> Acesso em 05/04/2021.

HEALTHCARE, Omron. Entenda o que é endorfina e como ela funciona no seu corpo. 16/03/2021. Disponível em: <https://conteudo.omronbrasil.com/o-que-e-endorfina/> Acesso em 05/04/2021.

MELLO, T. M.; VAISBERG, M. Exercícios na Saúde e na Doença. Barueri-SP: Manole, 2010.Pollock. Fisiologia Clínica do Exercício. Barueri-SP: Manole, 2013.

MINISTÉRIO DA SAÚDE. Núcleo ampliado de saúde e família. Brasília, 2008. Disponível em: $<$ https://aps.saude.gov.br/ape/nasf> Acesso em 03/06/2021.

OLIVEIRA, M.F.; SPECIALLI, J.G. Cefaléia crônica diária: conceitos e tratamentos. Medicina, Ribeirão Preto,35: 455-463, out./dez. 2002. Disponível em:

<http://www.revistas.usp.br/rmrp/article/view/867/879> Acesso em 01/04/2021.

PROVENZA, JR. et al. Fibromialgia, Revis.Bras.Reumatol.vol44.nf6. São Paulo: 2004. Disponível em: <http://www.scielo.br/scielo.php?script=sci_arttext\&pid=S0482-50042004000600008> Acesso em 27/03/2020.

SOCIEDADE BRASILEIRA DE REUMATOLOGIA. Tratamento da fibromialgia. São Paulo: 2011. Disponível em: <https://www.reumatologia.org.br/orientacoes-ao-paciente/tratamento-da-fibromialgia/ > Acesso em 01/03/2020.

ZANIN, TATIANA. Serotonina: o que é, para que serve e quando está baixa. Jornal Tua saúde. São Paulo 26/03/2021. Disponível em: <https://www.tuasaude.com/serotonina/ > Acesso em 03/06/2021. 


\section{Capítulo 4}

\section{doi $10.37423 / 211004852$}

\section{AVALIAÇÃO DA COBERTURA VACINAL DE CRIANÇAS MENORES DE 5 ANOS NO HAITI - 2016-2018}

Cirina Bayard

Olbichoo Lexius

Maria de Nazaré de Souza Ribeiro

Edinilza Ribeiro dos Santos

\section{Gianne Zupelari dos Santos Melo}

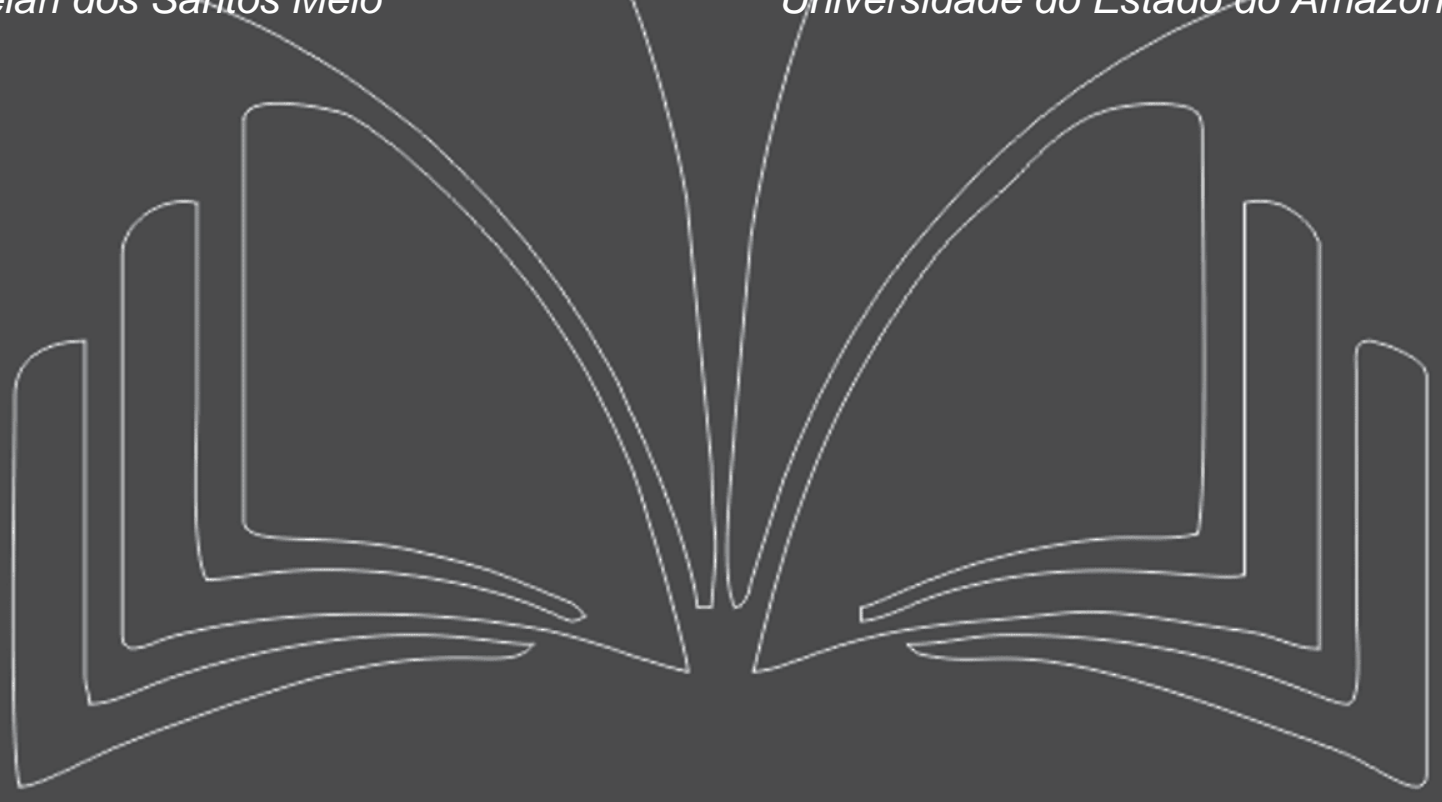




\section{Resumo:}

Introdução: O Haiti é conhecido como o país mais pobre do Hemisfério Ocidental, com alguns dos indicadores de saúde mais baixos do mundo devido a uma série de fatores, incluindo infraestrutura deficiente e baixos gastos com saúde pública, onde crianças morrem todos os anos de doenças que poderiam ser evitadas com vacinas, como difteria, coqueluche, sarampo e tétano neonatal. Objetivo: Avaliar a cobertura da vacinal de crianças menores de 5 anos no Haiti entre 2016-2018. Método: Estudo descritivo abrangendo análise temporal da cobertura vacinal de crianças menores de 5 anos no Haiti entre os anos de 2016 e 2018. Resultados: A cobertura melhorou com o tempo, no Haiti, e é importante manter e reforçar as medidas para melhorar o acesso aos serviços de imunização no momento recomendado, a fim de maximizar a proteção que as vacinas se destinam a proporcionar. Para além de visarem as populações mais vulneráveis, estas ações devem reduzir o número de contraindicações falsas, apoiar a importância de administrar múltiplas injeções, tanto aos vacinadores como aos pais, e encorajar ainda mais a utilização de horários acelerados nos casos em que os atrasos já estão a ocorrer ou são inevitáveis. Conclusão: Apesar das melhorias, a mortalidade infantil continua a ser uma preocupação, pelo que há espaço para otimismo nos próximos anos no que diz respeito à implementação de programas de imunização. A cobertura vacinal que atinge todas as crianças visadas, independentemente da sua localização, continua a ser um grande desafio para a gestão.

Palavras-chave: Haiti; Cobertura Vacinal; Imunização; Saúde da Criança 


\section{INTRODUÇÃO}

As vacinas estão entre as medidas de saúde pública mais eficazes para a prevenção, eliminação e controle das doenças transmissíveis. O Programa de Imunização Organizada é reconhecido como um dos investimentos mais rentáveis em saúde no Haiti. O Plano Ampliado de Vacinação (PEV), desenvolvido desde 1983, é gerido pelo Departamento do PEV do Ministério da Saúde Pública e da População (MSPP) (MSPP, 2013). O Comitê Coordenador Inter-Agências (CCI), presidido pelo Ministério da Saúde, é o responsável pela política de imunização no país, e assegura a coordenação e controle de atividades suscetíveis para tornar possível o controle ou erradicação de doenças que podem ser controladas por vacinação (BRASIL, 2014).

No Haiti, três novas vacinas têm sido introduzidas no esquema de vacinação infantil em torno dos últimos seis anos. A mais recente foi a vacina pentavalente, em 2012, que substituiu a DTP, passando a imunizar crianças contra difteria, tétano, coqueluche, pneumonia, hepatite $B$, meningite e outras infecções por Haemophilus influenzae; a vacina contra rotavírus, em 2013 (IHE, 2018); e a vacina pneumocócica (PCV13), em 2018, que protege as crianças contra pneumonia, meningite, sinusite, infecções de ouvido e sepse. A implementação adequada do PEV é a maneira mais eficaz e barata de reduzir significativamente a mortalidade infantil (JUSTE, 2018; UEP, 2019).

Em 2018, a população do Haiti era estimada em 11.123.183, o que correspondia a uma densidade de 404 pessoas por quilômetro quadrado, da qual 55,28\% da população residente em áreas urbanas. As Crianças menores de 15 anos representavam 33,24\% da população (BANQUE MONDIALE, 2021).

Em se tratando de divisão administrativa, o país está dividido em dez departamentos a saber: Oeste, Sul, Sudeste, Grande Anse, Nippes, Norte, Noroeste, Nordeste, Centro e Artibonite. Além disso, cada um desses departamentos é dividido em comunas e estas em seções comunais totalizando 140 comunas e 570 seções comunais. A capital do país é Porto Príncipe (IHE, 2017).

O Haiti é conhecido como o país mais pobre do Hemisfério Ocidental, com alguns dos indicadores de saúde mais baixos do mundo devido a uma série de fatores, incluindo infraestrutura deficiente e baixos gastos com saúde pública, onde crianças morrem todos os anos de doenças que poderiam ser evitadas com vacinas, como difteria, coqueluche, sarampo e tétano neonatal. De acordo com os dados mais recentes do inquérito EMMUS-VI, a taxa de mortalidade infantil é muito elevada, 59 mortes por mil nascidos vivos (IHE, 2017). 
As razões apresentadas são a inacessibilidade devido ao afastamento dos centros de saúde, a falta de disponibilidade de vacinas, a falta de pessoal de saúde qualificado, infraestrutura de saúde de má qualidade etc. Por outro lado, deve-se notar que o MSPP, em colaboração com certas organizações locais e internacionais, tem feito grandes esforços para reduzir a taxa de mortalidade infantil.

As doenças evitáveis por vacinação continuam sendo uma das principais causas de morbidade, incapacidade e mortalidade no Haiti. O sarampo e o tétano neonatal, em particular, são as causas da maioria das mortes registradas a cada ano em crianças menores de 5 anos de idade (IHE, 2019), portanto, a imunização infantil é um passo fundamental para o desenvolvimento saudável de todas as crianças. Esta medida continua a ser um excelente meio de avaliar a saúde de populações e se apresenta como um bom reflexo da susceptibilidade a doenças evitáveis por vacinação, uma vez que são necessários níveis elevados de cobertura de imunização para atingir os objetivos de redução de doenças preveníveis por vacina (VPD) (ZAMBONIN et al, 2019). É importante monitorizar as diferentes medidas de cobertura de imunização de forma contínua. No mesmo sentido, um bom controle da cobertura da imunização permite um olhar crítico sobre o desempenho e a organização dos serviços de imunização, bem como sobre a aceitabilidade das vacinas por uma população (MORAES e RIBEIRO, 2008).

\section{OBJETIVO}

Avaliar a cobertura da vacinal de crianças menores de 5 anos no Haiti entre 2016-2018.

\section{MÉTODO}

Trata-se de estudo descritivo abrangendo análise temporal da cobertura vacinal de crianças menores de 5 anos no Haiti entre os anos de 2016 e 2018. Os dados foram obtidos do Levantamento de Mortalidade, Morbidade e Uso de Serviços (EMMUS VII 2016-2017), da Avaliação da prestação de serviços de saúde (EPSSS 2017-2018) e o relatório estatístico do ano de 2018, do Ministério da Saúde Pública e População (MSPP) e da Organização Mundial da Saúde (OMS).

Os resultados e discussão estão categorizados da seguinte forma: Características dos serviços de imunização infantil no Haiti e oferta à população infantil; Cobertura vacinal de crianças menores de um ano em 2018 no Haiti; Cobertura de todas as vacinas básicas e planejamento de micro imunização; Frequência dos serviços de imunização; Posse e disponibilidade de registros de vacinação, comunicação e mobilização social 


\section{RESULTADOS E DISCUSSÃO}

\section{CARACTERÍSTICAS DOS SERVIÇOS DE IMUNIZAÇÃO INFANTIL NO HAITI E OFERTA À POPULAÇÃO INFANTIL}

O programa de vacinação no Haiti visa as seguintes doenças: Tuberculose, Poliomielite, Difteria, Tosse convulsa, Tétano, Infecções por Haemophilus influenzae tipo B (meningite, pneumonia), Sarampo, Rubéola, Diarreia por rotavírus e Infecções pneumocócicas.

A Tabela 1 mostra que pouco mais de 7 em 10 (71\%) das instituições que oferecem serviços de imunização infantil tinham diretrizes para imunização no momento da pesquisa. Nos hospitais (78\%) e instituições de saúde dos departamentos do Norte (89\%), Nippes (88\%) e Grande-Anse (82\%), esses percentuais são significativamente mais elevados. Por outro lado, este documento estava menos disponível nas instituições do setor privado sem fins lucrativos (61\%), bem como nas instituições dos departamentos do Ocidente (58\%) e do Centro (68\%) (IHE, 2019).

Os resultados por setor mostram que é no setor privado sem fins lucrativo, registra-se a menor proporção de instituições com pelo menos um prestador formado em PEV (25\%). Nos departamentos, vemos que o Nordeste registra a maior proporção de instituições, com, pelo menos, um prestador de serviço capacitado (55\%); em contrapartida, o Sudeste apresenta a proporção mais baixa (23\%) (Tabela 1).

Tabela 1 - Características dos serviços de imunização infantil no Haiti. 2017-2018

\begin{tabular}{|c|c|c|c|c|c|c|c|}
\hline Variáveis & Diretriz & $\begin{array}{l}\text { Equipe } \\
\text { treinada }\end{array}$ & $\begin{array}{c}\text { Refrigera } \\
\text { dor de } \\
\text { vacinas }\end{array}$ & $\begin{array}{c}\text { Portador de } \\
\text { vacina com } \\
\text { conservante } \\
\text { frio }\end{array}$ & $\begin{array}{l}\text { Caixas } \\
\text { de para } \\
\text { perfuro } \\
\text { cortante }\end{array}$ & $\begin{array}{c}\text { Seringas } \\
\text { agulhas }\end{array}$ & $\begin{array}{c}\text { Número de } \\
\text { instituições que } \\
\text { oferecem serviços } \\
\text { de imunização } \\
\text { infantil }\end{array}$ \\
\hline \multicolumn{8}{|l|}{ Tipo de instituição } \\
\hline Hospital & 78 & 32 & 79 & 37 & 100 & 92 & 78 \\
\hline Centro de saúde com cama & 74 & 35 & 74 & 51 & 92 & 87 & 106 \\
\hline Centro de saúde sem cama & 69 & 28 & 62 & 53 & 91 & 84 & 205 \\
\hline Dispensário & 70 & 44 & 72 & 47 & 93 & 91 & 262 \\
\hline \multicolumn{8}{|l|}{ Setor } \\
\hline Público & 73 & 39 & 79 & 44 & 95 & 91 & 300 \\
\hline $\begin{array}{lll}\text { Privado } & \text { sem } & \text { fins } \\
\text { lucrativos } & & \end{array}$ & 61 & 25 & 60 & 59 & 87 & 87 & 75 \\
\hline Privado para o lucro & 68 & 27 & 54 & 60 & 88 & 80 & 136 \\
\hline Misturado & 76 & 45 & 71 & 42 & 96 & 91 & 140 \\
\hline
\end{tabular}




\begin{tabular}{|c|c|c|c|c|c|c|c|}
\hline \multicolumn{8}{|l|}{ Departamento } \\
\hline Oeste & 58 & 29 & 53 & 67 & 89 & 81 & 211 \\
\hline Área metropolitana & 61 & 29 & 55 & 65 & 89 & 82 & 102 \\
\hline Resto oeste & 56 & 28 & 50 & 70 & 89 & 81 & 109 \\
\hline Sudeste & 77 & 23 & 84 & 53 & 100 & 98 & 43 \\
\hline Norte & 89 & 39 & 78 & 28 & 94 & 89 & 54 \\
\hline Nordeste & 73 & 55 & 91 & 27 & 95 & 86 & 22 \\
\hline Artibonite & 78 & 31 & 69 & 43 & 90 & 87 & 84 \\
\hline Centro & 68 & 32 & 90 & 10 & 100 & 97 & 31 \\
\hline Sul & 70 & 43 & 65 & 40 & 90 & 90 & 60 \\
\hline Grande-Anse & 82 & 47 & 84 & 33 & 98 & 98 & 45 \\
\hline Noroeste & 74 & 47 & 78 & 62 & 96 & 91 & 77 \\
\hline Nippes & 88 & 44 & 100 & 16 & 96 & 92 & 25 \\
\hline Juntos & 71 & 36 & 70 & 48 & 93 & 88 & 651 \\
\hline
\end{tabular}

Fonte: IHE, 2019

Entre as 651 instituições que oferecem serviços de vacinação infantil, quase metade (48\%) possuía refrigerador (porta-vacina) com briquete (bolsa de gelo) e 7 em cada 10 (70\%) possuía geladeira para vacinas. No Ocidente a proporção de instituições com geladeira é maior (67\%) e no Centro (10\%) é menor. A disponibilidade de um refrigerador de vacina varia significativamente, sendo maior em hospitais e clínicas sem leito (79\% e $72 \%$ respectivamente), nos setores público e misto (79\% e $71 \%$ respectivamente) e em instituições nos departamentos do Centro (90\%), Nordeste (91\%) e Nippes $(100 \%)$.

Quase todas as instituições (93\%) possuíam uma caixa de segurança para perfurocortantes. Em contrapartida, a proporção dos que possuíam seringas e agulhas foi menor (88\%), com exceção dos hospitais (92\%). Para vacinas, a variação foi significativa, sendo maior nos hospitais e dispensários/CSL (79\% e 72\% respectivamente), nos setores público e misto (79\% e $71 \%$ respectivamente) e nas instituições dos departamentos do Centro (90\%), Nordeste (91 \%) e Nippes (100\%).

No Gráfico 1 observa-se que quase 6 em cada 10 instituições (58\%) tinham, no dia da pesquisa, pelo menos um frasco ou ampola não expirado de cada uma das vacinas infantis básicas. A análise, de acordo com o departamento, revelou grandes variações: a porcentagem de instituições que tinham todas as vacinas infantis básicas variou de 36\% em Artibonite a 92\% em Nippes. 


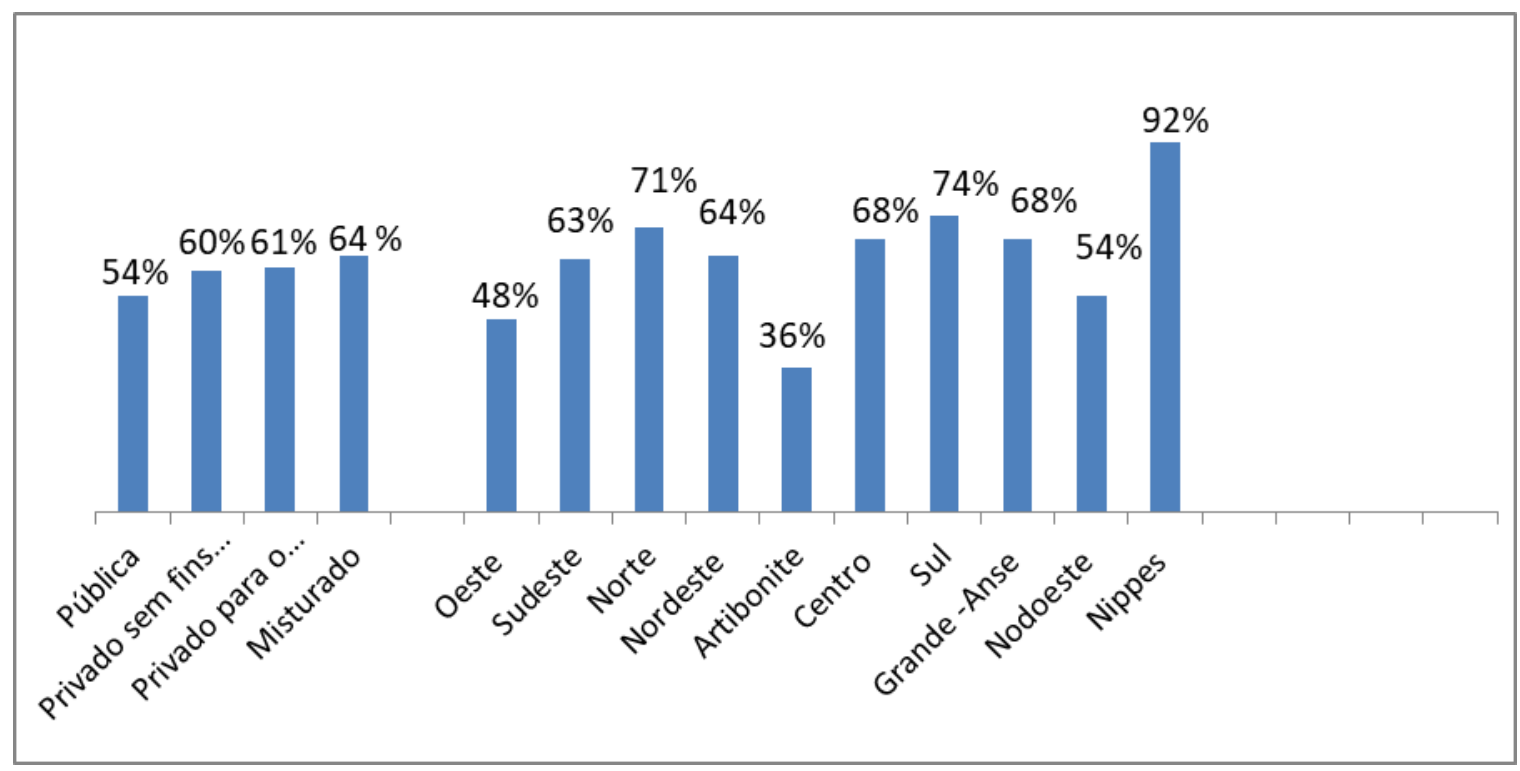

Gráfico 1- Porcentagem de instituições com todas as vacinas infantis linhas de base não expiradas observadas no dia da pesquisa, por setor e departamento

Fonte: IHE, 2019

Os resultados por tipo de instituição não mostraram variações significativas, a proporção de instituições que tinham todas as vacinas no dia da pesquisa variou de $56 \%$ em hospitais a $59 \%$ em centros de saúde, com leitos e clínicas com $57 \%$

Com relação ao tipo de vacina, mais de 9 dentre 10 unidades de saúde (95\%) tinham Pentavalente/DTP no dia da pesquisa. Os demais antígenos (poliomielite oral, poliomielite injetável, vírus Pentavalente e Rotavírus) foram observados em pouco mais de $80 \%$ das instituições; BCG e vacina contra sarampo em $79 \%$. Ressalta-se que o departamento de Nippes se destaca dos demais departamentos por elevados percentuais de instituições que, no dia da pesquisa, possuíam Pentavalente (100\%), vacina oral contra poliomielite (96\%), poliomielite injetável (100\%), vacina contra sarampo (96\%) e vacina BCG (100\%).

\section{COBERTURA VACINAL DE CRIANÇAS MENORES DE UM ANO EM 2018 NO HAITI}

A cobertura vacinal (CV) é a proporção de uma população alvo que recebeu as doses necessárias de uma vacina contra uma doença evitável por vacinação. Ela é calculada pelo número de doses aplicadas, dividido pela população alvo (MORAES e RIBEIRO, 2008). Outra medida amplamente utilizada de cobertura de imunização é também definida como a percentagem de crianças que receberam todas as doses necessárias de diferentes vacinas numa determinada idade. Isto é conhecido como a medida combinada de cobertura de imunização (ZAMBONI et al, 2019). 
A Coordenação Nacional do Programa de Vacinação (UCNPV) visa garantir a cobertura de $90 \%$ das crianças menores de um ano para todas as vacinas, exceto BCG. Essa meta é usada para medir os resultados do programa nos níveis nacional e departamental. No geral, os resultados obtidos são inferiores ao objetivo perseguido pela UCNPV. Os principais antígenos considerados nesta seção do relatório fazem parte do PAV. São eles: BCG, Sarampo/Rubéola (RR), Pentavalente, Pólio e Rotavírus. A análise dos dados da Tabela 2 mostra que cerca de 8 em cada 10 crianças (77\%) foram vacinadas com BCG e cerca de 7 em cada 10 crianças (69,9\%) com RR. Em nível departamental, o Centro e o Nordeste apresentam coberturas superiores a 100,0\% para o BCG, o que pode estar relacionado à subestimação das populações dessas áreas ou à inclusão de crianças de outras áreas de departamentos vizinhos entre os vacinados.

Em relação ao RR, o objetivo do programa foi alcançado apenas no departamento Nord-Est (94,2\%). Seja para BCG e RR, a menor cobertura é observada nos departamentos do Sul (RR: 34.7\% / BCG: 49.7\%) e Nippes (RR: 55,4\% / BCG: 59.0\%) (Tabela 2).

Tabela 2- Distribuição de crianças menores de um ano vacinadas contra sarampo, rubéola e tuberculose, por departamento geográfico, no Haiti em 2018.

\begin{tabular}{lccc}
\hline Departamento & $\begin{array}{c}\text { Crianças menores de 1 } \\
\text { ano (2,39\%) }\end{array}$ & Cobertura (\%) \\
\cline { 3 - 4 } & 42548 & BCG & RR \\
\hline Artibonite & 18379 & 89.1 & 75.2 \\
Centro & 11534 & 112.2 & 82.0 \\
Grande-Anse & 8436 & 99,4 & 88.6 \\
Nippes & 26284 & 59.0 & 55.4 \\
Norte & 9703 & 80,8 & 68.3 \\
Nordeste & 17950 & 100.9 & 94.2 \\
Nordoeste & 99249 & 65.4 & 60.5 \\
Oeste & 19087 & 68.3 & 69.7 \\
Sul & 15580 & 49.7 & 34.7 \\
Sudeste & $\mathbf{2 6 8 7 5 0}$ & 81.7 & 77.9 \\
\hline Total & (250.7 & $\mathbf{7 7 , 3}$ & $\mathbf{6 9 . 9}$ \\
\hline \hline
\end{tabular}

Fonte: Relatório estatístico do ano de 2018

A Tabela 3 refere-se à cobertura da primeira e terceira dose das vacinas Pentavalente e Pólio. No que se refere a Pentavalente 1, quatro departamentos (Centro, Grande-Anse, Nordeste e Sudeste) tiveram cobertura maior ou igual a 100\%, possivelmente devido a problemas de sobreposição de serviços nas 
intervenções das áreas dos departamentos vizinhos; a cobertura mais baixa foi observada nos departamentos do Sul (51\%) e Nippes (63\%). Para Pentavalente 3, exceto para o departamento Grande-Anse, os resultados mostram uma tendência semelhante ao de Penta 1.

Tabela 3 - Distribuição de crianças menores de um ano que receberam a primeira e terceira doses de vacina pentavalente e contra poliomielite, por área geográfica, no Haiti em 2018

\begin{tabular}{lccccc}
\hline \hline Departamento & $\begin{array}{c}\text { Crianças menor de 1 } \\
\text { ano (2,39\%) }\end{array}$ & \multicolumn{4}{c}{ Cobertura (\%) } \\
\cline { 3 - 5 } & & Penta 1 & Penta 3 & Polio 1 & Polio 3 \\
\hline Artibonite & 42548 & 90.3 & 80.2 & 77.5 & 63.8 \\
Centro & 18379 & 121.6 & 103.6 & 103.0 & 73.7 \\
Grande-Anse & 11534 & 101.8 & 89.4 & 86.6 & 71.8 \\
Nippes & 8436 & 61.7 & 59.0 & 47.7 & 42.4 \\
Norte & 26284 & 85.6 & 81.3 & 66.2 & 54.2 \\
Nordeste & 9703 & 101.6 & 105.6 & 83.0 & 69.4 \\
Nordoeste & 17950 & 81.1 & 74.1 & 63.0 & 61.0 \\
Oeste & 99249 & 81.4 & 76.5 & 67.2 & 61.0 \\
Sul & 19087 & 50.1 & 44.3 & 40.4 & 29.3 \\
Sudeste & 15580 & 100.0 & 100.5 & 66.2 & 68.5 \\
\hline \multirow{2}{*}{ Total } & $\mathbf{2 6 8} \mathbf{7 5 0}$ & $\mathbf{8 5 . 8}$ & $\mathbf{7 9 . 4}$ & $\mathbf{6 9 . 7}$ & $\mathbf{6 0 . 0}$ \\
\hline \hline
\end{tabular}

Fonte: Relatório estatístico do ano de 2018

Tabela 4 - Distribuição de crianças menores de um ano de idade que receberam Rotavírus dependendo da dose e do departamento geográfico MSPP, no Haiti no ano de 2018

\begin{tabular}{|c|c|c|c|}
\hline \multirow[t]{2}{*}{ Departamento } & \multirow[t]{2}{*}{$\begin{array}{c}\text { Crianças menores de } 1 \\
\text { ano }(2,39 \%)\end{array}$} & \multicolumn{2}{|c|}{$\begin{array}{c}\text { Cobertura da vacina contra Rotavírus } \\
(\%)\end{array}$} \\
\hline & & Dose 1 & Dose 2 \\
\hline Artibonite & 42548 & 88.6 & 82.6 \\
\hline Centro & 18379 & 107.0 & 91.5 \\
\hline Grande-Anse & 11534 & 103.2 & 100.6 \\
\hline Nippes & 8436 & 60.5 & 60.2 \\
\hline Norte & 26284 & 79.7 & 71.5 \\
\hline Nordeste & 9703 & 103.2 & 102.3 \\
\hline Nordoeste & 17950 & 77.7 & 68.6 \\
\hline Oeste & 99249 & 75.5 & 68.6 \\
\hline Sul & 19087 & 49.1 & 44.6 \\
\hline Sudeste & 15580 & 97.8 & 94.0 \\
\hline Total & 268750 & 81.4 & 74.8 \\
\hline
\end{tabular}


Para todas as vacinas consideradas, o Sul e o Nippes continuam sendo os departamentos em que a cobertura vacinal infantil é mais baixa.

\section{COBERTURA DE TODAS AS VACINAS BÁSICAS E PLANEJAMENTO DE MICRO IMUNIZAÇÃO}

No âmbito do Plano Ampliado de Vacinação (PEV), uma criança é considerada totalmente imunizada se tiver recebido BCG contra a tuberculose e a dose de vacina contra a poliomielite ao nascer; as doses Pentavalentes (DTP - Hepatite B - Hib); as três doses de DTP contra difteria, tétano e coqueluche; as três doses da vacina contra a poliomielite; e a vacina contra o sarampo e rotavírus. Todas estas vacinas devem ter sido administradas à criança no primeiro ano de vida.

De acordo com informações dos registos de imunização ou das declarações das mães, 4 em cada 10 crianças de 12-23 meses receberam todas as vacinas básicas. Em contrapartida, 10\% não receberam nenhuma vacina. Apenas $18 \%$ das crianças receberam todas as vacinas apropriadas para o seu grupo etário. Especificamente, $83 \%$ das crianças entre os 12-23 meses receberam BCG, 55\% receberam a terceira dose de DTP/Pentavalent, 54\% receberam a terceira dose de poliomielite, 58\% receberam a segunda dose de Rotavirus, e $61 \%$ de sarampo. Apenas $38 \%$ das crianças entre os $12-23$ meses de idade receberam a dose 0 de poliomielite (ao nascer). Há um desperdício significativo entre doses de vacina contra Pentavalente, poliomielite e Rotavírus (IHE, 2017).

De $84 \%$ da primeira dose de Pentavalente, a cobertura cai para 55\% na terceira. Para a poliomielite, a proporção cai de $84 \%$ da primeira dose para $54 \%$ na terceira. Quanto ao Rotavirus, entre a primeira e a segunda dose, a proporção cai de $73 \%$ para $58 \%$ (IHE, 2017).

O relatório assinala que a cobertura vacinal varia de acordo com certas características sociodemográficas. Diminui de acordo com a classificação de nascimento e é mais elevado entre as meninas do que entre os meninos ( $44 \%$ das meninas receberam todas as vacinas básicas em comparação com 38\% dos meninos). A proporção de crianças que receberam todas as vacinas básicas é maior nas zonas urbanas do que nas zonas rurais (50\% contra $37 \%$ ).

(IHE, 2017)

O planejamento da micro imunização é um processo que permite que a comunidade participe da melhoria da cobertura vacinal e que as equipes melhorem a cobertura vacinal por meio do monitoramento local periódico e da implementação de estratégias corretivas por todas as partes interessadas. A Avaliação da prestação de serviços de saúde EPSSS) estava interessada na existência de um microplanejamento para as atividades de imunização ao nível das instituições em 
causa. O estudo apresenta, nas instituições que oferecem serviços de imunização, o percentual das que possuem documento de microplanejamento.

Entre as 651 instituições que oferecem serviços de vacinação infantil, pouco mais da metade (53\%) tinha um documento de microplanejamento para atividades de imunização. A presença desse documento foi menos frequente em clínicas (48\%) e em instituições privadas com fins lucrativos (43\%). As instituições do Sul (27\%), Sudeste (44\%) e Oeste (47\%) registraram percentuais abaixo da média nacional.(IHE, 2019)

Certos elementos, como o mapa da área atendida, a população-alvo, o tipo, a hora e a localização da estratégia avançada, devem ser incluídos no documento de microplanejamento. Das 343 instituições com documento de microplanejamento de imunização, $72 \%$ possuíam documentos que continham informações sobre a área atendida e $81 \%$ tinham informações sobre a populaçãoalvo. Um pouco mais de 6 instituições em 10 inseriram as informações adicionais encontradas no documento de microplanejamento, a população-alvo é maior nos dispensários/CCS e hospitais (86\%), no setor público (87\%) e no departamento do Nippes (100\%). Além disso, os percentuais de instituições consideradas na área de atendimento no documento também são maiores nas clínicas / CCS (76\%), no setor publico (80\%) e no Departamento de Nippes (100\%).(IHE, 2019)

\section{FREQUÊNCIA DOS SERVIÇOS DE IMUNIZAÇÃO}

No geral, de acordo com a pesquisa, cerca de 6 em cada 10 instituições oferecem a vacina contra poliomielite, pentavalente, DTP e Rotavírus pelo menos 5 dias por semana, e cerca de uma em cada cinco instituições oferecem apenas um ou dois dias por semana. Por outro lado, em relação ao sarampo e ao BCG, as proporções são menores: apenas 35\% das instituições oferecem a vacina contra o sarampo pelo menos 5 dias na semana; para BCG, a proporção é de apenas 23\%. Quase 4 em cada 10 instituições (38\%) oferecem vacinação contra o sarampo 1 a 2 dias por semana e quase metade (47\%), BCG 1 a 2 dias por semana (IHE, 2019).

Seja qual for a vacina, a oferta de serviços pelo menos 5 dias por semana é mais frequente ao nível dos hospitais e instituições do setor público, exceto para a BCG que é oferecida tanto em instituições do setor público como na mista (27\%). Nos hospitais, a oferta de alta frequência de vacinação contra poliomielite, oral ou injetável, Pentavalente e Rotavírus está disponível em pelo menos 70\% dos casos. Por outro lado, a disponibilidade do serviço de vacina contra DTP (69\%), sarampo (49\%) e principalmente BCG (36\%) é menor. (IHE, 2019). 
Os resultados segundo os departamentos mostram que, globalmente, são nas instituições dos Departamentos de Grande Anse, Nord-Est e Nippes que a oferta de serviços de vacinação, pelo menos 5 dias por semana, é mais elevada. Em Grande-Anse, o percentual de instituições é de $87 \%$ para poliomielite e pentavalente e $84 \%$ para DiTePer. Em contraste, esses serviços de vacinação estão disponíveis pelo menos 5 dias por semana em 51\% -53\% das instituições no Sul para vacinas contra poliomielite, pentavalente e DiTePer e apenas em 10\% delas para sarampo e 5\% para BCG.(IHE, 2019)

\section{POSSE E DISPONIBILIDADE DE REGISTROS DE VACINAÇÃO, COMUNICAÇÃO E MOBILIZAÇÃO} SOCIAL

O boletim de vacinação é um documento importante que garante que a criança recebeu todas as vacinas recomendadas. No Haiti, o calendário de vacinação é proposto pelo PEV (Programa Estendido de Vacinação), do Ministério da Saúde Pública e População. O boletim de vacinação também é um dos documentos necessários para validar a matrícula da criança na escola. Em termos de saúde pública, e mesmo a nível individual, é um instrumento preventivo de grande importância. Assim como o médico, o diretor da escola deve advogar pela atualização das vacinas obrigatórias para todas as crianças que frequentam creche ou escola, para melhor proteção das principais patologias infecciosas: difteria, coqueluche, poliomielite, sarampo etc. É um meio indireto de participação no aumento da cobertura vacinal a nível nacional.

De acordo com as declarações, quase todas as crianças de 12-23 meses e 24-35 meses tinham registro de vacinação ( $92 \%$ e $90 \%$ respectivamente). No entanto, no momento da pesquisa, apenas $68 \%$ dos pais de crianças com idade de 24 e 35 meses 59\% daqueles com idade entre 24-35 meses apresentavam carteira de vacinação. A cobertura da vacinação é maior nas áreas urbanas do que nas rurais (50\% contra 37\%). A porcentagem de crianças de 12 a 23 meses que receberam todas as vacinas básicas aumenta com o nível de escolaridade da mãe e com o nível de bem-estar da família, de $28 \%$ entre as crianças cujas mães não receberam. Não tem escolaridade em $53 \%$ entre aqueles cujas mães têm ensino médio completo ou superior (IHE, 2017).

Para que o programa de vacinação alcance seus objetivos, é necessário promover a participação conjunta de todos os atores e instituições. A comunicação e a mobilização social atuam na mudança de comportamento de funcionários, beneficiários diretos da vacinação e grupos sociais (associações, grupos religiosos, etc.). Consiste no incentivo à participação efetiva dos atores - lideranças 
comunitárias, professores, pessoal de saúde, associações - para atuar no meio social imediato e para aumentar e fortalecer as atividades destinadas à consecução dos objetivos do programa.

Durante a EPSSS, foram feitas perguntas aos funcionários das instituições que oferecem serviços de vacinação infantil, a fim de saber sobre a existência de uma estratégia de comunicação e mobilização social, bem como o tipo de estratégia utilizada. O estudo apresenta inicialmente, entre as instituições que oferecem serviços de imunização, a porcentagem daquelas que possuíam uma estratégia de comunicação e mobilização social para atividades de imunização.

Os resultados mostram que das 651 instituições que oferecem serviços de imunização infantil, 88\% possuíam algum tipo de estratégia de comunicação e mobilização social. Relativamente, mais clínicas/CCSs (94\%), instituições públicas e mistas (91\% e 93\%, respectivamente) os tinham. As proporções variam de acordo com os departamentos, de $77 \%$ no Oeste a $100 \%$ no Nordeste. Observase também que entre as 571 instituições com estratégia de comunicação, a maioria utilizava pregoeiros (77\%), agentes comunitários de saúde (55\%) e igrejas (48\%). Os percentuais de instituições que utilizam outros tipos de estratégia de comunicação são menores.

Os benefícios dos programas de imunização para a saúde são significativos. A vacinação continua a ser uma das maiores armas de sucesso na saúde pública para prevenção de doenças.

A cobertura melhorou com o tempo, no Haiti, e é importante manter e reforçar as medidas para melhorar o acesso aos serviços de imunização no momento recomendado, a fim de maximizar a protecção que as vacinas se destinam a proporcionar. Para além de visarem as populações mais vulneráveis, estas acções devem reduzir o número de contra-indicações falsas, apoiar a importância de administrar múltiplas injeções, tanto aos vacinadores como aos pais, e encorajar ainda mais a utilização de horários acelerados nos casos em que os atrasos já estão a ocorrer ou são inevitáveis.

\section{CONCLUSÃO}

Apesar destas boas melhorias, a mortalidade infantil continua a ser uma preocupação, pelo que há espaço para optimismo nos próximos anos no que diz respeito à implementação de programas de imunização. A cobertura vacinal que atinge todas as crianças visadas, independentemente da sua localização, continua a ser um grande desafio para a MSPP. A falta de educação da maioria dos pais, o não cumprimento do calendário de imunização, o acesso geográfico limitado aos serviços de imunização, a falta de recursos humanos e financeiros e os problemas de exaustividade dos dados, 
dificultam o controle regular das atividades programadas, a disparidade interdepartamental e intercomunitária nos serviços. 


\section{REFERÊNCIA}

1. BANQUE MONDIALE. Perspective Monde. Outil pédagogique des grandes tendances mondiales depuis 1945. Banque Mondiale, 2021.

2. BRASIL. Ministério da Saúde; Secretaria Executiva Departamento de Economia da Saúde, Investimentos e Desenvolvimento. Cooperação em saúde no Haiti: quatro anos de construção. Brasília/DF: Ministério da Saúde, 2014

3. IHE. Institut Haïtien de l'Enfance (IHE) [Haïti] et ICF. Enquête Mortalité, Morbidité et Utilisation des Services (EMMUS VI 2016-2017). Haïti: Indicateurs Clés. Rockville, Maryland, et Pétion Ville, Haïti: IHE et ICF, 2017

4. IHE. Institut Haïtien de l'Enfance (IHE) et ICF International. Évaluation de la Prestation des Services de Soins de Santé (EPSSS 2017-2018). Haïti: Rockville, Maryland, USA: IHE et ICF International, 2019

5. JUSTE, E. PCV13: nouveau vaccin introduit dans le calendrier vaccinal. Le nouvelliste, 29 Oct. 2018. Disponível em : https://lenouvelliste.com/article/194409/pcv13-nouveau-vaccin-introduit-dansle-calendrier-vaccinal

6. MORAES, J.C.; RIBEIRO, M.C.S.A. Desigualdades sociais e cobertura vacinal: uso de inquéritos domiciliares. Rev Bras Epidemiol. 11: 24113, 2008.

7. MSPP. Ministère de la Santé Publique et de la Population. Plan Directeur de Santé 2012-2022. Haïti: MSPP, Oct 2013.

8. UEP. Unité d'Études et de Programmation (UEP) et MSPP. Rapport Statistique 2018. Haiti : MSPP, Novembre 2019.

9. ZAMBONIN, F.; LIMA, K.L.B.; SOUSA, P.A.C.; MUNIZ, T.R.; CALDART, R.V.; MACIEL, J. C. et al. Análise da cobertura vacinal em menores de cinco anos em um estado fronteiriço da Amazônia. Saúde em Redes. 5(2):289299, 2019. DOI: hp://dx.doi.org/10.18310/24464813.2019v5n2p289299 


\section{Capítulo 5}

doi $10.37423 / 211004881$

\section{VULNERABILIDADE DAS ISTS EM ADULTOS JOVENS NO BRASIL: PERFIL E SEXUALIDADE.}

Kamyla Chicarolli da Cunha

Priscila Moraes Henrique Paiva

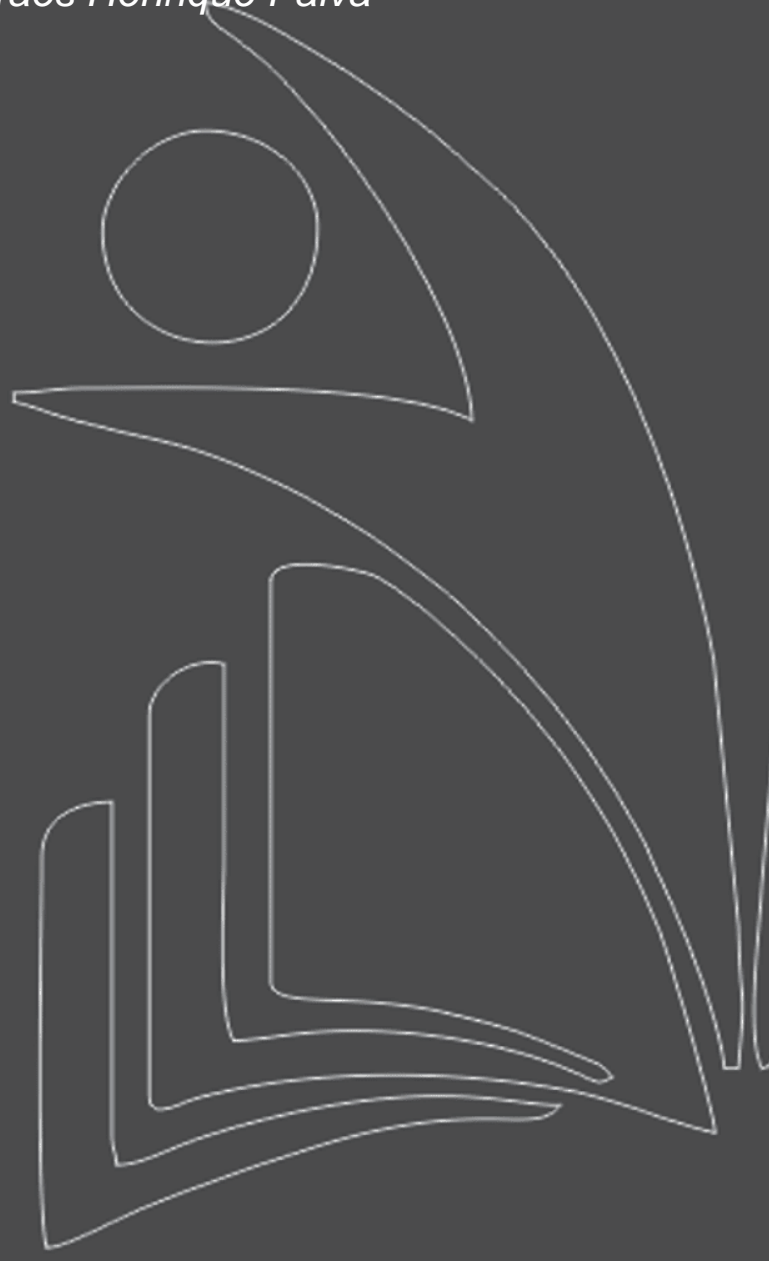

Centro Universitário do Sul de Minas

Centro Universitário do Sul de Minas 
Resumo: As Infecções Sexualmente Transmissíveis - ISTs estão entre os problemas de saúde pública mais comuns em todo o mundo, podendo gerar diversas consequências como infertilidade, doenças congênitas e o aumento do risco para a infecção pelo HIV (Vírus da Imunodeficiência Humana). O número de casos registrados por HIV nos últimos dez anos triplicou, em jovens com idades entre 15 a 19 anos, bem como os casos de sífilis que aumentaram expressivamente a partir de 2010. Por conseguinte, em virtude da grande vulnerabilidade dos jovens e da importância epidemiológica e de saúde pública das ISTs, objetivou-se nesse trabalho realizar um levantamento por meio de questionário online sobre o perfil do comportamento sexual, o conhecimento e prevenção das ISTs entre brasileiros de 18 à 30 anos. Participaram dessa pesquisa 669 voluntários, sendo 38,86\% (260) do sexo feminino e $61,14 \%$ (409) do sexo masculino, com média de idade de 24,12 anos e prevalência de heterossexuais. Ao determinar o nível de conhecimento dos participantes frente a estas infecções, 51,99\% (339) consideram apresentar médio conhecimento, 30,06\% (196) conhecimento aprofundado e $17,94 \%$ (117) pouco conhecimento. Ao serem questionados sobre o uso dos preservativos, $65,9 \%$ afirmaram utilizar, no entanto apenas $28,89 \%$ relataram usar sempre, sendo o principal motivo o de "diminuição do prazer". Entretanto, 99,09\% (652) afirmaram ter consciência do risco que está correndo ao não os utilizar em suas relações sexuais. Assim, foi possível verificar que a prática do sexo inseguro independe do conhecimento ou nível de escolaridade, uma vez que a grande maioria dos entrevistados tratavam-se de universitários e graduados em nível superior, dessa forma se faz necessário que as políticas públicas de prevenção as ISTs desenvolvam formas mais efetivas quanto a mudança de comportamento em relação a utilização dos preservativos.

Palavra-chave: IST. Adultos jovens brasileiros. Prevenção. Comportamento sexual 


\section{INTRODUÇÃO}

As infecções sexualmente transmissíveis (IST'S), são infecções transmitidas em especial por meio de contato sexual "oral, vaginal ou anal" desprotegido, podendo ser causadas por vírus, bactérias ou fungos. Existem ainda outros meios de transmissão como, de mãe para filho(a) na gestação, no parto, na amamentação, compartilhamento de objetos perfurocortantes, ou ainda por meio de secreções corporais de pessoas contaminadas sendo este um meio menos comum. Para algumas destas ainda se desconhece a cura, como por exemplo o HIV, todavia, existe o tratamento podendo interromper ou paralisar a cadeia de transmissão. Alguns sintomas são comuns como, feridas, corrimentos anormais, verrugas anogenitais, dor pélvica, ardência ao urinar, lesões de pele e linfoadenopatia (MINISTÉRIO DA SAÚDE, 2020).

Entre algumas IST'estão herpes genital, sífilis, gonorreia, tricomoníase, infecção pelo HIV, infecção pelo Papilomavírus Humano (HPV), hepatites virais B e C. Quanto ao diagnóstico, os exames físicos são essenciais, se for observado alguma manifestação clínica ou anomalia é indicado e necessário a coleta do material biológico para testes laboratoriais. O uso do preservativo masculino ou feminino (camisinha) é o melhor método de prevenção para a se evitar a contaminação (MINISTÉRIO DA SAÚDE., 2020).

O Brasil tem hoje uma prevalência elevada de ISTs na população de jovens adultos de idades entre 15 à 29 anos de ambos os sexos. Calcula-se que a cada ano exista uma ocorrência de 937.000 mil novos casos de sífilis; 1.541,000 de gonorreia; 1.967,200 de clamídia; 640.900 de herpes genital; 685.400 de papilomavírus humano (HPV). Com tudo, destaca-se o vírus da imunodeficiência humana (HIV) e a síndrome da imunodeficiência adquirida (AIDS), tendo uma incidência de 20,7 casos por 100 mil habitantes desde o início da pandemia em 1980 até 2016 (SALES et al., 2016).

Jovens adultos atravessam uma fase repleta de mudanças, passando por transformações onde buscam um caminho para seu futuro, tendo de se preocuparem com trabalho e a entrada em uma universidade. Com uma rotina sobrecarregada de atividades surgem ambientes de descontração e diversão, na tentativa de aliviar a tensão vivenciada diariamente. Com isso, muitas vezes inúmeros indivíduos que se enquadram no perfil de jovens adultos saem em busca de festas, bares e eventos podendo se deparar com bebidas e drogas como meio de auxílio para alívio de um turbilhão de acontecimentos e responsabilidades deixando-os expostos às IST's. Tendo em vista que a pressão em conjunto a busca por momentos de descontração e prazer dos pares no ambiente de descontração leva os jovens a se envolverem em relações sexuais casuais. Em momentos como estes com 
oportunidades distintas de proximidades, com os hormônios pulsantes surge então a questão do comportamento sexual. As sensações e emoções vivenciadas nesse momento trazem um sentimento de liberdade sexual, o que expõe os mesmos a comportamentos de risco, deixando-os muitas vezes vulneráveis em questão a saúde. Neste sentido apresentam maior vulnerabilidade as infecções sexualmente transmissíveis (SPINDOLA et al., 2019).

Embora os jovens adultos dos dias atuais terem um grau elevado de escolaridade e facilidade de acesso a informações, informações estas que podem ser adquiridas em excesso e incorretamente, de modo confuso e desconexo. Muitas vezes o verdadeiro conhecimento sobre as IST's pode ser escasso, sendo que muitos desses indivíduos até mesmo desconhece sobre seu real estado de saúde e status sorológico, pois não têm preocupação em saber, imaginando talvez que nunca uma doença desse gênero irá acometê-los. Falta de conhecimento e preocupação pode fazer com que comportamentos protetivos sejam negligenciados, arriscando- se a infectarem-se ou a infectar seus parceiros, fora a possibilidade de uma gravidez indesejada por ambas as partes relacionadas (PONTES et al., 2019). Sustenta-se que falte promoção a resiliência. Sendo um caminho de contribuição a diminuição da vulnerabilidade entre o perfil de Jovens Adultos e beneficiando um público geral. É importante que medidas sejam tomadas para que haja eventos promocionais e educativos para a população. $A$ promoção a saúde em associação a medidas educativas tem como objetivo a melhora da qualidade de vida da dos indivíduos mais vulneráveis às IST's. É importante ressaltar que medidas de promoção educativas a saúde em âmbitos de instituições de ensino é importante na contribuição desta causa deixando-os em alerta e os tornando críticos sobre situações de perigo (COSTA, 2017). O objetivo deste estudo foi analisar e discutir os conhecimentos as ists e comportamentos sexuais dos jovens adultos brasileiros de idades entre 18 a 30 anos. Sendo a população de jovens adultos o público com maior indice de infecção por IST's tendo ainda maior tendência para aumento futuramente, relacionando-os a exposição precoce às práticas sexuais (SPINDOLA et al., 2019) .

\section{METODOLOGIA}

Estudo transversal de base populacional fundamentado na aplicação de um questionário online desenvolvido na plataforma google forms e enviado através das redes sociais: whatsapp, facebook e instagram com a finalidade de obter dados a respeito do conhecimento sobre as ISTS e o comportamento sexual dos entrevistados.

A pesquisa tinha como critério de inclusão ser de nacionalidade Brasileira e idades entre 18 a 30 anos. 
Foram entrevistados 669 individuos de Janeiro de 2021 a Julho de 2021, os quais forneceram dados que foram adicionados em planilhas do Excel para análise e confecção de gráficos e tabelas.

\section{RESULTADOS}

Dos 669 participantes, 38,86\% (260) eram mulheres e 61,14\% (409) homens, todos de nacionalidade Brasileira e média de idade de 24,12 anos. O nível de escolaridade está demonstrado na tabela 1, assim como a naturalidade na tabela 2.

Tabela 1 - Classificação por escolaridade.

\begin{tabular}{lcc}
\hline & $\begin{array}{c}\text { Escolaridade } \\
\mathbf{N}=\mathbf{6 6 5}\end{array}$ \\
\hline & $\mathbf{N}$ & $\mathbf{\%}$ \\
Fundamental completo & 10 & $1,50 \%$ \\
Fundamental incompleto & 07 & $1,05 \%$ \\
Médio completo & 146 & $21,96 \%$ \\
Médio incompleto & 12 & $1,80 \%$ \\
Superior completo & 229 & $34,44 \%$ \\
Superior incompleto & 261 & $39,25 \%$ \\
\hline
\end{tabular}

Fonte: (Os autores, 2021).

Tabela 2 - Classificação por Cidade e região.

\begin{tabular}{lcc}
\hline \multicolumn{3}{c}{$\begin{array}{c}\text { Cidade e região. } \\
\mathbf{N}=\mathbf{6 6 5}\end{array}$} \\
\hline & $\mathbf{N}$ & $\mathbf{\%}$ \\
Rio de Janeiro & 229 & $34,44 \%$ \\
São Paulo & 273 & $41,05 \%$ \\
São Gonçalo do Sapucaí & 146 & $21,96 \%$ \\
Belo Horizonte & 10 & $1,50 \%$ \\
Outros & 07 & $1,05 \%$ \\
\hline
\end{tabular}

Fonte: (os autores,2021)

\subsection{COMPORTAMENTO SEXUAL E GRAU DE CONHECIMENTO SOBRE AS ISTS}

Na tabela 3, estão descritos as prevalências da orientação sexual, tipos de relações sexuais e utilização de métodos contraceptivos. 
Tabela 3 - Comportamento sexual e utilização e tipos de métodos contraceptivos utilizados.

\begin{tabular}{lcc}
\hline Orientação sexual $(\mathbf{n}=\mathbf{6 6 2})$ & $\mathbf{N}$ & $\mathbf{\%}$ \\
& 556 & $83,99 \%$ \\
Heterossexual & 63 & $9,52 \%$ \\
Bissexual & 43 & $6,49 \%$ \\
Homossexual & & \\
\hline Tipos de relações sexuais (n= 670) & 390 & $58,21 \%$ \\
\hline Relacionamentos sérios & 229 & $34,18 \%$ \\
Relações casuais & 51 & $7,61 \%$ \\
Não mantém relações sexuais. & \\
\hline Faz uso de algum método contraceptivo (n $=\mathbf{6 6 3 )}$ & $69,23 \%$ \\
\hline Sim & 459 & $30,77 \%$ \\
Não & 204 & $42,54 \%$ \\
\hline Se sim, qual método (n = 489) & 208 \\
\hline Preservativos & 136 & $16,16 \%$ \\
Pílulas anticoncepcionais & 79 & $8,57 \%$ \\
Pílulas anticoncepcionais e preservativos & 38 & $5,73 \%$ \\
Dispositivo intrauterino (DIU) & 28 & \\
Outros & & \\
\hline
\end{tabular}

Fonte: (os autores,2021)

A fim de determinar o nível de conhecimento dos participantes em relação as IST'S, estes foram questionados sobre se conhecem ou não as IST'S, 94,61\% (632) afirmaram conhecer as IST'S, sendo que 51,99\% (339) consideram ter médio conhecimento, 30,06\% (196) conhecimento aprofundado e $17,94 \%$ (117) pouco conhecimento.

Para análise desse conhecimento, estes foram expostos ao questionamento quanto a como se transmite e previne mediante a alternativas, sendo a prevalência de respostas corretas foram de $39,5 \%$ e $65,8 \%$, respectivamente.

Os dados obtidos referentes ao histórico de ISTs, utilização de preservativos, frequência e motivos mencionados para não utilização dos mesmos estão apresentados na tabela 3. Enquanto a figura 2 apresenta a prevalência das respostas quando foram questionados sobre o principal motivo que os levam a utilização do preservativo (Figura 2). 
abela 3 -Dados referentes histórico de ISTs, utilização de preservativos, frequência e motivos mencionados para não utilização dos mesmos.

\begin{tabular}{lcc}
\hline Histórico de ISTS $(\mathbf{n}=\mathbf{6 6 7})$ & $\mathbf{N}$ & $\mathbf{0}$ \\
& & $14,24 \%$ \\
Sim & 95 & $85,76 \%$ \\
Não & 572 & $65,85 \%$ \\
\hline Faz a utilização de preservativos em suas relações sexuais $(\mathbf{n}=\mathbf{6 5 6}$ \\
\hline Sim & 432 & $34,14 \%$ \\
Não & 224 & \\
\hline Se sim, com qual frequência $(\mathbf{n}=\mathbf{4 0 5})$ & & $28,89 \%$ \\
\hline Sempre & 117 & $43,21 \%$ \\
Quase sempre & 113 & $27,90 \%$ \\
Raramente & 175 & $0,27 \%$ \\
\hline Se não, por qual motivo (n= 376) & & $9,57 \%$ \\
\hline Custo alto & 1 & $26,06 \%$ \\
Esquece & 36 & $10,90 \%$ \\
Não sente prazer ao utilizá-la & 98 & $53,20 \%$ \\
Incomoda & 41 & \\
Outros & 200 & \\
\hline
\end{tabular}

Fonte: (os autores,2021)

Figura 3 - Dados obtidos referente ao principal objetivo do grupo amostral em relação ao uso de preservativos.

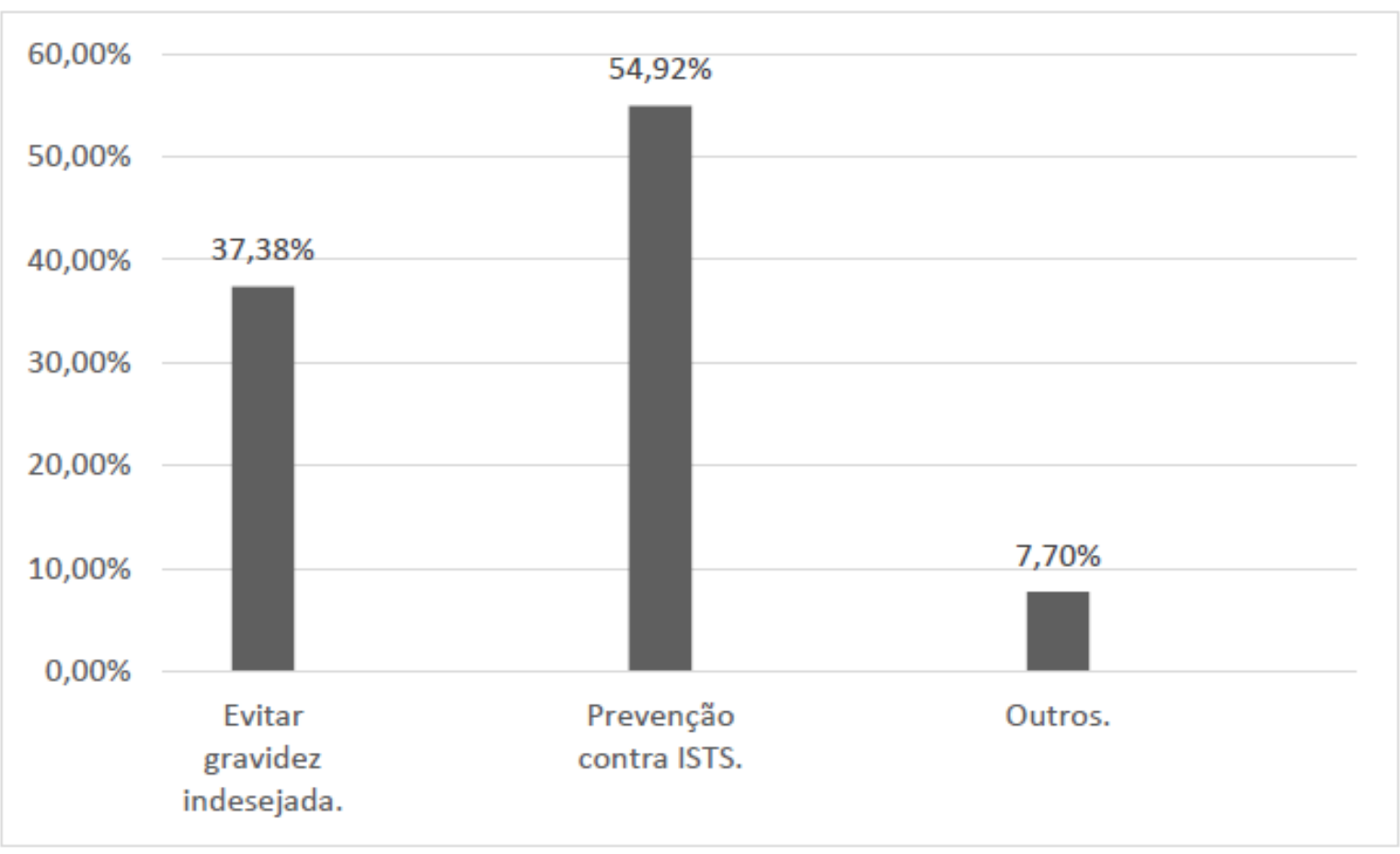

Fonte: (Os autores, 2021) 
Sobre o conhecimento dos riscos da utilização dos preservativos, 99,09\% (652) de um conjunto amostral de 658 respondentes afirmaram conhecer os riscos que estariam expostos ao não usar ou usar de forma incorreta e 0,91\% (6) afirmaram desconhecê-los.

Na tabela 4, está expresso resultado da análise do comportamento dos entrevistados em relação a ingesta de bebidas alcoólicas, drogas ilícitas e comportamento sexual após a utilização dos mesmos.

Tabela 4 -Dados comportamentais associados a ingestão de bebidas alcoólicas e drogas.

\begin{tabular}{lcc}
\hline \multicolumn{3}{l}{ Costuma ingerir bebidas alcoólicas bares e festas $(\mathbf{n}=\mathbf{6 6 7})$} \\
\hline \multicolumn{3}{l}{$\mathbf{~}$} \\
Sim & 410 & $\mathbf{\%}$ \\
Não & 138 & $61,65 \%$ \\
Às vezes & 117 & $20,75 \%$ \\
\hline Costuma fazer uso de algum tipo de substância ilícita em bares e festas $(\mathbf{n}=\mathbf{6 6 6})$ \\
\hline Sim & 34 & $5,11 \%$ \\
Não & 575 & $86,34 \%$ \\
Às vezes & 57 & $8,56 \%$ \\
\hline Após a ingestão de alguns desses tipos de substâncias estariam preparados para \\
praticar um ato sexual seguro (n=550) & \\
\hline Sim & 284 \\
Não & 266 & $51,64 \%$ \\
\hline
\end{tabular}

Fonte: (os autores,2021)

\section{DISCUSSÃO}

O comportamento sexual de risco tem diferentes definições na literatura, no presente estudo foi analisado o relacionamento casual como um fator de risco, entretanto, muito variável e dependente da utilização do preservativo. Outros estudos também apontam que a maioria da amostra de jovens alegam ter parceiros fixos (SPINDOLA, 2019; ARAÚJO et al., 2019; CAVALCANTE et al., 2020), o que não os isentam do risco de contaminação pelas ISTs.

Desse modo, ao serem questionados sobre a utilização dos preservativos, 65,9\% afirmaram utilizar, no entanto apenas $28,89 \%$ relataram utilizar sempre, demonstrando que ainda não é uma prática efetiva. Outros estudos brasileiros em jovens apontam dados semelhantes (CAVALCANTE et al., 2020; MAIA et al., 2008; SILVA et al., 2015) e isso pode estar impactando diretamente no aumento das ISTs registradas nos últimos anos. 
Barbosa (2019) verificou em sua pesquisa que o uso de preservativos nas relações sexuais podem demonstrar insegurança ou causar desconfiança no parceiro (a). Fazendo com que os mesmos apesar de terem ciência sobre os riscos que estariam sendo expostos e conhecerem as ISTs preferem não arriscar ter uma situação desconfortável com a sua parceria seja esta casual ou principalmente fixa (DOURADO et al., 2015; SPINDOLA et al., 2019; PEREIRA et al., 2019) causando assim vulnerabilidade nesse público.

Segundo Nogueira (2018) em um estudo feito com 1.372 participantes sobre o motivo para o não uso de preservativos em suas relações sexuais, foi visto que, o principal motivo com 442 ocorrências seria o não gostar de fazer a utilização do mesmo, e a menor ocorrência dita foi o parceiro não aceitar sendo este motivo relatado apenas por participantes femininos. Já em um estudo realizado por Teixeira (2006) observou-se que de um total de 4.019 participantes que já tiveram algum tipo de relação sexual, $60 \%$ das mulheres e $63,8 \%$ dos homens usaram preservativo na primeira relação, já na última relação sexual desse grupo amostral a utilização do preservativo caiu para 38,8\% e 56\%, para moças e rapazes, respectivamente. Entre os motivos para a não adesão do uso de preservativos em suas relações foram citados "não pensaram nisso", 69,6\% e 73,9\%; "pensava que não podia engravidar", 13,3\% e 9,6\%, "não sabiam como obter métodos", entretanto o uso do anticoncepcional diário aumentou nas ultimas relações sexuais (JARDIM, 2012; GELUDA et al., 2006; CARRENO; COSTA, 2006; SOUZA et al., 2011), demonstrando assim uma maior preocupação com uma gravidez em relação a ISTs.

Além dos motivos expostos acima, as drogas podem influenciar na tomada de decisão quanto à não utilização dos meios preventivos, prejudicando a execução preventiva e aumentando a probabilidade de exposição as ISTS, na atualidade com distintas opções de lugares para momentos de descontração a maioria com $61,65 \%$ do conjunto amostral ingerem bebidas alcoólicas nessas ocasiões e 5,11\% fazer a utilização de algum tipo de droga, quanto a consciência sobre estarem ou não preparados para uma relação sexual segura ou não esses indivíduos se mostram divididos onde 51,64\% afirmam estar preparados mesmo após o uso dessas substâncias e 48,36\% não.

Um dado bastante relevante do Boletim Epidemiológico HIV/Aids revelou um aumento de 64,9\% das ISTs entre jovens de 15 a 19 anos e de 74,8\% para os de 20 a 24 anos, entre 2009 e 2019. Especialistas sugerem que esse crescimento se deve a uma falsa sensação de segurança que essa parcela da população sente, principalmente por não ter vivenciado as epidemias de HIV e Aids na década de 1980. Ainda assim, dados da Sociedade Brasileira de Urologia (SBU), publicados em 2020, embora homens 
adultos saibam o que são as infecções sexualmente transmissíveis, $80 \%$ se consideram fora de risco para a contaminação e somente $11 \%$ afirmam que podem estar em perigo.

Os adultos jovens, em geral, mostram possuir conhecimento sobre a relevância do uso do preservativo na prevenção das ISTs. Contudo, investigações têm apresentado falhas no conhecimento sobre as IST e as formas de prevenção das infecções não são tão evidentes (FONTE et al., 2018).

A Pesquisa Nacional de Saúde (PNS), divulgada pelo Instituto Brasileiro de Geografia e Estatística (IBGE) 2019, mostrou que apenas 22,8\% das pessoas acima de 18 anos no Brasil afirmaram usar preservativo em todas as relações sexuais que tiveram nos 12 meses anteriores à entrevista. Dessa forma, fica claro que o modo de intervenção das campanhas de prevenção são ineficientes em relação a conscientização desse público no que diz respeito a utilização do preservativo.

\section{CONCLUSÃO}

Foi possível sugerir que a prática do sexo inseguro entre os jovens entrevistados independe do seu conhecimento ou nível de escolaridade, ressaltando que as políticas públicas de prevenção às ISTs devem estar atentas a esses resultados para que sejam desenvolvidas formas mais eficientes de conscientizarem esses jovens, uma vez que a incidência dessas infeç̧ões aumentou nos últimos anos entre essa faixa etária.

\section{VULNERABILITY OF ISTS IN YOUNG ADULTS IN BRAZIL: PROFILE AND SEXUALITY.}

Sexually Transmitted Infections - STIs are among the most common public health problems around the world, which can generate several consequences such as infertility, congenital diseases and increased risk for HIV infection (Human Immunodeficiency Virus). The number of reported cases of HIV in the last ten years has tripled, in young people aged 15 to 19 years, as well as the cases of syphilis that have increased significantly since 2010. Therefore, due to the great vulnerability of young people and the importance of epidemiological and public health of STIs, the aim of this study was to carry out a survey through an online questionnaire on the profile of sexual behavior, knowledge and prevention of STIs among Brazilians aged 18 to 30 years. A total of 669 volunteers participated in this study, 38.86\% (260) female and $61.14 \%$ (409) male, with a mean age of 24.12 years and prevalence of heterosexuals. When determining the participants' level of knowledge about these infections, 51.99\% (339) consider they have medium knowledge, 30.06\% (196) deep knowledge and 17.94\% (117) little knowledge. When asked about the use of condoms, $65.9 \%$ said they used it, however only $28.89 \%$ reported using it always, the main reason being "decreased pleasure". However, 99.09\% (652) claimed to be aware of 
the risk they are running by not using them in their sexual relations. Thus, it was possible to verify that the practice of unsafe sex is independent of knowledge or education level, since the vast majority of respondents were university students and college graduates, thus it is necessary that public policies for prevention STIs develop more effective ways to change behavior in relation to condom use. 


\section{REFERÊNCIAS}

ARAÚJO, A. S. D. B., OLIVEIRA, C. S. R., MARINHO, D. F. S., WOODTLI, R. R., FARIA, T. T., \& SPINDOLA, T. Uso de preservativo por estudantes universitárias e a prevenção de infecções sexualmente transmissíveis. Uso de preservativo por estudantes universitárias e a prevenção de infecções sexualmente transmissíveis, 1-388.

BARBOSA, K. F., BATISTA, A. P., NACIFE, M. B. P. S. L., VIANNA, V. N., OLIVEIRA, W. W. D., MACHADO, E. L., ... \& MACHADO-COELHO, G. L. L. (2019). Fatores associados ao não uso de preservativo e prevalência de HIV, hepatites virais B e C e sífilis: estudo transversal em comunidades rurais de Ouro Preto, Minas Gerais, entre 2014 e 2016. Epidemiologia e Serviços de Saúde, 28, e2018408.

CARRENO, I., \& COSTA, J. S. D. D. (2006). Uso de preservativos nas relações sexuais: estudo de base populacional. Revista de saúde publica, 40, 720-726.

CAVALCANTE, E. G. F., GALVÃO, M. T. G., LIMA, I. C. V. D., \& ALMEIDA, P. C. D. (2020). Estratégias de notificação de parceiros sexuais de pessoas com infecções sexualmente transmissíveis: ensaio clínico randomizado. Revista da Escola de Enfermagem da USP, 54.

COSTA, Maria Isabelly Fernandes da. Adolescentes em situação de pobreza: resiliência e vulnerabilidade às IST/HIV/AIDS. Universidade Federal do Ceará - 2017.

DOURADO, I., MACCARTHY, S., REDDY, M., CALAZANS, G., \& GRUSKIN, S. (2015). Revisitando o uso do preservativo no Brasil. Revista Brasileira de Epidemiologia , 18 , 63-88.

FONTE, V. R. F., SPINDOLA, T., LEMOS, A., FRANCICO, M. T. R., \& OLIVEIRA, C. S. R. (2018). Conhecimento e percepção de risco em relação às infecções sexualmente transmissíveis entre jovens universitários. Cogitare Enfermagem, 23(3).

GELUDA, K., BOSI, M. L. M., CUNHA, A. J. L. A. D., \& TRAJMAN, A. (2006). " Quando um não quer, dois não brigam": um estudo sobre o não uso constante de preservativo masculino por adolescentes do Município do Rio de Janeiro, Brasil. Cadernos de Saúde Pública, 22, 1671-1680.

JARDIM, D. P., \& DOS SANTOS, E. F. (2012). Uso do preservativo masculino por adolescentes no início da vida sexual. Adolescencia e Saude, 9(2), 37-44.

MAIA, C., GUILHEM, D., \& FREITAS, D. (2008). Vulnerabilidade ao HIV/Aids de pessoas heterossexuais casadas ou em união estável. Revista de Saúde Pública, 42, 242-248.

MINISTÉRIO DA SAÚDE. Infecções sexualmente transmissíveis, 2020. Disponível em: <http://www.aids.gov.br/pt-br/publico-geral/o-que-sao-ist>. Acesso em 24 de out de 2020.

NOGUEIRA, F. J., SARAIVA, A. K. M., DA SILVA RIBEIRO, M., DE FREITAS, N. M., CALLOU FILHO, C. R., \& MESQUITA, C. A. M. (2018). Prevenção, risco e desejo: estudo acerca do não uso de preservativos. Revista Brasileira em Promoção da Saúde, 31(1), 1-8.

PEREIRA, GFM, PIMENTA, MC, GIOZZA, SP, CARUSO, AR, BASTOS, FI, \& GUIMARÃES, MDC (2019). HIV / aids, hepatites virais e outras IST no Brasil: tendências epidemiológicas. 
PONTES, D. S.; RODRIGUES, E. S.; ALMEIDA, L. C.; BATISTA, M. H. J. Educação sexual e ist's - a percepção dos universitários frente a essa temática. Rev. JRG. Est. Acadêmico., v. 2, n. 5, ago/dez 2019.

RODRIGUES, T. S., COSTA, G. D. S., DA SILVA, A. S., DA SILVA, A. M., \& GOIANO, P. D. D. O. L. (2017). Vulnerabilidades para o hiv/aids em pósgraduandos em saúde pública e da família no piauí. revista uningá, 53(2).

SALES, W. B.; CAVEIÃO, C.; VISENTIN, A.; MOCELIN, D.; COSTA, P. M.; SIMM, E. B.Comportamento sexual de risco e conhecimento sobre IST/SIDA em universitários da saúde.Rev. Enf. Ref. vol.serIV no.10, set. 2016 .

SILVA, G. S., LOURDES, L. A. D., BARROSO, K. D. A., \& GUEDES, H. M. (2015). Comportamento sexual de adolescentes escolares. Revista Mineira de Enfermagem, 19(1), 154-166.

SOUZA, Alex Alexandre et al. Conhecimento de jovens escolares sobre formas de prevenção das doenças sexualmente transmissíveis e gravidez indesejada no município de promissão-sp. Revista Estudos \& Pesquisas Unilins, v. 1, n. 1, p. 25-29, 2017.

SOUSA, L. B. D., CUNHA, D. D. F. F., XIMENES, L. B., PINHEIRO, A. K. B., \& VIEIRA, N. F. C. (2011). Conhecimentos, atitudes e prática de mulheres acerca do uso do preservativo. Rev. enferm. UERJ, 146151.

SOUZA, M. M.; PELLOSO, S.M.; UCHIMURA, N.S; SOUZA, F. Utilização de métodos contraceptivos entre as usuárias da rede pública de saúde do município de Maringá-PR. Revista Bras Ginecol Obstet, v.28, p. $271-277,2006$.

SOUSA NOGUEIRA, F. J., SARAIVA, A. K. M., DA SILVA RIBEIRO, M., DE FREITAS, N. M., CALLOU FILHO, C. R., \& MESQUITA, C. A. M. (2018). Prevenção, risco e desejo: estudo acerca do não uso de preservativos. Revista Brasileira em Promoção da Saúde, 31(1), 1-8.

SPINDOLA, T.; OLIVEIRA, C. S. R.; SANTANA, R. S. C.; SODRÉ, C. P.; ANDRÉ, N. L. N.O.; BROCHADO, E. J. Práticas Sexuais, Conhecimento e Comportamento dos Universitários em Relação às Infecções Sexualmente Transmissíveis. Revi. Fund. Care. Online., Dezembro 2019.

TEIXEIRA, A. M. F. B., KNAUTH, D. R., FACHEL, J. M. G., \& LEAL, A. F. (2006). Adolescentes e uso de preservativos: as escolhas dos jovens de três capitais brasileiras na iniciação e na última relação sexual. Cadernos de Saúde Pública, 22, 1385-1396 


\section{Capítulo 6}

\section{doi $10.37423 / 211004889$}

\section{A INFLUÊNCIA DA LIRAGLUTIDA NOS RECEPTOR GLP-1 DURANTE O PROCESSO DE EMAGRECIMENTO}

Raquel Araújo de Carvalho

Valdemiro Freitas Neto

Rômulo Diego Marinho Siqueira

Paula Simplicio Viana de Carvalho

Clara Simplício Viana de Carvalho

Yuri Nascimento Fróes

Flaviana Manuella Froés Abreu Pavão

João Jorge Jinkings Pavão Filho

\section{Darlan Ferreira da Silva}

Maria Raimunda Chagas Da Silva
Universidade Central del Paraguay- Paraguai

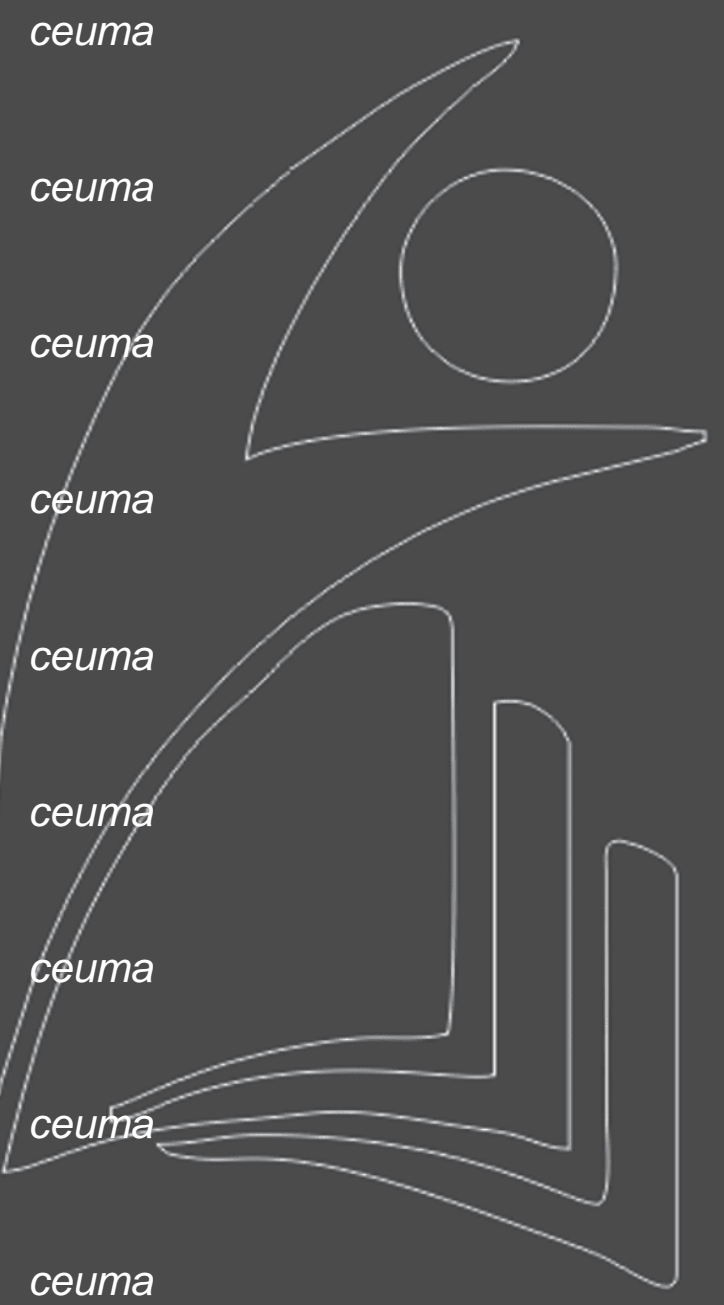


Resumo: As incretinas são uma classe de substâncias produzidas pelo pâncreas e pelos intestinos que regulam o metabolismo da glicose. São elas: insulina, glucagon, amilina, GLP-1 (glucagon-like peptide1) e GIP (glucose-dependent insulinotropic polypeptide). A liraglutida é um agonista do receptor GLP1, que reduz o efeito deste e melhora o controle glicêmico com baixo risco de hipoglicemia. Trata-se de uma das opções mais recentes para o tratamento da diabetes mellitus tipo 2 (DM2), com eficácia bem estabelecida na redução da glicemia e da hemoglobina glicada (A1C). Objetivo deste estudo foi abordar o uso de agonistas do receptor GLP-1 no processo de emagrecimento de pacientes obesos e com excesso de peso. Através de uma revisão de literatura baseada em artigos científicos publicados com a finalidade de destacar os descritores primários: obesidade; excesso de peso; liraglutina; GLP-1; agonista do GLP-1. Portanto vale ressaltar que independentemente se a indicação da liraglutida para uso como emagrecedor for comprovado ou não, o uso de medicamentos para perda de peso tem que ser a última alternativa. Para um emagrecimento saudável é sempre recomendável uma alimentação balanceada associada a atividades físicas regulares.

Palavras chave: Incretina, Liraglutida, Glucagon-like peptide-1, Emagrecimento 


\section{INTRODUÇÃO}

O consumo excessivo de alimentos industrializados, dieta rica em carboidratos, falta de atividade física e alterações hormonias são alguns dos principais pilares para o desenvolvimento de várias doenças crônicas. Dados da Pesquisa de Vigilância de Fatores de Risco e Proteção para Doenças Crônicas por Inquérito Telefônico (Vigitel) indicam que o Brasil registrou um aumento de 67,8\% nos índices de obesidade nos últimos 13 anos. Se em 2006, a doença atingia 11,8\% da população, em 2018 acometeu $19,8 \%$. Os resultados também indicam que o crescimento da obesidade é significativo entre adultos com 25 a 34 anos $(84,2 \%)$ e 35 a 44 anos $(81,1 \%)$. Mais comum entre os homens, a obesidade agora prevalece entre as mulheres, que apresentaram índice superior (20,7\%), em comparação à população masculina (18,7\%) (VIGITEL BRASIL, 2019).

O excesso de peso também cresceu, atingindo mais da metade da população brasileira $(55,7 \%)$. Um aumento de $30,8 \%$ foi observado em relação ao percentual de 2006 , que era de $42,6 \%$. A prevalência foi maior entre pessoas com 18 a 24 anos de idade $(55,7 \%)$, sendo este crescimento mais evidente entre as mulheres (40\%) do que os homens (21,7\%) (VIGITEL BRASIL, 2019).

Os medicamentos são indicados para pacientes com índice de massa corporal (IMC) $\geq 30 \mathrm{~kg} / \mathrm{m}^{2}$ e em indivíduos com IMC $\geq 27 \mathrm{~kg} / \mathrm{m}^{2}$, que apresentam ao menos uma condição de comorbidade relacionada ao peso (como diabetes, dislipidemia, hipertensão) e quando as metas não são atingidas com mudanças na dieta e aumento dos níveis de atividade física. A cirurgia bariátrica, por sua vez, deve ser considerada para pacientes com IMC $\geq 40 \mathrm{~kg} / \mathrm{m}^{2}$ ou com IMC $\geq 35 \mathrm{~kg} / \mathrm{m}^{2}$ e pelo menos uma comorbidade relacionada à obesidade. Diretrizes também recomendam a intervenção cirúrgica a indivíduos com diabetes ou síndrome metabólica e IMC de 30-34,9kg/m². (MECHANICK et al, 2013).

Associados a eventos adversos graves, vários medicamentos para perda de peso foram retirados do mercado, sendo os atualmente disponíveis também relacionados a riscos. Enquanto a fentermina é associada a problemas cardiovasculares e pulmonares, o orlistate é relacionado a efeitos gastrointestinais. Embora em menor escala, a lorcaserina atinge os mesmos receptores de serotonina (5-HT2B) que a fenfluramina, elevando o risco de doença cardíaca. A combinação fenterminatopiramato, por sua vez, apenas é encontrada em farmácias certificadas e requer testes mensais de gravidez. Considerando-se os efeitos adversos associados a estes medicamentos, o uso off-label de uma série de drogas (como bupropiona, fluoxetina, metformina, pramlintide, topiramato, zonisamida) se tornou um dos principais recursos para a promoção da perda de peso em pacientes com comorbidades (GLANDT; RAZ, 2011). 
Incretina secretada pelo intestino delgado, responsável pelo aumento da secreção de insulina endógena em resposta à elevação da glicose, pela supressão da liberação de glucagon e regulação do apetite/saciedade, o GLP-1 (glucagon-like peptide 1) é secretado a partir da ingestão de nutrientes, sendo degradado pela enzima dipeptidil peptidase 4 (DPP-4) e endopeptidase neutra. Atua por meio de receptores acoplados a proteínas $\mathrm{G}$, presentes no trato gastrointestinal, sistema nervoso, coração, músculo vascular liso e rins (tubos proximais e glomérulos). O GLP-1 eleva a secreção de insulina dependente de glicose, reduz a secreção de glucagon, retarda o esvaziamento gástrico e diminui o apetite, exercendo ação agonista sobre seus receptores (MEIER, 2012).

A liraglutida é um agonista do receptor GLP-1, que reduz os efeitos do GLP-1, melhorando o controle glicêmico, com baixo risco de hipoglicemia. Trata-se de uma das opções mais recentes para o tratamento da DM2, com eficácia bem estabelecida na redução da glicemia e da hemoglobina glicada (A1c). Além de melhorar o controle glicêmico, estudos mostram ainda uma redução significativa do peso e da circunferência abdominal, principalmente de gordura visceral e subcutânea (VILSBOLL et al, 2012; MARSO et al, 2016).

Com base nesta realidade, esta revisão da literatura abordará, a partir de estudos realizados sobre o tema, quais são os principais benefícios e efeitos provocados pelo uso de agonistas do GLP-1 no processo de emagrecimento. O presente estudo tem como objetivo abordar o uso de agonistas do receptor GLP-1 no processo de emagrecimento de pacientes obesos e com excesso de peso.

\section{METODOLOGIA}

Este estudo constituiu-se de revisão de literatura com a finalidade de destacar a ação da liraglutina no processo de emagrecimento com base em artigos científicos publicados. Foram utilizados os bancos do LILACS, SCIELO e PUBMED e as seguintes palavras-chave: obesidade; excesso de peso; liraglutina; GLP-1; agonista do GLP-1. Estabelecendo posteriormente possíveis relações entre os termos selecionados.

\section{REVISÃO DA LITERATURA}

A alimentação de industrializados em excesso e sedentarismo são os principais pilares para doenças. Esses comportamentos têm suas raízes firmemente firmadas em uma sociedade que tem reduzido cada vez mais a prática de atividade física e valorizado a ingestão de alimentos com alto teor de gordura e calorias. Com isso, o baixo condicionamento aeróbico, uma consequência do estilo de vida sedentário, está associado a um risco 56\% maior de desenvolvimento de doenças cardíacas e 35\% 
maior de Alzheimer, em comparação a indivíduos com alto condicionamento cardiorrespiratório. Estima-se que a inatividade física represente uma em cada 10 mortes no mundo. Caso esse número fosse reduzido em 25\%, 1,3 milhão de mortes seriam evitadas todos os anos. Assim como o sedentarismo, as dietas ricas em gordura saturada são relacionadas a taxas mais altas de doenças cardíacas (WILLIS et al, 2012; LEE et al, 2012).

Correspondente ao alimento habitualmente consumido por um indivíduo, o termo dieta passou a ser atribuído ao cardápio alimentar que visa a redução de peso. Cerca de 1.000 dietas com esse objetivo já foram desenvolvidas, sendo a maioria disseminada pela literatura leiga e pela mídia. A disponibilidade de tantos planos de dieta sugere que, até o momento, nenhum deles foi universalmente bem-sucedido na indução e manutenção da perda de peso. Enquanto alguns são baseados em evidências científicas sólidas, outros simplesmente eliminam um ou mais grupos alimentares essenciais ou recomendam o consumo de um tipo de alimento à custa de outros, com pouca ou nenhuma evidência de apoio. Este último grupo se refere às dietas da moda (EBBELING et al, 2012).

Além dos conceitos da termodinâmica, os fatores bioquímicos, fisiológicos, psicológicos, emocionais, econômicos e sociais que envolvem os mecanismos de perda de peso são multifacetados, interrelacionados e dinâmicos. Neste caso, a atividade física, por exemplo, influenciará a taxa metabólica, que por sua vez afetará a sensibilidade e a resistência à insulina. $\mathrm{O}$ suprimento de alimento nos humanos se tornou mais refinado, influenciando o valor da saciedade, devido à alta concentração de açúcar refinado e baixa concentração de fibra. Níveis de hormônios, como grelina e leptina, interferem no apetite e no nível de saciedade. O hipotálamo é um centro de processamento de informações que recebe os vários tipos de sinalizações como a concentração de nutrientes (entre eles, os níveis de glicose no sangue) ou o grau de distensão do estômago. Os níveis de hormônios como a colecistocinina (produzida pelo intestino) e a leptina (produzida pelo tecido adiposo) também são analisados. Com essas informações o hipotálamo produz comandos para a procura e ingestão de alimento e, ainda, prepara o trato gastrointestinal para receber e processar o alimento (ROLLS et al, 2006). O processo descriro pode ser obervado na Figura 1. 


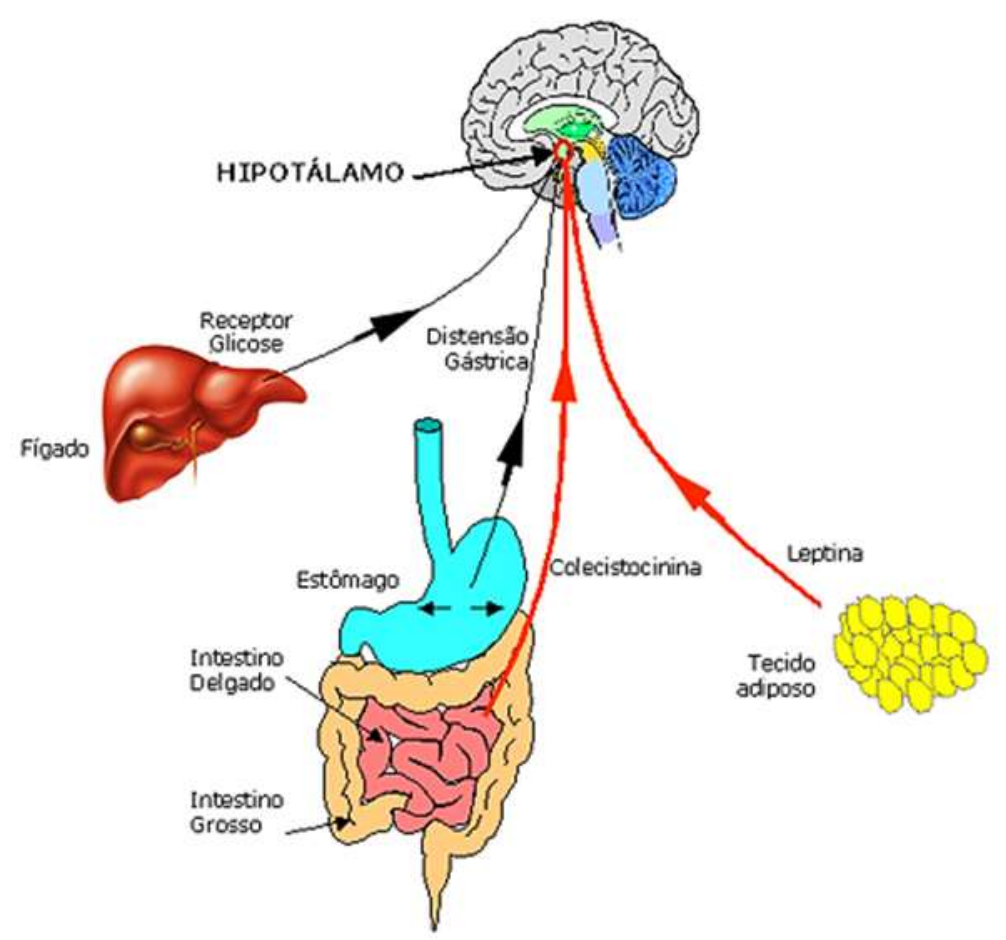

Figura 1 - Mecanismos responsáveis pela sensação de saciedade

Fonte: ROLLS et al, 2006

À medida em que o indivíduo envelhece, há uma redução na massa corporal magra, na taxa metabólica, no gasto de energia e na atividade física, resultando em ganho de peso, mesmo que o nível de calorias se mantenha inalterado ao longo da vida. Juntamente com outros fatores, isso afeta a microbiota intestinal, que, por sua vez, influencia o armazenamento e a liberação de energia. Este é, em parte, o motivo pelo qual é tão difícil conquistar uma perda de peso significativa e sustentada. $A$ obesidade é, portanto, um distúrbio complexo, com múltiplos fatores interrelacionados e dinâmicos, conforme mencionado (ROLLS et al, 2006).

Problema global, a obesidade está associada a várias condições crônicas, incluindo osteoartrite, apneia obstrutiva do sono, cálculos biliares, doença hepática gordurosa, câncer reprodutivo e gastrointestinal, dislipidemia, hipertensão, diabetes tipo 2, insuficiência cardíaca, doença arterial coronariana e acidente vascular cerebral. Mudanças no estilo de vida, como dieta e prática de atividade física, são essenciais na prevenção e no controle. A farmacoterapia pode ser considerada, caso as intervenções sejam ineficazes em indivíduos com índice de massa corporal (IMC) $\geq 30 \mathrm{~kg} / \mathrm{m} 2$ ou com IMC $\geq 27 \mathrm{~kg} / \mathrm{m} 2$ com comorbidades, a exemplo de hipertensão ou diabetes tipo 2, presentes. Os medicamentos contra obesidade, porém, são usados com frequência, principalmente quando a dieta é temporária, ou seja, não ocorre uma reeducação alimentar, e o peso é recuperado (JAMES, 2008; PARK et al, 2008). 
Os principais fármacos aprovados por agências reguladoras são: albiglutida, dulaglutida, exenatida, liraglutida e semaglutida. A albiglutida é um agonista com meia-vida superior a cinco dias e cuja administração é feita em intervalos semanais ou mensais. A dulaglutida também é um análogo de GLP1 muito resistente à DDP-IV, sendo uma droga de longa duração. A exenatida possui duas formulações de administração por via subcutânea, diária e semanal. A liraglutida é um dos análogos de GLP-1 mais conhecidos e pesquisados, mas não possui meia-vida longa, diferente da maioria dos análogos já citados. Por conta disso sua administração é feita diariamente e o escalonamento da dose ao longo das primeiras cinco semanas é comum. A semaglutida é mais um análogo cuja possibilidade de promover o emagrecimento através de doses maiores do que as convencionais ainda vêm sendo estudada (BROWN E, et al., 2018; SRIVASTAVA G, et al., 2018; GILBERT M, et al., 2020).

Muitos agentes recentes foram testados, sendo apenas o orlistate e a sibutramina aprovados para uso a longo prazo. Em outubro de 2010, a sibutramina, amplamente utilizada após a aprovação pela FDA em 1997, foi retirada do mercado em decorrência de sua associação com o aumento de eventos cardiovasculares e derrames. Em 2011, a FDA desaprovou o uso da combinação bupropiona/naltrexona (Contrave) devido a possíveis riscos cardiovasculares (POWELL, 2011).

\subsection{PEPTÍDEO TIPO GLUCAGON 1 (GLP-1)}

O GLP-1 é um peptídeo constituído por 30 aminoácidos, que é secretado a partir de células L epiteliais intestinais após uma refeição. O principal papel fisiológico deste hormônio endócrino é o estímulo da secreção de insulina (LIM et al., 2009), é derivado do produto de transcrição do gene de proglucagon. As formas 28 biologicamente ativas de GLP-1 são: GLP-1 (7-37) e GLP-1- (7-36) NH2. Uma vez na circulação, GLP-1 tem uma meia-vida de menos de 2 min devido à degradação rápida pela enzima DPP4 (PHAM et al., 2016).

Os agonistas do receptor do peptídeo 1 do tipo glucagon (GLP-1) oferecem um avanço único e inovador no tratamento do tratamento do diabetes tipo 2. Seus benefícios são observados não apenas no controle da glicose no sangue, mas potencialmente na preservação da função das células beta e na melhora de outras condições comórbidas relacionadas ao diabetes, a exemplo de hipertensão, hiperlipidemia e obesidade (DRUCKER et al, 2008). Os eventos fisiopatológicos que levam à hiperglicemia em pacientes com diabetes do tipo 2 podem ser observados na Figura 2. 


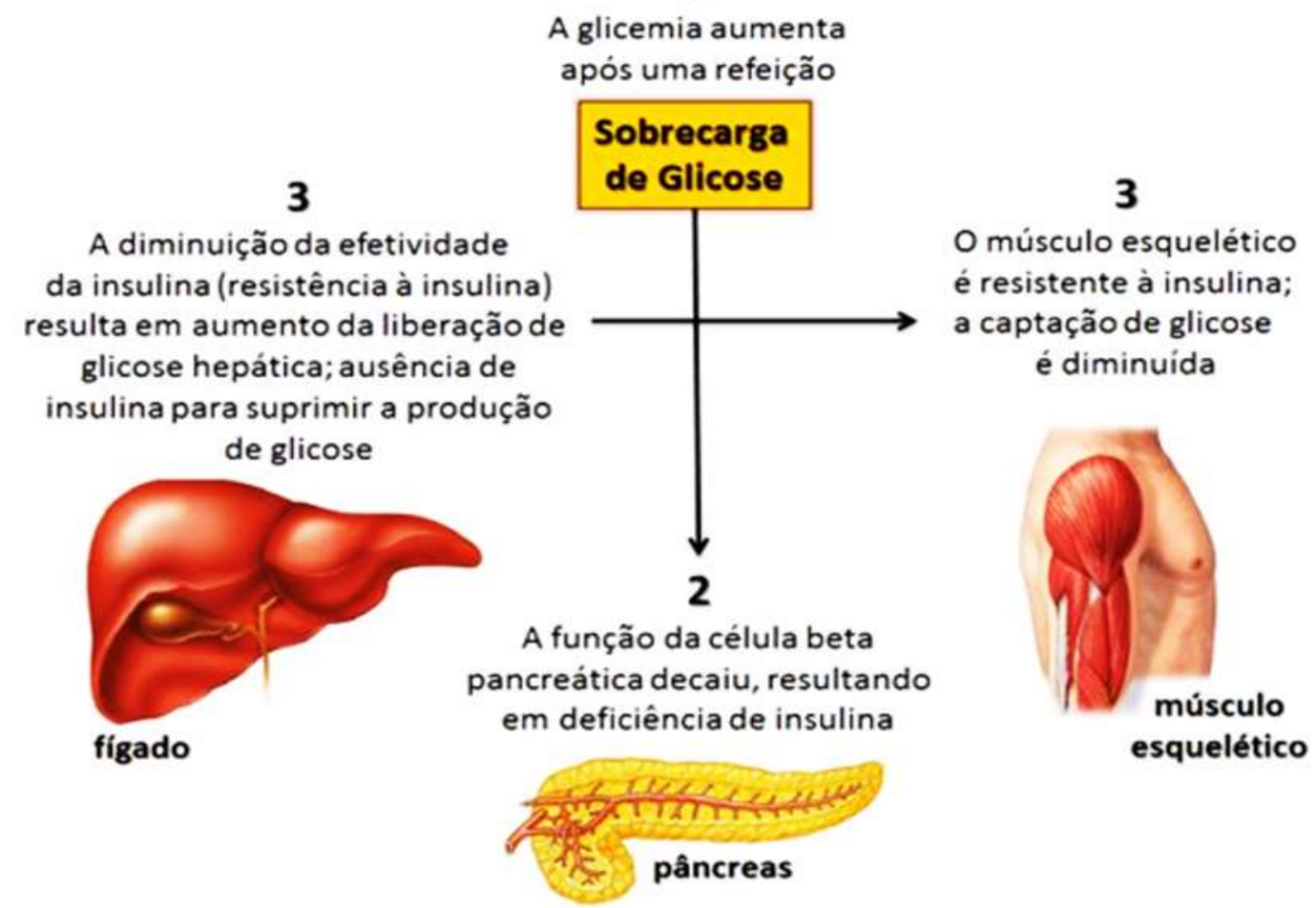

Figura 2 - Eventos fisiopatológicos que levam à hiperglicemia em pacientes com diabetes do tipo 2

Fonte: NETO, J.M.F.A (2012)

Embora a incretina exerça múltiplos efeitos que reduzem as concentrações de glicose, o GLP-1 oferece mais benefícios em comparação ao peptídeo inibidor gástrico (GIP). Com a ingestão de alimentos, as concentrações de GLP-1 e GIP aumentam de forma significativa.

Aparentemente, o GIP e o GLP-1 estimulam a secreção de insulina em resposta à ingestão de alimentos, ao elevarem a massa das células beta em modelos animais. Trata-se de algo promissor, considerando-se que cerca de $50 \%$ da massa de células beta é perdida nos casos de diabetes tipo 2 (MENTIS et al, 2011)

O GLP-1, no entanto, também reduz a secreção de glucagon e a gliconeogênese hepática, além de melhorar a sensibilidade à insulina e retardar o esvaziamento gástrico, promovendo saciedade central e diminuindo a ingestão calórica geral. Em pacientes com diabetes tipo 2, a promoção da saciedade central é uma outra vantagem, já que a perda de peso é importante para o autogerenciamento da diabetes. Ensaios clínicos revelam que a adição de GIP à infusão de GLP-1 não aumenta a resposta secretora de insulina do GLP-1, mas sim as concentrações de glicose, devido a um efeito antagônico significativo na supressão de glucagon (MENTIS et al, 2011) 
A utilidade dos hormônios endógenos da incretina na homeostase da glicose é limitada, decorrente da rápida degradação pela enzima DPP-4, resultando em meia-vida do GLP-1 de cerca de dois minutos. A infusão contínua de agonistas do receptor de GLP-1, administrados exogenamente, comprovou ser bem-sucedida ao superar a meia-vida e promover uma redução nas concentrações de glicose no sangue (GUPTA, 2013).

Em 2005, o primeiro agonista do receptor GLP-1 (exenatida) foi lançado no mercado, apresentando $53 \%$ de homologia com o GLP-1 nativo. Devido à sua semelhança estrutural com o GLP-1 nativo, a exenatida é capaz de se ligar ao receptor de GLP-1 in vivo e resultar em secreção de insulina dependente de glicose, restaurando a resposta à insulina de primeira fase, que geralmente é prejudicada em pacientes com diabetes tipo 2. A exenatida é indicada como complemento para dieta e exercício em pacientes com diagnóstico de diabetes tipo 2 (DRUCKER et al, 2008).

\subsection{GLP-1 E A PERDA DE PESO}

A obesidade está associada a risco aumentado de diabetes tipo 2, hipertensão e doenças cardiovasculares. O GLP-1 diminui a motilidade gastrointestinal, elevando o tempo de absorção dos nutrientes. Também aumenta a saciedade e a taxa metabólica em repouso, além de reduzir as concentrações plasmáticas de ácidos graxos livres. Em pacientes com diabetes tipo 2, o GLP-1 é diminuído. Em uma meta-análise que incluiu 21 estudos e 3.395 participantes, aleatoriamente designados para agonistas do receptor GLP-1, em comparação a 3.016 participantes de vários grupos controle, com diferentes agentes de tratamento do diabetes, os resultados mostraram uma redução no peso, com variação de $-0,2$ a $-7,2 \mathrm{~kg}$.

Doses mais altas de GLP-1 foram relacionadas a maior perda de peso. Comparadas aos pacientes em uso de pioglitazona e insulina glargina, que ganharam peso, as diferenças gerais de peso foram de 4 a $5 \mathrm{~kg}$. De forma geral, os pacientes tratados com GLP-1 sofreram perda de peso semelhante, com uma pequena variação relacionada às variáveis de cada estudo. Calcula-se que essa perda seja resultado da falta de apetite, redução da gordura corporal e melhora da função endotelial (SARAIVA; SPOSITO, 2014; VISBOLL et al, 2012; MUNDIL et al,. 2012).

Segundo a Food ando Drug Administration, um medicamento pode ser considerado um agente eficaz para perda de peso se, após um ano, pelo menos um dos seguintes critérios for cumprido:

a) A diferença na perda média de peso entre os grupos ativo e placebo é de pelo menos $5 \%$ e estatisticamente significativa; 
b) A proporção de pacientes que perdem pelo menos $5 \%$ do peso corporal basal é de pelo menos $35 \%$ e aproximadamente o dobro da proporção no grupo placebo, sendo estatisticamente significativa.

\subsection{LIRAGLUTIDA}

Análogo do GLP-1 humano endógeno, com 97\% de homologia de sequência, a liraglutida possui ácido graxo C-16 (ácido palmitoil) na ligação da glutamina à lisina na posição 26 e na substituição de lisina por arginina na posição 34 . 0 ácido palmitoil se liga reversivelmente à albumina plasmática, impedindo sua degradação pelo DPP-4. Primeira agonista do receptor GLP-1 aprovada especificamente para perda de peso em pacientes sem histórico de diabetes tipo 2, com o nome Saxenda (Figura 3), a liraglutida foi aprovada pela FDA para pacientes adultos, com IMC $\geq 30 \mathrm{~kg} / \mathrm{m} 2$ ou com IMC $\geq 27 \mathrm{~kg} / \mathrm{m} 2$ com presença de pelo menos uma comorbidade relacionada ao peso em excesso (STEENSGAARD et al, 2008).
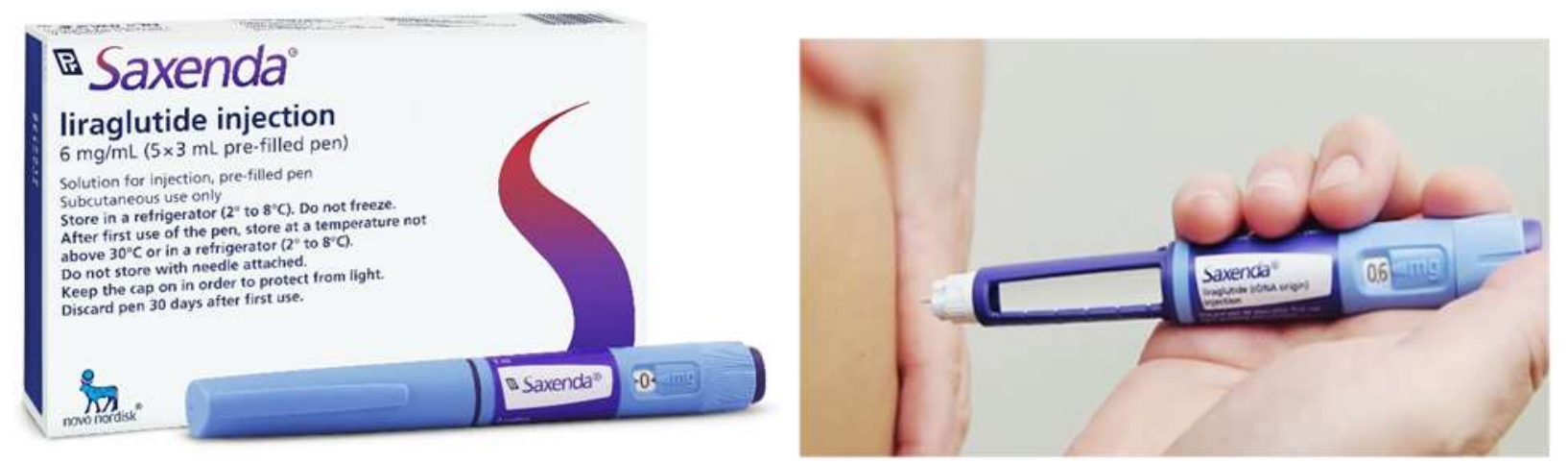

Figura 3 - Saxenda (Liraglutida) e aplicação subcutâneaa com seringa própria Fonte: NovoCare ${ }^{\oplus}$

Neste caso, a dose de liraglutida é de 3,0 mg/dia, superior à dose máxima de 1,8 $\mathrm{mg} / \mathrm{dia}$ aprovada para diabetes tipo 2. Em um estudo duplo-cego, controlado por placebo, que comparou o orlistate, placebo e diferentes doses de liraglutide, os participantes do grupo liraglutida perderam mais peso, equivalente a 7,2 kg após 20 semanas, comparado com 4,1 kg no orlistate e 2,8 kg no placebo. O prédiabetes também foi reduzido em 84-96\% no grupo com alta dose de liraglutida (SAXENDA, 2020).

Os efeitos da liraglutida na perda de peso têm sido objeto de inúmeros estudos e ensaios, cujos resultados, de forma geral, revelam-se satisfatórios. Com objetivo de verificar se a liraglutida é capaz de reduzir o peso a partir da modulação da composição da microbiota intestinal de ratos obesos e obesos diabéticos, Zhao et al (2018) trataram, aleatoriamente, ratos Wistar e Goto-Kakizaki (GK) com liraglutida e solução salina durante 12 semanas. Os parâmetros bioquímicos e hormônios metabólicos 
foram medidos. A produção hepática de glicose e o metabolismo lipídico foram também avaliados com traçadores de isótopos. Alterações na microbiota intestinal, por sua vez, foram analisadas por sequenciamento do gene 16SrRNA.

Como resultado, os autores registraram que tanto o metabolismo da glicose quanto dos lipídios melhorou significativamente com o uso de liraglutida, que também contribuiu para a redução do peso corporal, independentemente do status da glicemia. A abundância e diversidade da microbiota intestinal foram consideravelmente diminuídas. Além disso, a liraglutida reduziu os fenótipos microbianos relacionados à obesidade e aumentou os fenótipos relacionados à magreza. Com isso, eles constataram que a liraglutida pode impedir o ganho de peso, modulando a composição da microbiota intestinal em indivíduos obesos e obesos diabéticos (ZHAO et al, 2018).

Para avaliar a eficácia, segurança e aplicabilidade clínica da liraglutida para controle de peso dos ensaios clínicos de fase III, Mehta et al (2016) identificaram cinco ensaios clínicos randomizados, controlados com placebo. Além da dieta e atividade física recomendadas, a liraglutida resultou consistentemente em uma perda de peso de 4 a $6 \mathrm{~kg}$, em uma proporção maior de pacientes, atingindo pelo menos $5 \%$ e $10 \%$ de perda de peso em comparação com o placebo. Os efeitos adversos mais comuns foram gastrointestinais, que ocorreram, principalmente, no início do tratamento.

Os dados comparativos mostraram que a perda de peso com liraglutida foi maior do que a observada com orlistate ou lorcaserina, mas um pouco menos que a observada com fentermina/ topiramato. Um estudo de grandes resultados demonstrou que $1,8 \mathrm{mg}$ de liraglutida gera benefício cardiovascular, sendo a aplicabilidade desses resultados para a formulação de 3,0 mg em uma população de perda de peso mais diversificada e com alto risco cardiovascular não foi observada. Os obstáculos para seu uso clínico como agente de primeira linha incluem efeitos colaterais gastrointestinais, alto custo e necessidade de injeção. Com base nessas informações, os autores concluíram que a liraglutida ajuda a induzir e sustentar a perda de peso em pacientes com obesidade, sendo sua eficácia é comparável a outros agentes disponíveis. Além disso, oferece o benefício exclusivo de um controle glicêmico. Estudos adicionais, no entanto, são necessários para determinar seu perfil de eficácia e segurança a longo prazo (MEHTA et al, 2016).

Visando investigar a eficácia e a segurança da liraglutida versus placebo, no controle de peso em adultos com sobrepeso ou obesidade e diabetes tipo 2, Davies et al (2015) promoveram um estudo de 56 semanas, randomizado (2:1:1), duplamente cego, controlado por placebo, em grupo paralelo, com 12 semanas de acompanhamento observacional sem uso de drogas. 
O estudo abrangeu 126 locais, em nove países, sendo realizado entre junho de 2011 e janeiro de 2013. Dos 1.361 participantes avaliados quanto à elegibilidade, 846 foram randomizados. Os critérios de inclusão foram índice de massa corporal igual ou superior a 27anos, idade igual ou superior a 18 anos, em uso de 0 a 3 hipoglicemiantes orais (metformina, tiazolidinediona, sulfonilureia), com peso corporal estável e nível de hemoglobina glicada de 7\% a 10\%. A metodologia e resultados deste estudo podem ser observados na Tabela 1.

Tabela 1 - Detalhamento da Metodologia e Resultados do estudo.

Fonte: Adaptado de Davies et al., 2015.

\begin{tabular}{cccc}
\hline ID Paciente & $\mathbf{4 2 3}$ & $\mathbf{2 1 1}$ & $\mathbf{2 1 2}$ \\
\hline Fármaco & Liraglutida & $3,0 \mathrm{mg}$ & Placebo \\
Dose & $3,0 \mathrm{mg}$ & $1,8 \mathrm{mg}$ & $0 \mathrm{mg}$ \\
Via de Administração & subcutânea & subcutânea & subcutânea \\
Frequência & $1 \times /$ dia & $1 \mathrm{x} / \mathrm{dia}$ & $1 \mathrm{x} / \mathrm{dia}$ \\
Complemento & Nenhum & $-500 \mathrm{kcal} / \mathrm{d}$ & $-500 \mathrm{kcal} / \mathrm{d}$ \\
& & $+150 \mathrm{~min} / \mathrm{sem}$ & $+150 \mathrm{~min} / \mathrm{sem}$ \\
Peso Basal & $105,7 \mathrm{~kg}$ & $105,8 \mathrm{~kg}$ & $106,5 \mathrm{~kg}$
\end{tabular}

Ref Liraglutida 3,0 $\mathrm{mg}$

Perda de peso $\quad 6 \%(6,4 \mathrm{~kg}) \quad 4,7 \%(5,0 \mathrm{~kg})$

$2,00 \%$

Ref Liraglutida $1,8 \mathrm{mg}$

$2,71 \%$

Ref Liraglutida 3,0 mg

$21,4 \%$

Perda de peso $>\mathbf{5 \%} \quad 54,3 \% /$ amostra $\quad$ 40,4\%/amostra

Ref Liraglutida $1,8 \mathrm{mg}$

$32,9 \%$

Ref Liraglutida 3,0 $\mathrm{mg}$

$6,7 \%$

Perda de peso $>\mathbf{1 0} \% \quad 25,2 \% /$ amostra $\quad 15,9 \% /$ amostra

Ref Liraglutida $1,8 \mathrm{mg}$

$18,5 \%$

\footnotetext{
*Foram considerados IC 95\% e P<0,001 para todas as análises realizadas

*Foram notificados mais distúrbios gastrointestinais com liraglutida (3,0 mg) vs liraglutida (1,8 mg) e placebo.

*Não foi relatada pancreatite (DAVIES et al, 2015).
} 
Com resultado, os autores observaram, entre os participantes com sobrepeso e obesos com diabetes tipo 2, que o uso de liraglutida subcutânea $(3,0 \mathrm{mg})$ administrada diariamente, resultou em perda de peso ao longo de 56 semanas, em comparação com o placebo. Eles consideraram que mais estudos eram necessários para avaliar a eficácia e segurança a longo prazo (DAVIES et al, 2015).

Santilli et al (2017) buscaram, em estudo, determinar se a perda de peso promovida pela liraglutida ou por mudanças no estilo de vida tem um impacto diferenciado no tecido adiposo subcutâneo e no tecido adiposo visceral de indivíduos obesos com pré-diabetes ou diabetes tipo 2 precoce.

Para isso, 62 pacientes obesos tratados com metformina na pré-diabetes ou com diabetes tipo 2 recém-diagnosticado foram randomizados para liraglutida $(1,8 \mathrm{mg} / \mathrm{dia})$ ou aconselhamento sobre o estilo de vida. Alterações nos níveis do tecido adiposo subcutâneo e do tecido adiposo visceral (determinados pela ressonância magnética abdominal), sensibilidade à insulina (de acordo com o índice de Matsuda) e função das células b (índice de b) foram avaliadas durante um teste de tolerância à glicose oral com múltiplas amostras, enquanto níveis circulantes de IGF-I e IGF-II foram avaliados antes e após uma perda de peso comparável (7\% do peso corporal inicial).

Após perda de peso comparável, alcançada por 20 pacientes por grupo, e controle glicêmico sobreponível, conforme refletido pelo nível de $\mathrm{HbA1c}(P=0,60)$, foi observada uma redução do tecido adiposo visceral significativamente maior no grupo liraglutida em comparação ao grupo estilo de vida $(P=0,028)$, além de uma maior melhora no índice $b(P=0,021)$. Não foram observadas diferenças relacionadas à Redução de tecido adiposo subcutâneo $(P=0,64)$. Os níveis séricos de IGF-II, por sua vez, aumentaram significativamente $(P=0,024)$ apenas com a administração de liraglutida, e a elevação nos níveis de IGF-II foi correlacionada à diminuição do tecido adiposo subcutâneo $(r=20,435$, $P=0,056)$ e um aumento no índice $b(r=0,55, P=0,012)$. Os autores concluíram que os efeitos da liraglutida na obesidade visceral e na função das células b podem fornecer uma justificativa para o uso desta substância em indivíduos obesos na fase inicial da desregulação do metabolismo da glicose.

Vários ensaios clínicos investigaram a eficácia da liraglutida na perda de peso em pacientes não diabéticos e diabéticos. A eficácia da liraglutida como agente de perda de peso foi avaliada em um ensaio clínico controlado e randomizado de 56 semanas. Pacientes sem diabetes foram incluídos no estudo se o IMC fosse $\geq 30$ (ou $\geq 27$ com outras comorbidades). Em uma proporção de 2:1, os pacientes foram randomizados para receber liraglutida $(n=2487)$ ou placebo $(n=1244)$. A dose de liraglutida foi iniciada em 0,6 mg por via subcutânea por dia e titulada em 0,6 mg por semana até a dose alvo de 3,0 mg por dia. Ambos os grupos receberam aconselhamento sobre modificações no estilo de vida. Os 
principais objetivos deste estudo foram a alteração de peso em relação à linha de base, a proporção de pacientes que perderam pelo menos $5 \%$ do seu peso em relação à linha de base e a proporção de pacientes que perderam mais de $10 \%$ do seu peso corporal de linha de base (PI-SUNYER et al, 2015).

Após 56 semanas, os pacientes do grupo liraglutida perderam 8,4 kg $\pm 7,3 \mathrm{~kg}$, enquanto os pacientes do grupo placebo perderam $2,8 \mathrm{~kg} \pm 6,5 \mathrm{~kg}$ da linha de base ( $p<0,001 \mathrm{vs}$ placebo). A percentagem de doentes que perderam pelo menos $5 \%$ do seu peso corporal desde a linha de base foi de $63,2 \%$ no grupo liraglutida vs. $27,1 \%$ no grupo placebo ( $p<0,001$ vs placebo). Da mesma forma, 33,1\% dos pacientes no grupo liraglutida versus $10,6 \%$ dos pacientes no grupo placebo perderam pelo menos $10 \%$ do seu peso corporal desde o início $(p<0,001)$. Os pacientes do grupo liraglutida relataram mais comumente eventos adversos gastrointestinais, enquanto náuseas e vômitos foram relatados principalmente nas primeiras quatro a oito semanas de tratamento. Com base nos resultados deste estudo, os autores concluíram que a liraglutida 3,0 mg uma vez ao dia, em combinação com dieta e exercício, produziu perda de peso clinicamente significativa em pacientes obesos sem diabetes (PISUNYER et al, 2015).

Um pequeno estudo envolvendo 44 pacientes com compulsão alimentar e obesidade teve como objetivo avaliar a eficácia de 1,8 mg liraglutida diárias, durante 12 semanas. Os indivíduos foram randomizados para receber liraglutida combinada com dieta e exercício ou apenas orientados a realizar dieta e exercício. Foram excluídos os pacientes submetidos a tratamentos com medicamentos que afetam o peso ou o apetite e diagnosticados com diabetes, tolerância à glicose diminuída ou doença cardiovascular. Entre os desfechos primários, destacaram-se alterações nos escores da Binge Eating Scale (BES), IMC e circunferência da cintura em relação à linha de base. $\mathrm{O}$ tratamento com liraglutida resultou em reduções significativas no escore de BES, IMC e circunferência da cintura em relação à linha de base, enquanto nos pacientes do grupo controle observaram apenas uma diminuição significativa do BES em relação à linha de base. Os pesquisadores concluíram que 12 semanas de tratamento com liraglutida em pacientes com compulsão alimentar não diabética resultaram em melhorias significativas no BES e no peso corporal.

Um estudo observacional relatou os resultados de 84 mulheres com sobrepeso ou obesas com síndrome dos ovários policísticos (SOP) que foram tratadas com até 1,8 mg de liraglutida, diariamente, por pelo menos quatro semanas. As pacientes incluídas no estudo não deveriam ter perdido peso, apesar da terapia com metformina e intervenções no estilo de vida por seis meses. Os desfechos primários foram mudança no peso corporal e IMC em relação à linha de base. O peso corporal médio 
no início do estudo foi de 98,9 kg e a duração média do tratamento com liraglutida foi de 27,8 semanas. Os resultados deste estudo mostraram uma perda de peso média de 9 kg (IC95\% 7,8 - 10,1; p<0,0001) e uma alteração média no IMC de 3,2 kg / m2 (IC95\% 2,8 - 3,6; p <0,0001) da linha de base. Ao avaliar esses parâmetros em pacientes que foram tratadas por mais de 20 semanas, a perda média de peso e a mudança no IMC em comparação com o valor basal foram ainda maiores. A partir desses resultados, os autores concluíram que a liraglutida pode ser um complemento eficaz para a metformina, dieta e exercício em mulheres com sobrepeso e obesos com SOP (RASMUSSEN; LINDENBERG, 2014).

Também diagnosticadas com SOP, 84 mulheres com sobrepeso ou obesas foram submetidas a tratamento com liraglutida, em estudo que visou avaliar a eficácia do medicamento. Neste ensaio de 12 semanas, 32 mulheres obesas diagnosticada recentemente com SOP foram randomizadas para receber metformina $1000 \mathrm{mg}$, duas vezes ao dia, ou liraglutida 1,2 mg ao dia. Após 12 semanas, mudanças significativas no IMC, peso corporal, circunferência da cintura e massa gorda corporal foram observadas pelas pacientes em ambos os grupos em comparação à linha de base. Os efeitos adversos relatados pelos dois grupos foram de natureza gastrointestinal, com náusea e diarreia mais comumente relatadas. Com base nos resultados deste estudo, os investigadores concluíram que o tratamento a curto prazo com liraglutida foi associado a uma significativa perda de peso em mulheres obesas com SOP (JENSTERLE et al, 2015)

Um estudo menor, envolvendo 328 pacientes, teve como objetivo avaliar o efeito da liraglutida no peso corporal e na circunferência da cintura em pacientes chineses com sobrepeso e obesidade com DM2. Neste estudo aberto, os pacientes receberam até $1,8 \mathrm{mg}$ por dia de liraglutida por 24 semanas. Os desfechos primários foram definidos com alterações no peso corporal, IMC e relação entre circunferência da cintura e altura (RCQ) a partir da linha de base. Após 24 semanas de tratamento, foram observadas reduções significativas em todos os desfechos primários. Os autores compararam seus resultados a ensaios clínicos realizados em países ocidentais e concluíram que a liraglutida é mais eficaz em pacientes chineses do que nas populações ocidentais (FENG et al, 2015).

A eficácia da liraglutida na redução de A1c e peso foi investigada em um estudo prospectivo observacional de pacientes árabes com diabetes tipo 2. Este estudo foi realizado em três centros em Dubai e incluiu todos os pacientes adultos com diabetes tipo 2, entre 18 e 70 anos de idade, que receberam receita médica de liraglutida. A dose de liraglutida foi iniciada em 0,6 mg e titulada para 1,2 mg ou 1,8 mg por dia, conforme tolerado. Os desfechos primários foram definidos como alteração no peso e A1c da linha de base para seis meses. A mudança média no peso corporal da linha de base 
para 6 meses foi de 2,5\% ( $p<0,001)$. Além disso, a média de A1c diminuiu de 8,3\% na linha de base para 7,6\% após 6 meses $(p<0,001)$. Com base nesses resultados, os pesquisadores concluíram que a liraglutida é uma terapia complementar para diabetes, produzindo reduções significativas de peso e A1c nessa população árabe (BASHIER et al, 2015).

\section{CONCLUSÃO}

Análogo do GLP-1 humano endógeno, a liraglutida tem conquistado resultados satisfatórios no tratamento do diabetes tipo 2, mais especialmente na redução de peso promovido em pacientes obesos, diagnosticados com ou sem quadro diabetes mellitus tipo 2 associado.

Desde a associação deste medicamento à redução de peso, vários estudos têm sido promovidos com a finalidade de verificar a real eficácia da liraglutida. Se, a princípio, seus benefícios são registrados logo após o período de tratamento, por outro, um tempo maior de acompanhamento mostra-se necessário, considerando-se que, até o momento, nenhum estudo registrou o fato de tal fármaco ser comprovadamente benéfica no longo prazo.

Portanto vale salientar que independentemente se a indicação da liraglutida para uso como emagrecedor for comprovado ou não, o uso de medicamentos para perda de peso deve ser a última alternativa. Para um emagrecimento saudável é sempre recomendável uma alimentação balanceada associada a atividades físicas regulares. 


\section{REFERÊNCIAS}

BASHIER, A.M., HUSSAIN, A., ABDELGABIR, E., et al. Liraglutide effect in reducing hba1c and weight in arab population with type 2 diabetes, a prospective observational trial. Journal of Diabetes \& Metabolic Disorders. v. 14, p. 48-55, 2015.

BROWN E, CUTHBERTSON DJ, WILDING JP. Newer GLP-1 receptor agonists and obesity-diabetes. Peptides. v. 100, p. 61-67, 2018.

DAVIES, M.J.; BERGENSTAL, R.; BODE, B, et al. Efficacy of liraglutide for weight loss among patients with type 2 diabetes: The SCALE Diabetes Randomized Clinical Trial. JAMA. v. 314, n. 7, p. 687-699, 2015.

DRUCKER, D.J.; BUSE, J.B.; TAYLOR D.M.K., TRAUTMANN, M.; ZHAUNG, D.; PORTER, L. Duration-1 Study Group. Exenatide once weekly versus twice daily for the treatment of type 2 diabetes: a randomised, openlabel, non-inferiority study. Lancet. v. 372, n. 9645, p. 1240-1250, 2008.

EBBELING, C.B.; SWAIN, J.F.; FELDMAN, H.A. et al. Effects of dietary composition on energy expenditure during weight-loss maintenance. JAMA. v. 307, n. 24, p. 2627-2634, 2012.

FENG, P., YU, D., CHANG, B., et al. Liraglutide reduces the body weight and waist circumference in chinese overweight and obese type 2 diabetic patients. Acta Pharmacologica Sinica. v. 36, p. 200-208, 2015.

FOOD AND DRUG ADMINISTRATION. Guidance for industry: developing products for weight management (draft guidance). Center for Drug Evaluation and Research (CDER). 2007. Disponível em: <https://www.fda.gov/media/71252/download>. Acesso em: jun/2019.

GILBERT, M. e PRATLEY, R. (2020). GLP-1 Analogs and DPP-4 Inhibitors in Type 2 Diabetes Therapy: Review of Head-to-Head Clinical Trials. In Front Endocrinol (Lausanne) 2020 Apr 3;11:178. doi: 10.3389/fendo.2020.00178.

GLANDT, M.; RAZ, I. Present and future: pharmacologic treatment of obesity. J Obes. n. 636181, 2011.

GUPTA, V. Glucagon-like peptide-1 analogues: an overview. Indian J Endocrinol Metab. v. 17, n. 3, p. 413-421, 2013.

JAMES, W.P. The epidemiology of obesity: the size of the problem. J Intern Med. v. 263, p. 336-352, 2008.

JENSTERLE, M., KRAVOS, N.A., PFEIFER, M., KOCJAN, T. AND JANEZ, A. A 12-week treatment with the long-acting glucagon-like peptide 1 receptor agonist liraglutide leads to significant weight loss in a subset of obese women with newly diagnosed polycystic ovary syndrome. Hormones. v. 14, p. 81-90, 2015.

LEE, I.M.; SHIROMA, E.J.; LOBELO, F.; PUSKA, P.; BLAIR, S.N.; KATZMARZYK, P.T. Lancet Physical Activity Series Working Group. Effect of physical inactivity on major noncommunicable diseases worldwide: na analysis of burden of disease and life expectancy. Lancet. v. 380, p. 219-229, 2012. 
LIM, G. E. et al. Insulin regulates glucagon-like peptide-1 secretion from the enteroendocrine $L$ cell. Endocrinology, v. 150, n. 2, p. 580-591, 2009.

MARSO, S.; DANIELS, G.; BROWN-FRANDSEN, K.; KRISTENSEN, P.; MANN, J.; NAUCK, M. et al. Liraglutide and cardiovascular outcomes in type 2 diabetes. N Engl J Med. v. 375, p. 311-322, 2016.

MEHTA, A.; MARSO, S.P.; NEELAND, I.J. Liraglutide for weight management: a critical review of the evidence. Obesity Science \& Practice. p. 3-14, 2016.

MECHANICK, J.I.; YOUDIM, A.; JONES, D.B. et al. Clinical practice guidelines for the perioperative nutritional, metabolic, and nonsurgical support of the bariatric surgery patient - 2013 update: cosponsored by American Association of Clinical Endocrinologists, the Obesity Society, and American Society for Metabolic and Bariatric Surgery. Endocr Pract. p. e1-36, 2013.

MEIER, J. GLP-1 receptor agonists for individualized treatment of type 2 diabetes mellitus. Nat Rev Endocrinol. v. 8, p. 728-742. 2012.

MENTIS, N.; VARDARLI, I.; KÖTHE, L.D.; HOLST, J.J.; DEACON, C.F.; THEODORAKIS, M.; MEIER, J.J.; NAUCK, M.A. GIP does not potentiate the antidiabetic effects of GLP-1 in hyperglycemic patients with type 2 diabetes. Diabetes. v. 60, n. 4, p. 1270-1276, 2011.

MUNDIL, D.; CAMERON-VENDRIG, A.; HUSAIN, M. GLP-1 receptor agonists: a clinical perspective on cardiovascular effects. Diab Vasc Dis Res. v. 9, n. 2, p. 95-108, 2012.

NETO, J.M.F.A.; NADER, B.B,; Síndrome metabólica e exercício físico: fatores relacionados à resistência à insulina. EFDeportes.com, Revista Digital. Buenos Aires, Año 17, № 172, Septiembre de 2012.

PHAM, H. et al. A bitter pill for type 2 diabetes? The activation of bitter taste receptor TAS2R38 can stimulate GLP-1 release from enteroendocrine L-cells. Biochemical and Biophysical Research Communications, v. 475, n. 3, p. 295-300, 2016

PARK, H.S, PARK, C.Y.; OH, S.W., YOO, H.J. Prevalence of obesity and metabolic syndrome in Korean adults. Obes Rev. v. 9, p. 104-107, 2008.

PI-SUNYER, X.; ASTRUP, A.; FUJIOKA, K. et al. A randomized, controlled trial of 3.0mg of liraglutide in weight management. NEJM. v. 373, p. 11-22, 2015.

POWELL, A.G.; APOVIAN, C.M.; ARONNE, L.J. New drug targets for the treatment of obesity. Clin Pharmacol Ther. v. 90, p. 40-51, 2011.

RASMUSSEN, C.B.; LINDENBERG, S. The Effect of liraglutide on weight loss in women with polycystic ovary syndrome: an observational study. Frontiers in Endocrinology. v. 5, p. 1-6, 2014.

ROLLS, B.J.; ROE, L.S.; MEENGS, J.S. Reductions in portion size and energy density of foods are additive and lead to sustained decreases in energy intake. Am J Clin Nutr. v. 83, p. 11-17, 2006.

SANTILLI, F.; SIMEONE P.G.; GUAGNANO, M.T.; LEO, M.; MACCARONE, M.T. DI CASTELNUOVO, A.; SBORGIA, C.; BONADONNA, R.C.; ANGELUCCI, E.; FEDERICO, V.; CIANFARANI, S.; MANZOLI, L.; DAVÌ, G.; TARTARO, A.; CONSOLI, A. Effects of liraglutide on weight loss, fat distribution, and $\beta$-cell function 
in obese subjects with prediabetes or early type 2 diabetes. Diabetes Care Nov. v. 40, n. 11, p. 1556$1564,2017$.

SARAIVA, F.K.; SPOSITO, A. Cardiovascular effects of glucagon-like peptide-1 (GLP-1) receptor agonists. Cardiovasc Diabet. v. 13, n. 142. 2014.

SAXENDA. Disponível em:

<http://www.anvisa.gov.br/datavisa/fila_bula/frmVisualizar

Bula.asp?pNuTransacao=25912782016\&pldAnexo=4088697>. Acesso em: jul/2020.

SRIVASTAVA G, et al. Future Pharmacotherapy for Obesity: New Anti-obesity Drugs on the Horizon. Current Obesity Reports, v. 7(2), p. 147-161. 2018.

STEENSGAARD, D.B.; THOMSEN, J.K.; OLSEN, H.B.; KNUDSEN, L.B. The molecular basis for the delayed absorption of the once-daily human GLP-1 analoge, liraglutide, diabetes, Amer Diabetes Assoc. p. A164-A164, 2008.

VIGILÂNCIA DE FATORES DE RISCO E PROTEÇÃO PARA DOENÇAS CRÔNICAS POR INQUÉRITO TELEFÔNICO - VIGITEL BRASIL 2018. Estimativas sobre frequência e distribuição sociodemográfica de fatores de risco e proteção para doenças crônicas nas capitais dos 26 estados brasileiros e no Distrito Federal em 2018. Ministério da Saúde, Secretaria de Vigilância em Saúde, Departamento de Análise em Saúde e Vigilância de Doenças não Transmissíveis. 2019. Disponível em: <http://portalarquivos2.saude.gov.br/images/pdf/2019 /julho/25/vigitel-brasil-2018.pdf>. Acesso jun/2019.

VILSBOLL, T.; CHRISTENSEN, M.; JUNKER, A.E.; KNOP, F.K.; GLUUD, L.L. Effects of glucagon-like peptide1 receptor agonists on weight loss: systematic review and meta-analyses of randomised controlled trials. BMJ. v. 344, p. d7771. 2012.

WILLIS, B.L.; GAO, A.; LEONARD, D.; DeFINA, L.F.; BERRY, J.D. Midlife fitness and the development of chronic conditions in later life. Arch Intern Med. v. 172, p. 1333-1340, 2012.

ZHAO, L.; CHEN, Y.; XIA, F.; ABUDUKERIMU, B.; ZHANG, W.; GUO, Y.; WANG, N.; LU, Y. A glucagon-like peptide-1 receptor agonist lowers weight by modulating the structure of gut microbiota. Front. Endocrinol. v. 9, p. 233, 2018. 


\section{Capítulo 7}

\section{doi $10.37423 / 211004898$}

\section{CORONAVÍRUS}

Pedro Victor de Arruda Armelin

Universidade do Oeste Paulista - UNOESTE. Campus Presidente Prudente SP

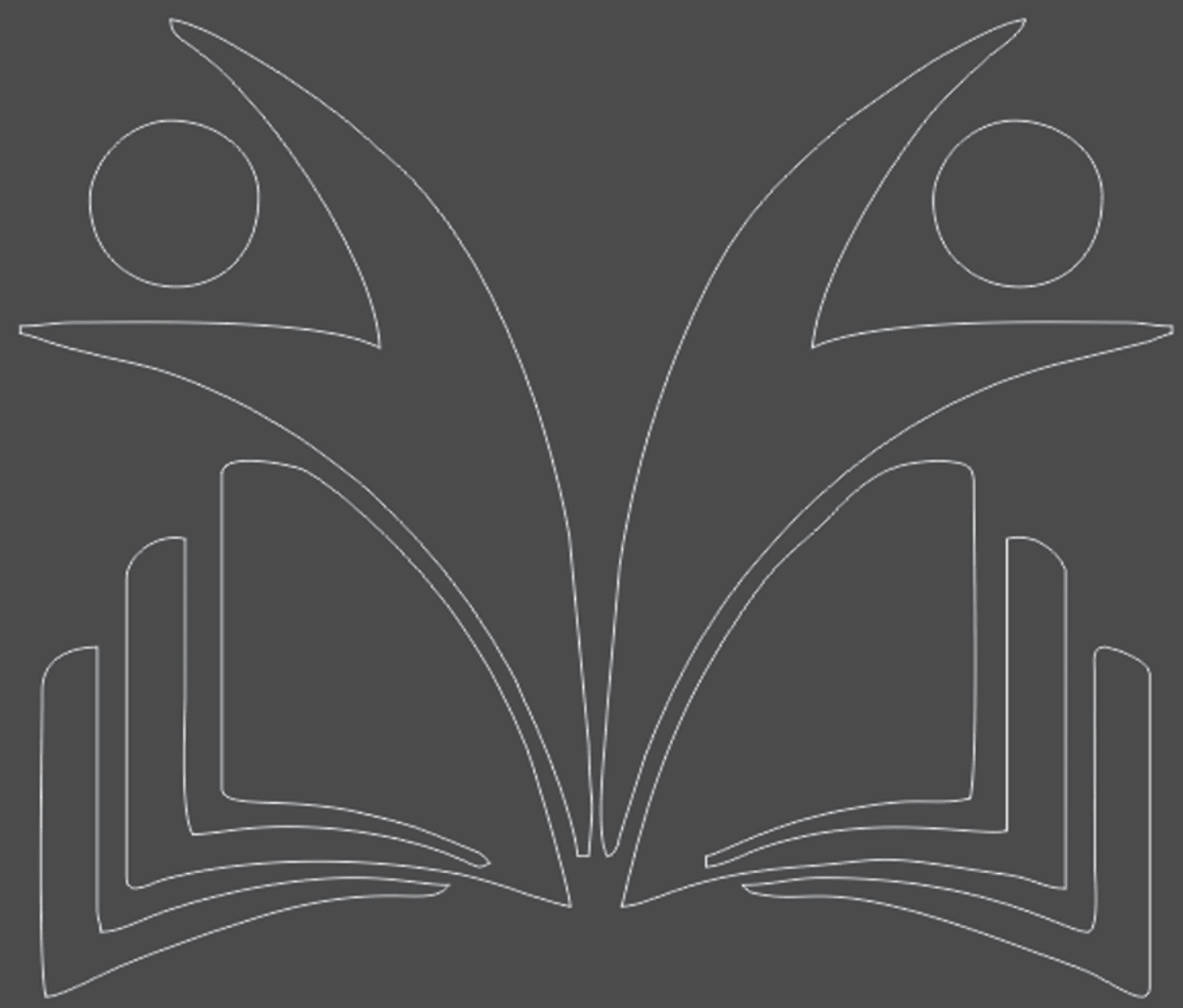




\section{Coronavírus}

Resumo: Os coronavírus (CoV) são uma grande família viral, conhecidos desde meados dos anos 1960, que causam infecções respiratórias em seres humanos e em animais. Os coronavírus pertencem à subfamília Coronavirinae, família Coronaviridae. São grandes vírus com uma única fita de RNA e um nucleocapsídeo (estrutura composta pelo ácido nucleico do vírus (neste caso RNA) e seu invólucro proteico, o capsídeo) helicoidal. Seu nome se deve a espículas (estruturas proeminentes) presentes na superfície do vírus, o que lhe dá a aparência de uma coroa solar (corona em latim). Há seis tipos de corona que infectam o homem.

Em 2019, uma doença respiratória grave, de agente etiológico até então desconhecido foi detectada na China, em Wuhan, cujos principais sintomas eram tosse, febre e dispneia (falta de ar). Na investigação da etiologia, foi descoberto o novo coronavírus, o COVID-19. Embora tenham sido feitos esforços para se fecharem os aeroportos na China e conter a transmissão viral, a doença se espalhou pelo mundo, tornando-se uma pandemia.

Palavras chaves: Coronavírus, vírus, doença respiratória grave. 


\subsection{VÍRUS}

\subsection{CARACTERÍSTICAS DA FAMÍLIA DOS CORONAVÍRUS}

A partícula completa, ou vírion, tem morfologia esférica, é dotado de envelopa e mede cerca de 100 a $160 \mathrm{~nm}$ de diâmetro. É um vírus com RNA de fita simples, polaridade positiva e com tamanho de aproximadamente $32 \mathrm{~Kb}$. A transmissão do Coronavírus ocorre principalmente através de aerossóis (suspensão de micropartículas sólidas ou líquidas, invisíveis) e de secreções nasais.

\subsection{TRANSMISSÃO}

Como os demais membros da família dos Coronavírus, o COVID-19 (também denominado SARS-CoV2) é transmitido através de secreções do trato respiratório (gotículas provenientes de tosse e espirro) e possivelmente de aerossois. A transmissão também pode ser feita pelas mãos pelo contato com secreções em outra pessoa ou em superfícies contaminadas. Nesse caso, só haverá infecção se as mãos forem levadas ao rosto (mucosa oral, nasal ou ocular), pois não há infecção através da pele. É importante ressaltar que paciente infectado pode transmitir a doença mesmo antes do aparecimento de sintomas. Os morcegos parecem ser a fonte primária (reservatório) do vírus, mas é provável que, para ter infectado o ser humano, outro hospedeiro animal esteja envolvido.

Estudos recentes detectaram também espécimes de vírus vivo em amostra de fezes de pacientes contaminados. É importante levar em consideração que a doença pode ter manifestações gastrointestinais, a saber, vômito e diarreia. Essas descobertas sugerem a possibilidade de transmissão fecal-oral, mas há necessidade de mais estudos.

\section{A EPIDEMIA}

Em 31 de dezembro de 2019, a Organização Mundial de Saúde (OMS) foi noticiada da ocorrência de casos graves de pneumonia na cidade de Wuhan, na província de Hubei, na China. No país, as autoridades de saúde tomaram medidas emergenciais para conter a epidemia e começaram os estudos epidemiológicos, microbiológicos e clínicos para descrever a nova doença e, assim, possibilitar seu controle. Em 7 de janeiro de 2020, cientistas chineses anunciaram a descoberta do novo coronavírus. Em seguida, desenvolveram um método de biologia molecular para confirmação diagnóstica.

A investigação dos primeiros casos apontou para mercados de frutos do mar e de venda de animais, corroborando com a hipótese de que o novo corona poderia ter sido inicialmente transmitido por 
animais. No entanto, não há evidência de transmissão por animais de estimação. A transmissão pessoa-a-pessoa foi rapidamente provada e é este o tipo de transmissão responsável pela epidemia. Em janeiro, a doença começou a ser registrada fora de Hubei e ocasionalmente em outros países. Em 30 de janeiro, a OMS declarou a doença como Emergência de Saúde Pública de Interesse Internacional. À ocasião, 7736 já haviam sido confirmados e 83 deles eram fora da China. No mês seguinte, a OMS oficialmente nomeou a doença como Doença por coronavírus 19 (simplificadamente: COVID-19) e renomeou o vírus para SARS-CoV-2.

Até o presente momento ( 26 de março de 2020), mais de 420 mil casos foram confirmados em todo o mundo e 22.185 mortes foram confirmadas. No Brasil, foram confirmados 2614 casos e 57 mortes.

\section{CLÍNICA}

Há dados que sugerem que mais de $80 \%$ das pessoas que contraem o COVID-19 são assintomáticas ou oligossintomáticas (com poucos sintomas) e se recuperam. No entanto, $15 \%$ das pessoas contrai doença grave, incluindo pneumonia e $5 \%$ se tornam críticos, p. ex., evoluindo com choque séptico ou falência múltipla de órgãos. Os principais sintomas são tosse, febre e dispneia. Outras manifestações possíveis incluem espirros, dor de garganta, coriza, cianose, disfagia (dificuldade para engolir), entre outros.

Nas crianças, os sintomas mais comuns documentados foram tosse, eritema faríngeo e febre. No entanto, casos assintomáticos e leves são comuns na criança - provavelmente mais comuns que no adulto.

Nos pacientes graves, há relatos de lesão renal aguda, Síndrome Respiratória Aguda Grave (SARS) e lesão cardíacas. Nesses casos, a maioria dos pacientes necessita de suporte ventilatório. Além disso, esses pacientes estão sob maior risco de contrair infecções hospitalares.

\section{EPIDEMIOLOGIA}

\subsection{FATORES DE RISCO E MORTALIDADE}

Os maiores fatores de risco para doença grave são idade, sendo a doença mais grave em maiores de 60 anos, e em pacientes com comorbidades, sobretudo cardiovasculares. A doença parece ser mais observada em homens. 


\section{Coronavírus}

A taxa de letalidade estimada pela OMS é de cerca de 5,6 óbitos/100 pessoas com a doença. No início da epidemia, na China, a letalidade pode ter sido ainda maior.

\section{PREVENÇÃO}

A higienização das mãos (mínimo 20 segundos) é uma medida de proteção efetiva contra a disseminação do vírus, bem como evitar contato com doentes, evitar tocar a face, etc. Os pacientes diagnosticados com COVID-19 devem ser isolados e os profissionais da saúde devem usar EPI e os ambientes devem ser adequadamente higienizados. Atualmente, há recomendação de isolamento social para a população geral para interromper a cadeia de transmissão.

\section{DIAGNÓSTICO}

O diagnóstico é feito em pacientes com síndrome gripal, por meio de técnica laboratorial denominada RT-PCR (reação em cadeia da polimerase em tempo real), que detecta o genoma do vírus. Aos exames de imagem de tórax, geralmente é possível observar infiltrados bilaterais e no hemograma, linfopenia (baixo número de linfócitos).

\section{TRATAMENTO}

Não há tratamento específico disponível. Casos leves da doença podem ser tratados ambulatoriamente com repouso, hidratação e nutrição adequada, além de anti-térmicos e analgésicos para controle dos sintomas. O paciente deve ser mantido em isolamento por, no mínimo, duas semanas.

Os casos graves devem ser estabilizados, muitas vezes requisitando ventilação mecânica, fluidoterapia e antibioticoterapia para infecção secundária.

Vale enfatizar a importancia da vacinação para redução de taxas de infectividade e letalidade, haja em vista que com a imunização há quedas desses índices. 


\section{Coronavírus}

\section{REFERÊNCIAS}

http://www.saude.sp.gov.br/resources/cve-centro-de-vigilancia-epidemiologica/areas-devigilancia/doencas-de-transmissao-respiratoria/coronavirus.html

https://www.sbmt.org.br/portal/new-coronavirus-disease-covid-19-more-questions-thananswers/?lang=en

https://www.thelancet.com/journals/lanpub/article/PIIS2468-2667(20)300736/fulltext\#seccestitle130

http://www.invivo.fiocruz.br/cgi/cgilua.exe/sys/start.htm?infoid=1438\&sid=8 http://repocursos.unasus.ufma.br/vigilancia_20161/curso_2/und1/46.html http://www.ufrgs.br/labvir/material/poligrafo1.pdf https://www.nejm.org/doi/full/10.1056/NEJMc2001468?query=featured_home https://www.nejm.org/doi/full/10.1056/NEJMc2005073?query=recirc_mostViewed_railB_article https://www.thelancet.com/journals/lanres/article/PIIS2213-2600(20)300795/fulltext\#seccestitle140

https://www.thelancet.com/journals/laninf/article/PIIS1473-3099(20)30195-X/fulltext http://189.28.128.100/dab/docs/portaldab/documentos/20200320_ProtocoloManejo_ver03.pdf https://www.nature.com/articles/s41575-020-0295-7https://www.nature.com/articles/d41586-02000895-8 


\section{Capítulo 8}

\section{doi $10.37423 / 211004902$}

\section{A PERCEPÇÃO DO ENFERMEIRO FRENTE A EUTANÁSIA}

Ciliana Antero Guimarães da Silva

Gabriel Henrique Carvalho Dionizio

Sarah do Couto Barbosa

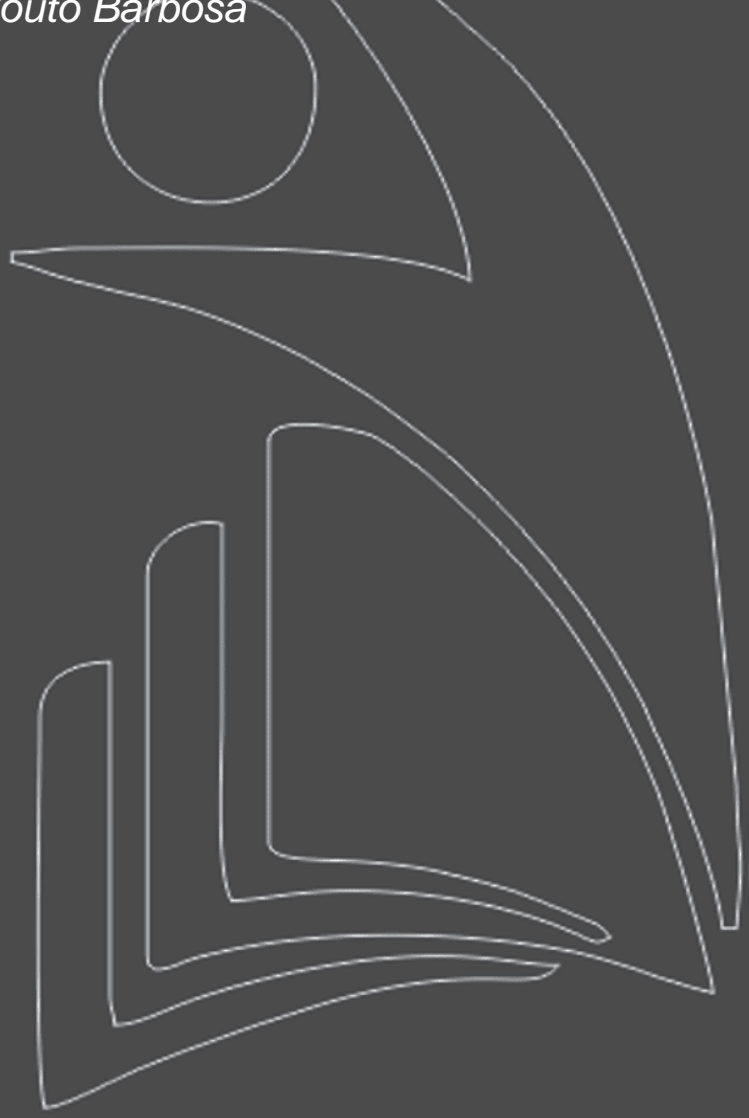

Centro Universitário Teresa D Ávila UNIFATEA

Centro Universitário Teresa D Ávila UNIFATEA

Centro Universitário Teresa Q Ávila UNIFATEA

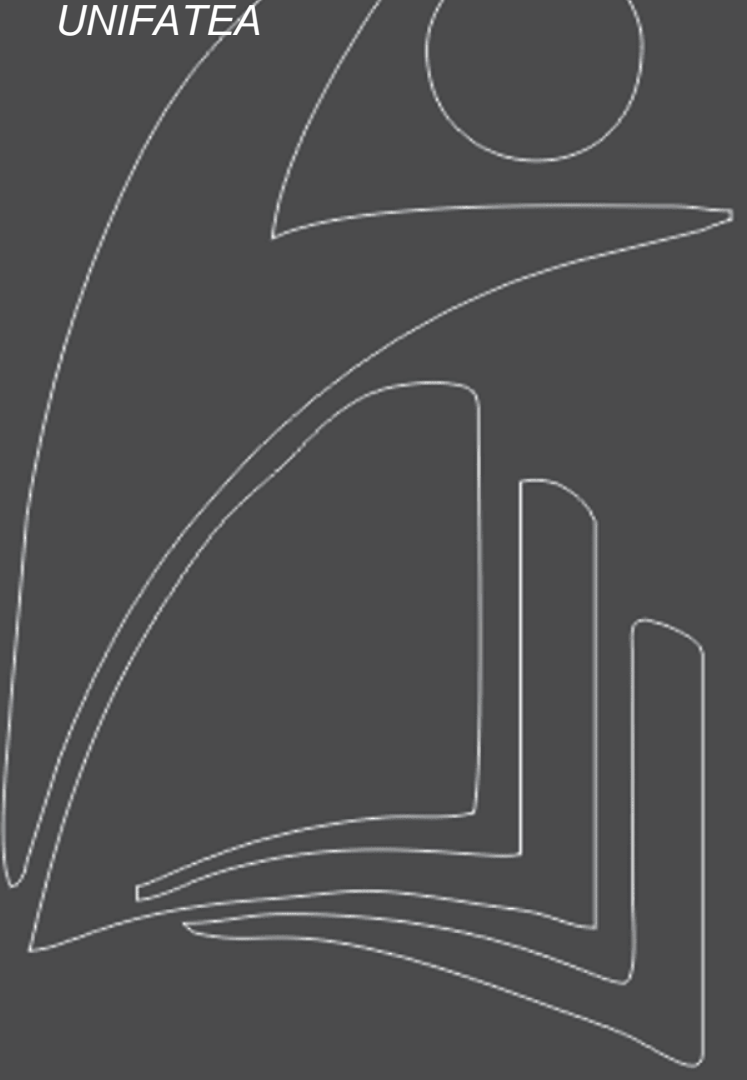




\section{A Percepção Do Enfermeiro Frente A Eutanásia}

Resumo: $O$ presente estudo explana indagações referente a percepção do enfermeiro frente a eutanásia, sendo o assunto de suma importância e relevância cientificadevido as discussões ocorridas em todas as esferas da sociedade. O objetivo é identificar a percepção do enfermeiro perante situações do processo de eutanásia. Trata-se de uma revisão da literatura do tipo narrativa, com foco qualitativo. Evidenciou-se que o tema é complexo, diversificando-se conforme os preceitos religiosos, os valores morais e éticos. Assim, devendo o profissional enfermeiro estar ciente sobre o assunto e no que diz respeito ao Conselho Federal de Enfermagem e a Legislação Brasileira, com o intuito de acrescentar melhorias da assistência prestada ao paciente e família, assegurando uma conduta ética e moral.Prevenindo situações de conflitos mediante a eutanásia.

Palavras-chave: Morte; Vida; Enfermeiro; Eutanásia. 


\section{A Percepção Do Enfermeiro Frente A Eutanásia}

\section{INTRODUÇÃO}

Atualmente, no Brasil a eutanásia tem sido cada vez mais debatida nos meios de comunicação, bem como nos meios científicos, envolvendo questões éticas, religiosas, morais, políticas e jurídicos. Dessa forma, gerando diversas discussões sobre o assunto.

A prática da eutanásia condiz com a morte premeditada e provocada, que teoricamente proporciona ao indivíduo o alívio da dor e sofrimento, ou seja, para se configurar uma ação como eutanásia é necessário que se tenha a intensão de beneficiar o paciente, porém, proporciona um impacto muito relevante em todos os que estão envolvidos no processo, seja na família, sociedade, profissionais de saúde ou até mesmo no paciente (LIMA, 2018 apud SOUSA et al., 2021).

A enfermagem é uma das categorias que mais se desgastam emocionalmente devido à constante interação com os pacientes enfermos, as constantes internações, muitas vezes acompanhando o sofrimento, como a dor, a doença e a morte do ser cuidado(HERMES e LAMARCA, 2013).

O processo de morte envolve diversos fatores cujos este vai além do paciente em seu estado geral hemodinamicamente, físico, psíquico, emocional e o ambiente em que o mesmo se encontra, o profissional enfermeiro como atuante e ser humano, precisa entender esses fatores.

Segundo Dias (2014), mesmo que os profissionais da saúde estejam atualmente esclarecidos sobre o tema em destaque, pouco se fala em assuntos a respeito de como lidar com o processo de morrer e morte. Existem lacunas se tratando de assuntos que proporcionam análise sobre a morte que poderiam beneficiar o profissional, tanto em seu aspecto físico quanto no emocional, durante o processo de cuidar do paciente e sua família, em situações de finitude humana. Desta maneira, reconhecer as produções imaginárias dos profissionais diante do processo de morrer, atentando para seus anseios, suas crenças, percepções e sentimentos, permite-se um aprofundamento sobre os sentimentos do profissional e o acolhimento dos pacientes e suas famílias.

\section{OBJETIVO}

Identificar a percepção do enfermeiro perante situações do processo de eutanásia. 


\section{A Percepção Do Enfermeiro Frente A Eutanásia}

\section{REVISÃO DA LITERATURA}

\subsection{PROCESSO DA VIDA}

O direito à vida é o mais fundamental de todos os direitos, já que se constitui em pré-requisito a existência e exercício de todos os demais direitos. A Constituição Federal, é importante ressaltar, protege a vida de forma geral, inclusive a uterina (MORAES, 2000 et al ROBERTO, 2011).

Segundo Roberto, (2011), é assegurado por lei, o direito à vida. Nota-se que é de extrema importância, tanto que este atual tema vem sendo debatido diversas vezes no Código Civil Brasileiro e na Constituição Federal. O procedimento da vida segundo alguns doutrinadores se dá no momento da concepção, assim sendo, no processo do desenvolvimento do feto, até seu nascimento com vida.

O direito à vida é o principal direito que existe, o primeiro a ser protegido, mas, ainda assim, pode sofrer restrições. É o que ocorre nos casos de defesa da própria vida quando a própria vida está em conflito com outro direito de viver, de outra pessoa, e o Poder Público não pode interceder, é permitida a violação do direito à vida de outrem, sem punição por parte do Estado (TAVARES, 2009 apud KRIEGER 2013).

Com efeito e fundamento no posicionamento de Krieger (2013) não existem bem maior do que a vida, ou seja, este direito precisa ser o primeiro a ser resguardado, contudo há determinadas restrições. 0 Poder Público pode vir a intervir com base nas violações de regra aos direitos humanos, sem que haja a punição do Estado para essas intervenções.

A vida se identifica com a simples existência biológica e que o direito à vida é essencial, tem como objeto um bem muito elevado, sendo um direito essencialíssimo. É um direito inato, adquirido no nascimento, portanto, intransmissível, irrenunciável e indisponível assim, o suicídio não constitui ato de exercício de um direito. Assim, o direito à vida deve ser associado a um direito à conservação da vida, em que o indivíduo pode gerir e defender sua vida, mas não pode dela dispor, apenas justificando ação lesiva contra a vida em casos de legítima defesa e estado de necessidade. Assevera, ainda, sobre tutela privada e pública do direito à vida, admitindo que o direito aos alimentos é uma tutela complementar da vida, sendo diferente do direito à vida, pois não é a vida o seu objeto, mas um bem material para servir a conservação da vida (ROBERTO, 2011).

Tendo a opinião sobre a vida definido por diferentes doutrinadores, é de suma importância a abordagem dos processos pertinentes a morte. 


\section{A Percepção Do Enfermeiro Frente A Eutanásia}

\subsection{PROCESSO DA MORTE}

Para a humanidade a experiência com a morte e o morrer é complexa de ser compreendida e aceita. Cada sociedade vê esses eventos de diversos olhares. Tal situação está intimamente ligada ao medo do desconhecido, expressado na concepção da finitude da vida, que traz grande temor e negação. Presente em todas as crenças, valores e culturas, a morte é um dos maiores enigmas que povoa o pensar da humanidade (RIBEIRO, 2008 apud PRAXEDES, 2018).

A morte e o morrer são inerentes à existência humana (ROSS, 2000 apud JÚNIOR et al., 2011). As incertezas e a imprevisibilidade que se dispõem em volta do binômio morte-morrer compelem o ser humano a conviver com a sua presença desde o início ao estágio final do seu desenvolvimento (ZORZO, 2004 apud JÚNIOR et al., 2011).

O significado dado à morte e o morrer sofreu diversas mudanças nas diferentes sociedades. Tais modificações, no modo de encará-la, ocorreram de acordo com cada fase histórica da organização sociocultural humana. O processo morte/morrer não é apenas um acontecimento biológico, mas sim, um fato construído socialmente e historicamente (MENEZES, 2004 apud PRAXEDES, 2018).

Apesar de a morte subsistir desde o princípio da humanidade, o processo morte e morrer tem sido motivo de aflição, agonia e desespero, já que mostra o quão susceptível, vulnerável e tênue é o estar vivo, ou seja, ser mortal, finito. É um processo simplesmente natural, universal e inevitável, mas mesmo assim o ser humano não suporta imaginar, pensar ou discutir sobre sua própria morte e acaba projetando-a no outro, tendo em vista a impossibilidade de conceber o mundo sem sua presença (CARVALHO et al., 2006 apud PRAXEDES, 2018).

\subsection{EUTANÁSIA}

A eutanásia é uma ação a pedido pelo paciente ou seus familiares com o intuito de proporcionar morte sem dor e sofrimento ao doente atingido por afecção incurável que produz dores intoleráveis, é praticado com fundamento moral e de piedade em pacientes em estado terminal que passam por um momento provável de morte eminente, embora seja um ato com intuito de parar o sofrimento, no Brasil é ilegal, porém, não existe na Legislação uma lei específica para tal ato, com isso, se incorrerá criminalmente no artigo 121, do Código Penal, se caracterizando como homicídio.

De acordo com a história, o termo eutanásia possui o significado de morte digna ou falta de sofrimento. No grego "eu" constitui bom e Thanatosé conexo a morte. Essas expressões foram 


\section{A Percepção Do Enfermeiro Frente A Eutanásia}

empregadas inicialmente por Suetônio, no século II d.C, para descrever a morte do imperador Augusto (BATISTA\& SCHRAMM, 2004).

Segundo os autores Batista\& Schramm (2004), a primeira vez que se ouviu a pronuncia do termo histórico eutanásia, foi no século II, d.C. que tem como o significado "eu" bom e Thanatosé tem uma relação com a morte. Com base na escrita dos autores esses meios de expressões foram utilizados primeiramente por Suetônio, para deixar registrado a morte do imperador.

Alguns períodos passados depois da citação de Suetônio, Thomas Morus, aprovado o santo da Igreja Católica, foi um dos que defendeu a utilização da eutanásia em sua obra escrita no ano de 1.516 (PESSINI\& BARCHIFONTAINE, 2000).

O segundo conto histórico foi empregado em 1.516 para expor uma obra que o Thomas Morus havia escrito em defesa da eutanásia.

Já no Renascimento, aproximadamente no ano de 1.623, Francis Bacon escreveu "História vitae et mortis", onde discorre sobre o conceito da eutanásia não relacionando absolutamente aos marcos gregos, mas sim, induzindo para um ponto filosófico, porque o método eutanásico sempre teve no transcorrer da história do homem (PESSINI\& BARCHIFONTAINE, 2000).

Depois 107 anos, foi verificado que Francis Bacon, contou na sua obra que os métodos eutanásico, vão muito, mas além do que os conceitos que os gregos utilizavam, virando parte de um enfoque filosófico.

Conforme Pessini \& Barchifontaine (2000), o procedimento de desenvolvimento da eutanásia se divide em três etapas diferentes: ritualizada, medicalizada e autonomizada.

Inicialmente a fase ritualizada, o nome já diz tudo, era feito através de rituais realizados no momento da morte da pessoa, fato feito por diferentes culturas para humanizar o atual ato. Quando ficava impraticável a realização do ritual de humanização social, esse ritual era apressado mediante aos familiares, feiticeiros, sacerdotes e outras pessoas(PESSINI\&BARCHIFONTAINE, 2000).

A eutanásia medicalizada nasce na Grécia com o surgimento da medicina científica, estendendo-se até a Segunda Guerra Mundial, quando o médico passou a ter a função de cuidar dos enfermos, deficientes e anciãos, devendo utilizar da eutanásia apenas quando necessário. Desde a antiguidade, várias culturas recomendavam a eutanásia, seja de forma direta ou indireta, diferentemente do cristianismo, que a desqualifica numa atitude de solidariedade para aqueles que sofrem (PESSINI\& BARCHIFONTAINE, 2000). 


\section{A Percepção Do Enfermeiro Frente A Eutanásia}

A etapa autonomizada, no ano de 1.973 foi exigido através da Carta dos Direitos dos Enfermos pela Associação American dos Hospitais Privados, a consideração dos direitos do enfermo. Os direitos humanos é um assunto de alta discussão atualmente, porém, é o direito de decidir (respeitando alguns limites) cirurgicamente o que fazer em seu corpo (PESSINI\&BARCHIFONTAINE, 2000).

Segundo Pessini e Barchifontaine (2000), o direito dos enfermos foi alvejado e reconhecido no ano de 1973. Contudo o contexto é de suma importância nos dias atuais, induzindo essa discussão para os teóricos cientistas sobre o método de decisão que o paciente pode fazer para com seu corpo.

\subsection{EUTANÁSIA PASSIVA E ATIVA}

A eutanásia pode ser classificada como passiva e ativa, a primeira trata-se da suspensão de cuidados médicos, no qual o profissional deixa de realizar procedimentos que dariam a chance do paciente viver por mais um tempo (CASTRO \& CESAR, 2019 apud SOUSA, 2021).

A segunda é quando ocorre a indução da morte por meio de substâncias letais.

Dependendo do caso a eutanásia pode ocorrer tanto a pedido do próprio paciente como por uma decisão de terceiros, que são métodos classificados como de caráter voluntário e involuntário respectivamente (SOUZA\& BULGARELLI, 2017 apud SOUSA, 2021).

\subsection{DISTANÁSIA}

A distanásia é um procedimento que busca delongar a morte ao máximo de tempo aceitável e utilizando todos os artifícios disponíveis para delongar a morte do doente, este ato versa em estender uma condição vegetativo de um doente, ficando de lado, os artifícios considerados formidáveis de reanimação que a ciência médica emprega nos dias de hoje (DINIZ, 2007).

De acordo com Diniz (2007), o significado de distanásia são intervenções médicas para enfermos sem expectativa de vida e que está em um estado terminal, afim de estender sua morte que será inevitável. O conceito jurídico e moral desse método pode não ser completamente abrangidos.

\subsection{MISTANÁSIA}

A mistanásia ou também conhecida como eutanásia social, o procedimento da morte não é apresentado como um método de escolha do doente, mas sim um meio utilizado pela sociedade, por meio da renúncia ou carência de aquisição quando o tratamento está com valores muitos altos para 


\section{A Percepção Do Enfermeiro Frente A Eutanásia}

prorrogação da vida do doente, penetrando em um assunto de custo versus benefício (PESSINI\&BARCHIFONTAINE, 2000).

Nada tem de boa, suave ou indolor. Dentro da categoria de mistanásia pode-se focalizar em três situações: primeiro, a grande massa de doentes e deficientes que, por motivos políticos, sociais e econômicos, não chegam a ser pacientes, pois não conseguem ingressar efetivamente no sistema de atendimento médico; segundo, os doentes que conseguem ser pacientes, para, em seguida, se tornar vítimas de erro médico e, terceiro, os pacientes que acabam sendo vítimas de má prática por motivos econômicos, científicos ou sociopolíticos. A mistanásia é uma categoria que nos permite levar a sério o fenômeno da maldade humana (MARTIN, 2001).

Neste sentido, Martin (2001) assevera, que a mistanásia não é um processo que garante ao enfermo uma morte sem dor da forma que lhe é desejado. Em diversas condições e motivos (políticos, sociais e econômicos), os doentes não obtêm o devido tratamento para tal técnica e acabam sendo vítimas fatais de erros médicos lesivos, abrangendo o tratamento a crueldade humana e vindo a falecer.

\subsection{ORTOTANÁSIA}

Primordialmente o termo ortotanásia foi oferecido pelo professor da LiegeUniversity, na Bélgica, o Dr. Jacques Roskam, aproximadamente no ano de 1950, formou a ideia que a eutanásia é uma morte justa sem dor em um mesmo argumento. A ortotanásia é um método de morte no seu tempo natural, ou seja, sem a obrigação de minimizar o andamento de vida do doente através de medicamentos. Estando assim, é uma morte honesta, sem há necessidade de realizar certos tipos de tratamentos superficiais para ocorrer este fenômeno natural. O procedimento da ortotanásia visa "humanizar" o momento atual do doente até a sua morte, sem demorar. Neste argumento, a morte do doente virá pela sua enfermidade, sem introdução de quaisquer métodos formidáveis por parte médica, com a meta de diminuir o sofrimento do paciente que se encontra enfermo (ERENO, 2014).

Conforme Ereno (2014), a ortotanásia é uma metodologia que visa obstruir um tratamento de uma enfermidade diagnosticada incurável, com o motivo de não prolongar o sofrimento ou as dores de um enfermo, com uma doença sem cura. A pessoa doente está em um quadro irreversível pronta para morrer onde a mesma, recebe apoio da equipe multidisciplinar, para chegar no resultado da morte natural. Para não dilatar a morte por meio de equipamentos artificiais (artifício conseguido pela distanásia), consentindo assim desenvolvimento espontâneo (método da ortotanásia). Somente um 


\section{A Percepção Do Enfermeiro Frente A Eutanásia}

médico é capacitado para cometer a ortotanásia, não sendo forçado a majorar a esperança de vida do enfermo sem o seu devido consentimento.

O princípio da autonomia parte da opinião da afinidade das condutas éticas da emancipação da pessoa e também da sua própria autodeterminação, em condição que está enquadra com uma afirmação da cidadania. A autonomia é imprescindível para definir uma apurada área, a ética. Sem o emprego da pessoa livre não é aceitável abrir uma contenda sobre julgamentos éticos que a pessoa comete. É avaliado como autônomo todo aquela pessoa que se aproveita da liberdade, ou seja, suas normas são de auto escolha. (ASSIS\&BAMBIRRA, 2010).

De acordo com Assis e Bambirra (2010), por pretextos particulares é que precisa se impor os direitos de agir e pensar, ainda que a terceiros isso acontece de caráter absurdo. A individualidade sempre deverá ser resguardada mesmo que exista determinada influência de fora, por mais mansa que seja.É de suma importância ressaltar que a autonomia de uma pessoa para ser apropriada a respeito de viver ou morrer, enquadra as pessoas totalmente apropriadas e afastada de proibições aos seus direitos, ou seja, a pessoa atingindo a maioridade penal de 18 anos ou por decisão judicial (pessoas emancipadas), que tem, com base no artigo $5^{\circ}$ do Código Civil, qualidades mentais para apoiarem esse direito.

\subsection{CONSELHO FEDERAL DE ENFERMAGEM 2017}

Proibições:

Art. 74. Promover ou participar de prática destinada a antecipar a morte da pessoa.

\subsection{CONSELHO FEDERAL MÉDICA 2018}

É vedado ao médico:

Art.29. Participar, direta ou indiretamente, da execução de pena de morte.

\subsection{CÓDIGO PENAL BRASILEIRO}

Com a alteração da parte geral do atual Código Penal, Lei no 7.209/84, acrescentou-se a causa de diminuição de pena do homicídio privilegiado, artigo 121, parágrafo 1ำ, cujo conteúdo vem sendo utilizado na prática jurídica para casos de homicídio eutanásico, uma vez que prevê a possibilidade de redução da pena pelo magistrado de um sexto a um terço, em casos de crimes praticados por motivo de relevante valor social ou moral. Uma vez que a garantia dada ao agente da eutanásia não é a despenalização, mas sim a remota possibilidade de que o juiz entenda o homicídio piedoso enquanto 


\section{A Percepção Do Enfermeiro Frente A Eutanásia}

homicídio privilegiado e apenas reduza a pena do autor, os profissionais de saúde no país acabam por temer as hipóteses de negligência caso não optem pelas reanimações ou medidas curativas de pacientes terminais, mesmo sem o consentimento dos mesmos, prolongando a vida com procedimentos distanásicos (PÍCOLO, 2012 apud BARBOSA; LOSURDO, 2018).

Segundo Barbosa e Losurdo (2018), no Brasil, não tem legislação específica no que tange à eutanásia. Neste caso, contrariando-se tendência recente de despenalização da prática do dito homicídio piedoso ou homicídio eutanásico, o atual Código Penal (Decreto-Lei 2.848/40) em nada explicita ou mesmo despenaliza a prática da morte por benignidade, alocando todas as condutas analisadas no item supra como sendo facetas de um mesmo crime, o homicídio tipificado no art. 121 do referido Código. Ora, causa estranhamento o arrojo punitivo do Estado brasileiro no Código Penal atual quanto ao homicídio eutanásico em comparação ao código anterior - a Consolidação das Leis Penais de 1932 -, o qual repetiu as disposições de seu antecessor, Código Penal do Império, de 1890, que propunha em seu artigo 295, parágrafo 2 :

\subsection{PERCEPÇÃO DO ENFERMEIRO PERANTE SITUAÇÕES DE EUTANÁSIA}

Em um estudo realizado com 7 profissionais enfermeiros de uma Unidade de Terapia Intensiva com o objetivo de identificar a posição do enfermeiro frente a eutanásia, evidenciou que dos participantes, 100\% são adeptos do catolicismo. Observa-se que $71 \%$ têm conhecimento razoável a respeito do tema, enquanto que $29 \%$ têm pouco conhecimento. Dos entrevistados, $86 \%$ afirmaram não ter vivenciado nenhum fato condizente a prática da eutanásia, enquanto que $14 \%$ afirmam ter passado por experiência em que o paciente ou seus familiares solicitassem o ato. $86 \%$ da amostra disseram que a eutanásia não é a única forma de aliviar o sofrimento de pacientes com doenças incuráveis, e que não são a favor da aprovação do Senado para a legalização da morte sem dor, destacando-se ainda $14 \%$ a favor. Relatam que se a prática fosse legal no país, os responsáveis pelo ato seriam os familiares (CARVALHO et al., 2016).

Diante do estudo de Carvalho (2016), evidenciou-se que a maioria dos profissionais entrevistados possuem conhecimento razoável sobre o assunto e são contra a prática da eutanásia. Sendo assim, é de suma importância que os profissionais que lidam com pacientes fora de possibilidades terapêuticas recebam apoio psicológico para melhor lidar com seus anseios e limitações na prática do cuidar e no processo de morte. 


\section{A Percepção Do Enfermeiro Frente A Eutanásia}

Em outro estudo realizado com 6 profissionais enfermeiros de uma Unidade de Terapia Intensiva com o objetivo de analisar os conhecimentos e sentimentos do enfermeiro intensivista em relação à eutanásia. Pode-se concluir que o tema possibilita vários conceitos e implicações, gerando polêmica quando discutida, o que a transforma em um objeto de grande importância, que necessita ser mais trabalhado no dia a dia de todos os profissionais envolvidos no processo do cuidar (SILVA et al., 2019).

Conforme o estudo de Carvalho (2016) e Silva (2019), fica evidenciado que a eutanásia possui diferentes opiniões, diversificando conforme os valores morais e éticos, os preceitos religiosos e a legislação brasileira. Contudo, vale reforçar que os enfermeiros estão diariamente expostos a situações que resultam em grande dor e sofrimento, no qual deixa o mesmo suscetível de receber o pedido da realização da eutanásia. Sendo assim, o profissional enfermeiro deve conhecer o processo, bem como o que rege a lei no Brasil e o Conselho Federal de Enfermagem em relação ao procedimento, com o intuito de proporcionar conhecimento e saber se posicionar diante da situação, a fim de que não ocorra irregularidades.

Em um estudo realizado com 9 artigos onde os mesmos atenderam aos critérios de inclusão e exclusão sobre o tema, com o objetivo de analisar a percepção jurídica e conceitual dos profissionais e estudantes na área da saúde diante da prática da eutanásia, suicídio assistido, distanásia e ortotanásia. Identificou-se quatro núcleos temáticos: como os profissionais conceituam os termos eutanásia, ortotanásia e distanásia; deficiência na abordagem da temática na formação profissional; dificuldades na comunicação entre profissionais de saúde e familiares e a percepção jurídica sobre este assunto. Constatou-se opiniões divergentes acerca da legalização da eutanásia a maioria dos participantes dos estudos são contra a legalização. Conclui-se que é necessário investir mais na educação sobre o tema durante a graduação e estimular a comunicação entre os profissionais de saúde e familiares(MOTA., et al 2021).

Mediante o estudo realizado, constatou-se uma grande carência presente na percepção dos profissionais e acadêmicos da área da saúde diante do exposto.

Acadêmicos e profissionais de saúde revelaram desconhecer ou conhecer parcialmente os significados dos termos como eutanásia, distanásia e ortotanásia (GUIMARÃES et al., 2018 apud MOTA et al., 2021).

Sendo assim, fica evidente a carência de preparo durante a formação e a necessidade de educação continuada para lidar com situações envolvendo o fim davida, sofrimento e mau prognóstico. Acredita-se que a falta de preparação bioética do profissional de saúde é um dos principais fatores 


\section{A Percepção Do Enfermeiro Frente A Eutanásia}

para proporcionar as situações de desgaste emocional e despreparo para tomar decisões conjuntas sobre como delinear a abordagem terapêutica dos pacientes, gerando prejuízos no cuidado dos pacientes que precisam de apoio emocional(MOTA et al., 2021).

\section{MATERIAS E MÉTODOS}

Trata-se de uma revisão da literatura do tipo narrativa, com foco qualitativo, feita nas principais bases de dados, de 2000 à 2021.

\section{RESULTADOS E DISCUSSÃO}

Com base nos critérios de inclusão, 17 artigos estiveram de acordo com o objeto de pesquisa, destes 3 são de estudo exploratório com o objetivo de analisar a percepção dos profissionais enfermeiros e acadêmicos mediante a situações de eutanásia. O período de estudo transcorreu entre os anos de 2000 a 2021.

Krieger (2013), afirma que o direito à vida é o principal direito que existe, o primeiro a ser protegido, mas, ainda assim, pode sofrer restrições. É o que ocorre nos casos de defesa da própria vida quando a própria vida está em conflito com outro direito de viver, de outra pessoa, e o Poder Público não pode interceder, é permitida a violação do direito à vida de outrem, sem punição por parte do Estado.

Segundo os autores Batista\& Schramm (2004), a primeira vez que se ouviu a pronuncia do termo histórico eutanásia, foi no século II, d.C. No entanto, a discussão sobre o tema se encontra entre os relevantes objetos de reflexão da atualidade, envolvendo questões éticas, religiosas, morais, políticas e jurídicos.

De acordo com Sousa (2021), a prática da eutanásia condiz com a morte premeditada e provocada, que teoricamente proporciona ao indivíduo o alívio da dor e sofrimento. Ela pode ser classificada como passiva que se trata da suspensão de cuidados médicos, no qual o profissional deixa de realizar procedimentos que dariam a chance de o paciente viver por mais um tempo e ativa que é quando ocorre a indução da morte por meio de substâncias letais.Dependendo do caso a eutanásia pode ocorrer tanto a pedido do próprio paciente como por uma decisão de terceiros, que são métodos classificados como de caráter voluntário e involuntário respectivamente.

No entanto, existem muitos tabus que limitam o parecer dos profissionais quando assunto é eutanásia. No artigo de Dias (2014), explana que existem lacunas se tratando de assuntos que proporcionam análise sobre a morte que poderiam beneficiar o profissional, tanto em seu aspecto físico quanto no 


\section{A Percepção Do Enfermeiro Frente A Eutanásia}

emocional, durante o processo de cuidar do paciente e sua família, em situações de finitude humana. Hermes e Lamarca (2013), relembram que a enfermagem é uma das categorias que mais se desgastam emocionalmente devido à constante interação com os pacientes enfermos, as constantes internações, muitas vezes acompanhando o sofrimento, como a dor, a doença e a morte do ser cuidado.

Segundo Carvalho (2016), é de suma importância que os profissionais que lidam com pacientes fora de possibilidades terapêuticas recebam apoio psicológico para melhor lidar com seus anseios e limitações na prática do cuidar e no processo de morte.

Praxedes (2018), relata em seu artigo que, o significado dado à morte e o morrer sofreu diversas mudanças nas diferentes sociedades. Tais modificações, no modo de encará-la, ocorreram de acordo com cada fase histórica da organização sociocultural humana. O processo morte/morrer não é apenas um acontecimento biológico, mas sim, um fato construído socialmente e historicamente. Apesar de a morte subsistir desde o princípio da humanidade, o processo morte e morrer tem sido motivo de aflição, agonia e desespero, já que mostra o quão susceptível, vulnerável e tênue é o estar vivo, ou seja, ser mortal, finito. É um processo simplesmente natural, universal e inevitável, mas mesmo assim o ser humano não suporta imaginar, pensar ou discutir sobre sua própria morte e acaba projetando-a no outro, tendo em vista a impossibilidade de conceber o mundo sem sua presença.

No mesmo sentido Júnior (2011), cita que a morte e o morrer são inerentes à existência. As incertezas e a imprevisibilidade que se dispõem em volta do binômio morte-morrer compelem o ser humano a conviver com a sua presença desde o início ao estágio final do seu desenvolvimento.

Existem outros tipos do processo de morte, Diniz (2007), expõe que a distanásia tem o intuito de promover o prolongamento da dor e sofrimento através de meios artificiais e desproporcionais, a vida de um enfermo incurável.

A mistanásia ou também conhecida como eutanásia social, segundo os autores Pessini e Barchifontaine (2000), é o procedimento da morte não é apresentado como um método de escolha do doente, mas sim um meio utilizado pela sociedade, por meio da renúncia ou carência de aquisição quando o tratamento está com valores muitos altos para prorrogação da vida do doente, penetrando em um assunto de custo versus benefício.

No mesmo sentido, Martin (2001), assevera, que a mistanásia não é um processo que garante ao enfermo uma morte sem dor da forma que lhe é desejado. Em diversas condições e motivos (políticos, sociais e econômicos), os doentes não obtêm o devido tratamento para tal técnica e acabam sendo 


\section{A Percepção Do Enfermeiro Frente A Eutanásia}

vítimas fatais de erros médicos lesivos, abrangendo o tratamento a crueldade humana e vindo a falecer.

Ereno (2014), descreve a ortotanásia como um método de morte no seu tempo natural, ou seja, sem a obrigação de minimizar o andamento de vida do doente através de medicamentos. Estando assim, é uma morte honesta, sem há necessidade de realizar certos tipos de tratamentos superficiais para ocorrer este fenômeno natural. O procedimento da ortotanásia visa "humanizar" o momento atual do doente até a sua morte, sem demorar. Neste argumento, a morte do doente virá pela sua enfermidade, sem introdução de quaisquer métodos formidáveis por parte médica, com a meta de diminuir o sofrimento do paciente que se encontra enfermo.

Segundo o COFEN (2017), em seu artigo 74, é proibido ao profissional da enfermagem promover ou participar de prática destinada a antecipar a morte da pessoa.

No mesmo sentido o CFM (2018), em seu artigo 29, afirma que é vedado ao médico participar, direta ou indiretamente, da execução de pena de morte.

Já, o Código Penal Brasileiro, Segundo Barbosa e Losurdo (2018), no Brasil, não tem legislação específica no que tange à eutanásia. Neste caso, contrariando-se tendência recente de despenalização da prática do dito homicídio piedoso ou homicídio eutanásico, o atual Código Penal (Decreto-Lei 2.848/40) em nada explicita ou mesmo despenaliza a prática da morte por benignidade, alocando todas as condutas analisadas no item supra como sendo facetas de um mesmo crime, o homicídio tipificado no art. 121 do referido Código.

Mediante o estudo realizado por Mota (2021), constatou-se uma grande carência presente na percepção dos profissionais e acadêmicos da área da saúde diante dos termos como eutanásia, distanásia e ortotanásia. Acredita-se que a falta de preparação bioética do profissional de saúde é um dos principais fatores para proporcionar as situações de desgaste emocional e despreparo para tomar decisões conjuntas sobre como delinear a abordagem terapêutica dos pacientes. Constatou-se opiniões divergentes acerca da legalização da eutanásia a maioria dos participantes dos estudos são contra a legalização. Sendo assim, necessário investir mais na educação sobre o tema durante a graduação e estimular a comunicação entre os profissionais de saúde e familiares.

Com relação a pratica em si, em nenhum dos artigos analisados ocorreu alegação de que a eutanásia faz parte do dia a dia dos profissionais. 


\section{A Percepção Do Enfermeiro Frente A Eutanásia}

\section{CONCLUSÃO}

Os artigos revisados neste trabalho nos permitiram refletir sobre questionamentos presentes no cotidiano do profissional enfermeiro sendo eles: como os profissionais conceituam os termos eutanásia, ortotanásia, distanásia e mistanasia; deficiência na abordagem da temática na formação profissional; dificuldades na comunicação entre profissionais de saúde e familiares; e a percepção dos mesmos sobre este assunto. Atualmente existem diversas discussões envolvendo esse tema, gerando grande polêmica em nossa sociedade.

A formação na grade curricular acadêmica, seria de suma importância para a eficácia destes profissionais possibilitando assim conhecimento sobre o assunto, autonomia, solução efetiva para grande parte dos desafios apresentados no dia a dia com resolutividade eficaz dos mesmos. Educações permanentes voltadas para o assunto possibilitariam aptidão em lidar com questões pertinentes para lidar de forma coesa, ética, moral, cuidando da saúde do paciente de maneira integral preservando sua saúde mental.

Observa-se opiniões divergentes sobre o tema, por vezes favoráveis e outras contrárias à eutanásia. Ficando evidente que a maioria dos participantes dos estudos utilizados para esta revisão se posicionaram contra a eutanásia. Uma limitação que este trabalho apresentou foi a escassez de estudos recentes sobre o tema, sendo necessário o desenvolvimento de novos e mais complexos estudos e pesquisas científicas acerca da percepção do profissional enfermeiro mediante situações do processo de eutanásia.

\section{REFERÊNCIAS BIBLIOGRÁFICAS}

SOUSA, A. de A. Perspectiva da equipe multiprofissional de saúde sobre a eutanásia. Centro Universitário de Patos Curso de Medicina 2021. Disponível em: 


\section{A Percepção Do Enfermeiro Frente A Eutanásia}

<https://jmhp.unifip.edu.br/index.php/jmhp/article/view/80/39>. Acesso em 24 de mai. de 2021.

HERMES, H.R.; LAMARCA, I.C.A. Cuidados paliativos: uma abordagem a partir das categorias profissionais de saúde. Rio de Janeiro: Departamento de Ciências Sociais, 2013. Disponível em: <https://www.scielo.br/pdf/csc/v18n9/v18n9a12.pdf>. Acesso em 21 de mai. de 2021.

DIAS, M.V. et al., Formação do enfermeiro em relação ao processo de morte-morrer: percepções à luz do pensamento complexo. Revista Gaúcha de de Enfermagem, 2014. Disponível em: <file://C:/Users/alexa/Downloads/45177-214153-2-PB\%20(1).pdf>. Acesso em 18 de mai. de 2021.

ROBERTO, L. M. O direito á vida. 2011. Disponível em

<http://www.uel.br/revistas/uel/index.php/iuris/article/view/11138>. Acesso em 21 de mai. de 2021.

KRIEGER, M. A. Dos direitos fundamentais: direito à vida. Revista online: conteúdo jurídico, 2013. Disponível em: <http://www.conteudojuridico.com.br/artigo,dos-direitos-fundamentais-direito-avida,41932.html>. Acesso em 23 de jan. 2021.

PRAXEDES, A. M.; ARAÚJO, J. L. de.; NASCIMENTO, E. G. C. do. A morte e o morrer no processo de formação do enfermeiro. Universidade do Estado do Rio Grande do Norte, 2018. Disponível em: $<$ https://www.researchgate.net/profile/Ellany-Nascimento-

2/publication/327796963_Death_and_dying_in_the_process_of_nursing_education/links/5ba8a676 299bf13e60482fbd/Death-and-dying-in-the-process-of-nursing-education.pdf $>$. Acesso em 22 de mai. de 2021.

JÚNIOR, F. J. G. da S. et al., Processo de morte e morrer: evidências da literatura científica de Enfermagem. Revista Brasileira de Enfermagem, Brasília, 2011. Disponível em: <

https://www.scielo.br/pdf/reben/v64n6/v64n6a20.pdf>. Acesso em 22 de mai. de 2021.

BASTISTA, R.S.; SCHRAMM, F,R. Eutanásia: pelas veredas da morte e da autonomia. Ciência \& Saúde Coletiva. Rio de Janeiro, 2004. Disponível em:

<https://www.scielo.br/j/csc/a/YzfWXq4yZvc9whnZpktyWHs/?lang=pt\&format=pdf>. Acesso em 23 de jan. 2021.

PESSINI, L.; BARCHIFONTAINE, C. de P. Problemas Atuais de Bioética. 5 ed. rev. e aum. São Paulo: Ed. Loyola, 2000. 527p.

DINIZ, D. Quando a morte é um ato de cuidado. In: PIOVESAN, Nos Limites da Vida: Aborto, Clonagem Humana e Eutanásia sob a Perspectiva dos Direito Humanos. Rio de Janeiro. Ed. Lumen Juris. 2007.

MARTIN, L, M. Eutanásia e Distanásia. Bioética segundo CFM, 2001. Disponível em: <http://bio-neuropsicologia.usuarios.rdc.puc-rio.br/assets/02_bioetica_(distanasia).pdf $>$. Acesso em 23 de jan. de 2021.

ERENO, L. F. A. Ortotanásia e medicina paliativa. Trabalho de Conclusão de Curso Bacharel em Direito pela Pontifícia Universidade Católica do Rio Grande do Sul - PUCRS, 2014. Disponível em: 


\section{A Percepção Do Enfermeiro Frente A Eutanásia}

<http://www3.pucrs.br/pucrs/files/uni/poa/direito/graduacao/tcc/tcc2/trabalhos2014_1/leticia_ere no.pdf $>$. Acesso em 26 de jan. de 2021.

ASSIS, Z.; BAMBIRRA, N. V. Eutanásia, distanásia e ortotanásia sob a égide da constituição federal do brasil de 1988. Doutoranda em Direito Processual pela PUC/Minas, 2010. Disponível em: <http://www.fmd.pucminas.br/Virtuajus/2_2010/docentes/EUTANASIA,\%20DISTANASIA\%20E\%200 RTOTANASIA\%20SOB\%20A\%20EGIDE\%20DA\%20CONSTITUICAO\%20FEDERAL\%20DO\%20BRASIL\%20 DE\%201988.pdf>. Acesso em 02 de fev. de 2021.

BARBOSA, G. S. D. S; LOSURDO, F. Eutanásia no Brasil: entre o Código Penal e a dignidade da pessoa humana. Revista de Investigações Constitucionais, Curitiba, 2018. Disponível em: <https://www.scielo.br/j/rinc/a/MKcqnSGvQrkG3z5HSHRkLhF/?lang=pt\&format=pdf>. Acesso em 01 de jun. de 2021.

CARVALHO, R. S. Eutanásia: opinião de enfermeiros atuantes em unidades de terapia intensiva. João Pessoa, 2016. Disponível em:

<https://temasemsaude.com/wp-content/uploads/2016/09/16325.pdf>. Acesso em 21 de mai. de 2021.

SILVA, I. G. da. et al., EUTANÁSIA: conhecimentos e sentimentos do enfermeiro intensivista. João Pessoa, 2019. Disponível em:

<https://temasemsaude.com/wp-content/uploads/2019/07/FSM02.pdf $>$. Acesso em 21 de mai. de 2021.

MOTA, A. E. Z. et al., A percepção dos profissionais de saúde sobre os aspectos jurídicos e conceituais da eutanásia. Brazilian Journal of Development, 2021. Disponível em:

<https://www.brazilianjournals.com/index.php/BRJD/article/view/25047>. Acesso em 23 de mai. de 2021. 


\section{Capítulo 9}

\section{doi $10.37423 / 211004904$}

\section{DIVULGAÇÃO CIENTIIFICA E INCLUSÃO SOCIAL ATRAVÉS DE SITES ACESSÍVEIS: NOVOS CENÁRIOS EM VELHOS PROBLEMAS}

Luciana Fernandes Rêgo

Neuza Rejane Wille Lima

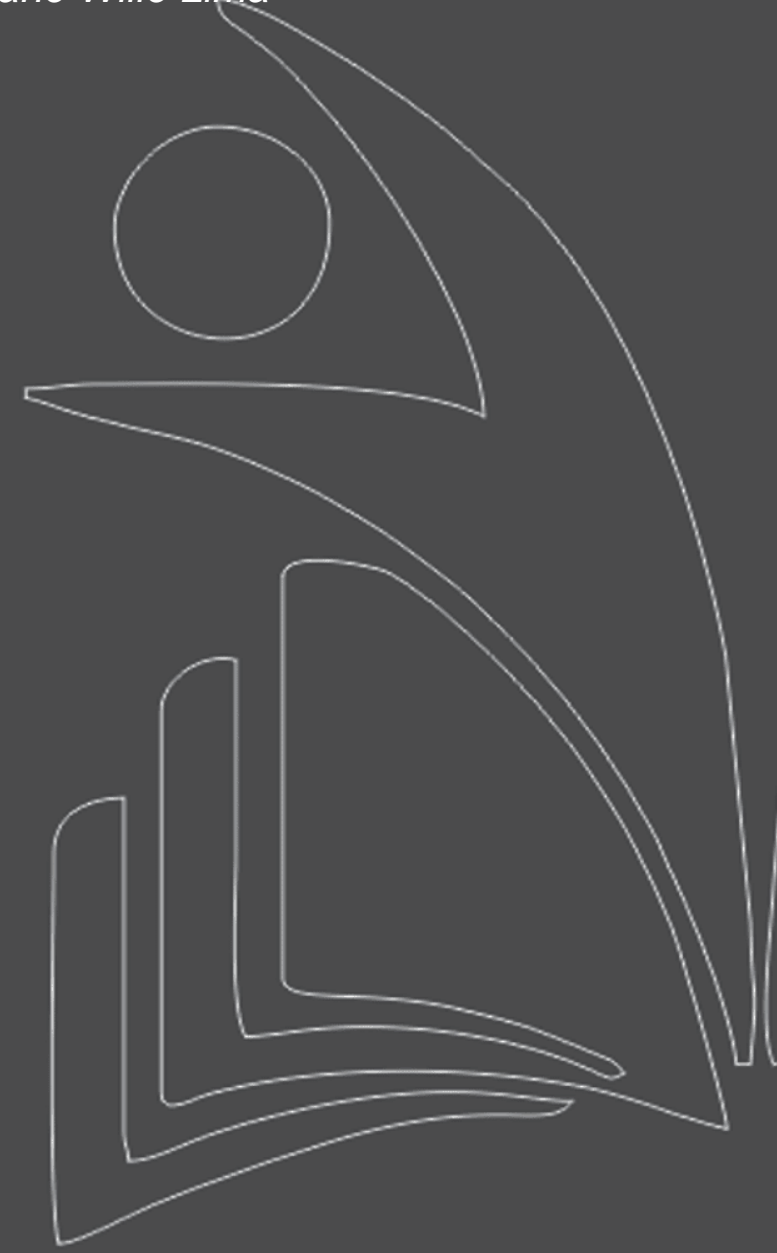

Instituto de Biologia, Universidade Federal Fluminense

Instituto de Biologia, Universidade Federal Fluminense

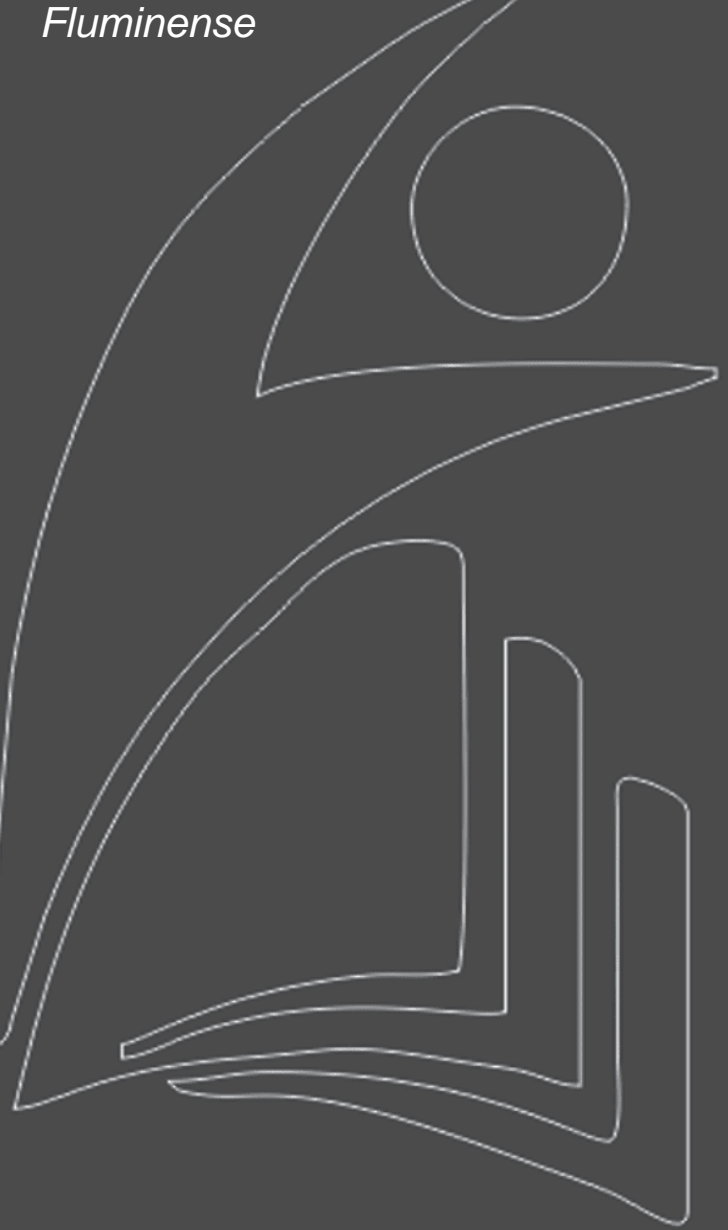


Resumo: Todos os cidadãos têm direito a acessar conhecimentos científicos, uma vez que estes são imprescindíveis para a nossa sobrevivência e conhecimento da natureza em suas diferentes facetas e apropriação das tecnologias desenvolvidas pela sociedade. Em palavras, é através da informação que o indivíduo compreende o seu entorno, se torna capaz para alcançar melhores oportunidades por se apropriar, compartilhar e contribuir na construção dos saberes. Assim, a divulgação científica cumpre o papel informar aos mais variados grupos populacionais todo e qualquer produção de conhecimento. Esta deve veicular conteúdos de forma precisa e acessível através de uma linguagem de fácil compreensão, envolvendo, principalmente, ferramentas que possibilitem o acesso para pessoas com deficiências físicas e/ou cognitivas. Nesse cenário, o objetivo do presente foi alertar sobre a necessidade de se construir sites acessíveis a todos.

Palavras-chave: acessibilidade, plataforma digital, pessoas com deficiências. 


\section{NOVOS CENÁRIOS EM VELHOS PROBLEMAS}

No século atual, o desenvolvimento e uso da Internet vem crescendo vertiginosamente, sendo cada vez mais necessário para meios de obtenção de informações, para construção de conhecimentos e obtenção de serviços, especialmente, em tempos de pandemia que vivemos em função do novocorona vírus (SARS-CoV-2) que causa a Covid-19 - (co)rona (vi)rus (d)isease) que surgiu em 20(19). Essa situação emergencial demanda muitos esclarecimentos e correções de informações distorcidas e, até mesmo, inverídicas que vem sendo veiculadas, apesar das inúmeras publicações de divulgação cientificas sobre dessa pandemia (LIMA; REZENDE, 2020; LIMA; PAIXÃO, 2021).

Ações como o Projeto COMPROVA (2021), resultante da coalizão de veículos de comunicação que foi formada em 2018, prima em investigar, colaborativamente, conteúdos suspeitos sobre as eleições presidenciais, índices da pandemia causada pelo SARS-CoV-2, indicadores economia, entre outros.

Nesse universo de informações há inúmeros sites e blogues que veiculam diversas notícias veiculadas sobre essa pandemia, contendo informações relevantes e verídicas, porém sem qualquer acessibilidade às pessoas com deficiência (FREITAS et al., 2015, CABRAL et al., 2019b; RÊGO; LIMA, 2018; RÊGO, 2019; FONSECA; LIMA, 2020).

Num mundo funcional, os sites deveriam conter as características da plataforma do Centro de Pesquisa em Ciência, Tecnologia Sociedade do IPEA (Instituto de Pesquisa Econômica Aplicada). Este possui alto contraste que auxilia pessoas com baixa visão e VLibras para atender surdos e deficientes auditivos, entre outros recursos como ampliação de letra e leitor de tela (NEGRI et al., 2020).

Assim, apesar de todos os esforços em investimento financeiro, e promulgações de leis novas tecnologias assistivas e uma parcela da sociedade ainda continua excluída desse contexto, especialmente as pessoas com barreiras causadas por limitações e dificuldades sensoriais, físicas e/ou mentais que são, aparentemente, infrequentes nas populações por não serem claramente reconhecidos (ALONSO, 2010; CABRAL, 2018, CABRAL et al. 2019a, b).

Como descreve o site do Modelo de Acessibilidade em Governo Eletrônico,

\footnotetext{
"Muitas pessoas também apresentam outras limitações relacionadas à memória, resolução de problemas, atenção, compreensão verbal, leitura e linguística, compreensão matemática e compreensão visual. Uma pessoa com dislexia, por exemplo, pode apresentar dificuldade de leitura de uma página devido a um desenho inadequado. Por isso, um sítio desenvolvido considerando a acessibilidade deve englobar diferentes níveis de escolaridade, faixa etária e pouca experiência na utilização do computador, bem como ser compatível com
} 
as diversas tecnologias utilizadas para acessar uma página da Web." (BRASIL, 2014).

É imprescindível que sejam disponibilizadas ferramentas de acessibilidade para possibilitar a participação e contribuição desses indivíduos no contexto dos ambientes digitais, promovendo, assim, uma efetiva inclusão social (CONFORTO, 2002).

\section{O QUE É UM SITE ACESSÍVEL?}

O termo acessibilidade significa incluir a pessoa em atividades como o uso de produtos, serviços e informações. Alguns exemplos são os prédios com rampas de acesso adequado para cadeira de rodas e banheiros adaptados para deficientes e características dos meios de comunicação como os canais de televisão e os sites (FREITAS et al. 2015; RÊGO, 2019; RÊGO; LIMA, 2019).

\section{DIVULGAÇÃO CIENTÍFICA: UMA INCLUSÃO SOCIAL}

Na internet, a acessibilidade refere-se, principalmente, às recomendações do WCAG (World Content Accessibility Guide) do W3C e no caso do Governo Brasileiro ao e-MAG (Modelo de Acessibilidade em Governo Eletrônico) (BRASIL, 2014a, b). Esse modelo está alinhado as recomendações internacionais, mas também estabelece padrões nacionais de comportamento acessível para sites do governo brasileiro (FREITAS et al., 2015; CABRAL et al. 2019a, b).

Por exemplo, na parte superior do Portal do Governo do Brasil existe uma barra de acessibilidade onde se encontra atalhos de navegação padronizados e a opção para alterar o contraste. Essas ferramentas estão disponíveis em todas as páginas do portal (CABRAL, 2018; CABRAL et al. 2019a, b).

O portal do Governo do Brasil e da maioria das Universidades Federais do Brasil seguem o modelo de identidade digital padrão do governo federal, que atende às principais recomendações de acessibilidade indicadas para web (ACESSIBILIDADE, 2017; CABRAL, 2018; CABRAL et al., 2019a, b). Todo esse cenário se delineou a partir das leis e decretos sobre acessibilidade nos últimos 18 anos (Quadro 1); 
Quadro 1 - As principais leis e decretos sobre acessibilidade no Brasil

\section{Leis e Decretos e Fontes}

- Decreto o 5.296 de 02 de dezembro de 2004 (Fonte: http://www.planalto.gov.br/ccivil 03/ Ato2004-2006/2004/Decreto/D5296.htm)

- Decreto no 6.949, de 25 de agosto de 2009 - Promulga a Convenção Internacional sobre os Direitos das Pessoas com Deficiência e seu Protocolo Facultativo, assinados em Nova York, em 30 de março de 2007 (Fonte: http://www.planalto.gov.br/ccivil 03/ ato2007-2010/2009/decreto/d6949.htm)

- Decreto no 7.724, de 16 de maio de 2012 - Regulamenta a Lei No 12.527 de maio de 2011 que dispõe sobre o acesso a informações (Fonte:

http://www.planalto.gov.br/ccivil 03/ ato2011-2014/2012/Decreto/D7724.htm)

- Modelo de Acessibilidade de Governo Eletrônico (Fonte: http://www.governoeletronico.gov.br/acoes-e-projetos/e-MAG)

- Portaria no 03, de 07 de Maio de 2007 - formato pdf (35,5Kb) - Institucionaliza o Modelo de Acessibilidade em Governo Eletrônico - e-MAG (Fonte: http://www.governoeletronico.gov.br/biblioteca/arquivos/portaria-no-03-de-07-052007)

- Lei oㅜ 13.416 de 6 de julho de 2015 - Lei Brasileira de Inclusão da Pessoa com Deficiência (Estatuto da Pessoa com Deficiência) conhecida como a Lei Brasileira de Inclusão. (Fonte: http://www.planalto.gov.br/ccivil 03/ ato20152018/2015/lei/l13146.htm)

Cabe ressaltar que a Lei Brasileira de Inclusão (Lei no 13.146/2015) definiu no art. 27:

"A educação constitui direito da pessoa com deficiência, assegurados sistemas educacionais inclusivo em todos os níveis e aprendizado ao longo de toda a vida, de forma a alcançar o máximo desenvolvimento possível de seus talentos e habilidades físicas, sensoriais, intelectuais e sociais, segundo suas características, interesses e necessidades de aprendizagem." (BRASIL, 2015).

É real e louvável que o acesso de pessoas com deficiência ao computador e à Internet representam um enorme passo para a inclusão de pessoas com deficiência, promovendo autonomia e independência. As pessoas com deficiência utilizam o computador de diferentes modos conforme as suas necessidades especiais (Quadro 2). 
Quadro 2 - As quatro principais situações vivenciadas por usuários com deficiência.

1. Acesso ao computador sem mouse: no caso de pessoas com deficiência visual, dificuldade de controle dos movimentos, paralisia ou amputação de um membro superior.

2. Acesso ao computador sem teclado: no caso de pessoas com amputações, grandes limitações de movimentos ou falta de força nos membros superiores.

3. Acesso ao computador sem monitor: no caso de pessoas com cegueira.

4. Acesso ao computador sem áudio: no caso de pessoas com deficiência auditiva.

(Fonte: BRASIL, 2014).

Tanto a ciência como a tecnologia e as artes são ferramentas essenciais para o desenvolvimento econômico e psicossocial e da humanidade (SILVA NETO, 2015). A evolução tecnológica caminha na direção de tornar a vida mais fácil. Ferramentas e recursos são pensados e desenvolvidos especialmente para beneficiar e facilitar as atividades desenvolvidas na rotina cotidiana, melhorando o desempenho em realizar funções pretendidas.

Segundo Conte e Besegio (2015),

A investigação possibilitou conhecer o cenário das pesquisas sobre essas tecnologias e as inter-relações com a inclusão na complexa sociedade contemporânea, para afirmar que existem uma tensão e um subaproveitamento dessas tecnologias nos processos pedagógicos, embora seus avanços tenham dado respostas positivas à qualidade de vida das pessoas com necessidades especiais. (CONTE; BESEGIO, 2015, p. 28).

\section{TECNOLOGIAS ASSISTIVAS}

Nos últimos 30 anos a tecnologia assistiva vem obtendo um grau de desenvolvimento bastante elevado, porém vale salientar que desde os primórdios tal alternativa de acessibilidade vem sendo aplicada. A acessibilidade é um tema relativamente novo, se comparado à existência da deficiência em si. As invenções mais antigas descobertas ainda são aplicadas e melhoradas com o decorrer das décadas até os dias de hoje (CABRAL et al., 2019a, b).

Sartoretto e Bersch (2021) mencionaram a atuação da acessibilidade ainda na Idade da Pedra, período em que um dos primeiros dispositivos de tecnologia assistiva seria concebido, descoberto e colocado em uso: uma vara, a qual seria utilizada para auxiliar e sustentar, como uma bengala, um dos integrantes do bando que teria quebrado a perna durante uma expedição de caça. Outro destaque foi a utilização de um chifre vazio de um animal, atuando como um aparelho auditivo, o qual compensaria a audição desgastada daqueles que teriam idades mais avançadas os fazendo ouvirem melhor. 


\section{NOVAS TECNOLOGIAS APLICADA À SAÚDE: INTEGRAÇÃO DE ÁREAS TRANSFORMANDO A}

\section{SOCIEDADE}

Com o passar dos anos, muitos outros equipamentos de acessibilidade foram desenvolvidos. Durante o século XIX, houve várias descobertas que abriram horizontes para a criação de melhorias para pessoas com deficiência.

Em 1808, o italiano Pellegrino Turri, na tentativa de encontrar um novo sistema de escrita mais veloz e ágil, inventou a máquina de datilografia que inicialmente seria criada para pessoas sem dificuldades visuais, porém deu origem a outra importantes tecnologias assistivas. Em 1817, a escola Gallaudet para os deficientes auditivos foi aberta por Thomas Hopkins (RUZZA, 2016).

As aplicações descobertas há décadas passaram por muitas alterações. Apesar de algumas manterem a mesma estrutura, foram alterados os materiais utilizados para fabricá-las. Contudo, algumas aplicações só puderam ser criadas após o avanço da tecnologia. Durante a Guerra Civil dos Estados unidos começou-se a desenvolver próteses para membros inferiores, visto que muitos soldados após a guerra acabavam se tornando inválidos por perderem a locomoção (RUZZA, 2016).

Pode-se citar também a invenção do Braile em 1824, por Louis Braille e a invenção de Alexander Graham Bell durante década 1870, que na tentativa de desenvolver um dispositivo para fazer com que sua esposa surda pudesse ouvir, acabou inventando o telefone (RUZZA, 2016). Tais inventos foram inovadores para a época e foram essenciais para o promissor desenvolvimento das tecnologias assistivas do atual século. A evolução da eletrônica é a razão para a maior parte desses ganhos favoráveis e os computadores são os veículos através dos quais os avanços têm sido concretizados (RUZZA, 2016).

Oficialmente, a tecnologia assistiva foi criada como um elemento da legislação norte-americana em 1988, intitulada como Public Law 100-4007, na qual foi composta também a American with Disabilities Act (ADA). Com essas leis, os cidadãos norte-americanos com deficiência passaram a dispor legalmente dos capitais públicos para compras dos recursos que eles necessitam e que favorecem uma vida mais incluída no contexto social; além de regularizar seus demais direitos como cidadãos que expressão deficiência (POLITIZE, 2017).

Tais recursos envolvem em sua descrição produtos, sistemas fabricados genericamente ou sob medida, equipamentos, aparelhos assistivos, itens ou auxiliadores utilizados nesse contexto para dispor, facilitar ou melhorar as capacidades funcionais das pessoas com deficiência (RUZZA, 2016). 
No Brasil, a Tecnologia Assistiva foi implantada em 16 de novembro de 2006 pela Secretaria Especial dos Direitos Humanos da Presidência da República (SEDH/PR), através da Portaria no 142, onde foi instituído o Comitê de Ajudas Técnicas (CAT) formado por um grupo de especialistas e representantes governamentais (BRASIL, 2007).

No CAPÍTULO III sobre as Novas Tecnologias: Internet e Comunicação, Health verificou-se que é evidente que a tecnologia é uma grande aliada das pessoas portadoras de alguma deficiência, pois possibilita substituir ou compensar sentidos que foram perdidos ao longo da vida ou congênitos.

Dificuldades de executar as mais simples tarefas cotidianas são vividas diariamente por aqueles que possuem alguma deficiência, porém, graças aos diferentes recursos tecnológicos, essas pessoas vêm conseguindo conquistar uma maior independência para realizar suas tarefas.

A acessibilidade e a inclusão são pontos fundamentais para a inserção dessas pessoas na sociedade. Para permitir autonomia e tornar mais fácil a vida das pessoas que tem necessidades especiais, foram desenvolvidas as chamadas Tecnologias Assistivas (TA), que buscam soluções voltadas à inclusão social com intervenções do contexto de vida do paciente, assegurando oportunidades iguais para cada indivíduo e atendendo particularmente às suas diferenças.

As TA se concentram nas necessidades de pessoas especiais de todas as idades, essas pessoas podem possuir variedades de deficiências, limitações ou desafios que limitam a sua participação na vida diária. Desse modo, a assistência especial torna-se necessária, seja motora, cognitiva ou linguísticas.

Porém, a tecnologia pode ser considerada assistiva a partir do momento em que é utilizada para auxiliar no desenvolvimento do desempenho funcional de atividades de pessoas portadoras de deficiência, reduzindo as incapacidades de realização de atividades no cotidiano (BRASIL, 2006).

O termo TA é utilizado para identificar todo o arsenal de recursos e serviços que contribuem para proporcionar ou ampliar habilidades funcionais de pessoas com deficiência e, consequentemente, promover vida independente e inclusão, como cita (SARTORETTO; BERSCH, 2021). Em outras palavras, a TA pode ser definida como processos, métodos, ou invenções que dão suporte às pessoas com deficiência.

No Brasil, a TA é um direito adquirido pelo cidadão, bem como os recursos e serviços aliados a ela. Porém, a legislação brasileira remete outro termo à Tecnologia Assistiva, as chamadas Ajudas Técnicas (AT). As ATs permitem compensar limitações motoras, sensoriais ou mentais, possibilitando uma plena inclusão social (BRASIL, 2006; 2007; 2014a, b; 2015). 


\section{CATEGORIAS E EXEMPLOS}

As tecnologias assistivas podem ser aplicadas em uma vasta categoria de necessidades, abrangendo aspectos sociais, políticos e educacionais, com o objetivo de amenizar dificuldades, reduzindo as barreiras no cotidiano. As categorias a seguir representam as mais comuns áreas de aplicação das TA: deficiência visual, física ou motora, auditiva e cognitiva. Na maioria dos casos, as pessoas utilizam combinações de várias aplicações de TA em cada uma dessas áreas que o compõem.

\section{NOVAS TECNOLOGIAS APLICADAS À SAÚDE: INTEGRAÇÃO DE ÁREAS TRANSFORMANDO A SOCIEDADE}

Existem na literatura e no mercado incontáveis possibilidades, projetos e recursos simples e de baixo custo que são desenvolvidos com o objetivo de ajudar às pessoas com deficiência física, conforme as necessidades específicas de cada um.

Tais projetos visam possibilitar às pessoas portadoras de alguma deficiência a realizarem desde as mais corriqueiras tarefas até aquelas que requerem mais habilidades para ser executadas. Esses meios favorecem o desempenho autônomo e independente em ações (BRASIL, 2007; 2014a, b; 2015). São considerados exemplos para auxílio à vida prática e diária de portadores de deficiência produtos e artefatos que podem variar desde uma simples adaptação de um talher a um sistema computadorizado de comunicação.

Com relação às pessoas com dificuldades visuais, existem vários dispositivos que utilizam o Braile em conjunto com outras tecnologias para desenvolver equipamentos com acessibilidade. Como exemplo existem as impressoras de Braile que permitem a criação de livros e conteúdo que dão acesso à literatura (DUARTE et al., 2020).

Além deste exemplo, pode-se citar também os sintetizadores de voz, leitores de telas para celulares e computadores, ampliadores de conteúdo, bengalas, instrumentos musicais adaptados, teclados braile, sistemas digitais que possibilitam aos portadores de deficiência visual interagirem com sistemas computacionais, animais que auxiliam na dificuldade, dentre outros (LEITE; ROSA, 2017). Prosseguem os autores, aduzindo que o trabalho de cientistas e pesquisadores deve caminhar para a consolidação de um modelo de desenvolvimento global capaz de atender às demandas sociais de todos os indivíduos. 
Entretanto, diz ele que, muitas vezes, somente os detentores deste conhecimento científico e tecnológico têm acesso aos benefícios da vida em sociedade gerados como resultado desse trabalho. Para que não haja populações excluídas, é preciso que este conhecimento seja transmitido ao maior número de pessoas por meio da divulgação científica, uma vez que ele é capaz de mudar qualquer condição social. Assim, na lição de Silveira (2001, p. 18):

[...] a exclusão digital impede que se reduza a exclusão social, uma vez que as principais atividades econômicas, governamentais e boa parte da produção cultural da sociedade vão migrando para a rede, sendo praticadas e divulgadas por meio da comunicação informacional. Estar fora da rede é ficar fora dos principais fluxos da informação. Desconhecer seus procedimentos básicos é amargar a nova ignorância.

No Brasil, a inclusão social é um grande desafio dado o desenrolar da sua história marcada por grande desigualdade social. Isto se dá em razão da concentração de riquezas, acesso a bens culturais, materiais e detenção de conhecimento científico-tecnológico nas mãos de uma parcela minoritária da sociedade (SILVA NETO, 2015).

A inclusão social deve ter como objetivo criar meios e ações que combatam a exclusão a benefícios da vida em sociedade causada por diferenças de classe econômica, social, sexo, idade, raça e deficiência física ou mental. Portanto, é necessário criar oportunidades e condições aos indivíduos para que possam usufruir desses bens. É por meio do estabelecimento dessas condições que os habitantes do país poderão viver como cidadãos plenos de direitos, detentores de conhecimentos, meios e mecanismos que os capacitem a agir de forma fundamentada e consciente, possibilitando sua plena participação em sociedade (SILVA NETO, 2015).

Nesse sentido, Silva Neto (2015) afirma que um dos escopos da inclusão social é permitir que cada brasileiro tenha oportunidade de obter conhecimento básico sobre a ciência e seu funcionamento que Ihe dê condições de entender o seu entorno, de ampliar suas oportunidades no mercado de trabalho e de atuar politicamente de forma consciente, pois a informação é essencial à produção do conhecimento, que possibilita a mudança de qualquer contexto social.

Numa via de mão dupla, a inclusão social na cultura cientifica é fundamental para o desenvolvimento da Ciência, uma vez que a disseminação das ideias e resultados de pesquisas, atingindo um maior número de indivíduos, fomenta o debate científico, despertando a curiosidade de possíveis novos talentos para o meio científico. 
Assim, a motivação para a elaboração deste trabalho pautou-se na necessidade de promover o exercício da cidadania, buscando respeitar as diferenças e favorecer a igualdade de oportunidades perante o acesso à informação, utilizando as melhores práticas e diretrizes de acessibilidade digital adotadas no Brasil e em outros países no que tange à Divulgação Científica.

\section{O que é Divulgação Científica?}

Segundo Albagli (1996) a divulgação científica, também conhecida como popularização da ciência, consiste na utilização de processos e recursos técnicos para a comunicação da informação científica e tecnológica ao público em geral, buscando traduzir a linguagem científica de forma que possa ser compreendida por este público. Para Reis (1968), a divulgação científica permite que se construa uma proximidade entre a sociedade e a ciência para que o cidadão tenha instrumentos suficientes para analisar as situações criticamente e participar da tomada de decisões.

De acordo com Albagli (1996, p. 397), “o papel da divulgação científica vem evoluindo ao longo do tempo, acompanhando o próprio desenvolvimento da ciência e tecnologia". Para esse autor, a divulgação científica compreende vários objetivos, como o educacional, o cívico e a mobilização popular.

O objetivo é educacional quando a informação científica é transmitida com um caráter prático, visando a esclarecer o desvendamento e a solução de problemas referentes a fenômenos que foram cientificamente estudados (RÊGO, 2019; RÊGO, LIMA, 2019; LIMA; REZENDE, 2011). Nesse caso, ocorre a ampliação do conhecimento e compreensão do público leigo sobre a lógica do processo científico, tendo como estimulá-lo à curiosidade científica enquanto atributo humano (ALBAGLI, 1996).

O caráter cívico da divulgação científica consiste em transmitir informações voltadas para a ampliação da consciência do cidadão a respeito de questões sociais, econômicas e ambientais associadas ao desenvolvimento científico e tecnológico. Desse modo, o cidadão se torna apto formar uma opinião fundamentada sobre os impactos do desenvolvimento científico e tecnológico sobre a sociedade, sobretudo em áreas que envolvem a tomada de decisões (ALBAGLI, 1996).

A divulgação científica é fundamental para a mobilização popular, possibilitando a ampliação da participação da sociedade na formulação de políticas públicas e na escolha de opções tecnológicas. 
Isso é, a disseminação do conhecimento científico garante que o indivíduo tenha instrumentos para participar das decisões intrínsecas à sua vida em sociedade (ALBAGLI, 1996).

Diante desses aspectos objetivos, as possibilidades das atividades de divulgação científicas são amplas, variando de acordo com o público-alvo que se deseja alcançar, sejam estudantes, cientistas de outras áreas ou da mesma, agentes públicos, população letrada etc. (ALBAGLI, 1996).

Por fim, a divulgação científica não se confunde com comunicação científica. Enquanto aquela destinase a um público leigo, esta tem seu foco na comunidade científica. Nesse sentido, afirma Bueno (2010),

A comunicação científica visa, basicamente, à disseminação de informações especializadas entre os pares, com o intuito de tornar conhecidos, na comunidade científica, os avanços obtidos (resultados de pesquisas, relatos de experiências etc.) em áreas específicas ou a elaboração de novas teorias ou refinamento das existentes. A divulgação científica cumpre função primordial: democratizar o acesso ao conhecimento científico e estabelecer condições para a chamada alfabetização científica. Contribui, portanto, para incluir os cidadãos no debate sobre temas especializados e que podem impactar sua vida e seu trabalho (BUENO, 2010, p. 1).

A divulgação científica tem como importante missão contribuir para a atenuação da exclusão social, que é um dos aspectos estruturais da desigualdade, pois se trata de um instrumento de transformação social na medida em que colabora para a democratização do acesso à educação e à cultura de qualidade - em geral, inacessíveis à população mais vulnerável -, em favor do desenvolvimento humano. Assim, a disseminação do conhecimento científico contribui para a promoção da qualidade de vida e inclusão social, uma vez que fornece as bases para a formação do pensamento crítico que, consequentemente, influencia na tomada de decisão e na construção do saber (RÊGO, 2019; RÊGO, LIMA, 2019; LIMA; REZENDE, 2011).

Neste sentido, Alonso (2010), afirma que, além do desenvolvimento econômico, a ciência e a tecnologia são fundamentais para que ocorra a democratização de oportunidades na sociedade. Segundo a autora, o atendimento justo às demandas sociais de todos os membros da sociedade e a construção da soberania nacional são determinados pelo trabalho de pesquisadores, cientistas e técnicos.

Na mesma esteira, Moreira (2006) afirma que, no que tange a ciência e tecnologia, conhecer seus principais resultados, métodos e usos, riscos e limitações e também os interesses e determinações (econômicas, políticas, militares, culturais etc.) que presidem seus processos e aplicações, são fundamentais para a educação de qualquer cidadão no mundo contemporâneo 
Chassot (2003), por sua vez, considera a ciência como uma "linguagem" para facilitar a leitura que o indivíduo faz do mundo natural e propiciar o seu entendimento. Ele chama a elaboração dessa leitura de "fazer alfabetização científica". Para esse autor, saber a descrição do mundo natural ajuda a entendermos a nós mesmos e o ambiente que nos cerca.

Por conseguinte, há uma necessidade contínua de fazer com que a ciência seja, não apenas medianamente entendida por todos, mas, e principalmente, "facilitadora do fazer parte do mundo". Além disso, o autor firma que é desejável que os alfabetizados cientificamente, além de poder compreender o mundo em que vivem, possam também entender as necessidades de transformá-lo para melhor (FRANÇA, 2015).

Numa via de mão dupla, além da divulgação científica fomentar o desenvolvimento humano dos indivíduos, estimula também o desenvolvimento científico e tecnológico do país. Isso porque propicia a formação de profissionais qualificados em número suficiente e com aproveitamento adequado, além do aumento do conhecimento científico e do interesse pela ciência e tecnologia entre a população em geral, promovendo a descoberta de novos talentos. Desse modo, a instituição deve fomentar o uso social da informação científica como uma forma de retornar à sociedade o produto do investimento público (REIS, 1968).

Devido à importância, ressaltada pelos autores supracitados, da divulgação científica tanto para o indivíduo quanto para a sociedade, destaca-se a necessidade de observá-la por uma perspectiva inclusiva. Falar da inclusão social como consequência da disseminação dos conhecimentos científicos e tecnológicos básicos compreende, portanto, atingir, não apenas as populações mais pobres, que tem menos acesso à educação e à cultura de qualidade, mas também outras parcelas da população que encontram barreiras físicas e/ou sensoriais quanto à acessibilidade destas informações, como pessoas com deficiência (CABRAL, 2018).

A disseminação de informações ocorre através dos diversos meios de comunicação, buscando um amplo alcance e através da participação de profissionais de múltiplas áreas do conhecimento. Alguns destes meios são os centros e museus de ciência, os programas de extensão universitários, os eventos de divulgação, a educação à distância e outros (MOREIRA, 2006).

Comunicar é o papel principal da divulgação científica e, por isso, os pesquisadores devem atentar para a necessidade de construir uma comunicação efetiva para que o conhecimento científico atinja o seu uso social. Assim, deve-se buscar uma veiculação da informação científica adequada e acessível 
para o público, utilizando-se uma linguagem compreensível e meios de comunicação acessíveis ao maior número de pessoas.

Isso será possível buscando-se uma aproximação de todos aqueles que podem ajudar no processo de democratização do conhecimento, objetivando o estabelecimento de parcerias, a definição de estratégias de atuação, o fortalecimento do sistema educacional, o desenvolvimento de políticas que promovam a acessibilidade à informação para pessoas com deficiência e o debate amplo sobre o papel da ciência e da tecnologia numa sociedade em desenvolvimento (MOREIRA, 2006).

Nesse contexto, percebe-se a necessidade de gerir o conhecimento buscando novos paradigmas a serem enfrentados pela administração pública, sob os critérios de ética e sustentabilidade e com a busca de uma inteligência coletiva capaz de assegurar a melhoria das condições humanas, ambientais e sociais.

Atualmente, o Brasil não disponibiliza uma política pública ampla especializada na divulgação da ciência e tecnologia. Porém, há a necessidade urgente de se estabelecerem políticas gerais e de se formular e executar um programa nacionalmente articulado nesta direção. Essa ausência de legislação oficial tende a comprometer a oferta de oportunidades e ações de modo abrangente (NATAL, 2018).

Contudo, como explicitado anteriormente, é necessária a atuação do poder público com planejamento e atividades sistemáticas para que a divulgação científica alcance todas as esferas sociais.

\section{A DIVULGAÇÃO CIENTÍFICA E O USO DA INTERNET}

Nas últimas décadas houve uma expansão vertiginosa da internet, compreendendo um grande alcance global e rompendo barreiras físicas e geográficas. Esse avanço se deu à baixa onerosidade deste meio de comunicação e pelo fato de abarcar um vasto conteúdo e facilidade de utilização, através de sites, aplicativos, fóruns, redes sociais, além de recursos de mídia, vídeo, áudio, imagens, dentre outros.

No Brasil, observa-se que o acesso à informação passa diretamente pela utilização da internet, embora este acesso não contemple as parcelas mais pobres da população. De acordo com dados divulgados na primeira edição da "Pesquisa Brasileira de Mídia 2016 - Hábitos de Consumo de Mídia pela População Brasileira" a internet é o segundo meio de comunicação utilizado com mais frequência pelos brasileiros (26\%), sendo o primeiro é a televisão (63\%). Consoante à pesquisa, a internet é usada todos os dias por $50 \%$ dos entrevistados e a televisão é assistida, diariamente, por $77 \%$. O percentual de uso diário do rádio é de 35\%; o dos jornais impressos, 8\%; e o de revistas semanais, 2\% (RÊGO, 2019; SECRETARIA ESPECIAL DE COMUNICAÇAO SOCIAL, s/d.). 
Contudo, no que se refere à intensidade de uso, o brasileiro passa mais tempo conectado na internet do que assistindo a televisão, pois $29 \%$ dos entrevistados passam mais de 300 minutos utilizando a internet de segunda a sexta-feira contra $13 \%$ dos que utilizam a televisão nesta mesma intensidade. A pesquisa evidenciou que a maioria dos entrevistados (91\%) acessa a internet pelo celular, seguido pelo computador (65\%) e uma parcela (12\%) dos pesquisados que acessa a rede via tablets. O levantamento ouviu 15.050 pessoas em 740 municípios, entre os dias 23 de março até 11 de abril de 2016. Dado o exposto, observa-se que, por ser hoje um dos meios de comunicação mais presente na vida das pessoas, a inacessibilidade dos sites resulta na exclusão de parcela significativa da sociedade (RÊGO, 2019; SECRETARIA ESPECIAL DE COMUNICAÇAO SOCIAL, s/d).

Para Amiel (2012, p. 23), “o desenvolvimento das mídias digitais proporcionou um impulso para novas configurações de ensino". Porém, observa-se que a internet não está modificando apenas os sistemas educativos formais, mas também a educação informal através da produção e disseminação de conhecimento, pois o leva ao alcance de um maior número de pessoas. Ainda segundo esse autor, a educação científica no País e, em especial, na região Nordeste, ainda encontra barreiras de acesso à internet em relação às regiões Sul e Sudeste e até mesmo aos países em desenvolvimento.

\section{ACESSIBILIDADE NA WEB}

A Cartilha Acessibilidade na Web, fascículo 1, desenvolvida pelo W3C Escritório Brasil, com o objetivo de orientar gestores, desenvolvedores, auditores, procuradores, promotores e cidadãos sobre a importância de se preocupar e investir em acessibilidade na web, define:

Acessibilidade na web é a possibilidade e a condição de alcance, percepção, entendimento e interação para a utilização, a participação e a contribuição, em igualdade de oportunidades, com segurança e autonomia, em sítios e serviços disponíveis na web, por qualquer indivíduo, independentemente de sua capacidade motora, visual, auditiva, intelectual, cultural ou social, a qualquer momento, em qualquer local e em qualquer ambiente físico ou computacional e a partir de qualquer dispositivo de acesso (BRASIL, 2014b, p. 24).

Neste sentido, Rocha e Duarte (2012) também afirmam que:

A acessibilidade na Web deve possibilitar que qualquer usuário, assistido por agentes de software ou hardware compatíveis com suas necessidades, possa entender e interagir com determinado conteúdo, tendo garantido seu direito de inclusão na sociedade, não obstante suas limitações e particularidades (ROCHA; DUARTE, 2012, p. 73).

É relevante notar que a acessibilidade comumente é vista como uma via de mão única, como se as pessoas fossem apenas receptoras. Contudo, trata-se de um equívoco, pois a acessibilidade permite 
que os indivíduos integrados ao meio, seja ele qual for, deem a sua contribuição à sociedade (BRASIL, 2014b). De acordo com documentos da Iniciativa para a Acessibilidade na Web (W3C-WAI), acessibilidade na web significa que "pessoas com deficiência podem perceber, compreender, navegar e interagir com a web e podem também contribuir com a web". Assim, "quanto mais sítios e programas acessíveis estiverem disponíveis, mais efetivamente pessoas com deficiência poderão usar e contribuir com a web" (BRASIL, 2014b, p. 23) e, através dela, para a sociedade

Corroborando esse pensamento, segundo Henry (2005) que "a acessibilidade permite que pessoas com deficiência possam perceber, entender, navegar, interagir e contribuir com a Web" (apud ROCHA; DUARTE, p. 74).

\section{PADRÕES DE ACESSIBILIDADE NA WEB}

Nas últimas décadas, a internet sofreu uma expansão vertiginosa, reduzindo distâncias e possibilitando um vasto acesso a produção e divulgação de conteúdo, evidenciando um potencial para a inclusão social.

A internet está cada vez mais presente e necessária no nosso quotidiano, sendo utilizada para os mais diversos fins, como profissionais, entretenimento, utilidades práticas do dia a dia, redes sociais, entre outros. Portanto, em contrapartida, ela também pode contribuir para a exclusão social, quando houver privação do acesso a determinados usuários.

Neste sentido dispões a Cartilha Acessibilidade na Web:

A web é cada vez mais um recurso essencial em muitos aspectos da vida: educação, emprego, governo, comércio, saúde, diversão, interação social, e muito mais. É usada não apenas para receber informações, mas também para fornecer informações e interagir com a sociedade. Portanto, é essencial que seja acessível, a fim de proporcionar igualdade de acesso e de oportunidades para pessoas com deficiência." (BRASIL, 2014b, p. 29).

Assim, a sociedade deve estar consciente de que não basta disponibilizar os conteúdos na Web, é preciso identificar as barreiras que comprometam seu uso efetivo pelos mais diversos grupos de indivíduos e buscar eliminá-las para que a internet possa ser usufruída por todos os cidadãos. Isto porque a possibilidade de igualdade de acesso aos conteúdos informacionais digitais por todos, independentemente de suas características, é um fator que impulsiona a inclusão informacional e digital desses cidadãos.

Podem ser encontradas barreiras aos usuários, por diversos motivos, como por razões econômicas ou por necessidades especiais de acesso devido às limitações sensoriais/físicas de pessoas com 
deficiência, idosos com alterações em suas habilidades, usuários de dispositivos móveis e pessoas com deficiências temporárias, causadas por acidentes e patologias diversas (FREITAS et al., 2015; CABRAL et al., 2019; RÊGO, 2019).

No caso das necessidades especiais para o acesso, essas barreiras surgem, na maioria das vezes, devido à inadequação dos ambientes informacionais digitais às normas, padrões e diretrizes de acessibilidade encontrada em documentos oficiais elaborados por várias entidades de diversos países na tentativa de universalizar padrões de acessibilidade na Web.

Essas diretrizes são compostas por recomendações a serem seguidas no processo de construção de sites com o objetivo de evitar e de solucionar diversos problemas que dificultam ou impedem a acessibilidade deles, privando as pessoas com deficiência da sua utilização do conteúdo disponibilizado.

O processo de eliminação dessas barreiras na acessibilidade de conteúdos digitais é difícil e contínuo, pois a multiplicidade de necessidades especiais dos usuários com deficiência é vasta e, cada vez mais, essas pessoas estão se inserindo e precisam se integrar ao mundo digital.

Algumas pessoas com deficiência precisam de recursos de apoio para tarefas para navegar nos ambientes informacionais digitais. Esses recursos são denominados Tecnologia Assistiva e tem como objetivo transmitir a seu usuário o conteúdo apresentado na tela do computador, ou facilitar o acesso e interação dele com tal conteúdo. Contudo, a Tecnologia Assistiva só funciona corretamente se os sites forem construídos em conformidade com diretrizes de acessibilidade.

Atualmente, há uma vasta gama de documentos elaborados por entidades de diversos países com o intuito de criar padrões para a construção de sites através de normas e diretrizes que promovem a acessibilidade na web. Entretanto, segundo Tangarife (2007), essa grande quantidade de documentos dificulta ainda mais a padronização, pois eles diferem muito entre si.

Todavia, grande parte desses documentos apresentam também semelhanças, por terem sido elaborados a partir do Web Content Accessibility Guidelines (WCAG), criadas pelo World Wide Web Consortium (W3C). É importante conhecer as semelhanças e diferenças entre esses padrões para que se possa definir quais diretrizes se adequam mais à população a qual será destinada essas normas, levando em consideração aspectos sociais, educacionais, econômicos, demográficos, a infraestrutura, dentre outros. 


\section{MODELO DE ACESSIBILIDADE EM GOVERNO ELETRÔNICO (EMAG)}

O World Wide Web Consortium (W3C) surgiu em 1994, como uma comunidade internacional em que organizações membros, com uma equipe em tempo integral, trabalhando junto ao público visando regulamentar os assuntos ligados à Web e elaborar padrões para a construção de seus conteúdos, tornando-a universalmente acessível (W3C, 2013).

Em 1999 foi criado um grupo de trabalho no W3C denominado Web Accessibility Initiative (WAI) com o objetivo de elaborar diretrizes para tornar a Web acessível a pessoas com deficiência ou com necessidades especiais (BRASIL, 2018) Como resultado desses trabalhos foi elaborada, em 1999, a primeira versão das Web Content Accessibility Guidelines (WCAG 1.0), um documento que continha catorze diretrizes para a acessibilidade de websites (BRASIL, 2007) e que, em 2008, foi atualizado para a sua segunda versão, o WCAG 2.0.

Baseando-se nas recomendações do WCAG 2.0, por meio de uma parceria entre o Departamento de Governo Eletrônico Brasileiro e o Projeto de Acessibilidade Virtual da Rede de Pesquisa e Inovação em Tecnologias Digitais (Renapi), foi desenvolvida, no Brasil, a versão 3.0 do Modelo de Acessibilidade em Governo Eletrônico (eMAG), mas o texto brasileiro procurou se manter dentro do contexto e das necessidades brasileiras.

Dessa forma, o eMAG consiste em um conjunto de recomendações e diretrizes a serem seguidas para que a implementação da acessibilidade dos sítios e portais do governo brasileiro seja conduzida de forma fácil e padronizada.

Visando a assegurar de forma progressiva a acessibilidade de serviços e sistemas de Governo Eletrônico, em 2007, o e-MAG foi institucionalizado pela Portaria no 3, de 7 de maio de 2007 e seu uso passou a ser obrigatório para todos os sítios e portais do governo federal brasileiro (BRASIL, 2014a, b).

No seu primeiro capítulo, intitulado Introdução, há uma descrição de como a versão 3.1 foi desenvolvida, destacando-se algumas de suas diferenças no que concerne a sua versão anterior. Destaca ainda as principais leis que norteiam a promoção da acessibilidade em websites e portais governamentais por meio do eMAG e explica como acontece o acesso de pessoas com deficiência à Web (BRASIL, 2014a, b).

O segundo capítulo, intitulado processo para desenvolver um sítio acessível, elenca três passos para desenvolver websites acessíveis. O primeiro passo trata-se de seguir os padrões web internacionais 
definidos pelo W3C, seguir as regras de formatação sintática e garantir que o código seja semanticamente correto. Conforme o eMAG:

\begin{abstract}
Uma página desenvolvida de acordo com os padrões Web deve estar em conformidade com as normas HTML, XML, XHTML e CSS, seguindo as regras de formatação sintática. Além disso, é muito importante que o código seja semanticamente correto, ou seja, que cada elemento seja utilizado de acordo com um significado apropriado, valor e propósito. A conformidade com os padrões Web permite que qualquer sistema de acesso à informação intérprete a mesma adequadamente e da mesma forma, seja por meio de navegadores, leitores de tela, dispositivos móveis (celulares, tablets etc.) ou agentes de software (mecanismos de busca ou ferramentas de captura de conteúdo). Páginas que não possuem um código de acordo com os padrões do W3C apresentam comportamento imprevisível, e na maioria das vezes impedem ou pelo menos dificultam o acesso (BRASIL, 2014a, p. 13).
\end{abstract}

O segundo passo consiste em seguir as diretrizes ou recomendações de acessibilidade, explicando a criadores de sites ou programadores de ferramentas para criação de conteúdo como tornar o conteúdo Web acessível a todas as pessoas.

O terceiro passo refere-se a realizar a avaliação de acessibilidade, validando os códigos HTML e CSS, utilizando navegadores textuais e leitores de telas, desabilitando imagens e scripts, verificando a funcionalidade das barras de acessibilidade, usando validadores automáticos e checklists manuais. Segundo o eMAG:

No que diz respeito às diretrizes de acessibilidade, é necessário realizar, inicialmente, uma validação automática, que é realizada através de softwares ou serviços online que ajudam a determinar se um sítio respeitou ou não as recomendações de acessibilidade, gerando um relatório de erros. [...] Os validadores automáticos por si só não determinam se um sítio está ou não acessível. Para uma avaliação efetiva, é necessária uma posterior validação manual (BRASIL, 2014b, p. 13).

O terceiro capítulo do eMAG, intitulado Recomendações de Acessibilidade, aponta 45 recomendações a serem seguidas para promover a acessibilidade dos sites, organizadas nas seguintes seções.

As Recomendações para acessibilidade dos sites segundo o eMAG dispõe orientações referentes à construção do código HTML das páginas dos sites, para a Utilização da marcação, que consiste nas tags aplicadas ao texto para adicionar informações sobre ele. Isso refere-se a orientações no que tange ao comportamento das páginas dos sites Comportamento (atualização, redirecionamento automáticos e outros) e dos elementos nelas contidos (scripts, flash, conteúdos dinâmicos e outros). 
Esta seção traz orientações referentes ao conteúdo/informação-conteúdo das páginas dos sites e das informações nelas contidas. São recomendações como utilizar títulos e links objetivos, sucintos e significativos, mecanismos para indicar a localização do usuário no website, descrição textual de conteúdos gráficos, por exemplo. O eMAG constitui em orientações sobre o design eMAG das apresentação/design páginas dos websites, como layout, contraste, redimensionamento de textos, por exemplo.

Também ponta orientações sobre a inserção de elementos a multimídia (vídeos e áudio) nas páginas dos sites, como legendas, audiodescrição, controles de áudio e de animação, por exemplo. Contém orientações para os formulários presentes nas páginas dos sites, como alternativas textuais - ter um Formulário para botões em formato de imagens, ordem lógica de navegação/tabulação, instruções para a entrada de dados, CAPTCHA5 acessível, por exemplo.

O quarto capítulo, intitulado Elementos Padronizados de Acessibilidade Digital no Governo Federal, cita um conjunto de elementos que devem estar presentes, por padrão, em todas as páginas do governo federal. São eles:

- Atalhos por teclado para pontos estratégicos da página,

- Teclas de atalho permitindo que o usuário possa ir diretamente a esses pontos, para ir ao conteúdo; para ir ao menu principal; para ir à caixa de pesquisa.

- Primeira folha de opção "alto contraste" deve gerar uma página em que a contraste relação de contraste entre o plano de fundo e os elementos do primeiro plano seja de, no mínimo 7:1 (contraste otimizado). O sítio deverá conter uma barra de acessibilidade no topo de Barra de cada página contendo os seguintes itens: Alto contraste, acessibilidade.

- Atalhos (para Menu, Conteúdo e Busca), Acessibilidade (link para a página contendo os recursos de acessibilidade do sítio).

- Apresentação o mapa do sítio deve ser disponibilizado em forma de lista do mapa do sítio hierárquica (utilizando os elementos de lista do $\mathrm{HTML}$ ), podendo conter quantos níveis forem necessários. Esta página apresenta os recursos de acessibilidade presentes no sítio, como as teclas de atalho disponíveis.

- Página com a opções de alto contraste, detalhes sobre testes de descrição dos recursos de acessibilidade realizados (validadores automáticos, leitores) 
A cessibilidade de tela e validação humana) no sítio e outras informações pertinentes a respeito de sua acessibilidade. O link para a página contendo os recursos de acessibilidade deve ser disponibilizado na barra de acessibilidade.

\section{ELEMENTOS PADRONIZADOS DE ACESSIBILIDADE DIGITAL NO GOVERNO FEDERAL}

Ainda no terceiro capítulo, são relacionados alguns elementos que podem prejudicar a acessibilidade do site e, portanto, não devem ser utilizadas nas páginas, como atualizações automáticas periódicas, situações com intermitência de tela e outras.

O quarto capítulo, intitulado Recursos e Ferramentas para Acessibilidade, disponibiliza links para sites de instituições que também oferecem recomendações e especificações nacionais e internacionais direcionadas para a construção de sites acessíveis. Além disso, apresenta links para validadores automáticos de código e de acessibilidade, ferramentas para análise de contraste; simuladores diversos; navegadores textuais; leitores de tela e documentos com tutoriais e checklists de validação manual.

O quinto capítulo, intitulado Leitura Complementar, disponibiliza links para documentos de diversos países contendo padrões e diretrizes de acessibilidade Web, além e links de sites de organizações relacionadas a este assunto.

O sexto capítulo, intitulado Glossário, reúne descrições dos principais termos referentes ao tema acessibilidade na Web utilizados neste documento para facilitar a compreensão do público. Finalmente, o anexo, intitulado Tabela de Contraste de Cores, contém duas tabelas de cores que, em fundo preto ou branco, exibem a relação exigida de contraste mínimo. Isto porque as cores do plano de fundo e do primeiro plano dos sites precisam apresentar um contraste suficiente para que pessoas com baixa visão, daltonismo ou que utilizam monitores de vídeo monocromático possam visualizá-las. Assim, verifica-se que várias etapas foram cumpridas, mas muito ainda há de se trilhar para incluir pessoas com deficiências no universo digital, pois é direito destas pessoas coexistirem com qualquer outra pessoa em ambientes plenos em acessibilidades para desenvolver e produzir conforme as suas habilidades, com autonomia e independência.

Finalizado, há um concento entre os educadores que tanto o Estado como a Instituições Privadas devem garantir essas acessibilidades, principalmente, por meio da formulação, implantação e acompanhamentos do cumprimento das políticas públicas, formuladas não só pelo poder público, pela 
sociedade civil, como também por aqueles que enfrentam inúmeras adversidades por enfrentar viver em comunidade sem infraestrutura para que o nosso país seja de fato inclusivo e acessível. 


\section{REFERENCIAS}

ACESSIBILIDADE. 2017. Disponível em: https://www.gov.br/pt-br/acessibilidade\# Acesso em: 10 jan. 2019.ALBAGLI, Sarita. Divulgação científica: informação científica para a cidadania? Ciência da Informação, v. 25, n. 3, p. 396-404,1996. Disponível em: http://revista.ibict.br/ciinf/article/view/639 Acesso em: 12 dez. 2018.

AMIEL, T. Educação aberta: configurando ambientes, práticas e recursos educacionais. In: Recursos Educacionais Abertos: práticas colaborativas e políticas públicas, 1a. $\quad$ Edição, 2012. Disponível em:

http://www.artigos.livrorea.net.br/2012/05/educacao-aberta-configurando-ambientespraticas-erecursos-educacionais/ Acesso em: 9 dez. 2018.

ALONSO, L. B. N.; FERNEDA, E.; SANTANA, G. P. Inclusão digital e inclusão social: contribuições teóricas e metodológicas. Barbaroi, Santa Cruz do Sul, n. 32, p. 154-177, 2010. Disponível em: http://pepsic.bvsalud.org/scielo.php?script=sci_arttext\&pid=S010465782010000100010\&lng=pt\&nr m=iso Acessos em: 16 jun. 2018.

BRASIL. A inclusão escolar de alunos com necessidades educacionais especiais Deficiência Física. Ministério da Educação Secretaria de Educação Especial, Brasília, DF, 2006. Disponível em: http://portal.mec.gov.br/seesp/arquivos/pdf/deffisica.pdf Acessos em: 16 jun. 2018.

BRASIL. Portaria SEDH no 163 de 29/12/2006. 2007. Disponível em:

https://www.legisweb.com.br/legislacao/?id=196373 Acesso em: 10 nov. 2018

BRASIL. eMAG. Modelo de Acessibilidade em Governo Eletrônico. 2014a. Disponível em: http://emag.governoeletronico.gov.br Acesso em: 10 nov. 2018

BRASIL Cartilha de Acessibilidade na Web também está disponível em HTML no site do W3C Brasil, 2014b. Disponível em: http://www.w3c.br/Materiais/PublicacoesW3C Acesso em: 18 out. 2021.

BRASIL. LEI № 13.146, de 6 de julho de 2015. 2015. Disponível em:

http://www.planalto.gov.br/ccivil_03/_ato2015-2018/2015/lei/l13146.htm Acessos em: 18 out. 2018.

BUENO; Wilson Costa Comunicação cientifica e divulgação científica: aproximações e rupturas conceituais. Informação e Informação, v. 15, p. 1-12. 2010. Disponível em:

https://www.uel.br/revistas/uel/index.php/informacao/article/view/6585 Acessos em: 18 out. 2018.

CABRAL, Ana Modestina Pereira Lafetá. Acessibilidade e Inclusão: Criação do site do Curso de Mestrado Profissional em Diversidade e Inclusão. Dissertação. (Mestrado em Diversidade e Inclusão). Universidade Federal Fluminense. 2018.

CABRAL, Ana Modestina Pereira Lafetá; LIMA, Neuza Rejane Wille Lima. Legislação federal brasileira sobre acessibilidade: o que falta fazer? In: LIMA, Neuza Rejane Wille Lima.; PERDIGÃO, Luciana Tavares (org.). Pontos de Vista em Diversidade e Inclusão. v. 4, 1a. ed., Niterói, RJ. ABDIn/PERSE, v. 4, p. 95 106, 2018. Disponível em: 
https://www.researchgate.net/profile/Neuza-Wille-

Lima/publication/314242808_Ponto_de_vista_em_diversidade_e_inclusao/links/5b7cac8c4585151f d12685d9/Ponto-de-vista-em-diversidade-e-inclusao.pdf Acessos em: 18 out. 2018.

CABRAL, Ana Modestina Pereira Lafetá; DELOU, Cristina Carvalho; Castro Helena Carla Castro Rangel; LIMA, Neuza Rejane Wille Lima. Análise nos sites de 50 universidades públicas federais brasileiras. In: LIMA, Neuza Rejane Wille Lima.; PERDIGÃO, Luciana Tavares (org.). Pontos de vista em diversidade e inclusão. Vol. 6.1 ed. Niterói: ABDIn/v.1, p. 46-53, 2019a. Disponível em:

https://www.researchgate.net/publication/334279948_Pontos_de_Vista_em_Diversidade_e_Inclusa o_Volume_6 Acessos em: 18 out. 2018.

CABRAL, Ana Modestina Pereira Lafetá; RÊGO, Luciana Fernandes; Cláudia MACEDO, DELOU, Cristina Maria Carvalho; CASTRO, Helena Carla; LIMA, Neuza Rejane Wille. Accessibility on the Web: Subsidies for the Creation of a New Site for a Master's Course in Diversity and Inclusion. Creative Education, v. 10, n. 10, p. 2270-2282, 2019b. Disponível em:

https://www.scirp.org/journal/paperinformation.aspx?paperid=96123 Acessos em: 18 out. 2018.

CARR-HILL, Roy; Geoffrey; HARDMAN, Stephen MARTIN, Stuart PEACOCK, Trevor SHELDON; SMITH; Peter. A formula for distributing NHS revenues based on small area use of hospital beds. Center for Health Economic. University of New York. 1994. Disponível em:

https://www.york.ac.uk/media/che/documents/papers/occasionalpapers/CHE\%200ccasional\%20Pa per\%2022.pdf Acessos em: 18 out. 2018.

CHASSOT, A. Alfabetização científica: uma possibilidade para a inclusão social.

Revista Brasileira de Educação, no 21, p. 157- 158, 2002. Disponível em:

http://www.scielo.br/pdf/rbedu/n22/n22a09.pdf Acesso em: 12 dez. 2018. COMPROVA. Jornalismo Colaborativo Contra a Desinformação São Paulo, 10 de junho de 2021. 2021. Disponível em: https://projetocomprova.com.br/publica\%C3\%A7\%C3\%B5es/projeto-comprova-inicia-quarta-fasecom-33-veiculos-de-comunicacao/ Acessos em: 18 out. 2018.

CONFORTO, D.; Santarosa, L. M. C. Acessibilidade à web: internet para todos. Revista de Informática na Educação: Teoria, Prática, v. 5, p. 87- 102, 2002. Disponível em:

http://atividadeparaeducacaoespecial.com/wpcontent/uploads/2014/08/ACESSIBILIDADE_WEB_revi sta_PGIE.pdf Acesso em: 16 nov. 2018.

CONTE, Elaine; BASEGIO, Antônio Carlos. Tecnologias assistivas: recursos pedagógicos à inclusão humana. Revista Temas em Educação, v. 24, n. 2, p.28-44, 2015. Disponível em:

https://periodicos.ufpb.br/ojs/index.php/rteo/article/view/20242/14560 Acesso em: 18 out. 2018.

DUARTE, Thiago Ribeiro; TEDERIXE, Lisânia Cardoso; PINHO, Tania Maria Moratelli; DELOU, Cristina Maria Carvalho; FERNADES, Edicleia Mascarenhas. LIMA, Neuza Rejane Wille. Braille material production for special education teachers. Creative Education, v. 11, n. 5, p. 652-673, 2020. Disponível 
em:https://www.researchgate.net/publication/341320860_Braille_Material_Production_for_Special _Education_Teachers Acesso em: 18 out. 2018.

FONSECA, Grasielle Lopes Menezes da; LIMA, Neuza Rejane Wille. Acessibilidade Informacional à Pessoa com Deficiência Visual através do Livro Falado. Revista Informação na Sociedade Contemporânea, v. 1, p. 1-20. Disponível em:

http://https://periodicos.ufrn.br/informacao/article/view/21761/13437 Acesso em: 17 out. 2021.

FRANÇA, Andressa de Almeida. Divulgação científica no Brasil: espaços de interatividade na Web. Dissertação. (Mestrado em Ciência, Tecnologia e Sociedade). Universidade Federal de São Carlos, São Carlos, SP. 2015. Disponível em:

https://repositorio.ufscar.br/bitstream/handle/ufscar/7131/DissAAF.pdf?sequence=1 Acessos em: 18 out. 2018.

FREITAS, César Gomes de; DELOU, Cristina Maria; SOUZA, Sandreia Castro de; BRAGA, Mairene Nascimento; CASTRO, Helena Carla. People with special needs and the accessibility of websites of educational institutions: using the Brazilian system to point to a current and problematic global issue. Creative Education, 6, 2021-2027, 2015. Disponível

em: https://www.scirp.org/journal/paperinformation.aspx?paperid=60854 Acessos em: 18 out. 2018.

LEITE, Cicilia Raquel Maia; ROSA, Suélia de Siqueira Rodrigues Fleury. Novas Tecnologias Aplicadas à Saúde: Integração de Áreas Transformando a Sociedade. EDUERN, Mossoró, RN, 2017. Disponível em: http://www.sbeb.org.br/site/wp-content/uploads/LivroVersaoFinal15-07-2017.pdf Acesso em: 17 out. 2021.

LIMA, Neuza Rejane Wille. PAIXÃO, Izabel Christina Nunes de Palmer. Vivendo a nossa vigésima primeira pandemia e as outras doenças transmissíveis. Editora Conhecimento Livre, Piracanjuba, GO, 2021. Disponível

em:https://www.researchgate.net/publication/354587006_Neuza_Rejane_Wille_Lima_Izabel_Christ ina_Nunes_de_Palmer_Paixao_VIVENDO_A_NOSSAVIGESIMA_PRIMEIRA_PANDEMIA_E_AS_OUTRAS _DOENCAS_TRANSMISSIVEIS_1_ed_Piracanjuba-GO_Editora_Conhecimento_Livre_Piracanjuba Acesso em: 18 out. 2021.

LIMA, Neuza Rejane Wille; REZENDE, Carlos Eduardo. Extensão universitária e divulgação científica: quais são as diferenças? Reflexões a partir de uma LIVE promovida pelo projeto Além do Lattes (UENF/LCA/PPGERN). Revista de Extensão UENF, v. 4, n. 1, p. 98-121, 2020. Disponível em: http://https://www.researchgate.net/publication/342747071_Extensao_Universitaria_Divulgacao_C ientifica_Quais_sao_as_diferencas_Reflexoes_a_partir_de_uma_LIVE_promovida_pelo_Projeto_Ale m_do_Lattes_UENFLCAPPGERN Acesso em: 17 out. 2021.

MASSARANI, Luísa Medeiros; ALVES, Juliana Passos. A visão de divulgação científica de José Reis. Arquivo Ensaios, v. 71, n 1, p. 56-59, 2019. Disponível em:

http://cienciaecultura.bvs.br/scielo.php?script=sci_arttext\&pid=S0009-67252019000100015 Acesso em: 17 out. 2021. 
MOREIRA, I. C. A inclusão social e a popularização da ciência e tecnologia no Brasil. Inclusão Social (Online), v. 1, p. 11-16, 2006. Disponível em http://revista.ibict.br/inclusao/article/view/1512/1708 Acesso em: 12 dez. 2018.

NATAL, Camila Binhardi; ALVIM, Marcia Helena. A divulgação científica e a inclusão social. Revista do EDICC, v. 5, p. 76-86, 2018. Disponível em:

http://revistas.iel.unicamp.br/index.php/edicc/article/view/5964 Acesso em: 12 dez. 2019.

NEGRI, Fernanda De; ZUCOLOTO, Graziela; MIRANDA, Pedro; KOELLER, Priscila. Ciência e Tecnologia frente à pandemia. Como a pesquisa científica e a inovação estão ajudando a combater o novo coronavírus no Brasil e no mundo. 2021. Disponível em: https://www.ipea.gov.br/cts/pt/central-decontudo/artigos/artigos/182-corona Acesso em: 17 out. 2021.

POLITIZE. Acessibilidade e o direito das pessoas com deficiência. 2017. Disponível em: https://www.politize.com.br/acessibilidade-e-o-direito-das-pessoas-com-deficiencia/ Acesso em: 18 out. 2021.

RÊGO, Luciana Fernandes. Divulgação Científica e Inclusão Social: Criação de um site de Divulgação Científica Acessível. Dissertação. (Mestrado em Diversidade e Inclusão). Universidade Federal Fluminense. 2019.

RÊGO, Luciana Fernandes; LIMA, NEUZA REJANE. Divulgação científica: uma inclusão social. In: LIMA, Neuza Rejane Wille, PERDIGÃO, Luciana Tavares; DELOU, Cristina Maria. Pontos de vista em diversidade e inclusão. v. 6, 1․ Edição. ABDIn/PERSE. Disponível em: https://www.researchgate.net/publication/334279948_Pontos_de_Vista_em_Diversidade_e_Inclusa o_Volume_6 Acesso em: 17 out. 2021.

REIS, J. Educação é investimento. São Paulo: IBRASA, 1968.

RUZZA, Mara Lopes Figueira de. A inclusão educacional do sujeito surdo: direito garantido ou reprimido? Dissertação. (Mestrado em Educação). Pontifícia Universidade Católica, São Paulo, SP. 2016.

Disponível

em:

https://sapientia.pucsp.br/bitstream/handle/18841/2/Mara\%20Lopes\%20Figueira\%20de\%20Ruzza. pdf Acesso em: 19 out. 2021.

ROCHA, Janicy Aparecida Pereira; DUARTE, Adriana Bogliolo Sirihal. Diretrizes de acessibilidade web: um estudo comparativo entre as WCAG 2.0 e o e-MAG 3.0. Inc. Soc., Brasília, DF, v. 5 n. 2, p. 73-86, 2012. Disponível em:

https://www.brapci.inf.br/_repositorio/2017/01/pdf_a3913a8696_0000022365.pdf Acesso em: 17 out. 2021.

SARTORETTO, Mara Lúcia; BERSCH, Rita. Assistiva Tecnologia e Educação. 2021. Disponível em: https://www.assistiva.com.br/tassistiva Acesso em: 17 out.

SECRETARIA ESPECIAL DE COMUNICAÇAO SOCIAL, s/d. Disponível em: http://antigo.secom.gov.br/ Acesso em: 18 out. 2021. 
SILVA NETO, João Cirilo da. Importância da divulgação científica no contexto da inclusão social. VIII World Congress on Communication and Arts. Salvador, BA. 2015. Anais... Disponível em: http://copec.eu/congresses/wcca2015/proc/works/15.pdf Acesso em: 01 mai, 2018.

SILVEIRA, Sérgio Amadeu da, A exclusão digital: a miséria na era da informação. Fundação Perseu Abramo, São Paulo, SP. 2001. Disponível em:

https://www.trabalhosfeitos.com/ensaios/Exclus\%C3\%A3o-Digital-a-Mis\%C3\%A9riaNaEra/42607204.html Acesso em 02/01/2019.

TANGARIFE, T. M. A acessibilidade nos websites governamentais: um estudo de caso no site da Eletrobrás, 2007. Disponível em:

https://www.maxwell.vrac.pucrio.br/acessoConteudo.php?nrseqoco=33711 Acesso em: 28 jan. 2019. 


\section{Capítulo 10}

\section{doi $10.37423 / 211004906$}

\section{PRINCIPAIS CAUSAS DE INFERTILIDADE FEMININA E OS BENEFÍCIOS DOS MÉTODOS DE CRIOPRESERVAÇÃO: UMA REVISÃO BIBLIOGRÁFICA}

Gabriela Eugênio de Aguiar

Maria Clara Borges Nani

Giulia Maria de Castro Bani

Thiago Franco Nasser

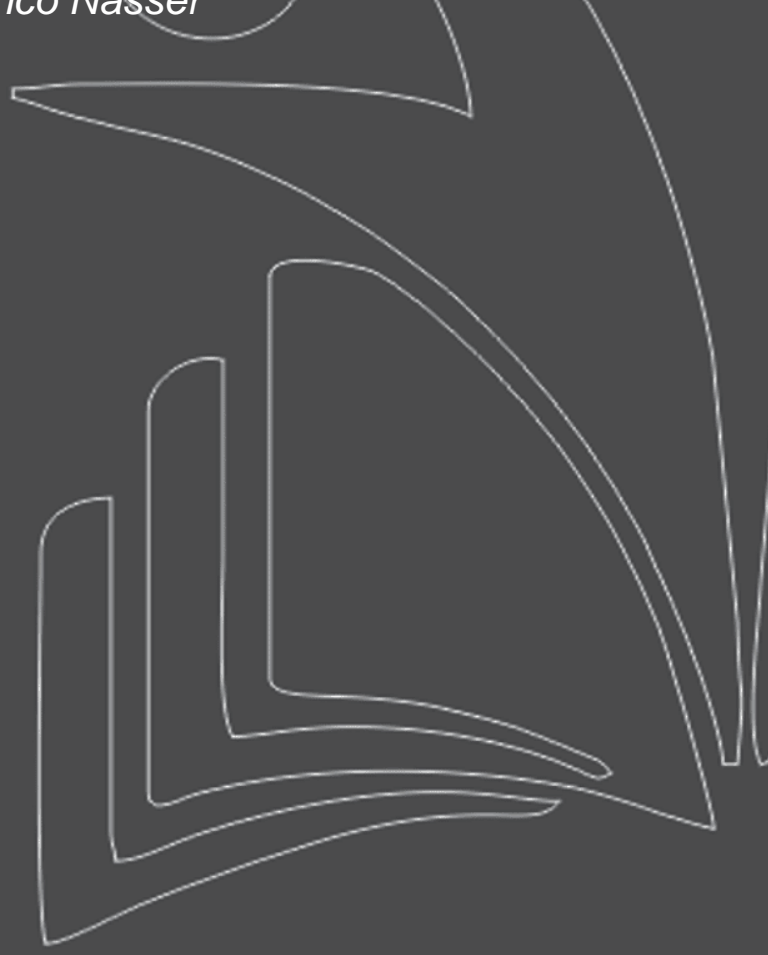

Centro Universitário do Sul de Minas

Centro Universitário do Sul de Minas

Centro Universitário do Sul de Minas

Centro Universitário de Sul de/Minas

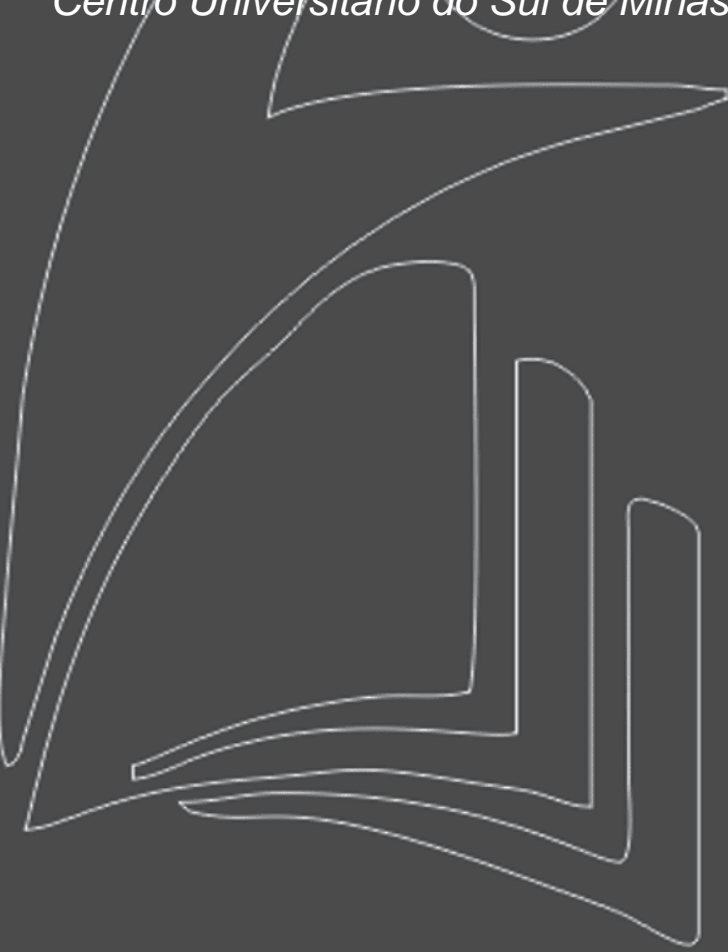


Resumo: Este trabalho analisa as principais causas de infertilidade feminina e os benefícios dos métodos de criopreservação. Tal abordagem se faz necessária devido a infertilidade feminina ter se tornado um problema de saúde pública e a existência dos vários métodos utilizados para a preservação da fertilidade deste modo é necessário entender qual a técnica mais adequado para cada situação. 0 objetivo deste estudo é evidenciar a eficácia dos métodos de criopreservação para as diferentes causas de infertilidade. Este intenso propósito será concluído mediante uma revisão bibliográfica através de um levantamento de dados em sites renomados como Google Scholar e Scielo, Pubmed, Fertility and Sterility, Human Reproduction, englobando artigos dos últimos 10 anos. A análise evidenciou a endometriose, anovulação e obstrução tubária como as principais causas de infertilidade feminina e revela que os métodos de criopreservação são utilizados como intuito de auxiliar mulheres que estão passando por alguma patologia ou simplesmente por aquelas que decidem adiar a gestação por decisão própria. É de extrema valia o estudo da clínica de cada paciente para utilização da técnica de criopreservação mais adequada e que garanta a eficaz do método.

Palavras-chave: Infertilidade. Feminina. Criopreservação. Reprodução Humana 


\section{INTRODUÇÃO}

O presente trabalho aborda as principais causas de infertilidade e os benefícios da técnica de criopreservação que vêm auxiliando diversos casais a conseguirem realizar o sonho de se tornarem pais.

O sistema ou aparelho reprodutor feminino exerce diversas funções importantes para o organismo da mulher. É através dele que ocorre o desenvolvimento embrionário. Este sistema é constituído de órgãos sexuais internos, útero, tubas uterinas e ovários, e estruturas externas, como os lábios maiores e menores do pudendo; monte do púbis; clitóris; vestíbulo; óstio da vagina; hímen e óstio externo da uretra (MOURA, 2018).

Tal abordagem se faz necessária, pois mesmo que o sistema reprodutor carregue uma gama de importâncias, é coerente dizer que, nem sempre ele consegue efetivar a maternidade biológica. A infertilidade é, para muitos, uma barreira para concretizar os desejos da maternidade e paternidade. Segundo a Organização Mundial da Saúde, a infertilidade já afetou de 60 a 80 milhões de pessoas em todo o mundo em algum momento da vida. Estimase que a infertilidade pode causar, também, uma série de sintomas importantes para o ramo da psicologia, dentre eles está a frustração, tristeza, ansiedade e vergonha (FARINATI et al., 2006).

Muitos são os métodos de reprodução humana assistida, por esse motivo, é de importância considerável construir e argumentar sobre o conjunto de informações e dados informativos sobre a incidência e as formas terapêuticas da infertilidade e dos benefícios das técnicas de criopreservação mais utilizadas, com intuito também de trazer mais informação para a população, já que um estudo feito no Ambulatório de Ginecologia da Universidade Federal de Pelotas revelou que 37\% das mulheres que fazem acompanhamento médico no local não conhecem os métodos de preservação da fertilidade feminina e $68 \%$ afirmam não se preocuparem com esta questão, estes dados revelam que a falta de conhecimento também pode ser considerado um indicador no crescente número de casos de infidelidade feminina no Brasil (ALEXANDRE; GUIMARAES; RIBEIRO, 2015).

O diagnóstico de infertilidade pode ser finalizado quando um casal, após dose meses de atividades sexuais ativas e reguladas sem o uso de nenhum método contraceptivo, não conseguem engravidar ou manter a gestação até o fim, sendo esta uma doença de saúde pública que atinge, somente no Brasil, seis milhões de casais e as causas podem ser as mais variadas (LẼ̃O; LINDOSO, 2020). 
Segundo Lima e Lourenço (2016), a infertilidade possui diversas causas, homens e mulheres são acometidos em porcentagens similares. A infertilidade masculina caracteriza-se por anomalias morfológicas ou baixa mobilidade e qualidade do espermatozoide e também distúrbios como azoospermia, gametogênese e oligospermia. Já nas mulheres as causas principais são problemas de ovulação, idade, interrupção da nidação, bloqueios das tubas uterinas, entre outros.

Devido à dificuldade em iniciar uma gestação de forma natural, muitos casais buscam apoio na ciência e optam pelas Técnicas de Reprodução Humana Assistida, a qual utiliza de métodos como fertilização in vitro convencional, injeção intracitoplasmática de espermatozoides, transferência intratubária de gameta ou zigoto, doação de óvulos e criopreservação de embriões e gametas. Deste modo o casal juntamente com um profissional especializado deve optar pela técnica que melhor se adéqua às suas necessidades (BATISTA; BITTENCOURT, 2020).

Uma das Técnicas utilizadas na Reprodução Humana Assistida é a criopreservação que consiste no congelamento em nitrogênio de espermatozóide, óvulos ou embriões em temperaturas extremamente baixas, ela também pode ser aplicada na preservação de células tronco (GASDA, 2015).

Este estudo objetiva analisar e compreender a eficiência do método de criopreservação e correlacionar com os impactos sociais da infertilidade na população brasileira através da literatura de diversos artigos publicados em revistas de alta relevância para a Associação de Reprodução Humana Brasileira.

O artigo trata-se de uma Revisão Bibliográfica de Literatura, metodologia que tem como objetivo a interação de dados e resultados de uma pesquisa, com a finalidade de proporcionar informações e questionamentos sobre o tema de modo ordenado e sistemático, colaborando para um estudo retrospectivo na qual serão analisados artigos científicos com temas direcionados ao sistema reprodutor feminino; infertilidade e os métodos de criopreservação.

As sínteses de informações procederão de pesquisas científicas nas plataformas Google Scholar e Scielo, Pubmed, Fertility and Sterility, Human Reproduction, englobando artigos dos últimos 10 anos

\section{PRINCIPAIS CAUSAS DE INFERTILIDADE FEMININA}

Lindsay e Vitrikas (2015) relatam em seu trabalho as principais causas de infertilidade, estas envolvem diversos fatores como distúrbios ovulatórios, obstruções tubárias, endometriose e também as infertilidades que não possuem causa aparente, nestes casos o recomendado é o casal optar rapidamente pelos métodos de reprodução humana assistida. 
Figura 1: principais causas de infertilidade.

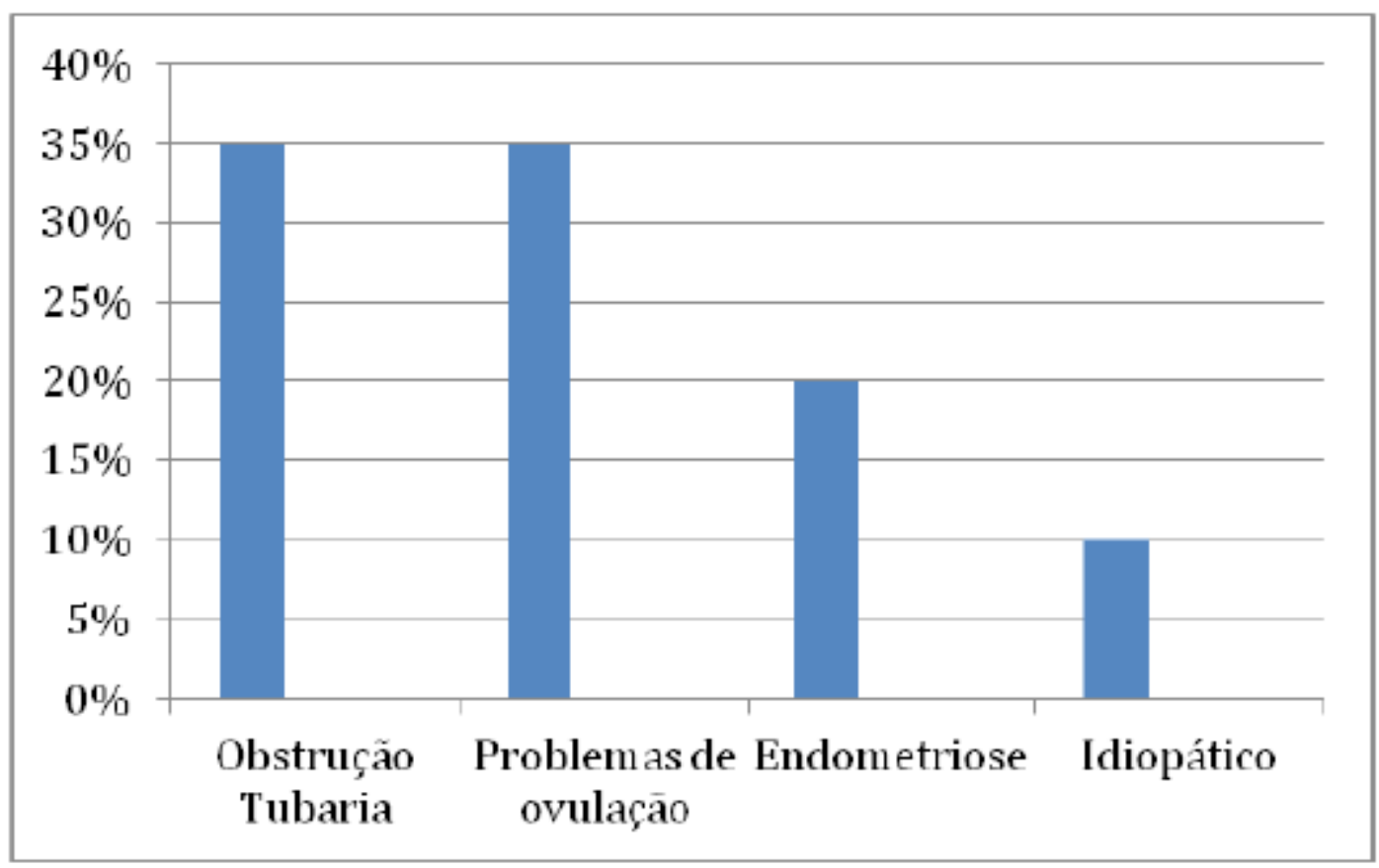

Fonte: Pro criar (2013)

\subsection{ENDOMETRIOSE E A INFERTILIDADE}

É possível citar a endometriose como uma das principais causas de infertilidade, sendo uma patologia na qual o tecido que reveste o útero, se desenvolve fora dele, podendo crescer também nos ovários, nas tubas uterinas e no intestino. Acomete mulheres principalmente na faixa de 30 a 33 anos podendo causar infertilidade em $50 \%$ destas, devido a este fator muitas mulheres precisam recorrer as Técnicas de Reprodução Humana Assistida (DUCCINI et al., 2019).

A revista The American Society for Reproductive Medicine (ASRM) classifica a endometriose em um sistema de pontuação na qual a localização e tamanho das células na extensão das aderências são levados em consideração para determinar a gravidade da patologia. As principais possíveis causas de infertilidade por endometriose são as aderências, inflamação crônicas causadas devido à presença das células endometriais fora do útero, interferências na fase lútea, resistência à progesterona, presença dos anticorpos antiendometriais e difícil acesso do espermatozoide (TAMBO, FEDORCSAK, 2017).

Um estudo realizado em 450 mulheres, por Oliveira e colaboradores (2015) no Instituto Ideia Fértil, também relaciona mulheres na faixa de 30 a 33 anos com maior prevalência de casos de endometriose e as principais causas da patologia revelada pelos autores são as alterações endócrinas, como diabetes 
tipo I e II, organismo hipoestrogênico, Síndrome do Ovário Policístico e fatores genéticos também possuem alta relevância.

\subsection{INFERTILIDADE POR ANOVULAÇÃO}

A Síndrome do Ovário Policístico (SOP), causada por uma disfunção hormonal, é responsável por gerar infertilidade anovulatória em $80 \%$ das mulheres que possuem esta patologia. 0 tratamento pode ser feito com a utilização de fármacos para estimular a ovulação e, quando os medicamentos não apresentam resultados, as pacientes podem optar pelos métodos de reprodução humana assistida (CARVALHO, 2019).

Romano e colaboradores (2011) corelacionam a anovulação com o aumento dos hormônios androgênios e fatores como a resistência à insulina, intolerância à glicose e síndrome metabólica que consequentemente são as alterações clínicas que mais afetam as mulheres com SOP principalmente as pacientes que se encontram acima do peso estima-se que $63,3 \%$ das mulheres com obesidades desenvolvem a patologia.

Outro estudo realizado por Fichman e colaboradores (2020) reafirma que a obesidade abdominal é a que traz maiores riscos para as mulheres em idade reprodutiva contribuindo para a infertilidade associada com o descontrole hormonal no eixo hipotálamo-hipofisárioovariano, desequilibrando o ciclo menstrual e, automaticamente, a fertilidade.

Estes distúrbios ovulatórios também podem ser causados por tratamentos oncológicos.

O câncer é uma doença que atinge milhares de pessoas, estima-se que afeta $5 \%$ da população feminina com menos de 50 anos. Mulheres diagnosticadas com câncer e em idade reprodutiva que ainda não tiveram filhos ou pensam na possibilidade de passarem por mais gestações, podem não conseguir realizar estes desejos devido aos quimioterápicos utilizados no tratamento da patologia causarem danos ao DNA das células germinativas, provocando apoptose dos oócitos e, consequentemente, falência ovariana prematura (BEDOSHI, NAVARRO, KUTLUK, 2016 ).

\subsection{OBSTRUÇÃO TUBÁRIA}

As causas de infertilidade podem ser distinguidas por meio de uma avaliação de imagem da anatomia uterina pelo método da histerossalpingografia - exame em que é utilizado contraste para a avaliação das estruturas reprodutoras femininas. Pérez e colaboradores (2001) descreveram a relevância da histerossalpingografia na pesquisa de causas de infertilidade sendo, uma delas, a obstrução tubária. 
De acordo com estes autores, a maioria dos casos de obstrução tubária vistos através deste exame de raio-x é resultante de infecção por Chlamydia trachomatis.

Como a Chlamydia trachomatis é capaz de parasitar o organismo feminino por quase um ano sem causar quaisquer sintomas em pelo menos $50 \%$ das mulheres, a exposição prolongada do microrganismo nas trompas ocasiona a formação de cicatrizes que se tornam barreiras e dificultam a chegado do espermatozoide no óvulo podendo impossibilitar o processo de fecundação (WITKIN et al., 2017).

Assim como a Chlamydia trachomatis a N. gonorrhoeae é responsável por ocasionar inflamações tubárias graves e consequentemente infertilidade, estudos recentes revelam que esta bactéria é responsável por $20 \%$ das doenças inflamatórias pélvicas agudas e mesmo sendo uma porcentagem baixa, este microrganismo também é capaz de causar nenhum sintoma no seu hospedeiro por um período longo de tempo, deste modo os danos ao sistema reprodutor podem ser irreversíveis (TSEVAT et al., 2017).

A infertilidade causada por obstrução tubária está associada também com a tuberculose genital, infecções que ocorrem em até 20 dias após a disposição de anticoncepcionais intrauterinos e a endometriose, diferente da infertilidade causada por anovulação, geralmente ela atinge mulheres um pouco mais velhas na faixa de 36 a 39 anos (BRICEAGE et al., 2015).

\subsection{OUTRAS CAUSAS DE INFERTILIDADE}

Machado (2010) ao realizar um estudo transversal, indicou possível relação entre a doença celíaca (DC) e a infertilidade. Mesmo com a escassez deste assunto na literatura, o estudo foi realizado com 170 mulheres na Bahia nas quais apresentaram infertilidade sem causa e com positividade para a doença celíaca. Como resultado deste estudo, houve prevalência de mulheres com doença celíaca e infertilidade, confirmando a possível discussão para a realização da triagem sorológica em mulheres que são submetidas a tratamentos de reprodução humana assistida.

Vier e colaboradores (2018) também apontam a doença celíaca (DC) como uma das causas de infertilidade não percebidas pelas mulheres. Há muitos questionamentos acerca das variadas manifestações clínicas extra intestinais da DC, sendo possível relacionar a restrição ao glúten como uma forma de favorecer a fertilidade em mulheres que não possuem causas aparentes. Estes autores realizaram um estudo observacional descritivo, avaliando 13 mulheres com infertilidade sem causa e/ou com dificuldade de manter uma gestação. As 13 pacientes foram confirmadas para a DC e 
atendidas em uma clínica privada de gastroenterologia, localizada em Criciúma - SC, e realizaram uma dieta sem glúten por um período de 2 meses. Após esse tempo, todas as mulheres engravidaram.

O tratamento realizado com glicocorticoides para doenças alérgicas também pode ser um fator influente para infertilidade feminina foi o que revelou um estudo realizado por Nan li et al. (2018). Os camundongos analisados eram estimulados com os corticoides e depois do acasalamento não conseguiam desenvolver o feto, isto porque a presença desta substância no organismo altera o ambiente uterino dificultando a continuidade da gestação. $O$ estudo não revelou qualquer alteração na síntese de óvulos.

\section{CRIOPRESERVAÇÃO}

A técnica de criopreservação consiste em congelar células reprodutoras em nitrogênio mantendo sua viabilidade através da redução do metabolismo e com ajuda dos agentes crioprotetores que apesar de protegerem as células contra desidratação e resfriamento possuem algumas substâncias tóxicas que podem dificultar o sucesso da técnica (MOURA et al., 2016).

\subsection{CRIOPRESERVAÇÕES DE EMBRIÕES}

Segundo Couy (2001) o método de criopreservação de embriões pode ser realizado quando a Fertilização in Vitro gera embriões excedentes, ou seja, embriões que não foram implantados no útero, mas estão em boa qualidade de desenvolvimento. Estudos revelam que esta técnica diminui as chances de gravidez múltipla e facilita a gravidez por ciclo.

Os embriões excedentes podem ser gerados pelo próprio casal ou podem ser de doadores, para realização deste procedimento é necessário um estímulo ovariano de duas a seis semanas podendo variar entre os indivíduos e a taxa de sucesso é muito alta, em sua maior parte este método é considerado mais eficaz em relação à técnica de criopreservação de oócitos (BEDOSCHI, OKTAY., 2013).

Para as pacientes que sofrem de SOP as taxas de gravidez são maiores em mulheres que realizam o congelamento e descongelamento de embriões em relação as que necessitam utilizar a fertilização com embriões frescos esse fator se deve, pois para a realização do presente método o endométrio é preparado com hormônios facilitando o processo de fertilização e diminui as chances de complicações na gestação como recém-nascidos pequenos para idada e pré-eclâmpsia, também aumentando os números de nascidos vivos (SHI et al., 2014). 
Por outro lado em mulheres com infertilidade causada por obstruções tubários o sucesso da técnica é muito influenciada pela idade da paciente é o que relata Sun et al. (2020) mulheres acima de 34 anos a taxa de gravidez é relativamente menor ao se comparar com mulheres mais jovens, deste modo as pacientes diagnostico precocemente possuem maiores chances de engravidar utilizando deste método.

Mesmo a técnica de criopreservação de embriões sendo muito procurada ela é considerada a mais burocrática e consequentemente a mais difícil de ser realizada, pois o método poderá ser utilizado somente após o consentimento por escrito e assinado pelo médico e casal. Neste documento devem conter informações como os riscos e limitações da técnica, sua duração, destino dos embriões doados para outros casais inférteis, doação para estudo, entre outros. (SYDOR, 2019).

Um levantamento realizado por Grangeiro e colaboradores (2020) revelou que o

Sudeste é a região do Brasil que mais utiliza do método de congelamento de embriões, de acordo com dados do SISEMBRIO, 65\% dos casais optam pela técnica principalmente no estado de São Paulo devido aos maiores centros de Reprodução Humana do Brasil, seguido pelo Sul com 14\% de adesão da técnica e em terceiro lugar a região Nordeste com $12 \%$.

\subsection{CRIOPRESERVAÇÕES DE O ÓCITOS}

Outra técnica frequentemente utilizada é a de criopreservação de oócito, geralmente é solicitada quando a paciente decide adiar a gravidez ou por solicitação médica. A porcentagem de chance de ocorrer gravidez por meio desta técnica é quase a mesma que o método natural. A idade da mulher é um fator determinante para a eficiência do procedimento

(CARVALHO, MARTINS, NASTRI, 2017).

A Criopreservação de oócitos pode ser fundamental para mulheres com endometriose que devem ser submetidas à cirurgia. Esse procedimento causa diminuição do hormônio antimulleriano podendo ocasionar dificuldades no processo de reprodução, deste modo, antes de realizar o procedimento o indicado é que médico responsável pelo caso converse com a paciente e sugira uma ação preventiva à criopreservação de alguns dos seus óvulos (CARVALHO, LIMA, 2020).

A técnica também pode ser utilizada em mulheres mais jovens que descobrem o câncer logo no início da doença e devem começar o tratamento oncológico rapidamente. Como relatam Kawwass e 
colaboradores (2020), os quimioterápicos podem dificultar a maturação dos óvulos, deste modo alguns médicos solicitam a criopreservação dos mesmos como uma ação preventiva.

Mesmo a técnica de criopreservação de óvulos ser a mais utilizadas normalmente para mulheres que estão passando por alguma patologia, elas podem ser adaptadas também para mulheres que decidem prorrogar a gravidez por uma vontade pessoal, foi o que revelou um estudo feito por Silva et al, (2015) está se tornando cada vez mais comum mulheres se tornarem mães com 35 a 39 anos, uma faixa etária considerada arriscada para dar início a uma gestação, por esta razão a técnica de criopreservação vem sendo muito utilizada. Ela é capaz de impedir o envelhecimento do ovário preservando os óvulos para que quando a mulher decida se tornar mãe passe por este processo sem enfrentar grandes complicações.

\subsection{CRIOPRESERVAÇÃO DO TECIDO OVARIANO.}

Essa técnica consiste no congelamento do tecido ovariano o qual é retirado através de procedimento cirúrgico minimamente invasivo, este método esta sendo muito utilizado por pacientes oncológicas mais velhas na faixa de 36 a 40 anos que desejam preservar sua fertilidade, pois após dois anos do fim do tratamento quimioterápico, pode ser realizada a reimplantação do enxerto na localização orto ópica localizada sobre a medula do ovário. Esse método reduz os efeitos de apoptose celular facilitando a ligação entre neurônios e, consequentemente, com vasos do hilo contribuindo para a maior vascularização do enxerto e sucesso da técnica, desta forma o tecido recupera sua funcionalidade em algumas semanas, podendo adiantar o processo de fertilização (FREITAS et al., 2011).

Para pacientes com leucemia ou câncer de ovário a técnica não é aconselhável devido ao risco de desenvolvimento de células cancerosas no tecido congelado ser muito alta, nestes casos as pacientes podem optar pelas técnicas de criopreservação de oócitos ou embriões, devendo ser avaliado todo seu histórico clínico antes da realização dos procedimentos (VILAR., 2018).

\section{CONSIDERAÇÕES FINAIS}

Em virtude dos argumentos mencionados o desejo de se tornar mãe é presente na maioria das mulheres, porém muita das vezes esse sonho pode não se realizar devido a complicações causadas por doenças, como endometriose, SOP, infecções sexualmente transmissíveis, câncer, entre outras. Deste modo o processo natural é dificultado, mas o avanço na tecnologia e o desenvolvimento seguro de técnicas de reprodução humana como a criopreservação de embriões, oócitos e tecidos ovarianos 
estão auxiliando casais ao redor de todo mundo no sonho de se tornarem pais, estes métodos podem ser utilizados para preservar a fertilidade de mulheres que estão passando por estas patologias ou que desejam adiar a gravidez por motivos pessoais. Para a realização deste procedimento a paciente deve realizar acompanhamento com especialistas na área de reprodução, pois a técnica utilizada em cada caso deve ser compatível com a clínica da paciente e analisada individualmente para garantir o sucesso do método. 


\section{REFERÊNCIAS}

ALEXANDRE,A; GUIMARÃES,M; RIBEIRO,J. Prevalência e práticas preventivas em infertilidade entre mulheres atendidas em um serviço o público de saúde. Reprod.Clim., v. 28, n. 2, p. 57-60, 2015.

BATISTA,C; BITTENCOURT,B. Reprodução Humana Assistida: Uma Abordagem da Gestação de Substituição no Âmbito Jurídico.Etic., v. 16, n. 16, p. 54-48, 2020.

BEDDOSCHI, G; OKTAY,K. Current approach to fertility preservation by embryo cryopreservation. Fertil Steril. 2013., v. 99, n. 6, p. 1496-1502.

BEDOSCHI,G; NAVARRO, P; OKTAY,K. Chemotherapy-induced damage to ovary: mechanisms and clinical impact. Future Oncol.,v. 12, n. 20, p. 2333-2334, 2016.

BRUCEAG, I; COSTACE,A; PURCAREA,V; CERGAN,R; DUMITRU, M; SANJIN,M; ISPAS,A. Fallopian tubes - literature review of anatomy and etiology in female infertility. J Med Life., v. 8, n. 2, p. 129-131, 2015.

CARVALHO,B; MARTINS,W, NASTRI,C. Há um Momento Ideal Para Uma Mulher Criopreservar seus Oócitos? Femina., v. 45, n. 2, p. 115-118, 2017

CARVALHO,M; LIMA,S. Criopreservação de oócitos no menacme: aconselhamento e indicações. Arq Med Hosp Fac Cienc Med Santa Casa São Paulo., p 65-44, 2020.

CARVALHO. B. Síndrome dos ovários policísticos: particularidades dos manejos da infertilidade. FEMINA., v. 47, n. 9, p. 518-14, 2018.

COUY, I. Implantação da Técnica de Criopreservação de Pré- Embriões Humanos pelo

Método Ultra Rápido., RBGO., v. 24, n. 3, p. 192, 2001.

DUCCINI, E.; MATOS, F.; SILVA, M.; SIQUEIRA, R.; LUNA,V.; ESTEVES, A.

Endometriose uma causa de infertilidade feminina e seu tratamento. UNIFESO., v. 2, n. 2. p. 46-55, 2017.

FARINATI, D. M.; RIGONI, M. S.; MULLER, M. C. Infertilidade: um novo campo da Psicologia da saúde. Estudos de Psicologia., v. 23, n. 4, p. 433-439, 2006.

FICHMAN, V.; COSTA, R. S. S.; MIGLIOLI, T. C.; MARINHEIRO, L. P. F. Associação entre obesidade e infertilidade anovulatória. Publicação Oficial do Instituto Israelita de Ensino e Pesquisa Albert Einstein., v. 18, p. $1-5,2020$.

FREITAS,C; BRANZÃO,K; FARINHA, A; VIEIRA,J; FERREIRA,M. Fertilidade na mulher com doença oncológica, Acta Med Port., v. 24, n. 4, p .881-888, 2011.

GASDA, E. Criopreservação de embriões humanos no contexto da saúde sexual e reprodutiva. Rev. Pistis Pras, Teol. Pastor., v. 7, n. 3, p. 635-661, 2015.

GRANGEIRO,Y; FEITOSA,P; CRUZ,P; MATOS, S; ALMEIDA,B. Reprodução Humana Assistida no Brasil: uma análise epidemiológica., Rev. Interface., v.8, n. 1, p. 437- 444, 2020. 
KAWWASS, J; SHANDLEY, L; BOULET, S; HIPP,H. Oncologic oocyte cryopreservation: national comparison of fertility preservation between women with and without cancer. JAssist Reprod Genet., v. 37, n. 4 , p. $883-839$.

LEAO, J. LINDOSO, Z. Infertilidade feminina: aspectos multidimensionais e a percepção da mulher. Revista Interinstitucional Brasileira Ter. Ocup., v. 4, p. 985-1003, 2020.

LIMA, A; LOURENÇO, J. Infertilidade humana: comentando suas causas e consequências. Saud. Desen.,v. 10, n. 5, p. 110-112, 2016.

LINDSAY, T; VITRIKAS,K. Evaluation and treatment of infertility. Médico Am Fam., v, 91, n. 5, p. 14-308, 2015.

MACHADO, A. P. S. L.; Prevalência da doença celíaca em mulheres com infertilidade. Universidade Federal da Bahia. p. 1-74, 2010.

MOURA, A. P. Sistema Reprodutor Feminino. Escola Bahiana de Medicina e Saúde Pública, Curso de Medicina. p. 3, 2018.

MOURA, B; PENNA, L; LOPES,M; SOARES,W; SOUZA J. Metodos de preservação da fertilidade: revisão de literatura. Braz. J. Surg. Clin. Res., v. 13, n.3, p. 56-64, 2016.

NAN LI,Q; HOU,G; WANG,Z; LIU,Z; SCHATTEN,H; SUN,Q. Glucocorticoid exposure affects female fertility by exerting its effect on the uterus but not on the oocyte: lessons from a hypercortisolism mouse model. Human Reproduction., v. 33, n. 12, p. 2285-2294, 2018.

OLIVEIRA, R; MUSICH,D; FERREIRA, M; VILARIANO, F; BARBOSA,C. Perfil Epidemiológico das Paciente inférteis com Endometriose. Reprao clim., v. 30, n.1, p. 5-10, 2015.

PÉREZ, J. A; MAURER, M. N.; ABREU, M.; PITREZ, L. H.; PELLANDA, R. C.;

MAURER, S. A. C.; FURTADO, A. P. A.; GENRO, C. H. Prevalência de alterações uterinas

e tubárias na histerossalpingografia em mulheres inférteis - estudo de 48 casos. Radiol Bras.,

v. 34, p. 79-81, 2001.

ROMANO, L; BEDOSCI, G; MELO,A; ALBUQUERQUE,F SILVA, A; FERRIANI, R;

NAVARRA, P. Anormalidades Metabólicas em Mulheres com Síndrome dos Ovários

Policísticos obesas e não obesas. Rev Bras Ginecal Obstet., v. 33, n.6, p. 310-6, 2011.

SILVA, F, PINELO, S; PIRES, I; FELGUEIRA,E. Feminine fertility preservation - New challenges. Acta Obstet Ginecol Port., v. 9, n. 2, p. 154-157, 2015.

SYDOR,A. Avaliação da eficiência da criopreservação de sêmen humano com diferentes métodos de envase e curvas de resfriamento. Reprod.Clim., v. 30, n. 5, p. 56-89, 2019.

SHI, Y; DAIMIN, W; LIANG, X; SUN, Y; LIU, J; CAO, Y; ZHANG, B; LEGRO,R; 
ZHANG, H; CHEN, Z. Live birth after fresh embryo transfer vs elective embryo cryopreservation/frozen embryo transfer in women with polycystic ovary syndrome undergoing IVF (FreFro-PCOS): study protocol for a multicenter, prospective, randomized controlled clinical trial. Trials.,v. 15, n. 1, p. 154.

SUN, Y; ZHANG, J; XU, Y; LUO, Z; SUN, Y. HAO, G; GAO, B. Effects of age on pregnancy outcomes in patients with simple tubal factor infertility receiving frozen-thawed embryo transfer. Sci Rep., v. 10, $\mathrm{n}$. 1, p. 2-8, 2020.

TOMBO, T; FEDORSAK, P. Endometriosis-associated infertility: aspects of pathophysiological mechanism and theatment options. Acta Obstet Gynecol Scand ., v. 96, n.6, p. 659-667, 2017.

TSEVAT,D; WIESENFELD, H; PARKS,C; PEIPERT,J. Sexually Transmitted Diseases and Infertility. Am J Obstet Gynecol.,v. 216, n.1, p. 1-9, 2017.

VIER, C. M; MARCH, E. M.; FARACO, A. J. Correlação entre infertilidade e doença celíaca: a melhora da fertilidade após a dieta isenta de glúten. UNESC. p. 1-19, 2018.

VILAR, L; DUARTE,D; LOPES, D; SILVA,J; SILVA,R. Preservação da fertilidade mulheres com câncer de ovário.Revista Brasileira de Inovação Tecnológica em Saúde., v. 8, n. 1, p. 41-50, 2018.

WITKIN,S; MINIS,E; ATHANASIOU,A; LEIZER, J; LINHARESA,I. Chlamydia trachomatis: the Persistent Pathogen. Clin Vaccine ImmunoL., v. 24, n.10, p. 17-2003, 2017 


\section{Capítulo 11}

doi $10.37423 / 211004918$

\section{SINDROME DE RAPUNZEL: TRICOBEZOAR GASTRODUODENAL GIGANTE}

ANA ANGELICA DE ARAUJO MEDEIROS

ALIANDRO WILLY DUARTE MAGALHAES

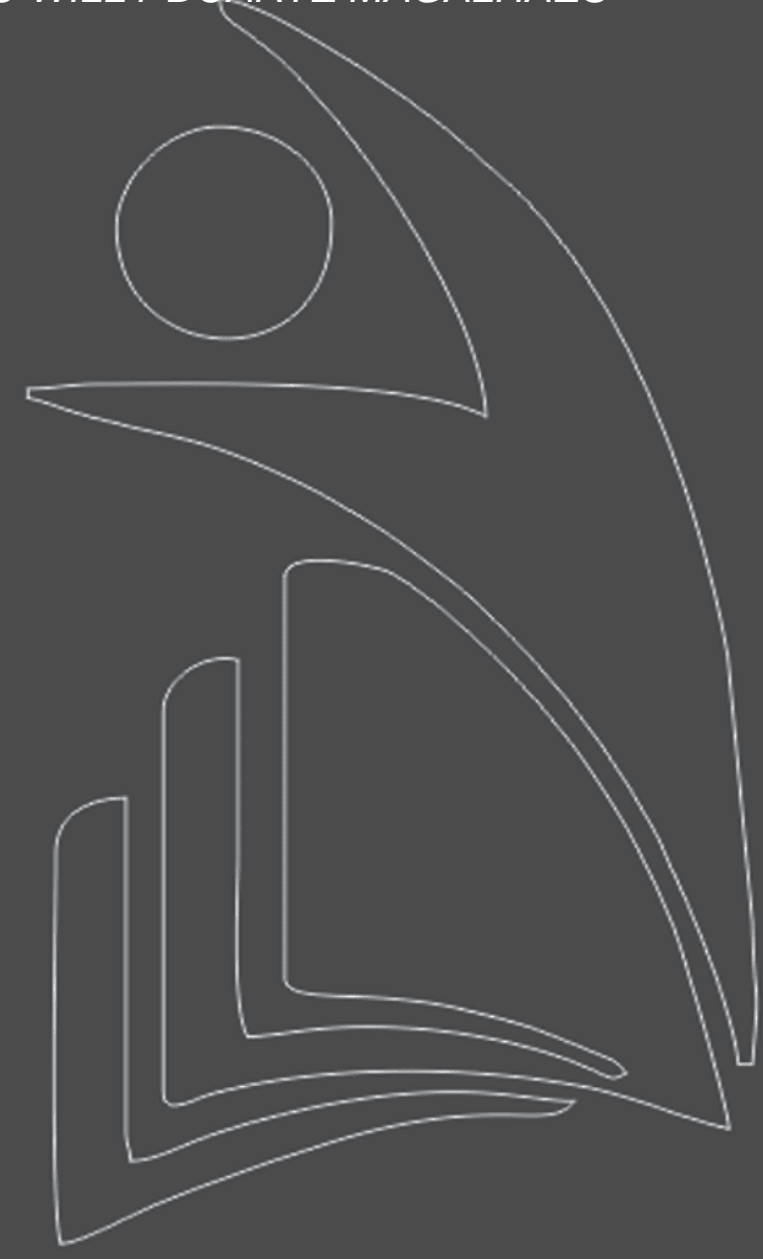

HOSPITAL PORTO DIAS

HOSPITAL PORTO DIAS, 


\section{Síndrome De Rapunzel: Tricobezoar Gastroduodenal Gigante}

Resumo: A Síndrome de Rapunzel é uma forma inusitada de tricobezoar gástrico que se estende até o intestino e adquire a forma de uma cabeça com trança. É composto por pêlos, muco e de restos de alimentos em decomposição. É caracterizada pela localização do corpo do bezoar no estômago e sua calda no intestino. Bezoares são concreções impactadas no trato digestivo resultantes da ingesta de diversas substâncias não digeríveis. Podem chegar a ter grandes proporções como no caso da Síndrome de Rapunzel, levando a complicações como obstrução e perfuração gastrintestinal, apendicite, intussuscepção, anemia, icterícia obstrutiva e pancreatite. Este relato descreve um caso de tricobezoar gástrico na forma de Síndrome de Rapunzel e faz uma análise dessa patologia e revisão da literatura. Os dados foram obtidos por meio de anamnese, exame físico completo e consulta ao prontuário da paciente. Paciente sexo feminino, 17 anos, solteira, parda, brasileira, procedente de Ananindeua- Pará, com alopécia circular e história de há 2 anos ter iniciado quadro de náuseas, vômitos pós-prandiais, anorexia, tumoração epigástrica, perda ponderal de $10 \mathrm{Kg}$, dor e desconforto abdominais, sensação de plenitude. História de assédio sexual e tricofagia desde os 10 anos. A paciente negou a tricofagia. O diagnóstico foi realizado pela endoscopia digestiva alta, cujas proporções justificaram o tratamento cirúrgico. Realizou-se a gastrotomia com remoção de tricobezoar gigante $(32 \mathrm{~cm} \times 11 \mathrm{~cm})$, que pesou 2.700g. Evoluiu bem no pós-operatório; recebeu alta hospitalar no $5^{\circ}$ dia P.O. Reiniciou quadro de tricotilomania e tricofagia um ano após o procedimento cirúrgico. 


\section{Síndrome De Rapunzel: Tricobezoar Gastroduodenal Gigante}

\section{INTRODUÇÃO}

Os cabelos sempre foram venerados em todas as culturas e em todas as épocas. O cabelo é um dos ornamentos mais importante para o homem, por isso passou a ser alvo fácil para manifestações culturais, como cortes, penteados e colorações bizarras, dreadloks, black power, megahair, e, não raro, para comportamentos auto-agressivos e até mesmo psicóticos, como as chamadas tricoses compulsivas, entre elas as mais comuns são a tricotilomania e a tricofagia. ${ }^{1}$

A Síndrome de Rapunzel é uma forma inusitada de tricobezoar gástrico que se estende até o intestino e adquire a forma característica de uma cabeça com trança. ${ }^{2,3}$ Existem poucos casos relatados mundialmente.3.4 É composto por pelos, muco, ácido, pepsina, fragmentos de restos de alimentos em decomposição e colônias bacterianas. ${ }^{2,4} \mathrm{~A}$ síndrome foi descrita pela primeira vez por Vaughan et al. ${ }^{4}$

Essa denominação reporta ao conto dos irmãos Grimm , que escreveram em 1812 sobre Rapunzel, uma jovem que tinha um enorme cabelo e lançava sua trança para seu príncipe subir na torre que se encontrava prisioneira. ${ }^{2,4}$

A síndrome é caracterizada pela localização do corpo do bezoar no estômago e sua calda no intestino delgado ou cólon direito, podendo produzir obstrução intestinal alta ou baixa. ${ }^{2}$

Bezoares são corpos estranhos impactados no trato digestivo resultantes da ingesta de diversas substâncias não digeríveis. Podem chegar a ter grandes proporções como no caso da Síndrome de Rapunzel, levando a graves complicações como obstrução intestinal, perfuração gástrica e intestinal, apendicite, intussuscepção, anemia ferropriva e megaloblástica, icterícia obstrutiva, pancreatite, gastrite crônica, melena, hematêmese, entre outras. ${ }^{1,4,5,6}$

Uma em cada 2000 crianças sofrem de tricotilomania, entre estas, 5 a $18 \%$ de tricofagia, mas poucas apresentam tricobezoares.1 Os tricobezoares são considerados os corpos estranhos mais achados em humanos, os pacientes tem idade inferior a 30 anos em $80 \%$ dos casos, sendo que $90 \%$ desses casos são do sexo feminino. ${ }^{7,8,9,10,11,12,13}$

As manifestações clínicas incluem sintomas abdominais inespecíficos como dor abdominal difusa, hálito fétido, anorexia, náuseas, vômitos e sensação de plenitude gástrica, astenia, perda de peso , gastrite crônica e, com freqüência erosões ou mesmo úlceras pépticas, hematêmese e melena. No exame físico podem ser observadas zonas de alopecia, além de tumoração abdominal, geralmente em 


\section{Síndrome De Rapunzel: Tricobezoar Gastroduodenal Gigante}

epigastro. A diferenciação clínica de neoplasias gástricas e hepatopatias crônicas e bezoares não pode ser feita com rigor. ${ }^{1,3,4}$

Os tricobezoares, em geral são compostos de cabelos do próprio paciente. Outras fontes incluem pêlos de bonecas, pêlos de animais e de tapetes. ${ }^{4,5}$

Alguns fatores predispõem o surgimento de tricobezoares: cirurgias gástricas pregressas, desmotilidade gástrica, motilidade intestinal diminuída, conteúdo aumentado de gorduras da dieta, ingestão de substâncias alcalinas e enzimas pancreáticas, gastroparesia diabética, distrofia miotônica, autovagotomia secundária a invasão tumoral. ${ }^{1,4,5,7}$

O diagnóstico pode ser suspeitado quando há relato da ingestão de corpos estranhos, antecedentes de transtornos psiquiátricos, retardo mental, ou pela observação de locais de alopecia. O estudo radiológico simples ou contrastado mostra falha de enchimento, semelhante a um "tumor transparente". A endoscopia digestiva alta é o método diagnóstico de eleição. A ecografia abdominal e tomografia computadorizada de abdome podem ser utilizadas para maior precisão diagnóstica préoperatória. A gastroscopia fecha o diagnóstico. ${ }^{1,3,4,6,7,8,9,11}$

O tratamento dos bezoares pode ser conservador ou cirúrgico. Indica-se a exérese cirúrgica (laparotomia ou laparoscopia) na falha dos métodos conservadores ou quando o bezoar adquire grandes proporções ou ainda, na vigência de complicações. ${ }^{8,9,11,12}$

No tratamento conservador usa-se a fragmentação e retirada por via endoscópica, litotripsia eletrohidraulica, além de YAG laser. 6,8,9,11,12,14,15,16,17,18

A psicoterapia ou mesmo tratamento medicamentoso com antidepressivos (imipramina, fluoxetina, clomipramine, desipramine), é importante para evitar recidivas, que ocorrem em $20 \%$ dos casos, em pacientes com transtornos psiqiátricos..$^{3,4,6,7}$

O presente relato tem como objeivo descrever um caso de tricobezoar gástrico na forma de Síndrome de Rapunzel, fazer uma análise dessa entidade mórbida e revisão da literatura.

Pela relativa raridade do achado este trabalho pretende encorajar clínicos e cirurgiões para a suspeita diagnóstica, fundamentada no caso clínico aqui descrito.

\section{OBJETIVO}




\section{Síndrome De Rapunzel: Tricobezoar Gastroduodenal Gigante}

Relatar o caso de uma paciente internada no Instituto Ofir Loyola Belem- Pa, portadora de Síndrome de Rapunzel e fazer uma breve revisão da literatura sobre o assunto.

\section{MÉTODO}

Este estudo relata o caso de um paciente portadora de Síndrome de Rapunzel, internada no Instituto Ofir Loyola.

O trabalho foi autorizado pelo diretor do Departamento de Ensino e Pesquisa do Hospital Ofir Loyola. O Núcleo de Pesquisa e Extensão em Medicina (NUPEM), da Universidade do Estado do Pará, autorizou a realização deste trabalho.

Os responsáveis pela paciente concordaram com o termo de consentimento livre e esclarecido.

Os dados foram obtidos por meio de anamnese, exame físico completo e revisão do prontuário do paciente.

Os exames complementares foram realizados no Hospital Ofir Loyola.

Realizou-se pesquisa bibliográfica através de livros e periódicos indexados, além de consultas em bancos de dados da Internet.A pesquisa norteou-se eticamente segundo a "Declaração de Helsinki V", "Código de Nuremberg" e "Código de Ética Médica".

\section{REVISÃO DA LITERATURA}

A Síndrome de Rapunzel é uma forma rara de bezoar gástrico que se estende até o intestino, ou seja, é uma evolução do bezoar não tratado e está associado a tricotilomania e tricofagia. É composto de cabelos, muco e fragmentos de alimentos em decomposição. Ocorre mais freqüentemente em mulheres de 15 a 20 anos com distúrbios psiquiátricos. ${ }^{1,2}$

O nome da síndrome reporta ao conto escrito em 1812 pelos irmãos Wilhelm e Jacob Grimm sobre uma moça chamada Rapunzel. Ela lançava sua grande cabeleira para seu príncipe subir até a torre que se encontrava presa. A síndrome foi descrita pela primeira vez em 1968 por Vaughan et al, que relataram os dois primeiros casos, em que foram acometidas duas garotas de 13 e 15 anos. ${ }^{1,3,4,5}$

Bezoar significa a concreção de material deglutido e não digerido2,13 que pode ser encontrado no estômago e, raramente no intestino delgado ou 


\section{Síndrome De Rapunzel: Tricobezoar Gastroduodenal Gigante}

grosso de homens e de outros animais como gatos, porcos, coelhos, ovelhas, ratos, cães, cavalos, etc. 5,7,11,13,14 O nome deriva do termo árabe badzehr, persa padzahr (pad= proteção; zahr= tóxico) ou turco panzehir e significa proteção contra veneno, antitóxico, antídoto. 5,6,7,12,13,15,17,18

Dentro da história da medicina, os bezoares estão envolvidos por misticismo e conceitos bizarros. ${ }^{6,12.16}$ Eram muito apreciados por suas propriedades medicinais mágicas contra diversos males como a velhice, impotência, epilepsia, lepra, picadas de cobras, pragas e espíritos do mal. ${ }^{6,8,12,16}$ Eram conhecidos pelos Hindus, já no século XII a.C.14 Eram tão preciosos que um bezoar banhado a ouro foi incluído num inventário das jóias da Rainha Elizabeth em 1922. ${ }^{3,16}$ Até meados do século 18 eram listados na Farmacopéia de Londres como remédio para todos os males e pragas. À medida que a medicina foi evoluindo, os seus poderes mágicos foram gradativamente se perdendo, tendo, hoje além do seu aspecto bizarro, significado apenas para a área da saúde. ${ }^{6}$

Contudo, mais do que uma mera curiosidade médica, quando encontrados no homem, os bezoares representam problemas médicos graves e que podem levar a complicações importantes. ${ }^{6,16}$

O primeiro estudo científico dos bezoares foi realizado pelo médico persa Mahamud Bin Masud, no século XVI. ${ }^{1,3,7,13}$ O primeiro bezoar humano, um tricobezoar foi descrito por Baudamant em 1779, num achado ocasional de autópsia de uma paciente portadora de tricobezoar. ${ }^{2,6,7,8,10,13,14,16} \mathrm{Em} 1883$, Schonborn, fez a primeira remoção cirúrgica de um bezoar. ${ }^{2,3,10,13,14}$ De Backey \& Oschner, em 1938, descreveram a maior série de tricobezoares publicada até o momento, com 303 casos. ${ }^{6,7,14}$

Essas concreções são encontradas mais frequentemente no estômago de certos indivíduos: crianças (ingerem geralmente corpos estranhos como botões, alfinetes de fralda, bolas, medalhas, com as quais brincavam); psicóticos, 5 gestantes com perversão do apetite; presidiários que fingem estarem doentes (ingerindo vários objetos); estofadores; exibicionistas de circo e de praças públicas que engolem faca, pregos, lâminas de barbear, tachas; costureiras (ingerem botões); faquires profissionais (ingerem agulhas ou pregos); carpinteiros e tapeceiros. Nos portadores de hipotonia gástrica pode haver formação de concreções com contrastes radiológicos. ${ }^{4,7,9,12}$

Os bezoares são classificados de acordo com sua composição. Os tipos principais são: tricobezoar (cabelos ou pêlos), fitobezoar (fibras ou sementes vegetais), mistos (tricofitobezoar), contudo outros tipos são descritos na literatura como:farmacobezoar (medicamentos), lactobezoar (leite artificial), litobezoar (cimento, areia e pedras), himantobezoar (cordão de sapato) e outras concreções como plástico, resina, alcatrão, asfalto, bezoar por ascaris, bezoares de leveduras, $5,6,7,8,9,12,15,16,18$ bezoar por algodão ${ }^{9,13}$ e até mesmo dentaduras. ${ }^{9}$ 


\section{Síndrome De Rapunzel: Tricobezoar Gastroduodenal Gigante}

Os tricobezoares aumentam de tamanho não só pela ingestão de cabelos ingeridos; formam uma mexa de cabelo junto com o muco, restos alimentares e colônias bacterianas. O crescimento pode ser lento e gradual, mas também podem chegar a ocupar todo o volume do estômago, tomando o molde do órgão. ${ }^{4,5,6}$

Os tricobezoares, em geral são compostos de cabelos do próprio paciente. Outras fontes incluem pêlos de bonecas, pêlos de animais e de tapetes. São sempre pretos independentes da cor do cabelo do paciente devido a desnaturação proteica pelo ácido do suco gástrico; possuem odor fétido, que emana principalmente da gordura não digerida da dieta e da colonização bacteriana. ${ }^{19}$ Uma grande bola de pode estar presente durante anos numa fase assintomática, aumentando lentamente para finalmente tornar-se molde em forma de J do estômago. 4,5,6,7,8,9,15,16

Não existe um período definido entre o começo da tricofagia e o início dos sintomas. Esse período pode ser de até 15 anos.2 Geralmente são formações únicas, mais raramente múltiplas, com peso e dimensões variadas. Existem relatos de tricobezoares até $3.250 \mathrm{~g} .{ }^{2,6,8,9} \mathrm{~A}$ síndrome pode ser insidiosa por anos e dramaticamente tornar-se aguda, geralmente na presença de complicações. ${ }^{20}$

A patogenia da doença ainda não foi totalmente esclarecida, mas acredita-se que alguns fatores poderiam predispor o estômago a uma incapacidade de propulsar e desembaraçar os cabelos. ${ }^{4,5,12}$ Os fatores predisponentes seriam: cabelos longos,5,8 má formação gástrica,9 mastigação deficiente, desmotilidade gástrica, diminuição do PH gástrico, alterações da mucosa e da secreção ácida, ingestão de substâncias alcalinas e de enzimas pancreáticas, dieta gordurosa, cirurgias gástricas pregressas, ${ }^{11,21}$ gastroparesia diabética, distrofia muscular, câncer gástrico, uso crônico de cimetidina, hipotireoidismo, ${ }^{6,9,12}$ neuropatia alcoólica e uso de opiáceos. ${ }^{8}$

A fisiopatogenia da Síndrome de Rapunzel é dada pela presença de cabelo no estômago que se entrelaçam nas pregas gástricas e são retidos por uma insuficiente superfície de atrito necessária para a propulsão, formando uma grande massa de cabelos que atua como uma âncora e que emite uma projeção através do piloro até o intestino delgado. ${ }^{4,5,8}$

Não existe sintomas ou sinais típicos dessa entidade, contudo podem aparecer características comuns a todos os bezoares: massa abdominal, sintomas gastrointestinais inespecíficos como dor abdominal generalizada, náusea, anorexia, sensação de plenitude gástrica, hematêmese, distensão abdominal, desconforto abdominal relacionado à alimentação. $5,6,7,8,9,11,12,13,14$ 


\section{Síndrome De Rapunzel: Tricobezoar Gastroduodenal Gigante}

Podem ocorrer anemia, alopecia circular, presença de sangue oculto nas fezes, astenia, perda de peso, mal estar geral, halitose. Os sintomas dependem da elasticidade do estômago, do tamanho do bezoar e da presença de complicações. . $, 6,7,8,9$

A síndrome de Rapunzel por si só já é uma complicação de tricobezoar, contudo podem ocorrer outras complicações associadas ou isoladas conforme mostra a figura 1.

\begin{tabular}{|l|l|}
\hline \multicolumn{1}{|c|}{ Complicações relatadas } & \multicolumn{1}{c|}{ Autores referenciados } \\
\hline Obstrução gastrointestinal & $(4)(5)(6)(7)(8)(9)(13)(14)(15)(16)(18)$ \\
\hline Migração & $(2)(6)(13)$ \\
\hline Síndrome de Rapunzel & $(3)(5)(6)(7)(8)(10)$ \\
\hline Úlcera gástrica ou intestinal & $(2)(4)(9)(12)(14)(19)(29)$ \\
\hline Perfuração gástrica ou intestinal & $(1)(3)(4)(5)(6)(7)(9)(12)(16)(28)$ \\
\hline Apendicite & $(2)(6)(13)(16)(18)$ \\
\hline Intussuscepção & $(2)(6)$ \\
\hline Anemia megaloblástica & $(4)(6)(13)$ \\
\hline Anemia ferropriva & $(6)(24)(25)(26)(27)(31)$ \\
\hline Icterícia obstrutiva & $(4)(6)(8)(18)$ \\
\hline Gastroenteropatia, perda protéica e & $(2)(4)(6)(8)(16)(27)(31)$ \\
esteatorréia & \\
\hline Pancreatite & $(2)(6)(7)$ \\
\hline Gastite crônica & $(6)$ \\
\hline Câncer gástrico & $(6)(16)$ \\
\hline Outras complicações (peritonite, & $(2)(4)(6)(7)(9)(12)(14)(16)(18)$ \\
\hline sangramento, pneumatose) & \\
\hline
\end{tabular}

FIGURA 1- complicações de tricobezoar relatadas e autores correspondentes

Uma em cada 2000 crianças sofrem de tricotilomania,2,5,8 destas, 5 a 18\% de tricofagia, mas poucas apresentam tricobezoares. 2

Dificilmente o paciente, adulto ou criança admite a hipótese de tricofagia. ${ }^{1,2,4,5,7}$ Geralmente o paciente não quer consultar o médico por apresentar tricotilomania e sim pelos sintomas gastrintestinais. Na maioria das vezes é o acompanhante que dá importância à doença. ${ }^{1}$ 


\section{Síndrome De Rapunzel: Tricobezoar Gastroduodenal Gigante}

Tricotilomania é o ato compulsivo de extrair os cabelos e pode estar associada a transtorno psiquiátrico e lesões dermatológicas no couro cabeludo, por isso deve ser avaliada e tratada por especialistas. Freqüentemente é acompanhada de tricofagia. ${ }^{1,2,22}$

A tricofagia é o ato compulsivo de engolir os cabelos e está associada à perversão do apetite e psicoses graves. Em $90 \%$ dos casos ocorrem em mulheres de cabelos longos, $80 \%$ desse percentual são menores

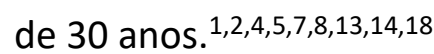

Sempre que houver um quadro de tricotilomania, deve-se lembrar que ele pode estar ingerindo os cabelos, podendo ocorrer a formação de tricobezoar. ${ }^{1,22}$

O diagnóstico da síndrome deve ser feito por meio de uma anamnese cautelosa, investigando-se (inclusive com familiares), hábito de tricofagia, ou presença de cabelos no vômito ou em material fecal. ${ }^{5,8}$ O exame físico denota algum comprometimento do estado geral e pode revelar alopecia. ${ }^{11}$ Exames de imagem auxiliam na visualização do tricobezoar. O exame físico deve começar pela boca em busca de cabelos. Deve-se procurar também áreas de alopecia. No exame do trato gastrointestinal, observa-se a formação de tumoração epigástrica em mais de 80\% dos tricobezoares; a palpação dessa tumoração algumas vezes é acompanhada de creptações. ${ }^{6,9,16,19}$

Radiografia simples de abdômem pode sugerir a presença de bezoar. Ecografia abdominal, radiografia com bário, tomografia computadorizada abdominal e gastroscopia auxiliam muito no diagnóstico. A endoscopia digestiva alta fecha o diagnóstico. ${ }^{2,4,5,6,7,8,12,15,16,19,23,24,25}$ A gastroscopia é a melhor técnica para diagnosticar e classificar os bezoares segundo alguns autores. ${ }^{2,7,16}$

O objetivo do tratamento é a remoção do bezoar e a prevenção de recidivas, que ocorrem em aproximadamente $20 \%$ dos casos. ${ }^{2,4,15}$ A mortalidade no tratamento cirúrgico é em torno de 5\%.2,5

O tratamento dos tricobezoares, quando pequenos pode ser feito de forma conservadora, contudo, no não sucesso dos métodos conservadores e quando atingem grandes proporções ou em casos de complicações deve ser cirúrgico, ${ }^{26,27,28,30}$ por meio de gastrotomia, e em alguns casos, enterotomia por via abdominal anterior. ${ }^{2,4,5,6,7,13,18}$ A gastrotomia deve ser longitudinal, suficientemente ampla para permitir o parto do bezoar, observando o estado da mucosa gástrica para que não restem fragmentos de pêlos nas pregas gástricas. ${ }^{2}$

Tem-se relatado diferentes métodos endoscópicos para tratamento dos tricobezoares, inclusive fragmentação a laser Nd: YAG,2 fragmentação endoscópica, litotripsia eletrohidráulica ou litotripsia extracorpórea com ondas de choque, ${ }^{2,4,5,6,13,15}$ fragmentação e remoção com pinças do tipo fórceps ou 


\section{Síndrome De Rapunzel: Tricobezoar Gastroduodenal Gigante}

com alças de polipectomia, utilizações de jatos d'água pulsáteis (sistema water pik) para fragmentar o bezoar.6,8 A eliminação endoscópica é mais demorada , necessitando de várias sessões. ${ }^{2,4,5}$

Wang et al (1998)29 relatam o uso endoscópico do bezótomo e do bezotriptor nos grandes bezoares de todos os tipos e afirmam que bezoares sólidos grandes podem ser tratados sem necessidade de cirurgia.

Nirasawa et al (1998)10 e Yao et al (2000)26 relatam com sucesso a retirada de grandes tricobezoares por laparoscopia, enfatizando o aspecto estético da mesma10 e pós-operatório menos doloroso,26 porém alerta para as desvantagens deste procedimento: alto custo e cirurgia demasiadamente demorada. ${ }^{10}$

Dos método endoscópico, a litotripsia eletrohidréulica tem se mostrado um método rápido de ser realizado e praticamente isento de complicações segundo Kuo et all (1999) ${ }^{15}$

O tratamento no pós-operatório deve abranger medicação gastroprotetora e tratamento psiquiátrico.2 Métodos como psicoterapia, hipnose e terapia comportamental ou uso de fármacos (clomipramina, desipramina, fluoxetina, sertralina e citalopram) tem sido tentados para o tratamento.

\section{RELATO DO CASO:}

Identificação: 18 anos, sexo feminino, solteira, parda, evangélica brasileira, procedente de Ananindeua- Pará.

História da doença atual: paciente admitida no Hospital Ofir Loyola (HOL) em fevereiro de 20014, com queixa de ter iniciado há aproximadamente 2 anos quadro de náuseas, vômitos pós-prandiais, anorexia, tumoração epigástrica, e há um ano apresentado perda ponderal de $10 \mathrm{Kg}$, dor abdominal difusa em cólica de moderada intensidade, que melhorava espontaneamente ou com o uso de medicação antiespasmódica, mal estar geral, astenia, desconforto abdominal, constipação intestinal. Associado ao quadro referia sensação de plenitude gástrica e aumento de tamanho da tumoração epigástrica.

Procurou atendimento médico, sendo encaminhada ao serviço de cirurgia geral do HOL. Foi internada neste serviço em fevereiro de 20014.

Antecedentes pessoais: paciente vítima de assédio sexual aos 7 anos, trauma por agressão física e outro episódio de assédio sexual aos 10 anos. Mãe relata que a paciente tinha os cabelos compridos e iniciou ingestão de cabelos (tricofagia) a partir do último episódio de assédio sexual aos 10 anos, 


\section{Síndrome De Rapunzel: Tricobezoar Gastroduodenal Gigante}

apresentando alopécia visível a partir dos 15 anos. Nega internações anteriores.Nega diabetis, tabagismo, etilismo ou uso de entorpecentes.

Exame físico: paciente em regular estado geral, hidratada, regular estado de nutrição, palidez cutâneo mucosa $(++/ 4)$, lábil emocionalmente, afebril, anictérica, acianótica, sem adenomegalias. Não apresentava gânglios palpáveis. Apresentava todos os pulsos palpáveis, similares com o homônimo. Funções de eliminação presentes e normais. Apresentava alopecia circular em região occipital Sinais vitais: PA: $100 / 60 \mathrm{mmHg}$; FC: $100 \mathrm{bcpm}$; FR: $18 \mathrm{irpm} ; \mathrm{T}: 36.5^{\circ} \mathrm{C}$.

Aparelho respiratório: inspeção: tórax de conformação normal, compatível com o biótipo. Ausência de abaulamentos ou retrações. Respiração predominantemente torácica. Freqüência respiratória: 20 mrpm; palpação: frêmito tóraco-vocal e amplitude respiratória normal; percussão: som claro pulmonar; ausculta: murmúrio vesicular fisiológico preservado bilateralmente, ausência de ruídos adventícios. Broncofonia normal.

Precórdio: inspeção: ausência de abaulamentos ou retrações; ausência de circulação colateral. Ictus cordis não visível; palpação: Ictus cordis palpável; ausculta: bulhas cardíacas rítmicas, normofonéticas, em dois tempos, sem sopros; freqüência cardíaca: 100 bpm.

Abdome: inspeção: abdome com abaulamento em região epigástrica. Ausência de cicatrizes ou estrias. Distribuição feminina de pêlos. Ausência de circulação colateral. Cicatriz umbilical normoposicionada; palpação: presença de massa palpável em epigastro, levemente dolorosa, móvel, endurecida, de limites imprecisos, com aproximadamente $25 \mathrm{~cm}$ de diâmetro. 0 fígado era palpável na altura do rebordo costal direito, com características normais; ausculta: ruídos hidroaéreos presentes; ausência de sopros.

Sistema Nervoso: consciente, orientada em tempo e espaço. Sem déficit motor. Sem sinais meníngeos. Todos os reflexos fisiológicos presentes. Foi detectado na avaliação clínica inicial distúrbio psicológico pois a paciente negou durante a primeira consulta e durante a intenação qualquer fato relacionado à ingestão de cabelos, todavia, a mãe da paciente relatou que a filha sofria de tricotilomania desde os 10 anos e foi percebido alopecia desde os 15 anos.

Exames Complementares: 


\section{Síndrome De Rapunzel: Tricobezoar Gastroduodenal Gigante}

\section{ENDOSCOPIA DIGESTIVA ALTA:}

Grande quantidade de cabelo ocupando todo o estômago, impedindo a adequada realização do exame e impossibilitando a ultrapassagem do aparelho através do piloro.

\section{TOMOGRAFIA COMPUTADORIZADA DE ABDOME:}

Hipotonia associada à gastrectasia com acentuado resíduo intra luminal, configurando características compatíveis com fitobezoar ou tricobezoar, e associada à distensão gasosa no intestino grosso.

Realizados exames hematológicos: hemácias: 3,87g/dL; hemoglobina: 11,1g/dL; hematócrito: 33,2\%; VCM: 85,78\%; HCM: 28,68\%; CHCM: 33,93\%; leucograma dentro da normalidade. Coagulograma sem alterações

O diagnóstico de tricobezoar gástrico foi confirmado pela endoscopia digestiva alta e cujas proporções justificavam o tratamento cirúrgico.

\section{CONDUTA ADOTADA}

A paciente foi submetida a gastrotomia anterior, com remoção de um volumoso tricobezoar, medindo $32 \times 11 \mathrm{~cm}$, o qual moldava todo fundo, corpo e antro gástricos. Ao exame macroscópico da massa, a mesma apresentava-se endurecida, com odor fétido, pesando $2700 \mathrm{~g}$, sendo constituída exclusivamente de cabelos, como mostra a FIGURA 2

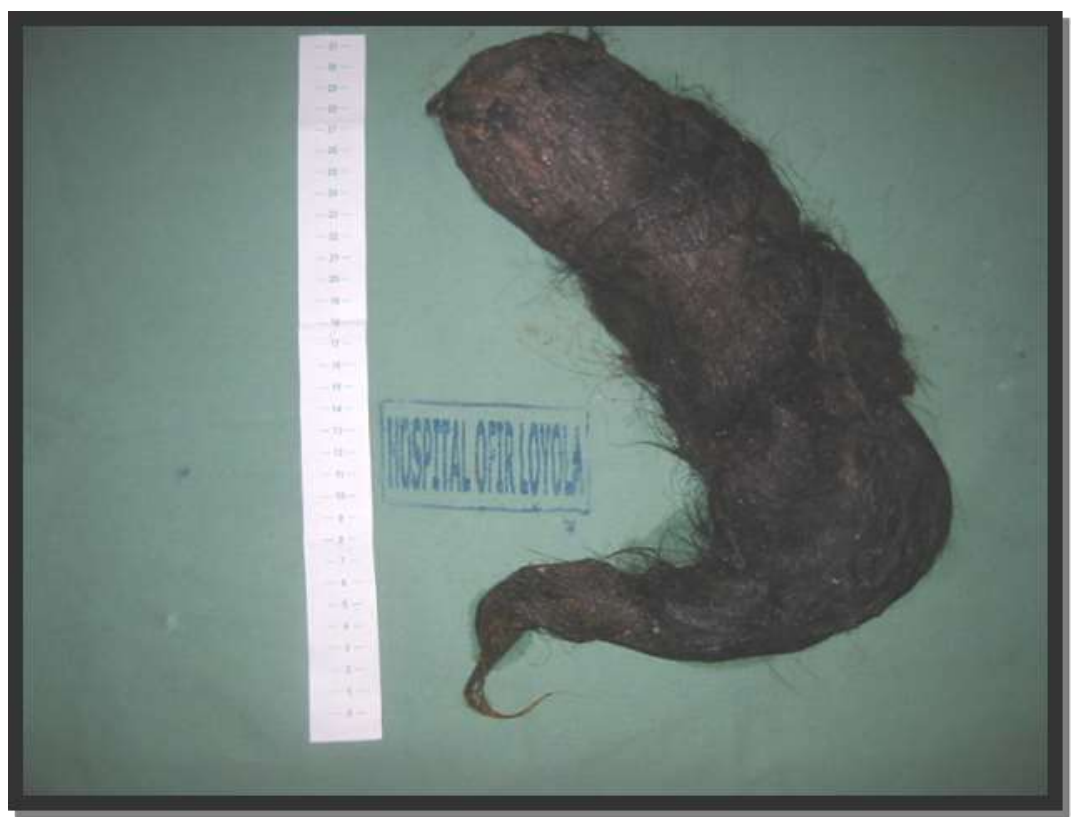

FIGURA 2- Peça cirúrgica capturada mostrando tricobezoar gastroduodenal gigante medindo 32 $\mathrm{X} 11 \mathrm{~cm}$, pesando $2.700 \mathrm{~g}$. 


\section{Síndrome De Rapunzel: Tricobezoar Gastroduodenal Gigante}

\section{EVOLUÇÃO:}

A paciente evoluiu sem intercorrências no pós-operatório, iniciando alimentação no 3 o dia pósoperatório (PO) recebendo alta hospitalar no 5o dia P.O. No domicílio ainda foi medicada com 300 mg de ranitidina/dia durante 30 dias e, também, encaminhada ao Serviço de Psiquiatria da Fundação Hospital de Clínicas Gaspar Viana para acompanhamento. A paciente não compareceu para consulta com o psiquiatra.

Paciente reiniciou quadro de tricotilomania e tricofagia um ano após o procedimento cirúrgico, apresentando novamente alopecia em região occipital.

\section{DISCUSSÃO}

Tricobezoares são os corpos estranhos mais comumente encontrados no estômago do homem. ${ }^{10,22}$ São mais freqüentes em mulheres (90\%) e relatados em pessoas jovens com menos de 30 anos (80\%). Tal fato também foi descrito por autores como Vilchez et al (2002)4 e Arbelo et al (20012) ${ }^{8}$, sendo reafirmado neste trabalho.

Neste relato, o caso ocorreu no sexo feminino, numa adolescente com história de fortes traumas psicológicos na infância.

Muitos pacientes portadores de tricobezoares, possuem distúrbios da personalidade, componente depressivo não tratado e conflitos familiares determinando a tricofagia. ${ }^{4,16,18}$

O estresse psicossocial vigente no cotidiano, assim como os dois episódios de assédio sexual e a agressão física sofrida pela paciente foram fatores certamente determinantes no início do quadro de tricotilomania, contudo provavelmente poderiam ter sido amenizados se houvesse uma iniciativa de fazer acompanhamento psicológico após esses episódios, o que não ocorreu.

Spadella et al $(1998)^{6}$, Gutiérrez (2000)20 e Huggins et al $(1999)^{9}$, referem tempo de um a quatro meses de início desses sintomas, mas a paciente teve um longo período de sintomas gastrointestinais até a realização do procedimento cirúrgico, aproximando-se mais dos relatos de Loja et al (2003)2 e, que relatou um caso que os sintomas duraram 4 anos.

A demora no tempo entre a primeira consulta e a internação contribuiu na prorrogação do quadro. Isso se deveu às dificuldades existentes no Sistema Único de Saúde, no que diz respeito ao tempo 


\section{Síndrome De Rapunzel: Tricobezoar Gastroduodenal Gigante}

transcorrido entre o pedido de internação e a realização da mesma, que neste caso foi de aproximadamente seis meses.

A sintomatologia presente na paciente era muito rica no aparelho gastrointestinal e juntamente com o exame físico sugeriram o diagnóstico desde o início. Todos os sintomas e sinais referidos concordaram com a descrições feitas por Pereira $(2003)^{1}$, Loja et al (2003)2, Vilchez et al $(20012)^{4}$ e Gutiérrez $(2000)^{20}$.

Presumia-se, pelo quadro clínico e pela endoscopia, uma anemia moderada ou intensa, pois há dois anos existia a queixa de vômitos pós-prandiais e anorexia , mas a análise hematimétrica revelou uma discreta anemia com hemoglobina de $11,11 \mathrm{~g} / \mathrm{DI}$, fato até mesmo inesperado e discordante com os relatos de Loja et al (2003)2 e Arauz et al (2003)

O início da tricotilomania ocorreu desde os 10 anos, segundo relatos da mãe da paciente, entretanto, o início da tricofagia foi uma variável que não pode ser determinada, pois a paciente a negou, mesmo após ter sido confirmado o diagnóstico. Essa negação dos sintomas também foi referida por Pereira (2003)1, Loja et al (2003)2, Vilchez et al (2002)4 e Spadella et al (1998) ${ }^{6}$.

A tricotilomania é um transtorno compulsivo, tornou a paciente em questão uma candidata ao tratamento psiquiátrico, e, justificou a labilidade emocional presente durante a internação.

O diagnóstico diferencial, neoplasia abdominal, foi cogitado antes da confirmação diagnóstica pela endoscopia, pois os achados de perda ponderal, astenia e massa abdominal dolorosa estavam presentes no exame inicial.

A Endoscopia digestiva alta foi de difícil realização pois existia uma massa de cabelos muito volumosa, fato este que impediu a passagem do aparelho pelo piloro.

A não existência, no HOL, de métodos conservadores para a eliminação do bezoar, a grande dimensão do mesmo e a presença de complicação-Síndrome de Rapunzel-, determinaram a escolha da conduta , que foi o procedimento cirúrgico.

A massa obtida da cirurgia mostrou características compatíveis com os achados obtidos por Loja et al $(2003)^{2}$.

A evolução pós-operatória foi relativamente satisfatória, excluindo-se a recidiva de tricotilomania que ocorreu sem dúvida pela ausência de tratamento psiquiátrico após a cirurgia. 


\section{Síndrome De Rapunzel: Tricobezoar Gastroduodenal Gigante}

\section{CONCLUSÃO}

Os tricobezoares são concreções de cabelos localizadas no estômago e que mantém íntima relação com a tricofagia. O típico portador dessa entidade é um individuo jovem, menor de 30 anos, do sexo feminino, que apresenta alopécia e uma massa móvel em epigastro,com patologia psiquiátrica associada.

Quando, a partir da tumoração principal no estômago, existe a formação de uma calda que se estende até o intestino delgado, o tricobezoar passa a denominar-se Síndrome de Rapunzel.

O quadro clínico inclui dor abdominal, hiporexia, perda de peso, náuseas, vômitos pós-prandiais, halitose, sensação de plenitude gástrica, associada à anemia, podendo complicar-se com obstrução e perfuração gastrintestinais, apendicite, pancreatite, icterícia obstrutiva entre outras.

O diagnóstico é dado através da endoscopia digestiva alta e o tratamento pode ser conservador ou cirúrgico.

A suspeita diagnóstica deve sempre ser suspeitada indivíduos com tricofagia ou alopécia, especialmente quando existe evidência de comportamentos fora dos habituais. 


\section{Síndrome De Rapunzel: Tricobezoar Gastroduodenal Gigante}

\section{REFERÊNCIAS}

1. Pereira JM. Tricoses compulsivas. Anais brasileiros de dermatologia. 20013; 79(5):609-18

2. Loja D, Alvizuri J, Vilca M, Sánchez M. Síndrome de Rapunzel: tricobezoar gastroduodenal. Anales de la Faculdad de Medicina (Perú) 20013; 64(1):71-7

3. Santos Filho PAB, Oliveira M, Evangelista GM, Eiras J. Relato de caso de tricobezoar gastrintestinal. Rev Col Bras Cir. 20013; 30 (supl.1): 457.

4. Vilchez WHC, Vega R, Abriojo C. Síndrome de Rapunzel: reporte de un caso y revisión de la literatura. Rev. Gastroenterol. Perú 20012; 22(2):168-172.

5. Arauz MA, Gutiérrez FR, Mena CH. Síndrome de Rapunzel: reporte de um caso. Acta Médica Costarricense 2003; 45(2): 80-3.

6. Spadella CT, Saad-Hossne R, Saad LHC. Tricobezoar gástrico: relato de caso e revisão da literatura. Acta Cir. Bras. 1998; 13(2):110-5.

7. Zeni Neto C, Coelho JCU, Campos ACL, Malafaia O, Salvalaggio PRO. Perfuração gástrica secundária a tricobezoar gigante: descrição de caso e revisão da literatura. Rev Col Bras Cir 1997; XXV(2): 144-6.

8. Arbelo TF, Fragoso EL, Lorenzo TD. Bezoares. Rev Cubana Pediatr 2002; 74(1):77-82.

9. Huggins DW, Medeiros LB, Farias Júnior HA, Melo SA, Tenório KPF. Tricobezoar gástrico: relato de um caso. Rev. Bras. Med. 1999; 56(1/2),jan.-fev.:57-9.

10. Nirasawa BY, Mori T, Ito $\mathrm{Y}$, Tanaka H, Seki N, Atomi Y. Laparoscopic removal of a larg gastric trichobezoar. Journal of Pediatric Surgery 1998; 33(4):663-5.

11. Tannuri U. Estômago e duodeno: bezoar, perfurações, tumores, volvo. In: Barbieri D, Koda Y-KL. Doenças Gastrenterológicas em Pediatria . São Paulo: Atheneu, 1996. p.141-2.

12. Bicalho SA. Divertículos, vólvulo, dilatação gástrica aguda, corpos estranhos (bezoares), infecções crônicas e outras doenças raras. In: Dani R, Castro LP. Gastroenterologia Clínica. 3a ed. Rio de Janeiro: Guanabara Koogan, 1993. p.618-9.

13. Coelho JCU, Madureira Filho D. Bezoar. In: Coelho JCU. Aparelho Digestivo: Clínica e Cirurgia. 2a ed. Rio de Janeiro: Medsi, 1996. p.321-3.

14. Tolosa EMC, Sakaki M, Ferreira EAB, Margarido NF, Behmer OA, Zanotto A, e col. Fitobezoar experimental e perda peso em ratos. Rev Hosp. Clín. Fac. Med. S. Paulo 1998; 43(2): 87-92.

15. Kuo J-Y, Mo L-R, Tsai C-C, Chou CY, Lin R-C, Chang K-K. Nonoperative treatment of gastric bezoars using eletrohydraulic lithotripsy. Endoscopy 1999; 31(5): 386-8.

16. Raffin SB. Bezoares. In: Sleisenger MH, Fordtran JS. Doenças Gastrointestinais: fisiopatologia, diagnóstico, tratamento. 4a ed. Rio de Janeiro: Guanabara Koogan, 1991. p.629-633. 


\section{Síndrome De Rapunzel: Tricobezoar Gastroduodenal Gigante}

17. Silva FG, Gonçalves C, Vasconcelos H, Cotrim I. Endoscopic and enzymatic treatment of gastric bezoar with acetylcysteine. Endoscopy 2002; 34: 845.

18. Sánchez BV, Esteban RMP. Tricobezoar: um problema psicológico. Anales Españoles de pediatría 2001; 55(4): 383-4.

19. Llerena RP, Gómez JG, Sandi KP. Tricobezoar: presentación de u caso clínico. Rev. Soc. Boliv. Pediatr. 2002; 41(1):15-7

20. Gutiérrez JO. Tricobezoar gástrico. Rev. colomb. cir..2000; 15(1):55-9.

21. White NB, Gibbs KE, Goodwin A, Teixeira J. Gastric bezoar complicating laparoscopic adjustable gastric banding, and reviwe of literature. Obesity Surgery 20013; 13 : 948-950.

22. Ians CE, Azulay DR, Azulay RD. Psicodermatologia. In: Azulay RD, Azulay DR. Dermatologia. 3ạ ed. Rio de Janeiro: Guanabara Koogan, 20014.p.477.

23. Henriques AC, Pezzolo S, Godinho CA, Gomes M, Speranzini MB. Tricobezoar gástrico. Arq. méd. $A B C .2016 ; 23(1 / 2): 6-8$.

24. Fernandez A, Cuba H, Parhuana A, Valcarcel M. Tricobezoar a propósito de un caso em el Hospital Nacional Dos de Mayo. An. Fac. Méd. (Peru). 1995; 56(1):54-6.

25. Romano JFH, Miguel MO, Mejía NPB, García JAJ. Tricobezoar en pediatria: presentación de un caso. 1999; 6(33):228-33.

26. Yao C-C, Wong H-H, Chen C-C, Wang C-C, Yang C-C, Lin C-S. Laparoscopic removal of larg gastric phytobezoars. Surgical Laparoscopy, Endoscopy \& Percutaneous Techniques 2000; 10(4): 2435.

27. Nóbrega CG, Maciel RM, Leal GN, Duarte CSLG, Nóbrega JCA. Tricobezoar gástrico. Rev. bras. cienc. Saúde. 2001; 5(1):93-8.

28. Cabrera M, Batista M, Otero H, Rivas A, Solano N, Indiana B. Tricobezoar gástrico: a propósito de un caso. $1997 ; 58(3): 52-4$.

29. Wang YG, Seitz U, Li ZL, Soehendra N, Quiao XA. Endoscopic management of huge bezoars. Endoscopy 1998; 30(4): 371-4.

30. Bakos L, Marchiori R, Azulay RD. Afecções dos pêlos. In: Azulay RD, Azulay DR. Dermatologia. 3a ed. Rio de Janeiro: Guanabara Koogan, 2004.p.488-89.

31. Ibarra, HS. Tricotilomanía: caso clínico. Rev. méd. Chile. 1997; 125(4):457-9.

32. Guerra G, Lago J, Figueras L, Aular M. Tricobezoar gástrico em niños: reporte de três casos Hospital Pediátrico "Dr. Elias Toro" IVSS. Rev. Soc. Méd.- Quir. Hosp. Emerg. Pérez de Leon. 1996; 27(1):57-62. 


\section{Capítulo 12}

\section{DIABETES MELLITUS E COMPORTAMENTO ALIMENTAR: OS RISCOS E IMPACTOS DE UM TRATAMENTO PAUTADO NUMA ALIMENTAÇÃO RESTRITIVA}

Camila Maria Mont'Alverne Frota

Kaline Sádie Sauaia Alves

Ananda da Silva Araujo Nascimento

Eduarda Gomes Bogéa

Júlio César da Costa Machado

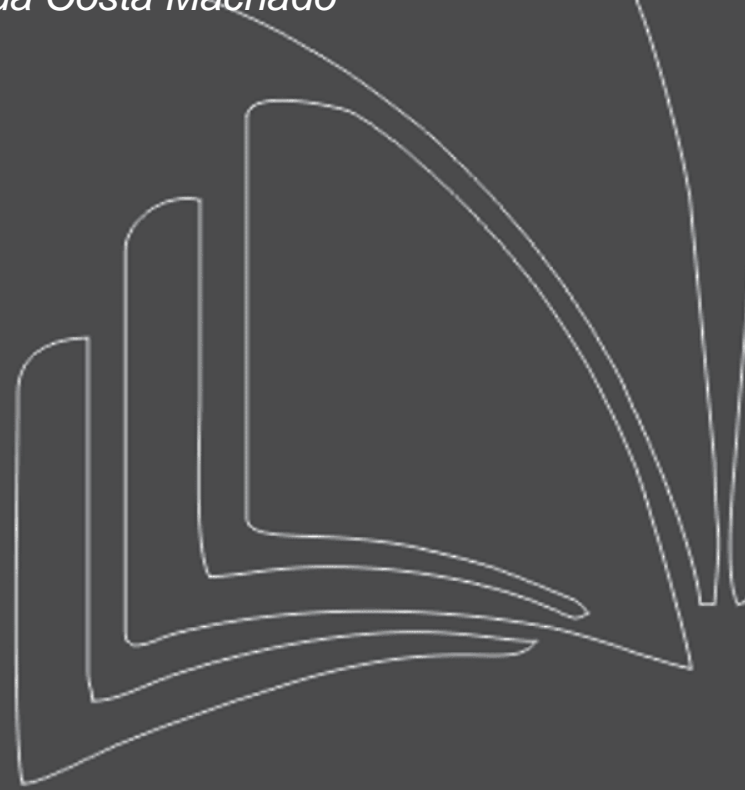

UNDB - Centro Universitário

UNDB - Centro Universitário

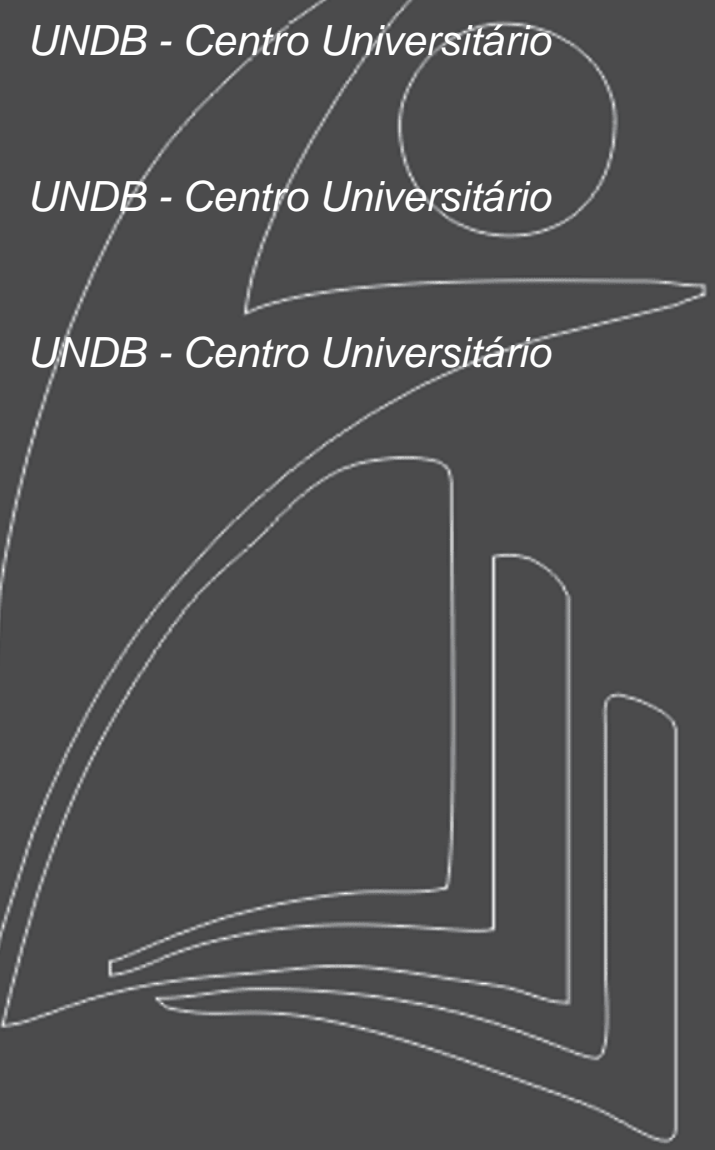


Resumo: Algumas condições metabólicas e fisiológicas específicas exigem, como parte do tratamento, uma alimentação mais restritiva que a dos indivíduos que não apresentam nenhuma patologia, de modo que, por vezes, é necessário que haja o consumo de alimentos para fins especiais. O diabetes mellitus é uma das patologias que exigem atenção especial, em razão de ser considerado uma doença crônica endócrino-metabólica, cuja principal característica é a hiperglicemia, decorrente de alterações funcionais da insulina no organismo ou, inclusive, da deficiência de sua produção. O indivíduo que convive com o diabetes deve seguir uma dieta com quantidades controladas de glicose, e adotar condutas que evitem picos de insulina. Entretanto, a restrição alimentar exacerbada com a qual convivem alguns portadores do DM, bem como as mudanças corporais decorrentes do uso constante da insulina para controle de glicose fazem com que o diabetes mellitus esteja bastante associado a transtornos alimentares, como anorexia nervosa, bulimia e diabulimia. Busca-se, através desse estudo, analisar a saúde física e, principalmente, mental e psicossocial daqueles que convivem com o Diabetes Mellitus, e, por conseguinte, com uma alimentação pautada no controle minucioso da glicose. Serão abordadas as suas limitações alimentares, os impactos psicossociais da alimentação restritiva à qual estão sujeitos, bem como os aspectos das terapias nutricionais e estratégias aplicáveis a esse público, com o intuito de proporcionar qualidade de vida apesar das restrições.

Palavras-chave: Diabetes Mellitus. Transtornos alimentares. Comportamento Alimentar. 


\section{INTRODUÇÃO}

$\mathrm{O}$ ato de se alimentar representa algo muito além da nutrição. Representa, dentre tantas coisas, prazer, afeto e efeitos sobre a saúde. Representa elementos de interação humana familiar e social, com conotações simbólicas e relacionadas à saúde, transcendendo o valor nutritivo e as características sensoriais do alimento, possuindo motivações ocultas relacionadas às carências psicológicas e às vivências emotivas e conflituosas que independem da fome (OLIVEIRA, 2019 et al, apud SOUTO, 2006).

As escolhas alimentares são influenciadas por uma ampla variedade de fatores, dentre eles a condição de saúde do indivíduo. Pessoas com diabetes, por exemplo, têm suas escolhas baseadas na condição de controle da patologia com a qual precisam conviver, ou seja, na restrição à ingestão de açúcares, e consumo reduzido de alimentos gordurosos.

O ato de comer tem um significado, representa elementos de interação humana familiar e social, com conotações simbólicas e relacionadas à saúde, transcendendo o valor nutritivo e as características sensoriais do alimento, possuindo motivações ocultas relacionadas às carências psicológicas e às vivências emotivas e conflituosas que independem da fome (OLIVEIRA, 2019 et al, apud SOUTO, 2006).

Diabetes Mellitus, considerado atualmente um problema de saúde pública, é uma doença crônica endócrino-metabólica, cuja principal característica é a hiperglicemia. Por razões como a não produção de insulina ou pela sua utilização de forma inadequada, os níveis de glicemia no organismo tornam-se elevados. Isso ocorre haja vista o fato de que a insulina, hormônio secretado pelo pâncreas, é quem controla a quantidade de glicose no sangue. No Brasil, são mais de 13 milhões de pessoas convivendo com a doença, que não tem cura, apenas tratamento, e que pode levar a óbito.

Os principais fatores de risco do Diabetes Mellitus são a hereditariedade, a obesidade, o sedentarismo, a idade, hipertensão arterial sistêmica, e resistência à insulina. É, portanto, uma condição multicausal, que envolve fatores genéticos, metabólicos, comportamentais e ambientais (TADDEI et al., 2017).

Quando do tipo 2, o diabetes é tido como o grande mal da humanidade, atualmente, explodindo endemicamente junto com sua “irmã gêmea”, segundo Ambrósio (2019), a obesidade, doença crônica, caracterizada por ser complexa, de múltiplas causas e que exige atenção multidisciplinar. No mundo, de 1,3 bilhão de pessoas obesas cerca de 500 milhões são diabéticos.

Segundo o Ministério da Saúde, no Brasil, em 10 anos (2006 a 2016), o número de brasileiros com diabetes aumentou $61,8 \%$. Assim, significa que a doença que atingia 5,5\% da população agora atinge $8,9 \%$ das pessoas, sendo $9,9 \%$ mulheres e $7,8 \%$ homens. 
Segundo Bosi (2015), uma alimentação adequada é capaz de prevenir e melhor manejar as desordens hormonais, bioquímicas e nutricionais presentes no paciente com diabetes.

Dentre os avanços da Nutrição, está a busca pela prática de uma terapia nutricional equilibrada e que promova saúde, ou seja, que esteja focada em promover melhor qualidade de vida ao paciente com diabetes em diversos aspectos da sua vida, sejam eles físicos, emocionais, mentais ou sociais. Buscase que a dieta seja encarada por ele como algo possível de se realizar (e de se manter), evitando-se que haja maior comprometimento das já existentes condições clínicas do paciente.

No mesmo sentido, Alvarenga, Costa e Medeiros (2019), afirmam que uma alimentação saudável é capaz de prevenir a introdução de novas medicações, por exemplo, a pacientes com Diabetes Mellitus tipo 2, promovendo melhoras à saúde superiores às obtidas através de medicamentos. Portanto a importância da Nutrição no tratamento da doença é indiscutível.

O Guia Alimentar para a população brasileira preconiza que devem ser incluídos alimentos variados na dieta do paciente com diabetes. Seguindo o mesmo raciocínio, para a American Diabetes Association (ADA), não há um plano alimentar único a todos os pacientes com diabetes, bem como também não há uma distribuição de macronutrientes ideal. Sendo, portanto, imprescindível que cada caso seja analisado isoladamente, considerando as características e preferências alimentares de cada um.

Entretanto a ADA defende, ainda, em uma de suas diretrizes, que além dos nutrientes contidos nos alimentos, deve ser enfatizada a importância de se ter prazer em comer. O nutricionista deve agir, portanto, no sentido de trazer mensagens positivas acerca das escolhas alimentares, e somente restringir alimentos quando, de fato, houver respaldo científico pra isso.

A dieta a ser seguida pelo paciente com diabetes é pautada, prioritariamente, na restrição e no controle de ingestão de carboidratos, o que acaba resultando em preocupação excessiva por parte do paciente, que, por vezes, vem a classificar alimentos como "bons" e "ruins", "perigosos" ou "proibidos", determinando, portanto, comportamentos de controle exacerbado sobre a alimentação e peso corporal (AZEVEDO; PAPELBAUM; D'ELIA, 2002).

A condição de saúde associada ao conhecimento acerca de como deve se pautar a alimentação da pessoa com diabetes não garantem um comportamento alimentar adequado. Ocorre que, para que haja melhor controle dos índices glicêmicos, o tratamento exige um plano alimentar mais restrito que o convencional e, por vezes, induz o paciente a direcionar sua atenção ao seu peso e ao controle 
daquilo que ingere, o que acaba por tornar-se um risco de que desenvolva algum quadro de transtorno alimentar, como bulimia, anorexia, compulsão alimentar, ou a diabulimia.

Transtornos alimentares caracterizam-se pela alteração severa nos hábitos e comportamento alimentar, associando-se a distúrbios de imagem, insatisfação corporal, alterações de saúde física e de saúde mental. Em pessoas com diabetes, os TAs são frequentes, e podem estar relacionados à insatisfação corporal e ao desejo de perder peso, a partir do uso constante da insulina. Em adolescentes e jovens adultos com diabetes, são comumente vistos.

O tratamento do diabetes implica um complexo conjunto de ações comportamentais de cuidados diários, e é amplamente reconhecido como extremamente desafiante pelo grau de envolvimento exigido do paciente, que, por vezes, também sente a necessidade de que seus familiares ajudem nesse processo.

Essa condição requer uma adesão ao tratamento de caráter multifatorial, amparada por variáveis de papel muito importante, as quais devem ser abordadas associadas a determinantes psicológicos para o sucesso da adesão e adaptação à nova rotina alimentar (CARDOSO et al., 2019).

O uso da Terapia Cognitivo Comportamental já vem se mostrado eficaz no tratamento desses pacientes, principalmente em casos de mulheres com diabetes tipo 1 e bulimia nervosa, haja vista que a TCC foca na mudança de comportamentos alimentares inadequados, mas acaba, consequentemente, melhorando o controle glicêmico dessas pacientes (AZEVEDO; PAPELBAUM; D’ELIA, 2002).

No mais, o comportamento alimentar está associado a aspectos técnicos e objetivos, mas também a aspectos socioculturais e psicológicos. Apenas oferecer informações não é estratégia suficiente para que mudanças sejam percebidas nos hábitos alimentares. Valores, aspectos emocionais e subjetivos estão relacionados e vinculados ao ato de comer, e devem ser compreendidos pelo profissional da Nutrição a fim de que o tratamento da pessoa com diabetes tenha maior eficácia, tendo em vista o rigoroso controle alimentar ao qual estão submetidos.

Neste trabalho, trataremos acerca da saúde física e, principalmente, mental e psicossocial daqueles que convivem com o Diabetes Mellitus tipo 1, em quem os transtornos alimentares estão presentes em maior índice, e também dos que convivem com Diabetes Mellitus tipo 2. 
Serão abordadas as suas limitações alimentares, os impactos psicossociais da alimentação restritiva a qual estão sujeitos, bem como os aspectos das terapias nutricionais, e estratégias da Nutrição Comportamental aplicáveis a esse público.

O trabalho enfatizará, ainda, a importância de se reconhecer os sinais de alerta e comportamentos de risco presentes em pessoas com transtornos alimentares, muitas das quais são pessoas com Diabetes, que desenvolvem tais comportamentos em face da extrema restrição a que estão sujeitas.

Discorreremos acerca das especificidades do acompanhamento nutricional voltado a esse público, esclarecendo que, caso venha a ser executado erroneamente, pode-se, inclusive, agravar a situação do paciente, afetando ainda mais sua qualidade de vida e toda a cascata de episódios perigosos decorrentes disso.

Por fim, observaremos o quanto uma alimentação rica em nutrientes específicos para esses pacientes e, ao mesmo tempo, livre de açúcares, ao contrário do que se pensa, pode entrar no dia a dia deles, sem deixá-los tão impactados, trazendo bem-estar, longevidade e benefícios que se repercutem no convívio deles em sociedade.

\section{METODOLOGIA}

De acordo com os critérios apresentados por Gil (2002), esta pesquisa pode ser classificada como bibliográfica e exploratória. As bases de dados utilizada para complementar o conteúdo do trabalho foi o SciELO (Scientific Electronic Library Online), o PubMed e o LiLacs.

A fim de que fosse realizada análise descritiva, também foram utilizados livros de acervo pessoal relacionados ao tema, visando aumentar a familiaridade com o problema e a sintetização das ideias apresentadas pelos pesquisadores.

\section{RESULTADOS E DISCUSSÕES DO TEMA}

O diabetes mellitus é uma doença crônico-metabólica não transmissível considerada um problema de saúde pública, tendo em vista sua alta frequência na população. É multifatorial e, como toda doença crônica, não é resolvida num curto espaço de tempo. Dentre as principais formas de tratamento, estão o controle adequado da alimentação, bem como a aplicação frequente de doses de insulina - hormônio diretamente relacionado à hiperglicemia característica de pessoas com diabetes, em decorrência da ausência de sua produção ou da sua utilização de maneira ineficiente pelo organismo. 
As DCNT têm como principais fatores de risco o tabagismo, a alimentação inadequada, o sedentarismo, o consumo de bebidas alcoólicas e o excesso de peso. Entretanto apesar de todos esses fatores serem reversíveis, dados epidemiológicos apresentados pelo Ministério da Saúde demonstram crescimento expressivo dessas doenças ao longo das últimas décadas (BRASIL, 2011; IBGE, 2014; BRASIL, 2019).

Oliveira, Pereira et al (2019) apontam que o ato de seguir dietas restritivas afeta o comportamento alimentar, gerando frustrações, compulsão e culpa, direcionando as pessoas a terem efeitos psicológicos negativos na autoestima, cognição, felicidade e afeto, além de poder desencadear crises de ansiedade e depressão capazes de trazer repercussões severas.

O presente estudo sugere passear pela repercussão dessas dietas que o apoio social, estratégias terapêuticas adotadas para lidar com os problemas de saúde e ansiedade estão modestamente correlacionadas com a adesão aos autocuidados da diabetes, o que poderá sublinhar a natureza multifatorial da adesão ao tratamento da diabetes.

Assim, nota-se a importância, sobretudo quando da prática clínica, o acompanhamento por psicólogos, por outros profissionais de saúde ligados ao diagnóstico, tratamento e educação na área da diabetes, valorizarem aspectos relacionados com a satisfação que esses pacientes revelam face ao apoio social e demais estratégias, uma vez que constituem fatores relevantes na adesão ao tratamento e, consequente, na prevenção de complicações crônicas e agudas. O foco, assim, resume-se nas bases do comportamento alimentar e desenvolver, efetivamente, ações interdisciplinares que permitam obter resultados eficazes no tratamento restritivo obrigatório.

$\mathrm{O}$ ato de se alimentar representa algo muito além da nutrição. Representa, dentre tantas coisas, prazer, afeto e efeitos sobre a saúde. As escolhas alimentares são, portanto, influenciadas por uma ampla variedade de fatores, dentre os quais a condição de saúde do indivíduo. Pessoas com Diabetes, por exemplo, têm suas escolhas pautadas no controle da patologia com a qual precisam conviver, ou seja, na restrição à ingestão de açúcares, no controle glicêmico, e no consumo reduzido de alimentos gordurosos.

Pensando em indivíduos com características fisiológicas e metabólicas específicas que exigem cuidado especial, e visando a proteção à saúde dessa população, encontra-se em vigor a Portaria № 29, de 13 de janeiro de 1998, que dispõe acerca do Regulamento Técnico referente aos alimentos para fins especiais, quais sejam aqueles alimentos "especialmente formulados ou processados, nos quais se introduzem modificações no conteúdo de nutrientes, adequados à utilização em dietas, diferenciadas 
e ou opcionais, atendendo às necessidade de pessoas em condições metabólicas e fisiológicas específicas" (BRASIL, 1998).

Os alimentos para fins especiais destinados a pacientes com diabetes são aqueles com restrição de carboidratos, vez que o DM tem como característica principal distúrbios no metabolismo de açúcares. Assim, alimentos diet e adoçantes dietéticos são os principais exemplos do que é recomendado a esses indivíduos.

Ocorre que, por diversas razões, sejam elas emocionais, cognitivas ou econômicas, por exemplo, muitos indivíduos que possuem diabetes tem uma relação disfuncional com a comida, o que acaba dificultando não apenas o consumo de alimentos estritamente destinados a pacientes diabéticos, como também a construção de hábitos que favoreçam o tratamento da doença com a qual convivem.

Em 2018, a Vigilância de Fatores de Risco e Proteção para Doenças por Inquérito Telefônico apresentou dados que demonstram aumento no consumo de frutas e hortaliças e a diminuição no consumo de refrigerantes e bebidas açucaradas, no período entre 2007 e 2018. Dados levantados pelo IBGE em 2019 também mostram aumento da prática de atividades físicas entre 2009 e 2018. Tal cenário nos leva a perceber que a população tem se preocupado mais com fatores de risco ambientais como a alimentação e o sedentarismo, entretanto os índices de DCNT e excesso de peso não foram impactados pelas melhoras apresentadas (BEDESCHI; PETRY, 2020).

Autores como RACINE et al. (2011) e CARBONNEAU et al. (2017) justificam o cenário atual de crescimento significante de doenças como o Diabetes Mellitus por razões que envolvem a saúde mental, comportamentos alimentares disfuncionais e prática de dietas restritivas. Para eles, 0 aumento nos casos de depressão e ansiedade estão interligados à alta das DCNT, assim como ao comer emocional e comportamentos alterados perante a comida e, por fim, o aumento na prevalência da prática de dietas, as quais, sob seu ponto de vista, relacionam-se com crescente número de quadros de compulsão alimentar e transtornos alimentares (BEDESCHI et al., 2020).

Transtornos alimentares são definidos pela Associação Americana de Psiquiatria como "quadros psiquiátricos caracterizados por profundas alterações no comportamento alimentar e disfunções no controle de peso e forma corporal, que levam a sérios prejuízos clínicos, psicológicos e de convívio social". O Manual de Diagnóstico e Estatístico de Transtornos Mentais subdivide os transtornos alimentares em anorexia nervosa, bulimia nervosa, transtorno de compulsão alimentar, transtorno alimentar restritivo/evitativo, transtorno de ruminação e pica (APA, 2013 apud Queirós et al., 2020). 
A Associção Brasileira de Diabetes (2020) traz, ainda, a diabulimia, caracterizada pela omissão intencional, redução ou retardo de aplicação das doses de insulina necessárias, com o objetivo de perda de peso. Essa prática pode, ainda, estar associada a comportamentos purgativos, como vômitos, laxantes, diuréticos ou exercícios físicos de forma excessiva.

Na restrição de grupos alimentares evidencia-se o desencadear de uma série de efeitos psicológicos negativos que incluem ainda perturbações no afeto, na autoestima, na cognição e no comportamento alimentar, e quando feita sem orientação ao transtorno de compulsão alimentar, caracterizado pela ingesta de grandes quantidades dos alimentos desejados em um curto período de tempo, seguido da sensação de perda de controle sobre o que ou o quanto se come, muito mais comum nas dietas desordenadas com foco no emagrecimento (STACHUKA e SANTOS, 2020).

Diante do diagnóstico do diabetes mellitus e de informações acerca do tratamento, muitos sentimentos acabam se fazendo presentes no paciente, tais como medo, tristeza e ansiedade. A ideia de lidar com restrições a algo que, para ele, tem grande significado pode vir a causar efeitos psicológicos e, inclusive, metabólicos, representando assim, um risco até dezoito vezes maior para o desenvolvimento de transtornos alimentares que de outros fatores (OLIVEIRA et al., 2019).

Almeida et al. (2018) realizaram estudo de caráter transversal observacional com 35 participantes com idades entre 54 e 65 anos, em sua maioria mulheres, a fim de avaliar o consumo alimentar de pessoas com diabetes mellitus tipo 2. Do total de participantes, apenas 18 informaram seguir orientações nutricionais. A maioria dos participantes afirmou realizar 3 a 4 refeições por dia, ou seja, número de refeições inferior ao recomendado a pessoas com diabetes, bem como também relataram descontinuação da dieta em decorrência de situações econômicas.

A Sociedade Brasileira de Diabetes (2019) apresentou dados de pesquisa baseada no estudo SEARCH for Diabetes in Youth, o qual recrutou crianças, adolescentes e adultos jovens diagnosticados com diabetes antes dos 20 anos, nos Estados Unidos, que identificou disfunções no comportamento alimentar dos participantes. Para o estudo, foram considerados os pacientes diagnosticados após os 10 anos de idade, entre 2002 e 2008, totalizando 2.156 indivíduos com diabetes tipo 1 e 149 com diabetes tipo 2.

Os resultados indicaram altas taxas de desordem alimentar em jovens com ambos os tipos de diabetes ( $21 \%$ no tipo 1 e $50 \%$ no tipo 2). Observou-se, ainda, que tal desordem aumentava com a idade, e que a prevalência era em meninas com diabetes tipo 1, porém taxas semelhantes também foram percebidas em meninos e meninas com diabetes tipo 2. O transtorno de compulsão alimentar foi a 
desordem mais frequente, e aqueles que tinham TCA também relataram sintomas de depressão e pior qualidade de vida.

O mesmo estudo associou a presença de hábitos alimentares alterados com o aumento dos episódios de cetoacidose diabéticas nos indivíduos com diabetes tipo 1. Observou-se que muitos dos pacientes relataram ter o costume de restringir a insulina a fim de eliminar calorias através da glicosúria.

Ademais, além da restrição intencional da insulina, o hábito de pular refeições e a compulsão alimentar foram fortemente associados ao maior IMC e à diminuição da sensibilidade à insulina. Sendo assim, o estudo concluiu que tais comportamentos podem contribuir, paradoxalmente, para o ganho de peso.

Percebe-se, portanto, certa dificuldade por parte dos pacientes com diabetes em seguir uma dieta adequada às suas condições, principalmente devido ao inconformismo com seu caráter restritivo, o qual, por vezes, é efetivo durante os primeiros dias, mas não tem a adesão desejada por um período prolongado.

As limitações consequentes do tratamento do Diabetes tiram, de cerca maneira, a liberdade daquele que convive com a doença, provocando, portanto, sentimentos como desânimo, tristeza, insatisfações. O declínio da qualidade de vida do paciente associa-se a momentos de prazer que a comida proporcionava e que lhe foram retirados e a possível dificuldade de socializar por se sentirem excluídos.

No mesmo sentido, a Associação Brasileira de Diabetes (2017) afirma que a maior prevalência de transtornos alimentares está em pacientes com diabetes mellitus tipo 1, alegando, ainda, que a administração de insulina e seus efeitos metabólicos, como o ganho de peso, a ingestão de carboidratos para tratar hipoglicemias e o fato de terem de pensar o tempo inteiro acerca do que comer e de quanto comer, associados à cobrança familiar e da equipe multiprofissional que acompanha o paciente no que tange ao plano nutricional são fatores que explicam a prevalência desses transtornos nesse público.

A perda do prazer em comer, o estresse causado pelo controle frequente do que pode ou não ser ingerido e de que maneira deve ser consumido, a perda de autonomia e o cerceamento da liberdade acerca do que comer ou beber e de quando realizar as refeições são algumas das principais razões que dificultam a aderência à dieta pelas pessoas com Diabetes. Tais características estão associados à dieta restritiva à qual, via de regra, estão submetidos (ANAD, 2014). 
Associado à baixa adesão ao tratamento, está o paradoxo das proibições alimentares, cuja premissa consiste no fato de que pessoas submetidas a algum tipo de restrição alimentar tendem a tornar-se obcecadas pelos alimentos restringidos. (HERMAN \& POLVY, 1985 apud BEDESCHI; PETRY, 2020).

Na mesma linha de raciocínio, Willing (2014 apud BEDESCHI; PETRY, 2020) e Wheeler et al. (2016 apud BEDESCHI; PETRY, 2020) entendem que orientações nutricionais focadas em restrição alimentar não são eficientes a longo prazo para controle de níveis glicêmicos.

O ajuste do plano alimentar com melhores escolhas alimentares e combinações inteligentes que evitem picos de insulina são opções plausíveis a quem convive com o diabetes mellitus. O DM é uma doença crônica que perdura ao longo da vida, portanto o tratamento não pode se basear em restrições exacerbadas, com exclusões absolutas de alimentos e proibições de comportamentos, o que claramente não terá continuidade a longo prazo, tendo em vista a dificuldade de levar adiante esse tipo de tratamento.

Diferentemente de condições agudas, como alergias alimentares, que necessitam da exclusão total de um componente alimentar, o indivíduo diagnosticado com DCNT pode manter uma alimentação composta dos mais variados alimentos, levando em consideração quantidades e composições que entrem em sintonia com os sinais internos e as especificidades do diagnóstico (BEDESCHI; PETRY, 2020).

Bernardi et. al (2005) e Macpherson-Sánchez (2015) têm o mesmo posicionamento referente ao fato de que uma abordagem restritiva costuma ser fundamentada numa visão dicotômica daquilo que é certo e errado, em proibições comportamentais, em autocontrole e disciplina, e na estigmatização do sujeito. Acreditam, ainda, que essa abordagem baseia-se no medo, no terrorismo e na culpabilização, deixando de considerar a individualidade de cada caso.

Tal fenômeno é capaz de justificar o fato de que muitos pacientes com diabetes relatam dificuldade em seguir um plano alimentar restritivo e, ao contrário, acabam por desencadear transtornos alimentares decorrentes da proibição e da necessidade de controle da alimentação, as quais podem vir a causar efeitos como a hipervalorização ou desejo exacerbado por alimentos "proibidos" (BEDESCHI; PETRY, 2020).

A preocupação excessiva por parte do paciente, que, nesta mesma linha de raciocínio, classifica alimentos como "bons" e "ruins", "perigosos" ou "proibidos", acaba, consequentemente, 
desencadeando comportamentos de controle exacerbado sobre a alimentação e o peso corporal (AZEVEDO; PAPELBAUM; D’ELIA, 2002).

De acordo com Bedeschi e Petry (2020), a negação do problema e a culpa decorrente da tomada de consciência sobre o problema são dois posicionamentos que costumam oscilar entre os indivíduos com diabetes em seu tratamento.

O estudo SHIELD (2008), realizado com 211.709 adultos, verificou que muitos pacientes com DM2 não reconhecem a seriedade da doença, fato que se dá, via de regra, pela ausência de sintomas de que ela existe. Acreditam, entretanto, que o DM1 seria mais grave. E, além disso, apesar de a grande maioria já ter recebido orientações de profissionais da saúde no sentido de ser importante a mudança no estilo de vida, menos de $27 \%$ se exercitavam regularmente e somente $33 \%$ seguiam algum tipo de plano alimentar. Concluiu-se, portanto, que conhecimento não significa mudança de comportamento.

Diante de diversas tentativas frustradas de controle da alimentação, da frequência de prática de atividades físicas, de controle do corpo e do peso, o indivíduo passa a criar um quadro de negação da doença. Por conseguinte, passa a buscar não mais pensar na sua condição como forma de encontrar alívio para aquela situação que, aparentemente, não possui solução:

Esta negação é alternada, geralmente, com lampejos de consciência, em que o indivíduo acessa a preocupação com sua saúde e sua vida, e a culpa aparece primeiramente trazendo uma certa motivação para a mudança, a qual, porém, geralmente se baseia na mesma abordagem da proibição alimentar, dietas restritivas e radiscalismo perpetuada culturalmente entre a população e os próprios profissionais da saúde. (...) Diante de novas tentativas frustradas, a culpa e o fracasso acabam por fortalecer ainda mais suas crenças errôneas de inferioridade e incapacidade para mudanças (BEDESCHI; PETRY, 2020).

Sem aceitar os fatos e os sentimentos deles decorrentes torna-se ainda mais complexo o planejamento e a execução de mudanças comportamentais necessárias. A fim de reverter tal situação, o emprego de técnicas multidisciplinares é uma estratégia considerada eficaz. Nesses casos, a adequação do indivíduo a tais estratégias de tratamento do diabetes sofre influência das suas experiências reforçadoras e das habilidades desenvolvidas para o domínio e adaptação do estresse que pôde ter se instalado em decorrência da doença.

Em contrapartida, o fato de o Diabetes tipo 2 ser, por vezes, assintomático, faz com que muitos pacientes acreditem que estão bem e saudáveis, e não deem continuidade ao tratamento nutricional 
estabelecido. A própria família da pessoa com diabetes sem sintomas visíveis pode vir a não dar o apoio necessário a esses indivíduos.

A literatura, por Cardoso et al. (2019), aponta algumas variáveis psicológicas que têm demonstrado desempenhar um papel relevante na adesão ao novo tratamento da diabetes. Uma variável psicológica importante é o chamado "humor negativo", capaz de desencadear uma cascata de falhas em mão dupla, ou seja, a presença de perturbações psicológicas, como depressão e ansiedade, associam-se à má gestão da doença e ao seu controle metabólico diretamente, interferindo, via sistema nervoso autônomo, ou indiretamente, mexendo com a capacidade de gerir a patologia.

Destaca-se também o apoio social como fator de grande valia, pois os conflitos, seja em família, seja em sociedade, predizem uma pior adesão ao tratamento e à nova condição de vida, enquanto níveis elevados de apoio social, maior coesão, organização familiar e comportamentos familiares positivos de apoio fazem o oposto, principalmente em meio a um ambiente "leve" e de controle mais flexível, o que, para o paciente, remete a maior apoio social (CARDOSO ET AL., 2019).

É interessante, portanto, que o paciente seja acompanhado de uma equipe multidisciplinar, composta por profissionais como nutricionista, médico e psicólogo. O nutricionista atua como terapeuta nutricional, auxiliando naquilo que serão as melhores escolhas e combinações alimentares e no entendimento de como as emoções influenciam no comportamento e atitudes alimentares. Ele vai ajudar o paciente a construir um percurso gradual, tornando viável a execução do planejamento alimentar, dando-lhe motivação nesse processo de mudança do seu comportamento alimentar.

O terapeuta nutricional é capaz de auxiliar o paciente com diabetes mellitus a entender melhor os mecanismos fisiológicos e psicológicos que interferem de alguma maneira no controle glicêmico. Seu papel também consiste em desconstruir crenças e mitos acerca da alimentação, muito presentes na vida de pacientes com DM, a fim de que esses indivíduos tenham maior flexibilidade alimentar, afastando-se dos pensamentos constantes de proibições (COSTA et al., 2020).

Incentivar o paciente a perceber os sinais de fome e saciedade, auxiliando-o a utilizá-los quando das suas escolhas do que comer, do quanto comer também pode ser uma atitude de grande valia a ser realizada por profissionais como o terapeuta nutricional e psicólogos.

Além disso, dissociar a comida dos sentimentos atrelados a ela, por meio de técnicas descritas por Catão e Tavares (2017), através das quais o TN deve esclarecer a seu paciente acerca do que seria o 
"comer desatento" e o "comer emocional", aplicando algumas atividades as esses indivíduos no intuito de que venham a criar consciência do seu comportamento alimentar.

O fato de o paciente conseguir se guiar pela alimentação intuitiva pode ser libertador, já que, via de rega, indivíduos com DM sentem que há algo de "errado" com seus corpos e que, portanto, não podem confiar neles. A partir dessa abordagem e desses ensinamentos, o paciente passa a ter melhor relação com a comida e com seu corpo, de modo que podem vir a se sentir mais capazes e motivados a conviver com a doença (COSTA et al., 2020).

É dessa forma que, alinhando-se às diretrizes da Associação Americana de Diabetes (ADA), a Nutrição Comportamental pode ser utilizada, promovendo o alcance das necessidades nutricionais do paciente, respeitando suas preferências pessoais, culturais, o conhecimento que aquele paciente tem em saúde, bem como levando em consideração o seu acesso a escolhas alimentares saudáveis, sua prontidão, sua motivação e suas habilidades desenvolvidas para que haja a mudança necessária, sem abdicar da manutenção e da promoção do comer aliado a bem estar e prazer (COSTA et al., 2020).

Técnicas de Terapia Comportamental, que passam por avaliações por uma Entrevista Motivacional, identificação do tipo de comer que o motiva a querer se alimentar e o uso da Terapia Cognitivo Comportamental, tratamento que proporciona remissão dos sintomas e manutenção de melhoras alcançadas, auxiliam o paciente a modificar suas crenças e, consequentemente, seus comportamentos disfuncionais, com êxito nas metas desejadas, através de uma abordagem de fatores cognitivos, emocionais e comportamentais (CATÃO e TAVARES, 2017).

Oferecer informações não é suficiente para que o indivíduo com diabetes mude seu comportamento alimentar e seus hábitos de vida. A abordagem utilizada pelo nutricionista no tratamento do DM não pode se limitar a apenas fornecer informações ou restringir determinados grupos alimentares, sem considerar outros aspectos particulares de cada paciente. Por isso, é interessante o papel da Nutrição Comportamental na vida de indivíduos com Diabetes, vez que convivem com a ideia de que devem viver em meio a proibições e restrições exacerbadas. Aspectos subjetivos e emocionais devem ser sempre considerados, tendo em vista o fato de que influenciam fortemente a adesão ao tratamento, ao bom convívio com a doença, e a qualidade de vida social e emocional. 


\section{CONCLUSÃO}

Atualmente, milhares são as vítimas de doenças crônicas não transmissíveis, de modo que cerca de 13 milhões de brasileiros têm diabetes, e outros milhares convivem com a doença sem saber, pela ausência de um diagnóstico.

As escolhas alimentares são influenciadas por uma ampla variedade de fatores, dentre eles a condição de saúde do indivíduo. Pessoas com Diabetes, por exemplo, têm suas escolhas baseadas na condição de controle da patologia com a qual precisam conviver, ou seja, na restrição à ingestão de açúcares, e consumo reduzido de alimentos gordurosos.

O controle de horários das refeições, do que comer, do quanto devem comer, da aplicação da insulina e a cobrança de cumprimento de uma rotina acabam resultando em consequências psicossociais, como estresse, ansiedade, cobranças exacerbadas referentes à estética corporal, que podem resultar em transtornos alimentares, haja vista o abalo psicológico que tais cobranças causam.

Transtornos alimentares são distúrbios da alimentação capazes de alterar a saúde e a vida psicossocial do indivíduo. Com etiologia multifatorial, a qual envolve aspectos genéticos, psicológicos, familiares, socioculturais e biológicos, são muito comuns em pessoas que convivem com diabetes, principalmente diabetes tipo 1.

Assim, mesmo diante das reflexões de que o comportamento alimentar envolve muitos fatores, fatores emocionais e culturais, independente de fome, há necessidade de avaliar as sensações sentidas no ato de comer, o local, as circunstâncias externas, o porquê, e até o pensamento no momento do ato como grandes influenciadores desses comportamentos.

Estratégias da terapia cognitivo-comportamental que estejam voltadas para a habilidade de comunicação do profissional que não demonstrem julgamentos ou censuras, reforçando a responsabilidade do paciente pela mudança através da troca de conhecimento, e do entendimento acerca da doença e de suas implicações fisiológicas são fundamentais à aderência de mudanças comportamentais do indivíduo com diabetes.

Limitar-se a crenças acerca de restrição de carboidratos e açúcares para que haja o controle ideal do diabetes não basta quando nos referimos a tratamento a longo prazo de uma doença que exige atenção durante a vida toda. Aspectos subjetivos e psicológicos também são decisivos no controle glicêmico e isso deve estar claro para o paciente. Incentivá-lo a perceber melhor seus sinais de fome e saciedade, bem como orientá-lo acerca de que não há proibições, mas sim combinações alimentares 
que permitirão uma flexibilização maior no que tange à sua alimentação podem ser a maneira mais eficaz de se conviver bem com o diabetes mellitus, mantendo a qualidade de vida. 


\section{REFERÊNCIAS}

ALVARENGA, Marle dos Santos; FIGUEIREDO, Manoela; TIMERMAN, Fernanda; et al. Nutrição comportamental. 2.ed. Barueri, Manole, 2019;

AMBRÓSIO, Cláudio. E se você viver mais de 100 anos? São Paulo: Gente, 2019;

AMERICAN DIABETES ASSOCIATION. Standards of medical care in diabetes - 2010. Diabetes Care, Alexandria, v. 33, n. Supl. 1, p. S11-61, Jan. 2010;

ASSOCIAÇÃO NACIONAL DE ATENÇÃO AO DIABETES. Departamento de Psicologia. Comportamento Alimentar no Paciente Diabético. Revista ANAD Informa. 2014;

AZEVEDO, Alexandre Pinto de; PAPELBAUM, Marcelo; D'ELIA, Fernanda. Diabetes e transtornos alimentares: uma associação de alto risco. Rev. Bras. Psiquiatr., São Paulo , v. 24, supl. 3, p. 77-80, Dez. 2002;

BAZATA, Debbra et al. Affecting behavior change in individuals with diabetes: findings from the Study to Help Improve Early Evaluation and Management of Risk Factors Leading to Diabetes (SHIELD). Diabetes Educ. 2008 Nov-Dec;34(6):1025-36. Acesso em: 15 mai 2021.

BEDESCHI, Lydiane B.; PETRY, Nathália. Alimentação intuitiva nas Doenças Crônicas Não Transmissíveis. In: REZENDE, Fabiane A. C.; PENAFORTE, Fernanda R. O.; MARTINS, Poliana C. Comida, Corpo e Comportamento Humano. São Paulo: IACI Editora, 2020. p. 151-169;

BRASIL. Ministério da Saúde. Secretaria de Vigilância em Saúde. Departamento de Análise de Situação de Saúde. Plano de ações estratégicas para o enfrentamento de doenças crônicas não transmissíveis (DCNT) no Brasil 2011-2022 / Ministério da Saúde. Secretaria de Vigilância em Saúde. Departamento de Análise de Situação de Saúde. - Brasília: Ministério da Saúde, 2011.

BRASIL. Ministério da Saúde. Vigitel Brasil 2016 Saúde Suplementar: vigilância de fatores de risco e proteção para doenças crônicas por inquérito telefônico [recurso eletrônico] / Ministério da Saúde, Agência Nacional de Saúde Suplementar. - Brasília: Ministério da Saúde, 2017.

BRASIL. Ministério da Saúde. Sociedade Brasileira de Diabetes. O que é Diabetes? Disponível em: https://www.diabetes.org.br/publico/diabetes/oque-e-diabetes. Acesso em: 12 abr. 2021;

BRASIL. Ministério da Saúde. Sociedade Brasileira de Diabetes. Diabetes tipo 1 e Transtornos Alimentares;

BRASIL. Ministério da Saúde. Sociedade Brasileira de Diabetes. Restrição calórica no diabetes tipo 2: esta conduta é efetiva?, abr., 2017;

BRASIL. Ministério da Saúde. Sociedade Brasileira de Diabetes. Transtornos alimentares pioram a saúde e a qualidade de vida de adolescentes com diabetes. Mai, 2019;

CARDOSO, Helena; PAIS-RIBEIRO, José; SILVA, Isabel. Variáveis Psicológicas Associadas à Adesão ao Tratamento do Diabetes Mellitus. Disponível em:

http://repositorio-aberto.up.pt/bitstream/10216/56405/2/82681.pdf. Acesso em: 22 abr. 2021; 
CATÃO, Larissa; TAVARES, Renata. Técnicas da Nutrição Comportamental no Tratamento dos Transtornos Alimentares. Rev. Campo do Saber, vol. 03, Jan./Jun. 2017;

CLARK, Nathaniel G.; FOX, Kathleen M.; GRANDY, Susan. Symptoms of Diabetes and Their Association With the Risk and Presence of Diabetes. Diabetes Care. Nov, 2007;

DE ALMEIDA, F. C. A.; LANDIM, M. A. T.; BORGES, K. M.; TORRES, R. DE A.; FERREIRA SILVA, J. B. N. Hábitos alimentares de indivíduos com diabetes mellitus tipo 2 atendidos pelo Programa Estratégia Saúde da Família na cidade de Cajaeiras, Paraíba, Brasil. RBONE - Revista Brasileira de Obesidade, Nutrição e Emagrecimento, v. 12, n. 71, p. 301-309, 25 jun. 2018.

GIL, A. C. Como elaborar projetos de pesquisa. São Paulo: Atlas, 2002;

IOP, F. C. S.; TEIXEIRA, E.; DELIZA, R. Comportamento alimentar de indivíduos diabéticos. Braz. J. Food Technol. II SSA. p. 36-43. 2009;

MACPHERSON-SANCHÉZ AE. Integrating Fundamental Concepts of Obesity and Eating Disorders: Implications for the obesity epidemic. Am J Public Health. 2015; 105(4):e71-e85;

MARQUES, Hélida; DOMINGOS, Neide A.; SOUSA, Luana. Diabetes tipo II: qualidade de vida e aspectos psicológicos. Disponível em: http://repositorio-racs.famerp.br/racs_ol/vol-19-2/ID464-Rev-19-abrjun-2012.pdf. Acesso em: 22 abr. 2021;

MELO, Paula. Rev. Afine-se. PUC- Minas Gerais, Set. 2020;

OLIVEIRA, Renata C.; PEREIRA, João P.; GOLDONI, Jaqueline; VASQUES, Raisa. Dietas Restritivas e a Felicidade: Revisão Narrativa sobre seus Efeitos Psicológicos. Rev. Semana de Iniciação Científica. Balneário Camboriú: Faculdade Avantis, v. 01, Out. 2019;

ONE, Giselle M. Nutrição Clínica: Os Desafios da Pesquisa na Atualidade. João Pessoa, 2021.

PERES, Denise Siqueira; FRANCO, Laércio Joel; SANTOS, Manoel Antônio dos. Comportamento alimentar em mulheres portadoras de diabetes tipo 2. Rev. Saúde Pública, São Paulo, v. 40, n. 2, p. 310-317, Abr. 2006;

STACHUKA, Allan; SANTOS, Andressa. Relação entre Dietas Restritivas e Transtorno de Compulsão Alimentar Periódica, Maringá, 2020;

TADDEI, José Augusto; LANG, Regina Maria Ferreira; LONGO-SILVA, Giovana; TOLONI, Maysa Helena de Aguiar; VEGA, Juliana Bergamo. Nutrição em saúde pública, Rio de Janeiro: Rubio, 2017. 


\section{Capítulo 13}

\section{doi $10.37423 / 211004928$}

\section{VIVÊNCIA DE IDOSOS EM INSTITUIÇÃO DE LONGA PERMANÊNCIA EM JOÃO PESSOA - PB: RELATO DE EXPERIÊNCIA}

Matheus de Sousa Carvalho

Laís Clark de Carvalho Barbosa

Letícia Diniz Aranda

Vívian Maria Vieira Moura de Holanda

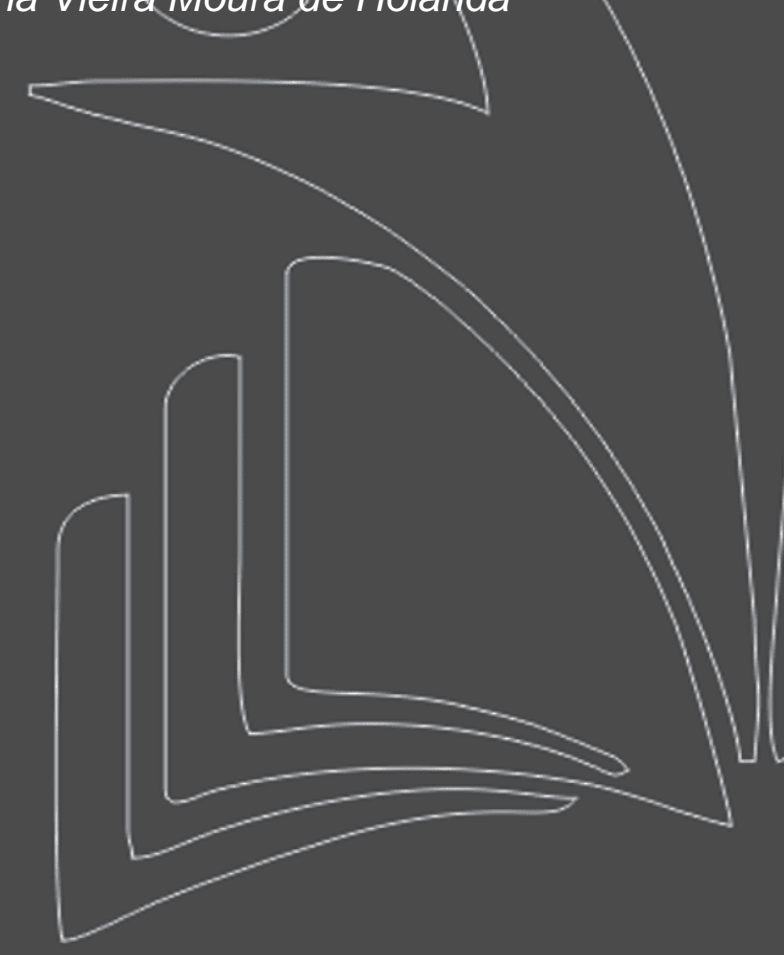

Faculdade de Medicina Nova Esperança

Faculdade de Medicina Nova Esperança

Faculdade de Medicina Nova Esperança

Faculdade de/Medicina Nova Esperança 


\section{INTRODUÇÃO}

O Processo de envelhecimento dos seres humanos é uma realidade constatada no Brasil e em um grande número de Nações. No contexto brasileiro, até a década de 50, as características demográficas indicavam uma população bastante jovem, com altas taxas de fecundidade e taxas de mortalidade que começavam a diminuir.

A partir da década de 60, destaca-se a brusca freada nas taxas de fecundidade e a diminuição na taxa bruta de mortalidade. A expectativa de vida ao nascer no Brasil, que era de apenas 33,7 anos em 1900, passa para 63,5 em 1990 e em 2014 sobe para 75,2 anos (IBGE). Para a Paraíba, 72,6 anos (2014), uma das maiores do nordeste.

As projeções para o futuro indicam que em 2050, a população acima de 65 anos será, aproximadamente, 50 milhões ( $25 \%$ do total da população). (CAMARANO, 2010) Com isso, aconteceram inúmeras modificações nos padrões das famílias, a partir da modernização da sociedade, como: a inserção da mulher no mercado de trabalho, a redução do tamanho das famílias e das moradias, a necessidade dos membros em trabalhar e a escassez de alternativas para as famílias manterem seus idosos em casa. Dessa forma, contribuiu-se para o surgimento de uma grande demanda de internações em espaços de convivência. Sendo assim comprovado, por meio de um estudo do sociólogo Francês Hôte (1984), que já se estimava que 0,6\% a 1,3\% de pessoas idosas em instituições, após uma investigação dos programas para idosos no Brasil. (ARAÚJO, 2016).

Além disso, o surgimento das instituições que albergavam idosos no Brasil (Asilos), data de muitos anos. Essas instituições tinham uma imagem de abandono, descaso e maus tratos; imagem esta, na maioria das vezes, relacionada às condições na quais estas instituições surgiram. (CREUTZBERG, 2008).

A Regulamentação do funcionamento das casas de repouso, clínicas geriátricas e outras instituições destinadas ao atendimento de idosos, consta na Portaria № 810 de 22 de setembro de 1989. Posteriormente, receberam o nome de ILPI (Instituições de Longa Permanência) na Legislação vigente da RDC № 283 de 26 de setembro de 2005, que estabelece os critérios mínimos para o funcionamento dessas instituições (garantia dos direitos humanos, recursos humanos, infraestrutura física, processos operacionais, saúde, alimentação e notificação de doenças e agravos compulsórios).

Essa regulamentação visa a qualificação dos serviços prestados aos idosos nas instituições, minimizando os riscos à saúde e aos quais eles estão expostos. Vale ressaltar também, a Constituição Federal 1988, a Lei Orgânica da Saúde (8.080 /1990), a Lei Orgânica da Assistência Social (8.742/1993), 
a Política Nacional do Idoso (8.842/1994) e o Estatuto do Idoso - Lei 10.741/ 2003, como aparatos legais "para assegurar direitos sociais à pessoa idosa, criando condições para promover sua autonomia, integração e participação efetiva na sociedade”. (DAVIM, 2004) .

Desta maneira, as Instituições de Longa Permanência para Idosos (ILPI) constituem-se espaços de residência coletiva, nos quais as pessoas com idades avançadas buscam proteção e amparo, que, na maioria das vezes não dispõem no seu ambiente familiar e social. (FREITAS, 2010).

Sendo o envelhecimento uma fase tão importante na vida do indivíduo faz-se necessário que a qualidade devida represente dignidade para a pessoa idosa.. Faz-se necessário a compreensão das pessoas em sua multidimensionalidade, inclusive suas concepções e comportamentos que busquem o bem estar. (LIMA, 2015) Desta forma, objetivou-se conhecer a estrutura física, funcionalidade das atividades desenvolvidas juntamente aos idosos de uma instituição de longa permanência.

\section{METODOLOGIA}

Trata-se de um relato de experiência baseado na vivência dos acadêmicos do curso de medicina do quinto período (P5B) da Faculdade de Medicina Nova Esperança (FAMENE), realizado no mês de novembro do ano letivo de 2016.

No decorrer do semestre várias aulas teóricas abordaram as Políticas Públicas Nacionais voltadas para as pessoas que necessitam de cuidados assistenciais e de atenção a saúde e saúde mental. Através de uma metodologia problematizadora, com rodas de conversas e apresentação de seminários e vídeos foram realizadas discussões e reflexões sobre as temáticas, que cujo conteúdo é integrante da disciplina Atenção Integral a Saúde Mental, ministrada por um grupo de três docentes.

Cada professor ficou responsável por um grupo de aproximadamente 23 discentes. Posteriormente, a sala foi dividida em subgrupos contendo 8 alunos, em que cada um destes realizou 4 visitas a serviços de saúde relacionados à Rede de Atenção Psicossocial e serviço de cunho filantrópico.O grupo em questão realizou todas as suas visitas no mês de Novembro de 2016.

A primeira realizada foi a uma instituição de longa permanência - ILPI , a segunda ao CAPS AD III, a terceira ao Centro de Referência Municipal de Inclusão da Pessoa com Deficiência (CRMIPD) e a última ao Centro de Práticas Integrativas e Complementares em Saúde no SUS (CPICS), todos localizados no município de João Pessoa. A visita foi realizada no dia 3 de novembro de 2016. Ao chegar à instituição, inicialmente foi realizada uma reunião, na sala de reuniões, com as professoras, onde foi apresentado todo o funcionamento da instituição. Em seguida, os alunos presentes foram, divididos em 2 
subgrupos, cada um orientado por uma das professoras. Dessa forma, seguiu-se com: a visita, a apresentação do local, mostrando os aposentos dos idosos, refeitório, enfermarias, entre outros.

\section{RESULTADOS E DISCUSSÕES}

A Instituição visitada é uma entidade filantrópica sem fins lucrativos, criada em 1944 e reconhecida como utilidade pública. Seu funcionamento é mantido através de doações e apoio de Igrejas, órgãos públicos, municipal e estadual, e de escolas que realizam atividades para arrecadar doações. Além das doações, ela retém $70 \%$ da aposentadoria de cada idoso para despesas com alimentação, medicamentos, insumos, pagamento de funcionários, entre outras despesas, sendo importante ressaltar, que isso é uma norma aplicável a todas as ILPIs.

Ademais, os $30 \%$ restantes ficam a cargo da administração do idoso, sendo aberta uma conta poupança para ele e o dinheiro depositado nela, todo mês.

Atualmente, ela abriga cerca de 60 idosos, sendo 29 homens e 33 mulheres, com idades entre 60 e 98 anos, exceto um, com 105 anos. De modo geral, a maioria dos idosos que nela residem são paraibanos, tendo apenas alguns naturais de Recife. Com relação a sua equipe profissional, a instituição conta com 25 funcionários contratados pela casa, entre eles há 4 técnicos de enfermagem, que atuam em sistema de rodízio 24 horas; voluntários (enfermeiros, recepcionista, etc.); fisioterapeuta (atende 3 vezes na semana); nutricionista. Além destes, há ainda, profissionais de saúde cedidos pela prefeitura (NASF) para atuação na instituição: assistente social; psicóloga (atendimento um dia na semana) e pedagoga.

Dessa forma, é válido salientar que a concepção do cuidado, por parte dos profissionais de saúde, é equivalente a uma ação técnica que existe a Política Nacional de Saúde do Idoso, regulamentada pela Portaria n. 1.395, de dezembro de 1999, que enfatiza a importância de se estabelecer uma parceria entre profissionais de saúde e cuidadores informais. (MICHEL, 2010).

Quanto aos atendimentos médicos, eles são realizados através de parceria com médicos voluntários. Os medicamentos são disponibilizados pela Gerencia de Abastecimento Farmacêutico do município de João Pessoa (GMAF) ou são comprados pela instituição. A assistência Hospitalar se dá através de encaminhamento para os hospitais do SUS, como o Trauminha, São Vicente e Edson Ramalho, já que a maioria dos idosos não possui plano de saúde privado.

Dentre as doenças prevalentes, estão as cardíacas; hipertensão; diabetes; Parkinson e Alzheimer. E quanto às doenças mentais, as mais prevalentes são a depressão, o transtorno bipolar e a esquizofrenia. Surge então, uma grande preocupação com o idoso, nas diversas áreas, pois ele 
constitui um grupo bastante diferenciado entre si e em relação aos demais grupos etários, e os custos econômicos e sociais decorrentes deles vêm ultrapassar as projeções para esse grupo, numa situação vigente do sistema espoliado de saúde pública. (KALACHE, 1987)

Ao receber o idoso, a assistente social conversa com a família sobre a importância de manterem o contato e de realizarem visitas ao familiar. Porém, em caso de abandono e/ou rompimento do vínculo familiar é resultada de solidão e muitas vezes ocasionando sofrimento psíquico.

Em relação às atividades desenvolvidas, todo domingo é celebrada a missa na capela às 9 horas da manhã. Os idosos com condições físicas e mentais têm a liberdade para sair da instituição para passeios, comprar algo de que necessitem e visitar amigos e familiares.

Além disso, a instituição promove passeios externos com os idosos, e todo último domingo do mês oferece, ainda, uma festa para os aniversariantes do mês.

Diante do discernimento de que as necessidades humanas abrangem interações e vínculos, uma das maneiras de relação com o ambiente externo é a programação de interação com grupos de visitantes, assim como, a participação dos idosos em eventos externos, sejam eles de caráter cultural ou político. Desse modo, a percepção de que o idoso integra a comunidade ligada à ILPI tem contribuído para a reflexão, ainda incipiente, mas crescente, de que o idoso pertence à área adjunta a serviços de saúde e, portanto, usufrui dos mesmos direitos dos demais idosos da comunidade.

Essa multiplicidade de acoplamentos estruturais com o meio social constitui importante contribuição para o desenvolvimento das ILPIs, assim como para uma nova percepção acerca dessas instituições. Conclusão A institucionalização de idosos em ILPI's se apresenta como uma valiosa alternativa de apoio ao processo de envelhecimento.

Utilizando-se da atenção dedicada, ações recreativas e eventos integrativos, além do cuidado oferecido pela equipe da ILPI em questão, constatou-se a melhora do estado geral e da percepção de vida em muitos dos idosos moradores, que passam a ter prazer nas tarefas realizadas e na rotina compartilhada com os demais.

A oportunidade de constatar a vivência dos idosos nestas instituições fez com que fossem refletidas as condições da assistência ofertadas a essa população, considerando que muitos usuários podem exigir cuidados mais especializados às suas condições de dependência física, mental ou social.

A experiência vivenciada ampliou os conhecimentos e o desenvolvimento de um novo olhar direcionado a pessoa idosa. Assim, foi visto que as ILPI's, apesar de abrigarem integralmente os 


\section{Vivência De Idosos Em Instituição De Longa Permanência Em João Pessoa - PB: Relato De Experiência}

usuários, são bem sucedidas no cumprimento da proposta de um cuidado efetivo e humano, abrangendo todos os aspectos da vida do idoso. 


\section{REFERÊNCIAS}

ARAÚJO C. L. O,; SOUZA L. A.; FARO A. C. M. Trajetória das instituições de longa permanência para idosos no Brasil. Disponível em: http://www.here.abennacional.org.br/here/n2vol1ano1_artigo3.pdf. Acesso em: 5 dez. 2016.

CAMARANO A. F.; KANSO S. As instituições de longa permanência para idosos no Brasil. Rev. bras. estud. Popul, v. 27, n. 2, jan-jun. 2010.

CREUTZBERG M.; GONÇALVES L. H. T.; SOBOTTKA E. A. Instituição de longa permanência para idosos: a imagem que permanece. Texto contexto - enferm, v. 17, n. 2, abr-jun. 2008.

DAVIM R. M. B.; TORRES G. V.; DANTAS S. M. M.; LIMA V. M. Estudo com idosos de instituições asilares no município de Natal/RN: características socioeconômicas e de saúde. Rev. Latino-Am. Enfermagem, v. 12, n. 3, mai-jun. 2004.

FREITAS A. V. S.; NORONHA C.V. Idosos em instituições de longa permanência: falando de cuidado. Interface - Comunic. Saude Educ, v. 14, n. 33, p. 359-69, abr-jun. 2010.

KALACHE A. Envelhecimento populacional no Brasil: uma realidade nova. Cad. Saúde Pública, v. 3, n. 3, p. 217-20, set. 1987.

KALACHE A. Envelhecimento populacional no Brasil: uma realidade nova. Cad. Saúde Pública, v. 3, n. 3, jul.-set. 1987.

LIMA R. J.; MEDEIROS F. A. L.; NÓBREGA M. M. L. Perfil das instituições de longa permanência para idosos (ILPIs) na região metropolitana do município de João Pessoa/PB. Anais CIEH, v. 2, n. 1. 2015.

MICHEL T. A vivência em uma instituição de longa permanência: significados atribuídos pelos idosos. Curitiba. Dissertação [Mestrado - Programa de Pós-Graduação em Enfermagem] - Universidade Federal do Paraná. 2010. 


\section{Capítulo 14}

doi $10.37423 / 211004933$

\section{PREVENÇAO DO CANCER CERVICO UTERINO; FATORES PARA NAO REALIZAÇAO}

ALIANDRO WILLY DUARTE MAGALHAES

ANA ANGELICA DE ARAUJO MEDEIROS

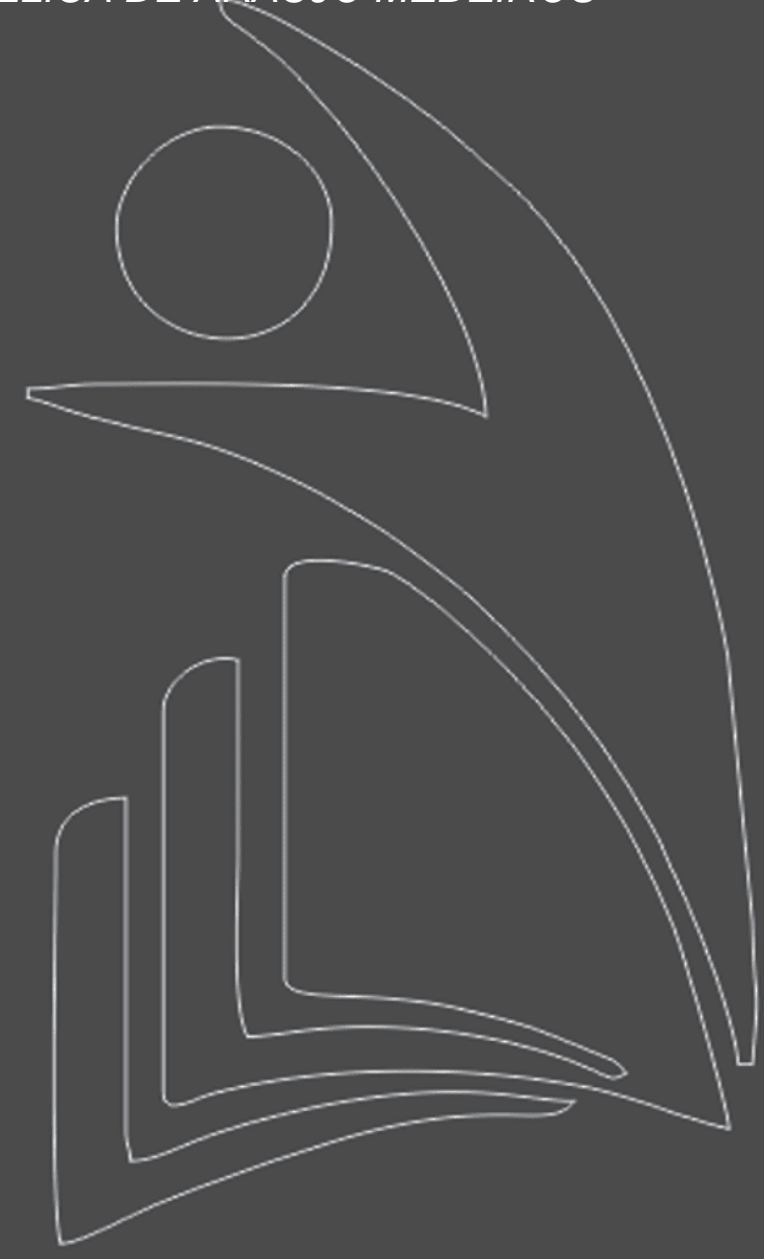

HOSPITAL PORTO DIAS

HOSPITAL PORTO DIAS, 
Resumo: Trata-se de um estudo analítico-descritivo, desenvolvido com o objetivo de identificar os fatores que influenciam a não realização do exame preventivo do câncer de colo uterino (pccu), em pacientes selecionadas de forma aleatória em uma unidade de saúde da família, do município de ananindeua- para. Concluiu-se a necessidade de ampliar as atividades educativas como instrumento formentador de otimização educativa, apontando a importância da realização do exame, aferindo também, o perfil de baixa escolaridade e nível socioeconômico das mulheres no estudo como um agravante motivo para a não realização do exame.

Palavras-chave: Câncer Cervico Uterino; Papanicolau; Exame. 


\section{INTRODUÇÃO:}

O câncer do colo do útero corresponde, aproximadamente, a 15\% de todos os cânceres que ocorrem no sexo feminino.Seu pico de incidência situa-se entre os 40 e 60 anos de idade, sendo pouco frequente abaixo dos 30 anos.

Estima-se que cerca de $40 \%$ das mulheres Brasileiras nunca tenham sido submetidas ao exame citopatológico (Papanicolaou).

\section{OBJETIVOS:}

Identificar os fatores que influenciam a não realização do PCCU na Unidade Saúde da Família CN VI, Ananindeua - PA, no período de abril a outubro de 2010.

\section{METODOLOGIA OU DESCRIÇÃO DA EXPERIÊNCIA:}

O estudo foi analítico-descritivo, desenvolvido no período de abril a outubro de 2010 , na Unidade Saúde da Família Cidade Nova VI, Ananindeua, Pará.Amostra de 200 pacientes, selecionados de forma aleatória. A identificação foi procedida por meio dos cadastros do Programa Saúde da Família. Critérios de inclusão: ter entre 20 a 60 anos de idade, do sexo feminino e assinar um termo de consentimento informado. Critérios de exclusão: pacientes virgens, menores de 20 anos ou maiores que 60 anos ou submetidas a histerectomia total. A coleta de dados foi realizada na Unidade Saúde da Família Cidade Nova VI, Ananindeua, Pará, por meio de entrevista semi-estruturada (Instrumento 1).

\section{RESULTADOS:}

Entre os motivos apontados para a não realização do exame, foram referidos com maior frequência, a dificuldade na marcação, a falta de conhecimento das mulheres acerca da realização do exame, o medo, a vergonha, e o sentimento de angustia frente à realização do exame. A escolaridade e o nível socioeconômico das mulheres também foram apontados como determinantes da não realização do exame de papanicolau.

\section{CONCLUSÃO OU HIPÓTESES:}

Dessa forma, é necessário fazer estudos locais com as pacientes da área de abrangência do PSF CNVI, tendo como variáveis direcionadoras os resultados dos estudos analisados neste trabalho, evidenciando a necessidade de ampliar as atividades educativas, colocando a importância da realização do exame e o rastreamento pela busca ativa das mulheres na faixa de idade preconizadas. 


\section{Capítulo 15}

\section{doi $10.37423 / 211004946$}

\section{EXÉRESE DE DISPLASIA CEMENTO-ÓSSEA PERIAPICAL ASSOCIADA À APICECTOMIA E ENXERTIA COM PLASMA RICO EM FIBRINA (PRF) - RELATO DE CASO}

Alexia Cristina da Cruz Gatti

Laís Santos do Nascimento

Caroline Águeda Corrêa

\section{Bruno Augusto Bènevenuto de Andrade}

Fabiano Luiz Heggendorn

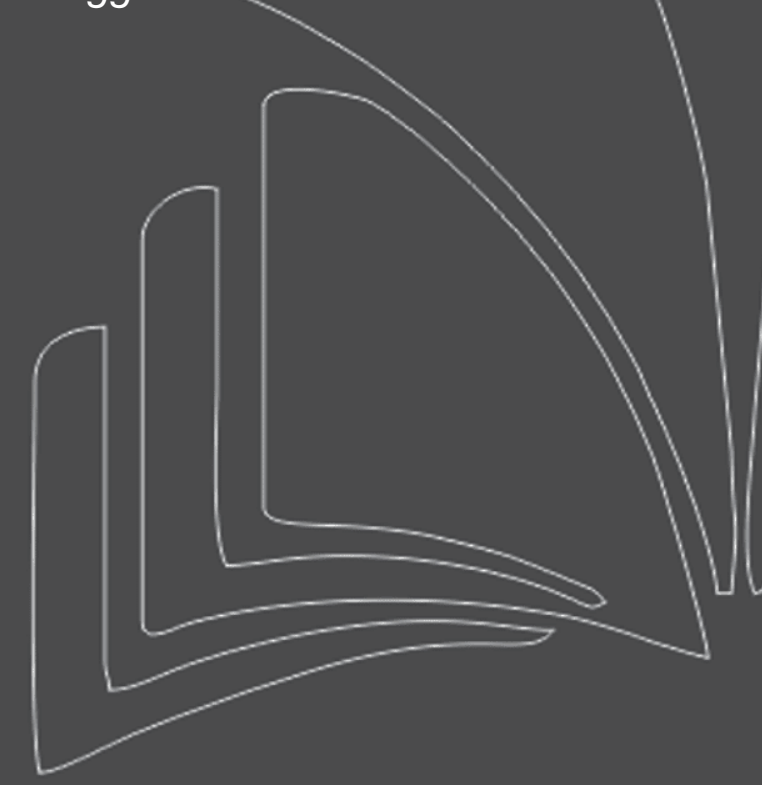

Unigranrio - Universidade do Grande Rio

Unigranrio - Universidade do Grande Rio

Unigranrio - Universidade do Grande Rio

Universidade/Federal do Rio de Janeiro

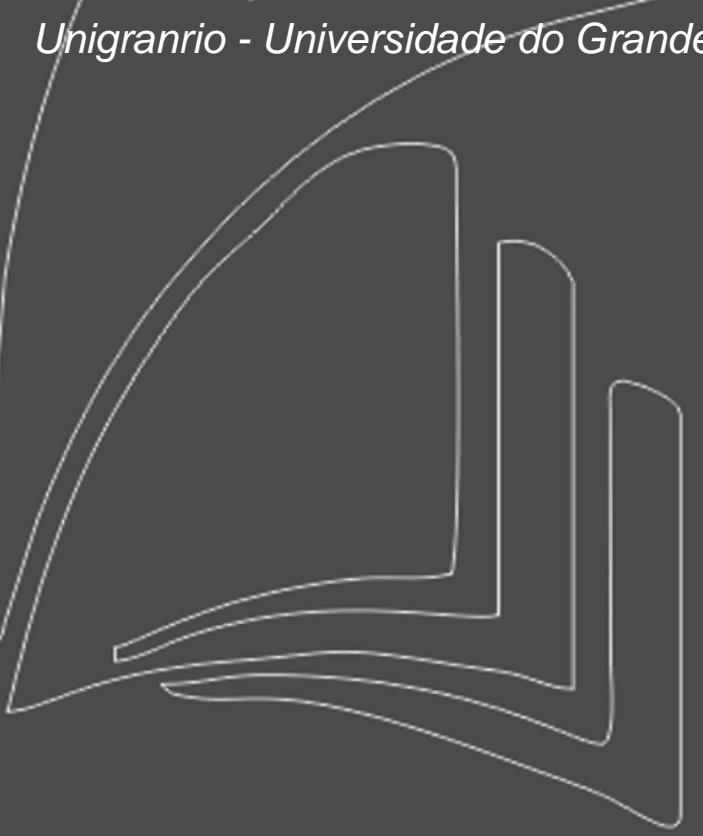


Resumo: O PRF é um agregado plaquetário composto por leucócitos, plaquetas, fibrinas e proteínas que visam a regeneração tecidual, apresentando-se também em forma de membrana - L-PRF. A utilização deste material associado a um material sintético possui alto potencial de neoformação óssea. Este trabalho tem como objetivo descrever as abordagens terapêuticas na resolução de uma Displasia Cemento-óssea Periapical associada a um cisto inflamatório de origem endodôntica de múltiplos elementos dentários. Nestas abordagens foram associadas diferentes técnicas e manobras como a técnica de apicectomia, a curetagem da lesão cística e o preenchimento da lesão pela técnica de Regeneração óssea guiada utilizando enxerto plaquetário autógeno, através da técnica de L-PRF. O acompanhamento a longo prazo revelou núcleos osteodensos indicando um osso maduro central com um osso neoformado circunjacente, possibilitando assim a manutenção do volume ósseo e dos dentes acometidos na lesão.

Palavras-chave: Displasia cemento-óssea periapical; L-PRF; PRF; Apicectomia. 


\section{INTRODUÇÃO}

As lesões fibro-ósseas têm como característica a mutação de seu osso original por tecido fibroso com presença de material mineralizado proveniente de neoformação. São categorizadas como: displasia fibrosa, displasia cemento-óssea e fibroma ossificante central. [1]

A displasia cemento-óssea é uma lesão sem sintomatologia, mais frequentemente encontrada na rotina clínica, sendo encontrada em maxila e mandíbula com origem indefinida e com maior propensão a mulheres melanodermas de meia idade. A partir de seus aspectos clínicos e radiográficos são classificadas como: focal, periapical e flórida. [1-3]

Na displasia cemento-óssea focal a região posterior da mandíbula ou maxila é comumente mais envolvida, exibindo apenas um sítio de envolvimento, enquanto na displasia cemento-óssea flórida há um envolvimento multifocal, envolvendo dois ou mais quadrantes da maxila e mandíbula. Quando há envolvimento na região periapical de incisivos inferiores na parte anterior da mandíbula, é denominada displasia cemento-óssea periapical [1,4], no entanto, pode ser encontrada em outros sítios. Habitualmente os dentes envolvidos na lesão são vitais e não apresentam tratamento restaurador, enquanto suas lesões usualmente são múltiplas e com tendências bilaterais, podendo também aparecer como uma lesão solitária. [5]

A displasia cemento-óssea periapical é uma lesão não sintomática, benigna, que normalmente é diagnosticada radiograficamente por razões que não envolvem a patologia descrita. [1,5] Os exames radiográficos são de extrema relevância na averiguação da região periapical, reconhecendo lesões que possam estar instaladas e, em virtude de seus padrões radiográficos, pode ter como diagnóstico diferencial uma lesão periapical inflamatória. [6]

Em suas características histopatológicas há presença de fragmentos de tecido conjuntivo celular, hemorragia entremeada pela lesão e uma mistura de osso imaturo, osso lamelar e partículas semelhantes a cemento. [1] Nas características radiográficas apresentam um contorno radiolúcido de dimensão volátil, envolta por uma faixa de osso esclerótico que também pode variar em dimensões. $[5]$

Em sua fase primitiva apresentam-se como áreas radiolúcidas limitadas envolvendo a área periapical, podendo raramente acometer a lâmina dura. Na fase mista pode possuir uma forma redonda, oval ou irregular composta de tecido radiopaco e radiolúcido. Em sua fase madura possui calcificação consistente limitada por uma margem radiolúcida afunilada. [1,5] 
O diagnóstico diferencial é mutável de acordo com a fase da lesão [7], que quando não há correta interpretação pode haver erros diagnósticos, como acidentes anatômicos e lesões perirradiculares [8]. Outras doenças como rarefação de osteíte periapical, cementoblastoma benigno, odontoma, osteosclerose idiopática e fibroma cemento-ossificante podem reproduzir características semelhantes a displasia cemento-óssea periapical [5].

O tratamento frequentemente não necessita de intervenções por conta de sua natureza benigna, entretanto na sua fase final há propensão de necrose e infecções secundárias, podendo acarretar seqüestro ósseo por osteomielite. Os tratamentos ortodônticos, endodônticos e cirúrgicos não estão indicados na presença desta lesão. [1,5,9] Nos pacientes que não apresentam sintomatologias são feitas consultas de acompanhamento profilático e reforço de instrução de higiene oral para prevenir doença periodontal e perda dentária. [1,5]

Em casos de associação de lesões císticas ósseas com a displasia óssea é indicada uma intervenção cirúrgica para estabelecer o diagnóstico. Nestes casos a progressão da lesão é esperada, resultando em uma osteomielite de difícil tratamento devido a esclerose generalizada, devendo ser realizada uma excisão ampla com curetagem da lesão cística e da proliferação fibro-óssea, a fim de permitir a resolução. $[1,10]$

Este trabalho tem como objetivo descrever, em forma de relato clínico, as abordagens terapêuticas na resolução de uma Displasia Cemento-óssea Periapical associada a um cisto inflamatório de origem endodôntica de múltiplos elementos dentários. Nestas abordagens foram associadas diferentes técnicas e manobras como a técnica de apicectomia, a curetagem da lesão cística e o preenchimento da lesão pela técnica de Regeneração óssea guiada utilizando enxerto plaquetário autógeno, através da técnica de L-PRF, a fim de minimizar a destruição óssea decorrente da extensão da lesão descrita.

\section{RELATO DE CASO}

O relato de caso foi submetido ao comitê de ética e pesquisa Humana da universidade do Grande Rio (UNIGRANRIO) sob o número CAEE:

Paciente de sexo feminino, 53 anos, melanoderma, portadora de hipertensão e diabetes controlada, apresentou-se no consultório queixando-se de aumento de volume em fundo de vestíbulo, na região mucogengival do dente 33 até o 43. Durante a anamnese foi observado o seu histórico radiográfico, de 12 de setembro de 2014, onde foi identificada uma extensa lesão nestes dentes. Já as radiografias datadas de 11 de outubro de 2016 e 05 de setembro 2017 revelaram a progressão da lesão. Nestas 
imagens radiográficas evidenciou-se a presença de tratamento endodôntico nos dentes 31, 32 e 41, com obturação inadequadados condutos radiculares, aquém dos ápices radiculares, nos dentes $31 \mathrm{e}$ 41. Porém, em 3 de janeiro de 2018 a avaliação clínica revelou aumento de volume na área de fundo de vestíbulo entre os dentes 43 e 33 há 6 meses, sem presença de fístula ou dor, com um aumento de volume periódico.

Após avaliação foram solicitados coagulograma, hemograma completo, glicemia, Radiografia periapical completa, Radiografia panorâmica e tomografia de mandíbula, para planejamento terapêutico e cirúrgico na paciente. A tomografia multi-slice de 64 canais (Software Pixeonv0.2.1) de 17 de janeiro de 2018 revelou uma lesão de aspecto insuflante, predominantemente hipodensa, acometendo o corpo da mandíbula com afilamento da cortical óssea com ruptura da mesma. A lesão possuía $21 \times 9,2 \mathrm{~mm}$ de extensão, nos maiores eixos do plano axial e sagital respectivamente, encontrando-se em correspondência com as raízes dos dentes 43 até o 33, com envolvimento do osso alveolar que os reveste. Já em 3 de março de 2018 a paciente retornou com outra tomografia dental slice, apresentando progressão da lesão com medidas de 26,58 x 17,27 mm de extensão, nos maiores eixos do plano axial e sagital respectivamente.

Figura 1 - Histórico radiográfico de 4 anos de progressão da lesão. Radiografia panorâmica inicial de 2014 (Imagem A) seguida de tratamento endodôntico inadequado dos dentes 32 e 41, no ano de 2016 (Imagem B), com continuidade de progressão da lesão em 2017 (Imagem C). Tomografia multi-slice de crânio do corte axial (Imagem D) e dos cortes sagitais (Imagem E e F) evidenciou o rompimento da cortical vestibular enquanto a tomografia dental Slice indicou as maiores medidas panorâmicas (Imagem G) e transversais (imagem H e I) da lesão cística.

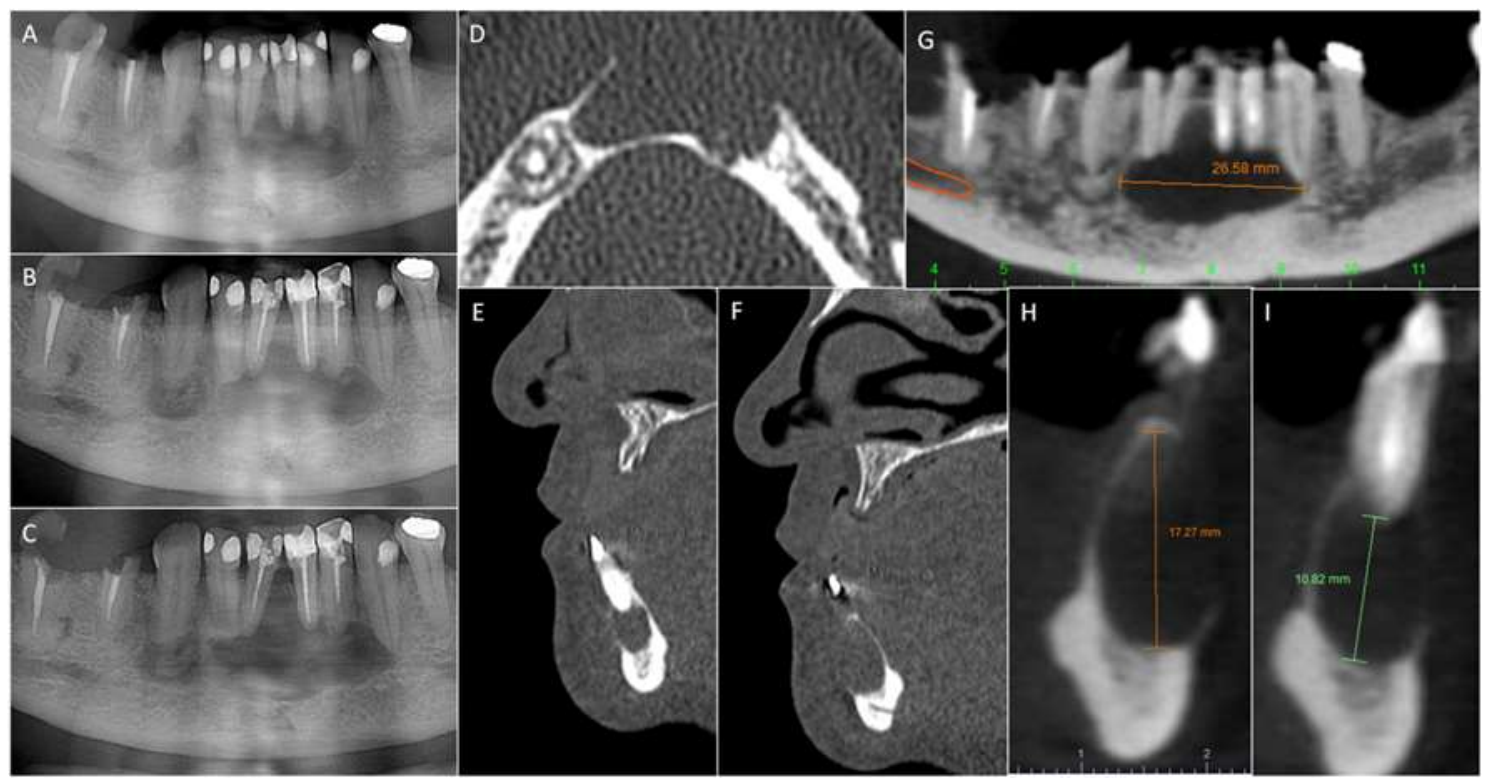




\section{DESCOMPRESSÃO, PUNÇÃO ASPIRATIVA E BIÓPSIA INCISIONAL}

Em 05/03/2018 foi realizada a descompressão da lesão comà instalação de dispositivo (Fig. 2). Paralelamente foram realizadas uma punção aspirativa e uma biópsia incisional da área onde foi feita a incisão para instalação do dispositivo de descompressão, e encaminhada para o Serviço de Anatomia Patológica e Programa de Pós-Graduação em Patologia do Hospital Universitário Antonio Pedro da Universidade Federal Fluminense (UFF).

Figura 2 - Etapas terapêuticas e cirúrgicas. Instalação do dispositivo de descompressão (A) seguida da obturação dos canais radiculares dos dentes 43,42 e 33 (B). A imagem C demonstra o aspecto inicial da lesão após acesso cirúrgico com perda da cortical óssea vestibular do osso mandibular entre os dentes 33 e 43. Exérese excisional da lesão com posterior apicectomia em 45ㅇo dos dentes 32, 31, 41, 42 e 43 (D) seguida de retro-preparo dos canais e exposição do canal mandibular esquerdo (seta preta) (E). A imagem F demonstra o PFR-Block, com posterior compactação no sitio cirúrgico (G), recobrimento com as membranas de L-PRF $(H)$ e finalização com a sutura (I).

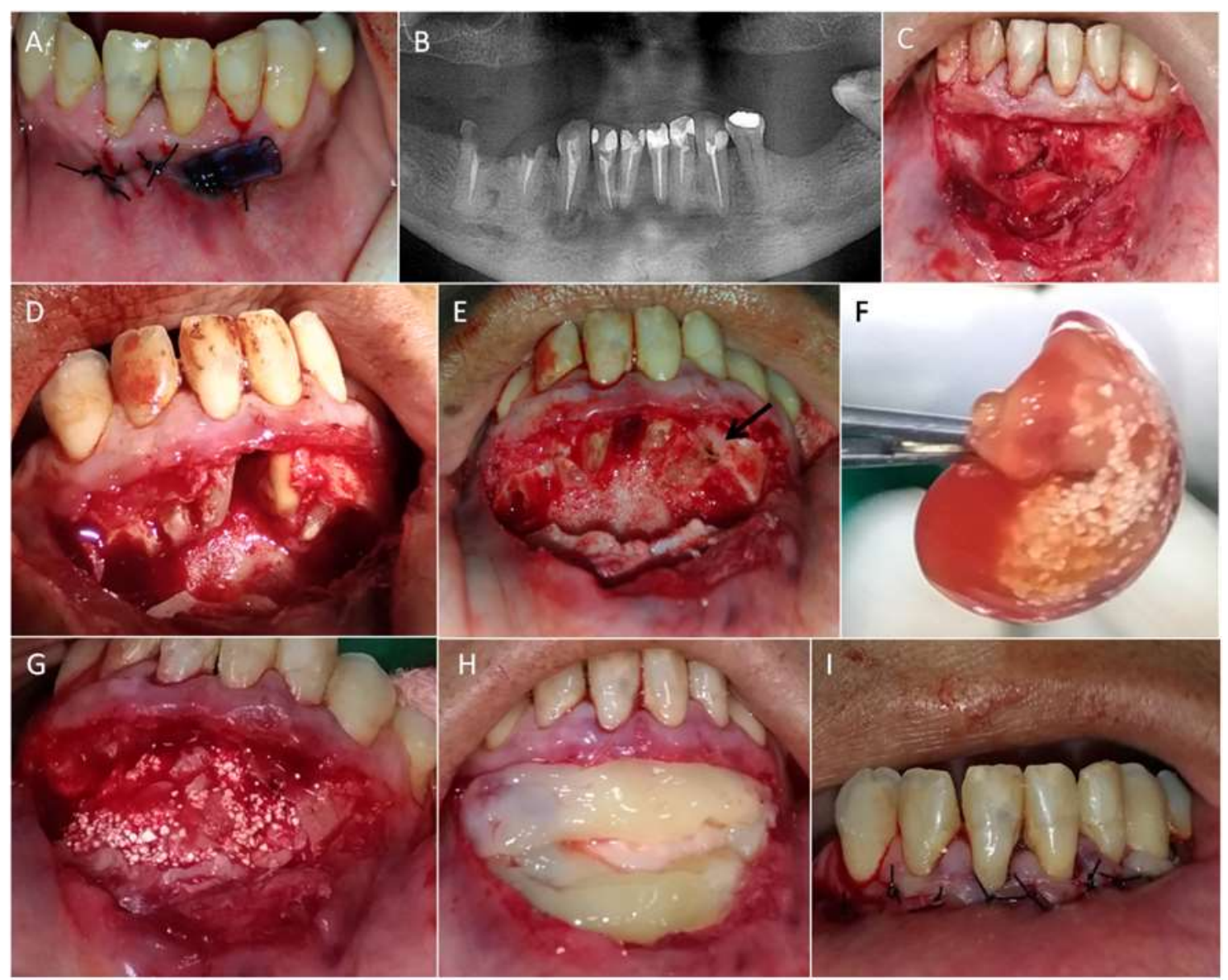

A punção revelou um material de cor amarelo citrino associada a sangue, com volume próximo de 4 ml. Durante a biópsia incisional foi realizada uma curetagem da lesão cística revelando uma reduzida 
quantidade de material coletado de coloração fibrosa amarelada. Posteriormente foi instalado um obturador para descompressão da cavidade cística, e por ele foram feitas irrigações intralesionais. A paciente foi orientada a manter a higiene da cavidade através do dispositivo de descompressão, mantendo as irrigações com seringa de luer 3 vezes ao dia com $20 \mathrm{ml}$ de soro fisiológico 0,9\% e Clorexidina 0,12\%, e prescrito Amoxicilina com ácido clavulânico 500 mg. / 125 mg. 8-8h por 7 dias e Nimesulida 100mg. 12/12 horas por 5 dias.

O resultado do exame histopatológico revelou um tecido conjuntivo fibrovascular e moderado infiltrado inflamatório misto enquanto na citopatologia foram visualizadas células inflamatórias e presença de bactérias. Tais achados indicaram como provável diagnóstico um cisto inflamatório ou uma displasia cemento-óssea.

Com os exames de imagens somados aos achados histopatológicos e citológicos foi elaborado o planejamento cirúrgico para a paciente consistindo em condicionamento endodôntico dos dentes englobados pela lesão, por meio de tratamento endodôntico dos dentes, a fim de prepará-los para a extensa cirurgia, que acarretaria na possível necrose pulpar dos dentes envolvidos na lesão, devido o rompimento dos feixes vásculo-nervosos.

\section{PREPARO DOS CANAIS RADICULARES}

Em 16/03/2018, onze dias após a instalação do dreno de descompressão, foi iniciado o tratamento endodôntico dos dentes 43 e 42 . Foi realizado o acesso, a instrumentação dos canais e aplicação de hidróxido de cálcio nos elementos 43 e 42, como curativo de demora. Nesta mesma sessão foi identificada a perda do dispositivo de descompressão, devido a dificuldade em manter tal dispositivo no fundo de vestíbulo do lábio inferior, permanecendo uma pequena fístula no local de drenagem.

A obturação dos canais ocorreu 27 dias após iniciado, permanecendo o curativo intracanal de hidróxido de cálcio neste período. Nesta ocasião foi verificada uma redução do tamanho do edema local.

\section{APICECTOMIA, BIÓPSIA EXCISIONAL E ENXERTIA}

Passados cinco dias da finalização do tratamento endodôntico, dia 18/04/2018, a lesão não apresentou mudança de padrão clínico permitindo iniciar a cirurgia de exérese excecional associada à apicectomia dos dentes englobados na lesão e enxertia de biomaterial particulado e autólogo de fibrina rica em plaquetas (PRF). 


\section{PRF - PREPARAÇÃO E APLICAÇÃO}

O PRF foi preparado seguindo o protocolo desenvolvido por Choukroun ${ }^{11}$. Antes da cirurgia, o sangue venoso foi coletado em 8 tubos estéreis de $10 \mathrm{ml}$ sem anticoagulante e imediatamente centrifugados por 2.700 RPM para a divisão da amostra de sangue em três camadas. A base com sangue vermelho, o meio com o coágulo de PRF e a parte superior com plasma acelular ${ }^{12}$. Dois tubos foram centrifugados por 3 min. para preparo do PRF-BLOCK e os demais seis tubos foram centrifugados por 12 min., para preparo das membranas de fibrina rica em plaquetas e leucócitos (L-PRF). Após a centrifugação de 12 min., foi coletado com pinça estéril o coágulo de PRF dos seis tubos, e posteriormente foi realizada a separação do corpúsculo vermelho do coágulo de PRF, mantendo o buff-colt intacto, seguindo para a compressão na PRF-BOX para obtenção das membranas de L-PRF.

Uma membrana de L-PRF foi picotada e misturada à fibrina líquida, dos dois tubos de PRF que foram centrifugados por 3 min. Esta mistura foi adicionada a 1g. do biomaterial Nanosynt (FGM, Dentscare Ltda, Brasil), um enxerto sintético a base de fosfato de cálcio, para a preparação do PRF-BLOCK, gerando assim um composto moldável para a área cirúrgica (Fig. 2).

\section{APICECTOMIA}

Após as incisões oblíquas com finalidade relaxante, foi realizado o retalho total da mucosa alveolar, com exposição total da área da lesão cística, via cortical óssea vestibular entre os dentes 33 e 43 . Após exposição da área cirúrgica foi realizada uma a curetagemdas paredes da lesão, sob irrigação de solução fisiológica, para remoção de tecido de granulação, com verificação de presença de coleção purulenta no sítio cirúrgico (Fig. 2). O material curetado da lesão foi acondicionado em solução de formol 10\% e encaminhado para análise histopatológica no Laboratório de Patologia Oral da Faculdade de Odontologia da Universidade Federal do Rio de Janeiro.

Posteriormente foi realizada a apicectomia em 45으 dos ápices radiculares dos dentes 32, 31, 41, 42 e 43, seguida de retro-preparo com broca esférica, limpeza com ultrassom e retro-obturação com cimento reparador endodôntico MTA (Angelus Ltda). Devido àextensão da cirurgia foi necessário realizar a cauterização do prolongamento da artéria alveolar inferior esquerda, exposta durante a cirurgia (Fig. 2).

Após a finalização da apicectomia foi realizada a enxertia com o PRF-BLOCK, ou Sticky Bone, preenchendo suavemente toda a cavidade cirúrgica com este biomaterial. Em seqüência, com o sítio 
já preenchido, foi realizado o recobrimento de toda a área enxertada com 4 membranas de L-PRF e finalizada com uma sutura colchoeiro horizontal e diversas suturas simples (Fig. 2).

A análise histopatológica do material curetado foi compatível com displasia cemento-óssea periapical com presença de áreas de inflamação (Fig. 3).

Figura 3 - Coloração Hematoxilina-eosina. Fotomicrografia (magnificação de x100) apresentando fragmentos de tecido conjuntivo fibroso celular contendo trabéculas irregulares de osso. Massa esclerótica focal de material ósseo (Setas).

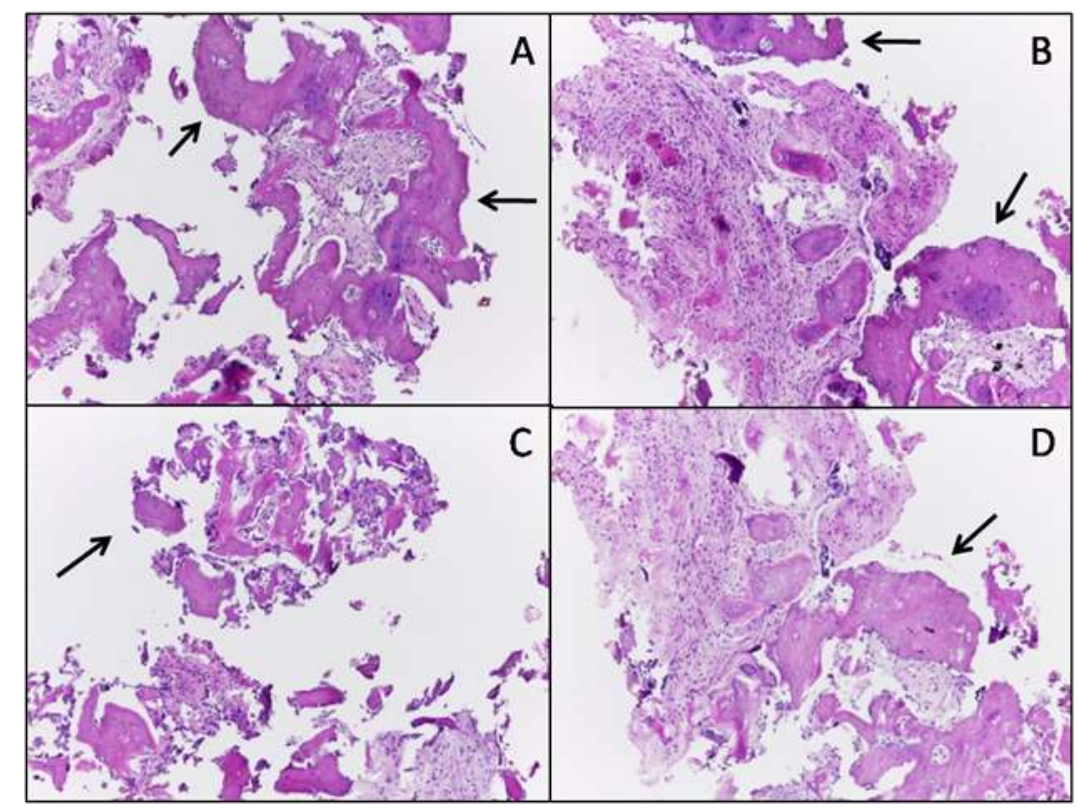

O acompanhamento pós-operatório ocorreu 15 dias após a cirúrgica com a remoção da sutura. $\mathrm{Na}$ ocasião a paciente apresentava recessão gengival e leve parestesia local, sem intercorrências adicionais. Clinicamente o sítio cirúrgico apresentava regressão do edema e ausência de fístula. Posteriormente a paciente permaneceu em acompanhamento clínico e radiográfico semestralmente. O acompanhamento radiográfico permitiu verificar a neoformação óssea local com a expansão e aumento da radiolucidez local no sítio cirúrgico. Com 54 dias foi possível visualizar, através da radiografia panorâmica, os locais onde se encontravam os núcleos de enxertia óssea, cercados por uma margem radiopaca. Com o tempo foi possível visualizar a expansão desses núcleos com aumento da radiopacidade a partir de 5 meses e 9 meses. Já a radiografia com 2 anos e 4 meses de pósoperatório sugere uma total osseointegração dos núcleos de enxertia e neoformação óssea. Já o elemento 43 ainda apresenta distinta área radiopaca o que sugere necessidade de controle local, entretanto nesta mesma área nota-se aumento da radiolucidez quando comparada as radiografias anteriores (Fig.4). 
Figura 4 - Acompanhamento pós-operatório. Radiografia panorâmica com 54 dias de pós-operatório demonstrando núcleos distintos do enxerto $(A)$ e recessão gengival nos elementos 31 e 41 (B). Com o tempo foi possível visualizar a neoformação óssea local nos períodos de 5 meses (C), 9 meses (D) e 2 anos e 4 meses (E) de pós-operatório.

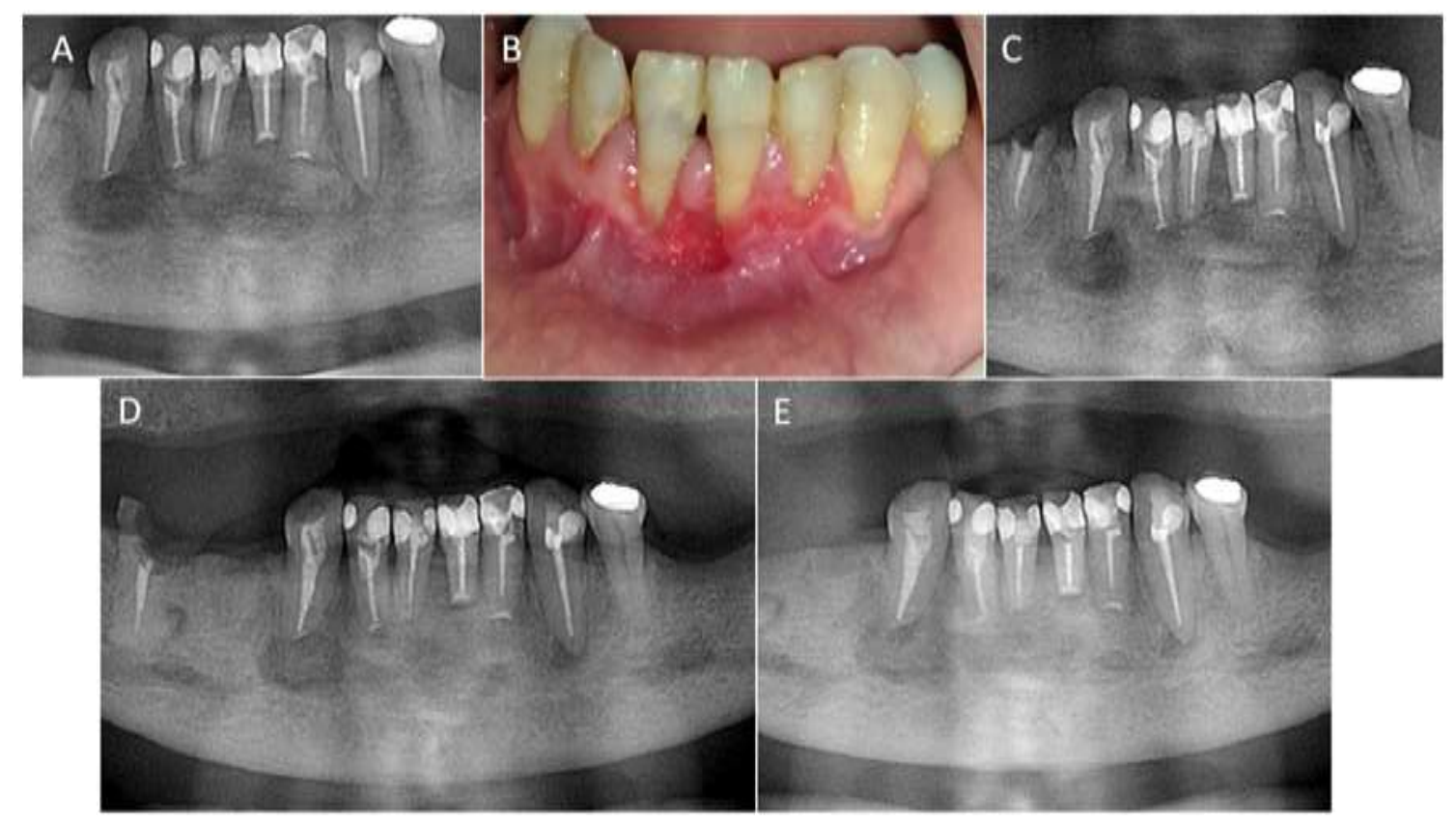

\section{DISCUSSÃO}

A associação de uma lesão cística dentro de uma área já alterada histologicamente pela presença da displasia cemento-óssea periapical dificulta a resolução do processo inflamatório devido a esclerose óssea generalizada $[1,10]$. Tal fato foi constatado com o histórico radiográfico de 4 anos da paciente, indicando a expansão progressiva da lesão, mesmo após o tratamento endodôntico dos dentes 41, 31 e 32. A progressão crônica do processo inflamatório resultou em uma osteomielite comprometendo os espaços medulares e rompendo a cortical vestibular e lingual da mandíbula. Sendo indicado um planejamento de excisão ampla com curetagem da lesão cística e da proliferação fibro-óssea $[1,10]$. Devido à característica da lesão foi necessário associar a técnica de apicectomia dos dentes envolvidos pela lesão, a fim de garantir a eliminação de possíveis focos perirradiculares.

A descompressão é uma técnica realizada sob anestesia local que realiza a instalação de um obturador que previne o fechamento da cavidade, com o objetivo de reduzir a pressão intracística promovendo a regressão da lesão e neoformação óssea [13-16]. É indicada quando há proximidade de estruturas anatômicas nobres e prevenção de deformações, diminuindo o percentual de complicações como lesão do nervo, fratura patológica e desconforto do paciente [14,15,17]. Durante seu uso deve ser feita 
a higiene com clorexidina a $0,12 \%$ e solução salina. Quando associada a enucleação a taxa de recorrência é menor, porém é necessário consultas periódicas para um bom prognóstico $[13,15,16,17]$. Os resultados de Tabrizi et al. [14] demonstraram uma menor taxa de recorrência na descompressão, seguida de enucleação em comparação com a enucleação pura. Tal evidência sugere que a primeira manobra realizada na paciente favoreceu a regeneração, que de forma parcial, do sítio cirúrgico reduzindo a carga microbiana intraóssea. Mesmo com o curto período de permanência do dispositivo, o acesso permitiu a manutenção de uma fístula permitindo a higienização com clorexidina e a drenagem do processo inflamatório.

A apicectomia é uma possibilidade cirúrgica para o tratamento endodôntico tradicional quando o mesmo fracassa ou não acessível. Ela constitui-se na exposição do ápice radicular, excisão apical, retropreparo apical seguido de retrobturação. Uma de suas indicações é a infecção apical crônica, podendo prevenir uma possível exodontia [18-20]. A secção apical da raiz pode ser realizada em ângulos de 30, 45ㅇo ou 90‥ Diferentes trabalhos sugeriram que o ângulo de 45을 apresenta maior microinfiltração, que pode ser minimizada pelo uso de ultrassom durante o retropreparo, possuindo maior efetividade do que a angulação de 90․ Em contrapartida, a secção em 90 o apresenta menor microinfiltração e melhor proporção coroa-raiz. Segundo os autores, o retropreparo em 45 facilita a inserção de material na cavidade $[18,20]$. Como desvantagem, no plano em 45 o pode haver alterações em radiografias pós-cirúrgicas, maior força biomecânica, perda dentinária, cementaria e óssea, podendo acarretar uma cicatrização ineficiente $[18,21]$. Contrariamente, a realização do retropreparo em 45, no caso apresentado, resultou em uma completa regeneração da região periapical, com neoformação. O retropreparo em 45 facilita a inserção do MTA na região periapical pela manutenção de uma parede lingual no retropreparo facilitando o escoamento do material no momento de inserção do biomaterial, não permitindo assim o deslocamento para uma região posterior, a região lingual da raiz.

Após a apicectomia é necessário ao menos $3 \mathrm{~mm}$ de profundidade no retropreparo $[18,20]$ a fim de garantir um volume adequado de biomaterial para o selamento apical adequado. Para a retrobturação, o Agregado de trióxido mineral (MTA) mostra-se o material de escolha por apresentar menor infiltração, devido a sua eficácia no vedamento e adaptação marginal e biocompatibilidade $[18,20]$. A apicectomia quando aplicada em todas as suas etapas técnicas, garante o controle infeccioso e a eliminação de possíveis focos bacterianos, demonstrando possível redução da lesão com 
neoformação óssea $[18,20]$ como relatado no presente caso com a preservação de 2 anos e 4 meses do sítio cirúrgico.

A regeneração óssea guiada (ROG) é um procedimento que promove uma melhor neoformação óssea em conjunto com a apicectomia [23,24], também sendo associado a tratamentos cirúrgicos endodônticos para tratamento de lesões do periápice [24]. Já o uso do composto de i-PRF em associação com materiais de enxertia óssea formam o agregado plaquetário chamado Sticky Bone, com fácil modelagem e manuseio por apresentar-se como um enxerto ósseo de fibrina estável, possuindo propriedades osteocondutoras e osteogênicas. A fibrina rica em plaquetas e leucócitos (LPRF) tem sido utilizada como uma membrana de cobertura, atuando como uma barreira, e por apresentar fatores de crescimento proporcionando uma mais rápida osteogênese e cicatrização [23]. A utilização destas técnicas sobre uma deiscência óssea pode impedir a propagação do epitélio oral e do tecido conjuntivo gengival proliferem no defeito ósseo, possibilitando que o tecido ausente seja reabilitado por células do ligamento periodontal e do endósteo, que invadem o coágulo sanguíneo [24].

O L-PRF é um aglomerado plaquetário de segunda geração, sem adição de antiplaquetários ou trombinas, podendo ser utilizado em forma de membrana (L-PRF) ou como substituto ósseo, permitindo a migração de células de osteogênicas a fim de possibilitar a diferenciação celular e a neovascularização. Alguns artigos relatam a redução de edema e dor pós-operatória, além de promover a regeneração óssea guiada por conter citocinas e fatores de crescimento, desempenhando um papel de barreira biológica, além garantir um ganho tecidual na mucosa inserida no sítio cirúrgico [25-27]. Em adição, tal técnica possibilita uma redução de custo, por reduzir o gasto com membranas industrializadas além de exigir um menor volume de material de enxertia para fazer o PRF Block [2527].

A junção deste agregado em sua forma fluida (i-PRF) ao biomaterial sintético resulta em uma substância mais adesiva e estável chamada de Sticky Bone ou PRF Block, que promove maior estabilidade dos enxertos, hemostasia, facilidade de manipulação, além de induzir rápida cicatrização, maturação óssea e melhor aspecto final periodontal $[23,25,28]$. Este material realiza osteoindução, acompanhada de osteocondução e osteoproliferação $[23,28]$.

Indicado como um coadjuvante na cicatrização, Stroparo et al. [23] relataram as vantagens da técnica de L-PRF quando empregado nas cirurgias de apicectomia reduzindo as seqüelas resultantes desta cirurgia. $\mathrm{O}$ uso deste recurso em associação com a apicectomia impede a migração celular epitelial e 
conjuntiva desenvolvendo a neoformação e aprimorando a qualidade do reparo e seu aspecto final cirúrgico; possui maior rapidez na osteogênese e na regeneração tecidual por conta de sua atuação como barreira. Como desvantagens o L-PRF apresenta um volume limitado, visto que é um material autólogo, possui o custo do equipamento elevado e necessidade de um operador capacitado [29-31]. A abordagem terapêutica de lesões císticas associadas a necessidade de cirurgia paraendodôntica do elemento dentário associado requer um acesso cirúrgico maior, com maior deslocamento tecidual, de mucosa e gengiva inserida, o que pode resultar em retração gengival, pregas mucosas e envolvimentos estéticos gengivais. No caso apresentado aqui a paciente apresentou como conseqüência uma leve retração gengival nos elementos dentários 41 e 31. Em abordagens terapêuticas semelhante, Kulkarni et al. [32] relataram perda óssea periapical no pós-cirúrgico de um caso relatado, enquanto no segundo caso, com a remoção de uma raiz mesiolingual, houve a perfuração do seio sinusal, sendo contornado tal incidente transcirúrgico com uma membrana de colágeno.

Assim como no relato apresentado, outros autores empregaram a técnica de ROG associada a apicectomia e PRF, apesar de apresentar pequenas variações na abordagem cirúrgica apresentada [3235]. Pode-se constatar o sucesso clínico em lesão extensa na região periapical anterior de maxila abordada com tratamento endodôntico dos dentes 11,12,23, enucleação da lesão, apicectomia com ponta ultrassônica e enxertia de osso autógeno, do ramo da mandíbula, associado a PRF e com posterior recobrimento L-PRF [35]. Já Jayalakshmi et al. [33] relataram uma abordagem semelhante, adicionando o fosfato $\beta$-tricálcico no aglomerado de PRF. Posteriormente, Uppada et al. [34] associaram hidroxiapatita e membrana amniótica a técnica de PRF durante uma cirurgia paraendodôntica. Outras variações incluem o preenchimento da cripta óssea com PRF e cobertura com membrana de colágeno [32], preenchimento com fibrina em gel CGF (fatores de crescimento concentrados) e cobertura com membrana CGF [36]. Também foi possível verificar o emprego isolado do A-PRF na enucleação de uma lesão cística maxilar, resultando em uma grande redução da lesão [37].

A associação da técnica de ROG, vastamente aplicada na implantodontia, com a cirurgia paraendodôntica é recente, ainda são poucos os relatos encontrados na literatura, com diferentes abordagens na associação dos biomateriais com o PRF, porém as vantagens dessa associação sugerem ser benéficas, especialmente para os casos de destruição ósseo extensa, com prognósticos duvidosos. 


\section{CONCLUSÃO}

Levando em consideração o extenso tamanho da lesão cística, os aspectos da técnica de apicectomia associada a regeneração óssea guiada com a técnica de PRF sugeriram ser benéficos quando associados, garantindo a neoformação óssea por toda a cripta cirúrgica. O acompanhamento a longo prazo revelou núcleos ósseo densos indicando um osso maduro central com um osso neoformado circunjacente, possibilitando assim a manutenção do volume ósseo e dos dentes acometidos na lesão. 


\section{REFERÊNCIAS BIBLIOGRÁFICAS}

1. Neville BW, Damm DD, Allen CM, Bouquot JE. Patologia Oral e Maxilofacial. 4ạ ed. São Paulo: Editora Elsevier; 2016.

2. Gaetti-Jardim EC, Santiago Júnior JF, Guastaldi FPS, Magro Filho O, Garcia Júnior IR, Gaetti Jardim Júnior E. Displasia Cemento-Óssea Florida: Relato De Caso. Rev Odontológica de Araçatuba 2010; 31(2): [4 p.].

3. Cavalcanti PHP, Nascimento EHL, Pontual MLA, Pontual AA, Marcelos PGCL, Perez DEC, Ramos-Perez FMM. Cemento-Osseous Dysplasias: Imaging Features Based on Cone Beam Computed Tomography Scans. Braz Dent J 2018; 29(1): [6 p.].

4. Belo AS, Silva RV, Pereira RP, Rodrigues JCB. Importance of endodontic diagnosis regarding periapical cemento-osseous dysplasia: literature review. Dental Press Endod 2017; 7(2): [7 p.].

5. White SC, Pharoah MJ. Radiologia Oral: Princípios e Interpretação. 7ạ ed. St. Louis: Mosby; 2015.

6. Oliveira LN, Líbera JD, Oliveira MEDFS, Carvalho MMD, Villela-Rosa ACM, Boer NCP, Fernandes KGC, Oliveira LESD. A radiologia no diagnóstico de displasia cemento-óssea periapical. Ver Odontol UNESP 2020; 49: [1 p.].

7. Marcucci G. Fundamentos de Odontologia: Estomatologia. 1a ed. Rio de Janeiro: Ed. Guanabara Koogan; 2005.

8. Hargreaves KM, Cohen S. Caminhos da Polpa - Endodontia. 10a ed. Elsevier: Rio de Janeiro; 2010.

9. Consolaro A, Hadaya O, Consolaro RB. A contraindication to orthodontic and endodontic treatment: periapical cemento-osseous dysplasia. Dental Press J Orthod 2020; 25(5): [6 p.].

10. Cawson RA; Odell EW. Cawson's essentials of oral pathology and oral medicine. 7ạ ed. London: Elsevier; 2002.

11. Dohan DM, Choukroun J, Diss A, Dohan SL, Dohan AJJ, Mouhyi J, et al. Platelet-rich fibrin (PRF): A second-generation platelet concentrate. Part I: Technological concepts and evolution. Oral Surg Oral Med Oral Pathol Oral Radiol Endod 2006; 101: [8 p.].

12. Ehrenfest DMD, Corso MD, Diss A, Mouhyi J, Charrier JB. Three-Dimensional Architecture and Cell Composition of a Choukroun's Platelet-Rich Fibrin Clot and Membrane. J. Periodontol 2010; 81(4): [10 p.].

13. Da Silva YS, Queiroz AGDS, Ferraz FWDS, Pinto DDS Júnior, Nunes FD, Elias FM. Effectiveness of surgical decompression in the treatment of a calcifying cystic odontogenic tumor. Autops Case Rep 2014; 30(4): [7 p.].

14. Tabrizi R, Kordkheili MRH, Jafarian M, Aghdashi F. Decompression or Marsupialization; Which Conservative Treatment is Associated with Low Recurrence Rate in Keratocystic Odontogenic Tumors? A Systematic Review. J Dent (Shiraz) 2019; 20(3): [7 p.]. 
15. Emam, H. A., Smith, J., Briody, A., \& Jatana, C. A. (2017). Tube Decompression for Staged Treatment of a Calcifying Odontogenic Cyst-A Case Report. J Oral Maxillofac Surg 2017; 75(9): [20 p.].

16. Riachi F, Khairallah CM, Ghosn N, Berberi AN. Cyst volume changes measured with a 3D reconstruction after decompression of a mandibular dentigerous cyst with an impacted third molar. Clin Pract 2019; 9(1): [6 p.].

17. Park JH, Kwak EJ, You KS, Jung YS, Jung HD. Volume change pattern of decompression of mandibular odontogenic keratocyst. Maxillofac Plast Reconstr Surg 2019; 41(1): [6 p.].

18. Post LK, Lima FG, Xavier CB, Demarco FF, Gerhardt-Oliveira M. Sealing ability of MTA and amalgam in different root-end preparations and resection bevel angles: an in vitro evaluation using marginal dye leakage. Braz Dent J 2010; 21(5): [4 p.].

19. Andelin WE, Browning DF, Hsu GR, Roland DD, Torabinejad M. Microleakage of Resected MTA. J Endod 2002; 28(8): [2 p.].

20. Oliveira GAA, Moreira Júnior G, Silveira AP, Pereira da Mata Santos R, Manzi FR. In vitro evaluation of apical microleakage in retrofillings with different resection angles. Acta Odontol Latinoam 2019; 32(3): [5 p.].

21. Mandava P, Bolla N, Thumu J, Vemuri S, Chukka S. Microleakage evaluation around retrograde filling materials prepared using conventional and ultrasonic techniques. J Clin Diagn Res 2015; 9(2): [4 p.].

22. Stroparo JLO, Stroparo GF, Stroparo JFO, de Oliveira GC, Neto ADT, La Forcada SMB et al. Apicectomia associada à regeneração óssea guiada: relato de caso. RSBO 2021; 18(1): [5 p.].

23. Goyal B, Tewari S, Duhan J, Sehgal PK. Comparative Evaluation of Platelet-rich Plasma and Guided Tissue Regeneration Membrane in the Healing of Apicomarginal Defects: A Clinical Study. J Endod $2011 ; 37(6):$ [8 p.]

24. Mauceri R, Murgia D, Cicero O, Paternò L, Fiorillo L, De Caro V, Campisi G. Leucocyte- and PlateletRich Fibrin Block: Its Use for the Treatment of a Large Cyst with Implant-Based Rehabilitation. Medicina (Kaunas) 2021; 57(2): [8 p.].

25. Heggendorn FL, Heggendorn C, Vidal F, Silva GCC, Gonçalves LS, Lione VOF. Leukocyte-platelet rich fibrin on the treatment of a large paradental cyst: a novel regenerative approach. Blood Coagulation \& Fibrinolysis: an International Journal in Haemostasis and Thrombosis 2021; 32(6): [7 p.].

26. Barbosa IMG, Albuquerque G, Amorim J. L-PRF Como Tratamento De Pacientes Com Osteonecrose. Revista Cathedral 2020; 2(1): [19 p.].

27. Vidhale G, Jain D, Jain S, Godhane AV, Pawar GR. Management of Radicular Cyst Using PlateletRich Fibrin \& Iliac Bone Graft - A Case Report. J Clin Diagn Res 2015; 9(6): [3 p.].

28. Francisco I, Fernandes MH, Vale F. Platelet-Rich Fibrin in Bone Regenerative Strategies in Orthodontics: A Systematic Review. Materials (Basel) 2020; 13(8): [15 p.]. 
29. Jovani-Sancho MM, Sheth CC, Marqués-Mateo M, Puche-Torres M. Platelet-Rich Plasma: A Study of the Variables that May Influence Its Effect on Bone Regeneration. Clin Implant Dent Relat Res 2016; 18(5): [14 p.].

30. Choukroun J, Diss A, Simonpieri A, Girard M, Schoeffler C, Dohan SL, Dohan AJJ, Mouhyi J, Dohan DM. Platelet-rich fibrin (PRF): A second-generation platelet concentrate. Part IV: Clinical effects on tissue healing. Oral Surg Oral Med Oral Pathol Oral Radiol Endod 2006; 101(3): [5 p.].

31. Kulkarni MR, Mohan J, Bakshi PV. Platet-Rich Fibrin as a Grafting Material in a Periapical Surgery: A Case Series. Int J Periodontics Restorative Dent 2019; 39(4): [5 p.].

32. Jayalakshmi KB, Agarwal S, Singh MP, Vishwanath BT, Krishna A, Agrawal R. Platelet-Rich Fibrin with $\beta$-Tricalcium Phosphate-A Noval Approach for Bone Augmentation in Chronic Periapical Lesion: A Case Report. Case Rep Dent 2012; (2012): [6 p.].

33. Uppada UK, Kalakonda B, Koppolu P, Varma N, Palakurthy K, Manchikanti V, Prasad S, Samar S, Swapna LA. Combination of hydroxyapatite, platelet rich fibrin and amnion membrane as a novel therapeutic option in regenerative periapical endodontic surgery: Case series. Int J Surg Case Rep 2017; 37(2017): [6 p.].

34. Camargo JMP, Braga T, Camargo R, Love RM, Reher P. Surgical management of a large radicular cystusing modified guided tissue regeneration techniques: a case report with 4 years follow-up. Oral Surgery 2019; 4(12): [9 p.].

35. Sureshbabu NM, Selvarasu K, Kumar VJ, Nandakumar M, Selvam D. Concentrated Growth Factors as an Ingenious Biomaterial in Regeneration of Bony Defects after Periapical Surgery: A Report of Two Cases. Case Rep Dent 2019; (2019): [6 p.].

36. Mitrea M, Rusu A, Călin DL. The Management Of Periapical Maxillary Cyst By Using The A-Prf (Platelet Rich Advanced Fibrin): A Case Report. Romanian J of Oral Rehabilitation 2015; 2(15): [9 p.]. 


\section{Capítulo 16}

\section{doi $10.37423 / 211104956$}

\section{UNIDADES HEMOTERÁPICAS E HEMOCENTROS DO SUL DE MINAS GERAIS: IMPACTOS DA PANDEMIA DA COVID-19 NOS ESTOQUES DE BOLSAS DE SANGUE E GESTÃO DOS SERVIÇOS}

Ana Cláudia de Oliveira Silva

Roberta Ribeiro de Carvalho

Amilton Marques

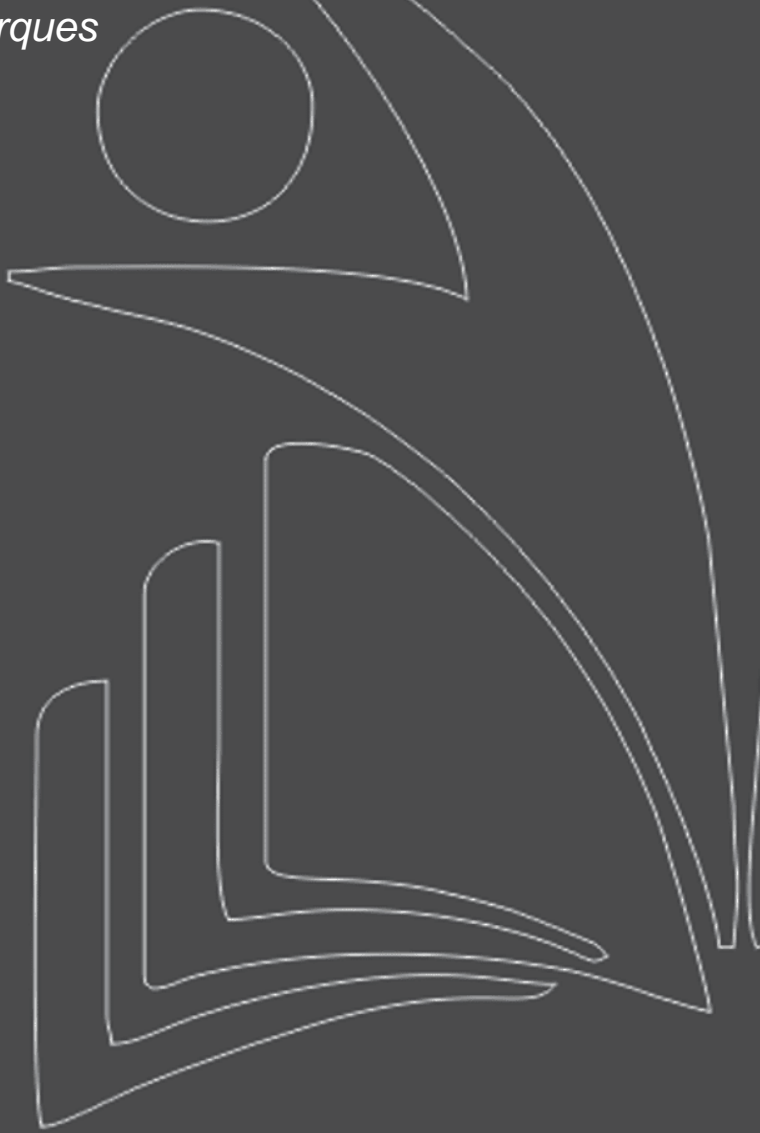

Centro Universitário do Sul de Minas

Centro Universitário do Sul de Minas

Centro Universitário do Sul de Minas

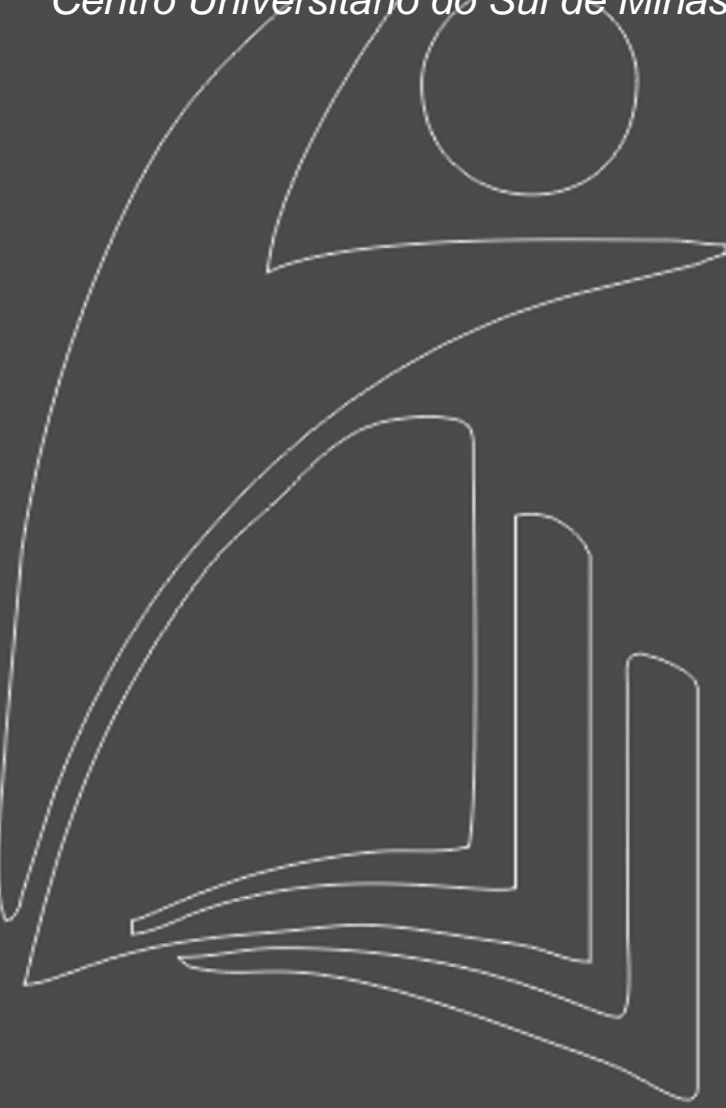


Resumo: Dentre os diversos impactos causados pela Covid-19, cabe destacar uma redução no número de doações de sangue, refletindo no abastecimento de produtos sanguíneos e nos serviços de saúde. O propósito deste estudo é evidenciar quais os principais efeitos que a pandemia da Covid-19 tem gerado nos serviços hemoterápicos, levando em consideração os níveis de estoque sanguíneo e estratégias de mudanças na gestão. Um questionário online foi aplicado aos profissionais responsáveis pelas unidades de coleta e transfusão e hemocentros da região do sul de Minas Gerais. Um total de 11 (onze) instituições responderam ao questionário, e 81,8\% relataram que houve uma diminuição dos estoques sanguíneos. Mais da metade dos centros hemoterápicos (54,5\%) perceberam essa redução ainda no primeiro semestre de 2020. Os tipos sanguíneos e plaquetários que mais sofreram queda foram $\mathrm{O}$ positivo e $\mathrm{O}$ negativo. Foram necessárias a realização de mudanças como intensificação das campanhas de doação, necessidade de adoção de novas medidas de trabalho e capacitação dos colaboradores. Medidas de proteção também foram adotadas, como uso máscaras de proteção, maior frequência de higienização das mãos e superfícies com álcool em gel e distanciamento social. 0 presente trabalho se apresenta como necessário para descrever que, mesmo com a pandemia os suprimentos sanguíneos são de extrema importância e que todas as medidas de segurança estão sendo tomadas visando a segurança dos pacientes e colaboradores.

Palavras-chave: Covid-19. Impactos. Unidades de coleta e transfusão. Hemocentro 


\section{INTRODUÇÃO}

A Organização Mundial da Saúde (OMS) declarou no mês de março de 2020 a pandemia causada pelo novo coronavírus (SARS-CoV-2), cuja doença recebeu o nome de COVID-19 (Coronavirus Disease 2019). O vírus, transmissível entre humanos, causa doenças respiratórias de amplo espectro clínico, variando de infecções assintomáticas a quadros considerados graves e muitas vezes fatais, o que levou diversos países a adotarem o distanciamento social para mitigar sua disseminação (YUKI; FUJIOGI; KOUTSOGIANNAKI, 2020; WANG et al., 2020).

Dentre os diversos impactos causados pela Covid-19, cabe destacar uma significativa diminuição no número de doações de sangue, pois muitas pessoas foram contaminadas houve isolamento social e, além disso, houve um aumento na rejeição de doadores possivelmente assintomáticos (LEITÃO, 2020). Referido período crítico dificultou ainda mais o ato da doação de sangue. O aumento no número de casos, o medo de ser contaminado e as restrições sanitárias têm sido uma barreira ao serviço hemoterápico, já que a doação de sangue é um ato que depende da disponibilidade e voluntariedade do doador. Além disso, o sangue é um produto perecível, há sempre a necessidade de seu reabastecimento (SILVA, 2021).

Os hemocentros e unidades de coleta e transfusão (UCT) possuem um papel de grande relevância no abastecimento dos hemocomponentes em diversos serviços de saúde, sendo o baixo nível de doações um risco para os estoques. Segundo Souza (2020), a pandemia trouxe diversos impactos no número de doações de sangue, trazendo também impactos no abastecimento de produtos sanguíneos e nos serviços de saúde.

De acordo com estimativa do Ministério da Saúde, os níveis de doação de sangue no Brasil durante pandemia sofreram uma redução de cerca de 15\% a 20\%, se comparados com o ano de 2019 (MINISTÉRIO DA SAÚDE, 2021a).

O sangue é considerado um elemento crucial para a vida humana, com impossibilidade de substituição. O ato de doar sangue é considerado voluntário e humanitário (OTERO et al., 2019). A doação de sangue se institui como uma prática valiosa em todo o mundo, um ato de extrema importância. Apesar da contínua evolução da ciência, saúde e tecnologia, o ato de doar sangue segue sendo necessário, pois o tecido sanguíneo não pode ser substituído (LEITE et al., 2021). 3 
Há uma constante preocupação das unidades hemoterápicas com os atendimentos e as necessidades de cada paciente. Existem diversos casos em que o paciente necessita de hemotransfusão, sendo ressaltados os casos de urgência, como acidentes graves, que necessitam de rápido atendimento, além dos pacientes que possuem doenças crônicas, consideradas graves, que requerem transfusões frequentemente, bem como os de indivíduos em hemodiálise, o que demonstra que as buscas por doadores são consideradas altas e constantes (LUDWING; RODRIGUES, 2005).

Somada à situação da redução do número de doações durante a pandemia, os profissionais que estão alocados em serviços hemoterápicos precisaram adotar diversas estratégias de prevenção à propagação do novo coronavírus, como o uso de equipamentos de proteção individual (EPI's) adicionais e incremento da higienização de superfícies, móveis e equipamentos, com o intuito de resguardar os profissionais e os doadores. Em muitos serviços também foram necessárias mudanças no hall de espera, garantindo o distanciamento entre as pessoas. Da mesma forma, alterações na gestão foram empregadas, a fim de garantir a adequação no número de pessoas, tempo de espera e horário de atendimento (MORAES; FONSECA; GALVÃO, 2020). Em alguns hemocentros foram registrados a suspensão dos atendimentos devido ao alto número de casos.

Nesse sentido, o presente artigo tem como objetivo discutir os principais efeitos da pandemia da Covid-19 em UCT's e hemocentros da região do sul do Estado de Minas Gerais, avaliando seus impactos na disponibilidade de bolsas de sangue e na gestão dos centros hemoterápicos. 0 conhecimento desses impactos no funcionamento, organização e gerenciamento das UCT's podem contribuir para um diagnóstico da situação regional e para a análise de estratégias que possam ser úteis para o enfrentamento dos desafios impostos pela pandemia nos serviços de saúde.

\section{MATERIAIS E MÉTODOS}

O presente trabalho adota como metodologia um estudo descritivo, transversal e de base institucional.

Primeiramente foi realizada uma revisão bibliográfica de artigos publicados entre os anos de 2005 e 2021. Em seguida, um questionário online foi aplicado aos profissionais responsáveis pela UCT e hemocentros da região do sul de Minas Gerais.

Os pontos norteadores para a presente pesquisa foram baseados nos principais apontamentos feitos por Souza (2020), em pesquisa que investigou as consequências das medidas de distanciamento social 
sobre a disponibilidade de sangue e a organização dos serviços hemoterápicos no início da pandemia de Covid-19 no Brasil, a partir de um banco dos sites das Hemorredes estaduais do Brasil.

Os dados foram coletados por meio de um questionário online realizado pela plataforma Google Forms, ocasião em que foi realizado contato telefônico, com o encaminhamento feito via postagem eletrônica (e-mail).

A amostragem ficou disponível entre 10 de agosto e 17 de setembro de 2021, sendo realizada nas seguintes cidades do sul de Minas Gerais: Alfenas, Boa Esperança, Caxambu, Itajubá, Passos, Poços de Caldas, São Lourenço, São Sebastião do Paraíso, Três Corações, Três Pontas e Varginha.

O questionário foi construído a partir de perguntas fechadas, contendo 11 (onze) questionamentos referentes à cidade em que se encontrava o UCT ou o hemocentro, às alterações nos níveis de estoque e doação de sangue, quais os fatores sanguíneos e plaquetários apresentaram maior escassez durante a pandemia, e quais estratégias na gestão foram adotadas no período da pandemia.

Após a coleta de dados, houve a elaboração de planilhas, disponíveis pelo programa Open Office (www.openoffice.org) para análise e confecção de gráficos, possibilitando a obtenção dos resultados e a comparação com outros trabalhos sobre o assunto pesquisado.

\section{RESULTADO E DISCUSSÃO}

Um total de 11 (onze) instituições da região Sul de Minas Gerais responderam ao questionário, sendo 8 (nove) caracterizadas como UCT, situadas nas cidades de Boa Esperança, Caxambu, Itajubá, São Lourenço, São Sebastião do Paraíso, Três Corações, Três Pontas e Varginha, e 3 (três) caracterizadas como hemocentro, localizadas nas cidades de Alfenas, Passos e Poços de Caldas.

A população das cidades que participaram do estudo totaliza cerca de um milhão de habitantes, segundo dados do Instituto Brasileiro de Geografia e Estatística (IBGE). Todos as instituições pesquisadas são vinculadas à Fundação Centro de Hematologia e Hemoterapia do Estado de Minas Gerais (HEMOMINAS), instituição vinculada à Secretária do Estado de Minas Gerais, cujo objetivo é direcionar todas as políticas relacionadas a hematologia e hemoterapia, garantindo assim a população todas as diretrizes que foram estabelecidas pela Política Estadual de Saúde, sendo elas a oferta de sangue e hemoderivados (HEMOMINAS, 2021a).

As unidades hemoterápicas e hemonúcleos são caracterizadas como órgãos essenciais para a saúde pública, tendo como finalidade a distribuição de resultados da captação para a manutenção do sistema 
de saúde (MARTINS et al., 2018). Já os hemocentros estuais e regionais são responsáveis pela captação e fornecimento de hemoderivados do sangue para instituições hospitalares através das unidades transfusionais. (BRASIL 2001).

Em grande parte dos países, a Covid-19 acarretou uma grande crise na saúde. O resultado das restrições sociais para combater sua disseminação foi a redução significativa nos números de doações de sangue (BARON et al., 2020).

Do total de UCT's e hemocentros da região Sul de Minas Gerais investigados, 81,8\% (9) relataram que os níveis de estoque sanguíneos reduziram em após o início da pandemia (Tabela 1).

Tabela 1. Alterações dos níveis de estoque sanguíneo durante a pandemia da Covid-19.

\begin{tabular}{lccc}
\hline & Hemocentro & UCT & Total \\
& $\%(\mathrm{n})$ & $\%(\mathrm{n})$ & $\%(\mathrm{n})$ \\
\hline \multicolumn{2}{l}{ Houve alteração nos níveis de estoque sanguíneo após o início da pandemia da Covid-19? } \\
\hline Não, o número se manteve & - & $12,5 \%(1)$ & $9,1 \%(1)$ \\
\hline Houve uma diminuição & $100 \%(3)$ & $75 \%(6)$ & $81,8 \%(9)$ \\
\hline Houve um aumento & - & $12,5 \%(1)$ & $9,9 \%(1)$ \\
\hline
\end{tabular}

Fonte: Os autores (2021).

Cabe destacar que os hemocentros são as instituições responsáveis pela captação de sangue, e os 3 hemocentros analisados relataram diminuição em seus estoques. Dentre as UCT's, que recebem os hemoderivados captados, para distribuição, 6 relataram diminuição em seus estoques, 1 afirmou não ter sofrido alteração e 1 relatou que seus estoques aumentaram na pandemia.

Tal cenário de redução nos níveis de estoque sanguíneo pode ser justificado pelas medidas de distanciamento social adotadas para controlar a propagação, pela transmissão do vírus e pelo medo da população em sair de casa, já que os centros de doações geralmente estão instalados em ambientes hospitalares. Segundo Souza (2020), os hemocentros dos estados de Alagoas, Rio de Janeiro, Amazonas e Maranhão relataram redução na doação de sangue no início da pandemia da Covid-19, chegando a uma redução de $35 \%$ no número total de doadores.

Em função da precipitada taxa de transmissão e contaminação pela Covid-19, a OMS orientou a implantação de ações de educação sanitária de cunho individual (lavagem das mãos, uso de máscaras de proteção e restrição social), ambiental (limpeza rotineira de ambientes e superfícies) e comunitária, 
como a restrição ou a proibição ao funcionamento de escolas e universidades, locais de convívio comunitário, transporte público, além de outros espaços onde pode haver aglomeração de pessoas (MALTA et al., 2020).

Para superar a pandemia, torna-se essencial a participação da população, através das orientações da OMS e de autoridades sanitárias locais sobre distanciamento social, uso de máscaras e sobre a vacinação (MASSARANI et al., 2021).

Além da necessidade do distanciamento social, seja por temor da agulha, falta de tempo ou até mesmo de informação, algumas pessoas acabam preterindo essa iniciativa, que pode salvar muitas vidas, pois a doação de sangue é um ato altruísta e voluntário, sendo levado em consideração que "as doenças continuam existindo apesar da pandemia" (FIOCRUZ, 2021).

Em relação ao período em que ocorreu alteração no número de doações e estoques, foi relatado por $54,5 \%$ (6) das instituições que a redução ocorreu ainda no 10 semestre de 2020 (Tabela 2), período coincidente com o início da pandemia da Covid-19, em que o mundo encontrava-se em uma situação inesperada, com a propagação rápida do vírus.

Tabela 2. Alteração nos níveis de doação

\begin{tabular}{lccc}
\hline & $\begin{array}{c}\text { Hemocentro } \\
\%(\mathrm{n})\end{array}$ & UCT & Total \\
& $\%(\mathrm{n})$ & $\%(\mathrm{n})$ \\
\hline $\begin{array}{l}\text { Quando foi observada uma alteração no número de doações e redução dos níveis de estoque de } \\
\text { bolsas de sangue? }\end{array}$ & & & \\
\hline Ainda no $1^{\circ}$ semestre de 2020 & $66,7 \%(2)$ & $50 \%(4)$ & $54,5 \%(6)$ \\
\hline No $2^{\circ}$ semestre de 2020 & $33,3 \%(1)$ & $12,5 \%(1)$ & $18,2 \%(2)$ \\
\hline Apenas em 2021 & - & $25,0 \%(2)$ & $18,2 \%(2)$ \\
\hline Houve um aumento & - & $12,5 \%(1)$ & $9,1 \%(1)$ \\
\hline
\end{tabular}

Fonte: Os autores (2021).

Segundo dados do Ministério da Saúde, em 2019, foram registrados cerca de 3,27 milhões de doações. Já no primeiro ano da pandemia do Covid-19, no país, foram registrados apenas 2,95 milhões de doações, uma queda de 11\% somente no 1o semestre de 2020 (Ministério da Saúde, 2021b).

Entre os meses de janeiro e julho de 2020 foi possível observar a necessidade de doadores de sangue devido à pandemia de Covid-19, com a imposição de desafios na construção de estratégias de adesão e de manutenção de potenciais doadores, exigindo que houvesse uma gestão para manter os já ativos, 
bem como para operacionalizar estratégias processuais e não imediatistas (SANTOS; GOMES; ANJO, 2021).

Em alguns centros hemoterápicos avaliados essa alteração nos níveis de estoque ou doação de sangue foi observada somente em 2021, já que com o avanço da pandemia o controle dos estoques ficou ainda mais difícil, sendo a falta de suprimento sanguíneo e a elevação no número de casos Covid-19 justificativas para tais dados. Souza (2020) relata que, após aumento no número de casos Covid-19, diversos centros hemoterápicos do país tiveram que suspender suas atividades, sendo impossível realizar a captação de sangue.

Apesar de na presente pesquisa não ter sido investigado resultados quantitativos do número de doações e bolsas de sangue em estoque, na visão dos gestores entrevistados, 81,8\% (9) dos hemocentros e UCT's analisados consideraram que as doações chegaram a um nível considerado crítico (Tabela 3)

Tabela 3. Nível de bolsa sanguíneas

\begin{tabular}{lccc}
\hline & Hemocentro & UCT & Total \\
& $\%(\mathrm{n})$ & $\%(\mathrm{n})$ & $\%(\mathrm{n})$ \\
\hline \multicolumn{2}{l}{ Os estoque de bolsas chegaram a ficar num nível considerado crítico? } \\
\hline Sim & $66,7 \%(2)$ & $87,5 \%(7)$ & $81,8 \%(9)$ \\
\hline Não & $33,3 \%(1)$ & $12,5 \%(1)$ & $18,2 \%(2)$ \\
\hline
\end{tabular}

Fonte: Os autores (2021).

Segundo Souza (2020), a diminuição no nível de doações de sangue é consequência das restrições sociais para combate da disseminação de casos da Covid-19. Isso se deve à rápida proliferação do vírus. Além disso, algumas unidades tiveram que suspender seus atendimentos em razão do aumento no número de casos e da falta de estrutura para atender com segurança a população.

Independentemente da própria Covid-19 ser um fator de grande desafio, há pacientes que apresentam diversas patologias/situações que necessitam do uso de sangue, como pessoas com câncer, bebês prematuros internados em Unidades de Terapias Intensivas (UTI's), gestantes que precisam de suporte hemorrágico durante o parto, doentes crônicos, pessoas com anemia falciforme, dentre outros. Os cuidados médicos continuam, o que carece, em alguns casos, de doações de sangue (IFF, 2020). 
Assim, demanda por suprimentos sanguíneos sempre vai existir, já que é um hemocomponente insubstituível, utilizado em diversas situações, inclusive as que demandam extrema urgência. A falta de transfusão sanguínea pode levar ao agravamento do quadro clínico do paciente e, em alguns casos específicos, ao óbito. A situação das UCT's mundiais se encontra em níveis críticos devido à crescente procura por transfusões sanguíneas. Vale ressaltar que há eventos diversos que induzem à demanda dos hemocomponentes do sangue, com destaque aos procedimentos cirúrgicos, desastres naturais e patologias (GREINACHER et al., 2007).

Avaliar os estoques sanguíneos, para igualar a demanda e a oferta não é uma função simples. Faz-se necessário garantir que os hemocomponentes estejam disponíveis quando forem solicitados em tempo hábil. Entretanto, é importante considerar que o produto é perecível e que a disponibilidade da matéria prima (sangue) para o processamento não é abundante (GURGEL; CARMO, 2014).

A situação da pandemia gerou um agravamento crítico dos estoques, com a falta de hemocomponentes sanguíneos considerado um problema estrutural de saúde pública. O Brasil precisa diariamente de aproximadamente 5500 (cinco mil e quinhentas) bolsas de sangue, sendo que, para atender a essa demanda, há a necessidade de mais doações (BUSS, 2005).

A Tabela 4 indica que, de acordo com 81,82\% (9) dos respondentes, os estoque sanguíneos ainda não foram normalizados. Contudo, já se percebe uma melhoria e, mesmo com a pandemia, muitos dos doadores não deixaram de fazer a sua parte e continuam a realizar esse ato tão importante.

Tabela 4. Situação atual dos hemocentros e UCT's.

\begin{tabular}{lccc}
\hline & $\begin{array}{c}\text { Hemocentro } \\
\%(\mathrm{n})\end{array}$ & $\begin{array}{c}\text { UCT } \\
\%(\mathrm{n})\end{array}$ & $\begin{array}{c}\text { Total } \\
\%(\mathrm{n})\end{array}$ \\
\hline \begin{tabular}{l} 
Fazendo uma análise ao longo da pandemia, como está a situação atual? \\
\hline Os níveis (estoque) já normalizaram
\end{tabular} & $33,3 \%(1)$ & $12,5 \%(1)$ & $18,2 \%(2)$ \\
\hline $\begin{array}{l}\text { Os níveis ainda não normalizaram mas já } \\
\text { melhoraram }\end{array}$ & $66,7 \%(2)$ & $87,5 \%(7)$ & $81,8 \%(9)$ \\
\hline $\begin{array}{l}\text { Os níveis estão melhores atualmente do } \\
\text { que era antes da pandemia }\end{array}$ & - & - & - \\
\hline
\end{tabular}

Fonte: Os autores (2021).

Informações sobre a falta de hemocomponentes nos estoques sanguíneos, em todo o Brasil, são comuns, o que gera, muitas vezes, adiamentos ou até mesmo cancelamentos de cirurgias urgentes. 
Levando isso em consideração, diversas campanhas são promovidas para a captação de doadores e para a reposição dos estoques sanguíneos, onde são determinadas metas para as coletas, com base em situações já vivenciadas e em documentações médicas (GURGEL; CARMO, 2014).

Antes da pandemia, diversas agências hemoterápicas já apresentavam escassez de suprimento sanguíneo, porém a Covid-19 potencializou a queda nos níveis de estoque sanguíneo.

Foi recomendado o cancelamento provisório de procedimentos cirúrgicos eletivos. Tal alternativa foi usada com o propósito de promover a segurança do paciente, já que para algumas cirurgias, consideradas complexas, faz-se necessária uma reserva de bolsa sanguínea, caso ocorra alguma intercorrência no ato cirúrgico (HOSPITAL PUC-CAMPINAS, 2020).

Em relação aos tipos sanguíneos, conforme evidenciado na Tabela 5, os tipos sanguíneos O positivo e O negativo são os que mais apresentam falta, segundo às instituições participantes do estudo, chegando em um nível considerado crítico, seguido do tipo sanguíneo $A B$ negativo.

Os resultados indicados foram compatíveis com o divulgado pela Fundação Hemominas (2021b), de que houve uma queda de cerca de $63 \%$ nos estoques de sangue do tipo 0 positivo e de $53 \%$ nos estoques dos grupos negativos, gerando grande preocupação, em razão do risco de desabastecimento sanguíneo no estado.

Tabela 5. Fatores sanguíneos que apresentam escassez durante a pandemia

\begin{tabular}{lccc}
\hline & Hemocentro & UCT & Total \\
& $\%(\mathrm{n})$ & $\%(\mathrm{n})$ & $\%(\mathrm{n})$ \\
\hline Quais são os fatores sanguíneos que apresentam maior escassez durante a pandemia & \\
\hline A POSITIVO & - & - & - \\
\hline A NEGATIVO & $66,7 \%(2)$ & $12,5 \%(1)$ & $27,3 \%(3)$ \\
\hline B POSITIVO & - & - & - \\
\hline B NEGATIVO & $33,3 \%(1)$ & - & - \\
\hline AB POSITIVO & - & $12,5 \%(1)$ & $81,8 \%(9)$ \\
\hline AB NEGATIVO & $33,3 \%(1)$ & $75 \%(6)$ & $100 \%(11)$ \\
\hline O POSITIVO & $100 \%(3)$ & $100 \%(8)$ & - \\
\hline O NEGATIVO & $100 \%(3)$ & & - \\
\hline
\end{tabular}

Fonte: Os autores (2021). 
Apenas $7 \%$ da população brasileira se enquadra na tipagem 0 negativo, que é considerado como doador universal, com utilização frequente em situações de extrema urgência, porém, o tipo $A B$ negativo é ainda mais raro, sendo encontrado somente em $1 \%$ da população (MEDICINA MITOS E VERDADE, 2019). Conforme informações da Fundação de Hematologia e Hemoterapia de Rondônia "não é a Covid-19 quem dita a demanda pelo sangue tipos O positivo e O negativo na UCT, muito menos, a redução do número de cirurgias e de acidentes no atual período de quarentena" (SOUZA, 2020)

Cabe destacar que o sangue doado, após coletado, passa por um processo separação em quatro tipos hemocomponentes, que serão utilizados em transfusões: concentrado de hemácias, concentrado de plaquetas, plasma fresco congelado e crioprecipitado; cada hemocomponente é usado para um tipo de situação, por isso é necessário estoque de todos eles (CRBM, 2021).

O concentrado de plaquetas é o segundo hemocomponente mais usado, ficando atrás somente do concentrado de hemácias. Seu uso é destinado ao tratamento de hemorragias geradas ou acompanhadas pela diminuição do número de plaquetas (DINIZ et al., 2001).

Segundo dados da Tabela 6, o fator plaquetário $O$ negativo e $O$ positivo são os que apresentam maior escassez, que é o tipo de sangue considerado raro, seguido do fator plaquetário A negativo.

Tabela 6. Fatores plaquetários que apresentam escassez durante a pandemia

\begin{tabular}{lccc}
\hline & Hemocentro & UCT & Total \\
& $\%(\mathrm{n})$ & $\%(\mathrm{n})$ & $\%(\mathrm{n})$ \\
\hline Quais são os fatores sanguíneos que apresentam maior escassez durante a pandemia \\
\hline A POSITIVO & - & $12,5 \%(1)$ & $9,1 \%(1)$ \\
\hline A NEGATIVO & $66,7 \%(2)$ & $37,5 \%(3)$ & $45,5 \%(5)$ \\
\hline B POSITIVO & - & $12,5 \%(1)$ & $9,1 \%(1)$ \\
\hline B NEGATIVO & $33,3 \%(1)$ & $12,5 \%(1)$ & $18,2 \%(2)$ \\
\hline AB POSITIVO & - & $12,5 \%(1)$ & $9,1 \%(1)$ \\
\hline AB NEGATIVO & $33,3 \%(1)$ & $25,0 \%(2)$ & $72,7 \%(8)$ \\
\hline O POSITIVO & $100 \%(3)$ & $62,5 \%(5)$ & $100 \%(11)$ \\
\hline O NEGATIVO & $100 \%(3)$ & $100 \%(8)$ & $(3)$ \\
\hline
\end{tabular}

Fonte: Os autores (2021). 
Em relação à demanda por transfusões sanguíneas durante a pandemia da Covid-19, é possível observar que cerca de 63,6\% (7) das unidades hemoterápicas relataram, na visão dos gestores, alterações na demanda dos serviços dessa natureza (Tabela 7).

Tabela 7. Alterações na demanda dos serviços hemoterápicos

\begin{tabular}{ccc}
\hline Hemocentro & UCT & Total \\
$\%(\mathrm{n})$ & $\%(\mathrm{n})$ & $\%(\mathrm{n})$ \\
\hline
\end{tabular}

Houve alteração na demanda pelos serviços hemoterápicos após a pandemia?

\begin{tabular}{lccc}
\hline Não houve alteração & $66,7 \%(2)$ & $12,5 \%(1)$ & $27,3 \%(3)$ \\
\hline A demanda diminuiu & - & $12,5 \%(1)$ & $9,1 \%(1)$ \\
\hline A demanda aumentou & $33,3 \%(1)$ & $75 \%(6)$ & $63,6 \%(7)$ \\
\hline
\end{tabular}

Fonte: Os autores (2021).

Países e regiões onde são realizados um maior número de procedimentos cirúrgicos, considerados avançados, como cirurgia cardíaca, transplantes de órgãos e quimioterapia, apresentam maior solicitação por sangue (SILVA; KUPEC; PERES, 2008).

No presente estudo, foi citado que houve aumento da demanda por transfusões sanguíneas, em que pese ter havido suspensão de muitas cirurgias eletivas (HOSPITAL PUC-CAMPINAS, 2020) e de a transfusão sanguínea não estar envolvida no tratamento de primeira linha de pacientes da Covid-19. Uma possível explicação pode ser o fato de que pacientes que apresentam a forma grave da doença podem apresentar distúrbios da coagulação, o que torna necessária a realização de transfusões sanguíneas. Como traz pesquisa de Lillicrap (2020), o SARS-Cov-2, em casos graves, influencia na chamada cascata/tempestade de citocinas que leva à ativação da cascata de coagulação, gerando fenômenos trombóticos. Também é citada a ligação entre parâmetros de coagulação anormais (dímero D e degradação de fibrina-produtos de distribuição).

Além da investigação a respeito dos níveis de estoques de bolsas de sangue, também foi questionado junto aos gestores dos hemocentros e UCT's quais mudanças e/ou estratégias foram necessárias para adaptar o serviço às mudanças provocadas pela pandemia da Covid-19. Os respondentes puderam assinalar quantas alternativas fossem necessárias, sendo os resultados apresentados na Tabela 8. 
Tabela 8. Gestão dos serviços hemoterápicos.

\begin{tabular}{|c|c|c|c|}
\hline & $\begin{array}{l}\text { Hemocentro } \\
\%(\mathrm{n})\end{array}$ & $\begin{array}{l}\text { UCT } \\
\%(n)\end{array}$ & $\begin{array}{l}\text { Total } \\
\%(\mathrm{n})\end{array}$ \\
\hline \multicolumn{4}{|c|}{$\begin{array}{l}\text { Sobre a gestão, organização e funcionamento do serviço hemoterápico, indique quais mudança } \\
\text { e/ou estratégias foram necessárias para adaptar o serviço às mudanças provocadas pela pandemia } \\
\text { da COVID-19 }\end{array}$} \\
\hline $\begin{array}{l}\text { Ampliação no horário de } \\
\text { funcionamento }\end{array}$ & 0 & $12,5 \%(1)$ & $9,1 \%(1)$ \\
\hline $\begin{array}{l}\text { Necessidade de } \\
\text { estabelecimento de novas } \\
\text { rotinas no serviço }\end{array}$ & $33,3 \%(1)$ & $62,5 \%(5)$ & $54,5 \%(6)$ \\
\hline $\begin{array}{l}\text { Alteração em POP'S } \\
\text { (Procedimento Operacional } \\
\text { Padrão) }\end{array}$ & 0 & $25,0 \%(2)$ & $18,2 \%(2)$ \\
\hline $\begin{array}{l}\text { Intensificação das } \\
\text { campanhas de doação }\end{array}$ & $66,7 \%(2)$ & $37,5 \%(3)$ & $45,5 \%(5)$ \\
\hline $\begin{array}{l}\text { Estabelecimento de novas } \\
\text { parcerias com instituições } \\
\text { para doações }\end{array}$ & 0 & 0 & 0 \\
\hline $\begin{array}{l}\text { Alteração/incorporação de } \\
\text { tecnologias de informação }\end{array}$ & $33,3 \%(1)$ & 0 & $9,1 \%(1)$ \\
\hline $\begin{array}{l}\text { Capacitação e treinamento } \\
\text { dos funcionários }\end{array}$ & $33,3 \%(1)$ & $50,0 \%(4)$ & $45,5 \%(5)$ \\
\hline $\begin{array}{l}\text { Alteração dos exames } \\
\text { realizados nas bolsas de } \\
\text { sangue }\end{array}$ & 0 & 0 & 0 \\
\hline
\end{tabular}

Fonte: Os autores (2021).

A pandemia transcorre por meio de um vírus respiratório, o que torna necessária a implementação de restrições de circulação de indivíduos (como bloqueios, quarentenas e toque de recolher), ações voluntárias (como distanciamento social e uso de máscaras de proteção), além de testagem de indivíduos para detecção de infectados e de medidas de monitoramento da pandemia, através de boletins epidemiológicos. O distanciamento e a quarentena são tópicos de grande dificuldade para alguns indivíduos (GARCIA et al., 2020).

De acordo com os dados da Tabela 8 é possível notar que ocorreram diversas mudanças e foram necessárias adequações por parte dos gestores de hemocentros e UCT's, como a redução da capacidade de atendimento, a intensificação nas campanhas de doação e de novas rotinas de serviço. 
A ampliação no horário de funcionamento foi uma alternativa usada por apenas uma instituição investigada (9,1\%). Tal ação pode contribuir para evitar a aglomeração de pessoas, pois, com o horário estendido, o número de pacientes é reduzido.

Com a queda no número de doações, 45,5\% dos centros hemoterápicos adotaram estratégias de intensificação das campanhas de doação. Desde o início da pandemia foram implementadas diversas campanhas de incentivo para a doação de sangue; uma delas é a campanha junho vermelho, uma iniciativa de instituições públicas e privadas para o incentivo da doação de sangue, sendo dia 14 de junho o dia mundial do doador de sangue (HEMOMINAS, 2020c).

Novas rotinas de trabalho foram implementadas a fim de gerar mais segurança para os colaboradores e pacientes, visto que o período enfrentado provocou diversas mudanças, sendo necessária a adaptação, para maior comodidade, sem deixar de exercer as atividades que são estabelecidas.

Apesar de todos os centros hemoterápicos terem citado algum tipo de mudança ou estratégia para se adaptar às mudanças provocadas pela pandemia da Covid-19, apenas 54,6\% (6) relataram ter havido necessidade de estabelecimento de novas rotinas no serviço, e somente $45,5 \%$ (5) afirmaram ter havido capacitação e treinamento dos funcionários.

Foi investigado quais as medidas de proteção (individual e coletiva) e organização do espaço físico para evitar a propagação e transmissibilidade do vírus foram adotadas pelos centros hemoterápicos (Tabela 9).

Tabela 9. Medidas de proteção contra a Covid-19

\begin{tabular}{lccc}
\hline & $\begin{array}{c}\text { Hemocentro } \\
\%(\mathrm{n})\end{array}$ & $\begin{array}{c}\text { UCT } \\
\%(\mathrm{n})\end{array}$ & $\begin{array}{c}\text { Total } \\
\%(\mathrm{n})\end{array}$ \\
\hline $\begin{array}{l}\text { Quais as medidas de proteção (individual e coletiva) e organização do espaço físico para evitar a } \\
\text { propagação e transmissibilidade do vírus foram adotadas? }\end{array}$ & $25,0 \%(2)$ & $100,0 \%(11)$ \\
\hline $\begin{array}{l}\text { Uso de óculos de proteção } \\
\text { Intensificação da } \\
\text { higienização das áreas e } \\
\text { superfícies }\end{array}$ & $100,0 \%(3)$ & $100,0 \%(8)$ \\
\hline $\begin{array}{l}\text { Maior disponibilização de } \\
\text { álcool em gel }\end{array}$ & $100,0 \%(3)$ & $87,5 \%(7)$ & $90,9 \%(10)$ \\
\hline $\begin{array}{l}\text { Adequação para } \\
\text { distanciamento social }\end{array}$ & $100,0 \%(3)$ & $62,5 \%(5)$ & $72,7 \%(8)$ \\
\hline
\end{tabular}

Fonte: Os autores (2021). 
Como medida de proteção contra a Covid-19, 27,3\% (3) das instituições estudadas implementaram o uso de óculos de proteção, um importante Equipamento de Proteção Individual (EPI), importante na eliminação dos riscos oferecidos por agentes biológicos. O equipamento é de uso exclusivo de cada profissional, passando por limpeza e desinfecção após seu uso

O uso de álcool em gel e a intensificação da higienização das áreas e superfícies foi adotado por todos os centros hemoterápicos estudados. Segundo Rossini (2020), o uso do álcool 70\% é recomendado para a eliminação de germes.

Como somente os hemocentros lidam diretamente com doadores, foi questionado somente com essas instituições se houve recomendação do uso de máscaras pelos doadores e medição da temperatura de todos que chegam à instituição, e todos os $100 \%$ (3) dos hemocentros afirmaram que adotaram tais medidas.

Conforme relatado por Ostroski e Pires (2020), as máscaras de proteção exercem uma barreira física para a liberação de gotículas no ar quando o indivíduo tosse, espirra e conversa. É importante fazer seu uso primordialmente em locais que é impossível o distanciamento social adequado. Apesar de ser eficaz, devem ser empregados outras medidas de proteção. O distanciamento social é uma medida tem por objetivo diminuir as interações sociais, ou seja, o contato físico entre os indivíduos, visto que o vírus é transmitido através de gotículas respiratórias, que exigem certa proximidade, com o distanciamento social é possível reduzir o número de transmissões.

Além disso, a Fundação Hemominas (2021d) possui plano estratégico em que são analisados cenários internos e externos, onde são dispostos todas as necessidades dos cidadãos e das demais partes (governo, sociedade, servidores, órgãos fiscalizadores). Tal plano é usado em situações como a que se vive atualmente, a pandemia da Covid-19. A fim de evitar o fluxo de doadores, foram implementadas diversas medidas para manter a segurança, sendo eles o atendimento somente mediante agendamento, avaliação das condições de saúde, tendo o doador não apresentado nenhum sintoma gripal, o doador deve comparecer a unidade de doação com cerca de 15 minutos de antecedência do horário marcado para doação e também medidas de higienização, como uso de álcool nas mãos em qual doador ou pessoa que for adentrar na unidade e a adoção de distanciamento social tendo como distância mínima 1 metro.

Todas estas medidas são necessárias para evitar a propagação do vírus, visto que seu contágio ocorre de forma rápida. A saúde e a segurança da população devem ser levados sempre em consideração. 


\section{CONSIDERAÇÕES FINAIS}

A pandemia da Covid-19 gerou diversas reflexões, sendo uma delas como a escassez de suprimentos sanguíneos. Foi possível observar que a pandemia impactou na disponibilidade de bolsas de sangue, com redução dos níveis de estoque, nos centros hemoterápicos do Sul de Minas Gerais.

Além disso, houve também impacto na gestão dessas instituições, sendo necessária a reorganização dos serviços hemoterápicos, para que assim a assistência fosse mantida. Entre as mudanças e estratégias para adaptar o serviço às mudanças provocadas pela atual pandemia, destaca-se a necessidade de estabelecimento de novas rotinas nos serviços, intensificação de campanhas de doação e treinamento e capacitação de funcionários, para que a assistência fosse mantida de maneira segura.

A pandemia da Covid-19 causou impactos em todo mundo, em que foi necessário priorizar a segurança dos pacientes e dos colaboradores, sem deixar de prestar um serviço hemoterápico de excelência visto que, mesmo com a pandemia, os suprimentos sanguíneos continuam sendo necessários,

O diagnóstico da situação dos centros hemoterápicos da região sul de Minas Gerais reforça a necessidade de constante discussão em relação às ações necessárias para o enfrentamento da pandemia da Covid-19, e pode fornecer subsídios para a elaboração de políticas de saúde pública.

Por fim, sugerem-se estudos que abordem de forma quantitativa a redução do número de doações de sangue e estoques de bolsas de sangue durante a pandemia da Covid-19, além de investigações adicionais acerca das causas de tais impactos nos centros hemoterápicos. 


\section{REFERÊNCIAS}

BRASIL. Resolução RDC no 151, de 21 de agosto de 2001. Aprova o "Regulamento técnico sobre níveis de complexidade dos serviços de hemoterapia" constante do anexo desta Resolução. Órgão emissor: ANVISA - Agência Nacional de Vigilância Sanitária Disponível em:

https://bvsms.saude.gov.br/bvs/saudelegis/anvisa/2001/res0151_21_08_2001.html

BARON, D.M; FRANCHINI, M; GOOBIE, S.M; JAVIDROOZI, M; KLEIN, A.A; LASOCKI, S; LIUMBRUNO, G.M; MUNOZ, M; SHANDER, A; SPAHN, D.R; ZACHAROWSKI, K; MEYBOHM, P. Patient blood management during the COVID-19 pandemic: a narrative review. Anaesthesia 2020, 75, p. 1105-1113.

BUSS, D. Sangue: fluido da vida, parte 5. 1. ed. São Paulo: Sala Comunicações, 2005.

CRUZ, Montezuma. Secom - Governo de Rondônia. Com estoque de O positivo e negativo baixo, Fhemeron convoca doadores na capital. Disponível em: https://www.tudorondonia.com/ Secom Governo de Rondônia noticias/com-estoque-de-o-positivo-e-negativo-baixo-fhemeron-convocadoadores-na-capital,48322.shtml. Acesso em: 22 agosto de 2021.

CONSELHO REGIONAL DE BIOMEDICINA. Da doação à transfusão: o caminho do sangue. Porto Alegre. Disponível em:

https://crbm5.gov.br/da-doacao-a-transfusao-o-caminho-

dosangue/\#: :text=Separa\%C3\%A7\%C3\%A3o\%20dos\%20hemocomponentes\%20Ap\%C3\%B3s\%20a\% 20coleta\%2C\%20cada\%20bolsa,em\%204\%20componentes\%3A\%20hem\%C3\%A1cias\%2C\%20plaquet as\%2C\%20plasma\%20e\%20crioprecipitado. Acesso em 22 de setembro de 2021.

DINIZ, E.M.A; ALBIERO, A.L; CECCON, M.E.J; VAZ, F.A.C. Uso de sangue, hemocomponentes e hemoderivados no recém-nascido. Jornal de Pediatria - Vol. 77, Supl.1, 2001.

ERICKSON, M. L., Champion, M. H., Klein, R., Ross, R. L., Neal, Z. M., \& Snyder, E. L. (2008). Management of blood shortages in a tertiary care academic medical center: the yale-new haven hospital frozen blood reserve. Transfusion, 48(10), 2252-2263. http://dx.doi.org/10.1111/j.1537-2995.2008.01816.x. Pmid:18631164.

LIMA, E. FIOCURZ. Bancos de sangue estão com estoque baixo na pandemia. Disponível em: https://portal.fiocruz.br/noticia/bancos-de-sangue-estao-com-estoque-baixo-na-pandemia-1. Acesso em 08 de outubro 2021.

GARCIA. P.J, Alarco A, Bayer A, Buss P, Guerra G, Ribeiro H, Rojas K, Saenz R, Snyder NS, Solimano G, Torres R, Tobar S, Tuesca R, Vargas G, Atun R. COVID-19 Response in Latin America. Am J Trop Med Hyg 2020; 103(5):1765-1772.

GREINACHER, A., FENDRICH, K., ALPEN, U. e HOFFMANN, W. Impact of demographic changes on the blood supply: mecklenburg-West Pomerania as a model region for Europe. Transfusion, v. 47, n.3, p. 395-401, 2007.

GURGEL, J. L. M; CARMO, B. B. T. Dimensionamento do estoque de derivados de sangue em um hemocentro do brasil baseado em um modelo de gestão de estoques e previsão de demanda. Revista Produção Online, Florianópolis, SC, v.14, n. 1, p. 264-293, jan./mar. 2014. 
HEMOMINAS. Missão e Valores. 2021a. Belo Horizonte. Disponível em: http://hemominas.mg.gov.br/a-hemominas/sobre-nos/missao-e-valores. Acesso em 19 de setembro de 2021.

HEMOMINAS. Convocação de doadores de sangue. 2021b. Belo Horizonte. Disponível em: http://www.hemominas.mg.gov.br/destaques/3272-convocacao-de-doadores-de-sangue-2. Acesso em: 19 de setembro de 2021.

HEMOMINAS. Junho Vermelho: a importância da doação de sangue em tempos de pandemia. 2021c. Belo Horizonte. Disponível em:http://hemominas.mg.gov.br/banco-de-noticias/3047-junhovermelho-a-importancia-da-doacao-de-sangue-em-tempos-de-pandemia. Acesso: 20 de setembro de 2021.

HEMOMINAS. Planejamento Estratégico.2021d. Belo Horizonte. Disponível em:

http://hemominas.mg.gov.br/a-hemominas/conheca/planejamento-estrategico. Acesso em 20 de setembro de 2021.

HOSPITAL PUC CAMPINAS. Retomada segura de cirurgias eletivas durante a pandemia de covid-19. Campinas. PROT - 0171 / Rev. 00 / Data: 19/06/2020 / Página 1 de 8. Disponível em: file:///C:/Users/anacl/Desktop/TCC\%20-\%20ARTIGOS/PROT-0171-RETOMADA-SEGURA-DE-

CIRURGIAS-ELETIVAS-DURANTE-A-PANDEMIA-DE-COVID-19.pdf. Acesso em: 19 set. 2021.

INSTITUTO NACIONAL DE SAÚDE DA MULHER, DA CRIANÇA E DO ADOLESCENTE FERNANDES FIGUEIRA (IFF). As pessoas precisam de sangue mesmo durante uma pandemia. Dados de 2020. Rio de Janeiro. Disponível em: http://www.iff.fiocruz.br/index.php/8-noticias/684-doacaodesangue

LEITE, Jussara et al. Impactos do Covid-19 em relação a doação de sangue no hemocentro coordenador de Porto Velho-RO (Estudo comparativo no ano de 2019 e 2020). v. 1 n. 2 (2020): Mostra de Inovação e Tecnologia São Lucas - Afya Educacional, 2021.

LEITÃO, Céu. COVID-19: Impacto nos serviços de sangue e de medicina transfusional. Saúde e Tecnologia, Escola Superior da Tecnologia da Saúde de Lisboa, SAÚDE \& TECNOLOGIA. OUTUBRO. P. e22-e28, 2020.

LILLICRAP, D. Pathological evidence of pulmonary thrombotic phenomena in severe COVID-19. Journal of thrombosis and haemostasis, 2020.

LUDWING, Silvia; RODRIGUES, ALZIRO. Doação de sangue: uma visão de marketing. Cad. Saúde Pública, Rio de Janeiro, 21(3):932-939, mai-jun, 2005.

MALTA, D.C; GOMES, C.S; SILVA, A.G; CARDOSO, L.S.M; BARROS, M.B.A; LIMA, G; JUNIOR, P.R.B.S; SZEARCWALD, C.L. Uso dos serviços de saúde e adesão ao distanciamento social por adultos com doenças crônicas na pandemia de COVID-19, Brasil, 2020. Ciência \& Saúde Coletiva, 26(7):2833-2842, 2021.

MARTINS, M. H; COSTA, J.V.L; NICOLETTI, R; CAMPOS, V. H; RODRIGUES, A.G; SILVA, J.B.M. A Importância do Banco de Sangue no Cenário Hemoterápico. 2020. 
MASSARANI, L; MENDES, I.M; FAGUNDES, V; POLINO, C; CASTELFRANCHI, Y; MAAKAROUN, B. Confiança, atitudes, informação: um estudo sobre a percepção da pandemia de COVID-19 em 12 cidades brasileiras. Ciência \& Saúde Coletiva, 26(8):3265-3276, 2021.

MEDICINA MITOS E VERDADES. São Paulo. 2019. Disponível em: https://www.medicinamitoseverdades.com.br/blog/tipos-sanguineos-e-fator-rh-diferencas-ecompatibilidade-para-doacao. Acesso em: 20 agosto 2021.

MINISTERIO DA SAUDE. 2021a. Pátria Voluntária estimula doação com a campanha "Bora doar Sangue. 2021a. Brasília: Ministério da Saúde, Secretaria de Atenção à Saúde, Departamento de Atenção Especializada e Temática, 2021. Disponível em: https://www.gov.br/pt-br/noticias/assistenciasocial/2021/03/patria-voluntaria-estimula-doacao-com-a-campanha-201cbora-doar-sangue201d.

Acesso em: 20 agosto 2021.

MINISTERIO DA SAÚDE. Agência Nacional de Vigilância Sanitária (ANVISA). 2021b. Campanha incentiva a doação de sangue. Disponível em: https://www.gov.br/pt-br/noticias/saude-e-vigilanciasanitaria/2021/06/campanha-incentiva-a-doacao-de-sangue. Acesso em: 20 de setembro de 2021.

MORAES, C.M.G. A experiência de profissionais atuantes na triagem clínica de candidatos a doação de sangue de um serviço público de hemoterapia diante da pandemia de covid-19. Hematologia, transfusão e terapia celular. v.42.s1.p.513, 2020.

OSTROSKI, K.C; PIRES, L, E.B; SALVI, E.S. F, FLORIANI, F.M. G; POMPERMAIER, C; BARRINOUEVO, V. Importância do uso da máscara durante a pandemia de covid-19: relato de experiência. ANUÁRIO PESQUISA E EXTENSÃO UNOESC XANXERÊ - 2020.

OTERO, LORENA; MARQUES, Ermelinda; SANTOS, Alba-Helena; GONZÁLEZ, Raquel; IGLESIA, Josefa. Conhecimento de estudantes portugueses de enfermagem sobre doação de sangue. Acta Paul Enferm. 2020; eAPE20190166.

ROSSINI, M. C. Por que você não deve fazer álcool gel caseiro. Super Interessante. Publicado em 2020. Disponível em: https://super.abril.com.br/saude/por-que-voce-nao-deve-fazer-alcool-gel-caseiro/. Acesso em 07 maio de 2021.

SCHIROLI, D; MEROLLE, L; MOLINARI, G; BARTOLOMEO, E.D; SELIGARDI, D; CANOVIL, L; PERTINHEZ, T.A; MANCUSO, P; ROSSI, P.G; BARICCHI, R; MARRACCINI, C. The impact of COVID-19 outbreak on the Transfusion Medicine Unit of a Northern Italy Hospital and Cancer Centre. Vox Sanguinis. 2021, p. 18.

SILVA, Marua et al. Programa "sangue bom": estratégias de mobilização para captação de doadores de sangue durante a pandemia da covid-19. Expressa Extensão. ISSN 2358-8195, v. 26, n. 1, p. 318327, Jan./Abr., 2021.

SILVA, R.M.G; KUPEK, E; PERES, K.G. Prevalência de doação de sangue e fatores associados em Florianópolis, Sul do Brasil: estudo de base populacional. Cad. Saúde Pública, Rio de Janeiro, 29(10):2008-2016, out, 2013.

SANTOS, J. I. L; GOMES, E.F; ANJO, J.E.S. marketing social para doação de sangue em tempos de pandemia de covid-19 na cidade de Maceió/al. Revista de Administração Hospitalar e Inovação em Saúde Vol. 18, n. Edição Especial. Belo Horizonte, MG, 2021. 
SOUZA, Mariluce. Medidas de distanciamento social e demandas para reorganização dos serviços hemoterápicos no contexto da Covid-19. Ciência \& Saúde Coletiva, 25(12):4969-4978, 2020.

WANG, X; CAIL, X; REN, M; CHEN, F; LI, L; LEIL, H. Blood transfusion during the Covid-19 out break. Blood Transfus.2020; 18(2):79-82.

YUKI; FUJIOGI; KOUTSOGIANNAKI. COVID-19 pathophysiology: A review. Clinical Immunology 215 (2020) 108427, 2020. 


\section{Capítulo 17}

\section{doi $10.37423 / 211104957$}

\section{AVALIAÇÃO DO GRAU DE CONHECIMENTO EM ALUNAS DE ÂMBITO UNIVERSITÁRIO SOBRE A CANDIDÍASE VULVOVAGINAL}

Milena Oliveira

Ana Clara Mendes

Hadassa Cristhina de Ażevedo dos Santos

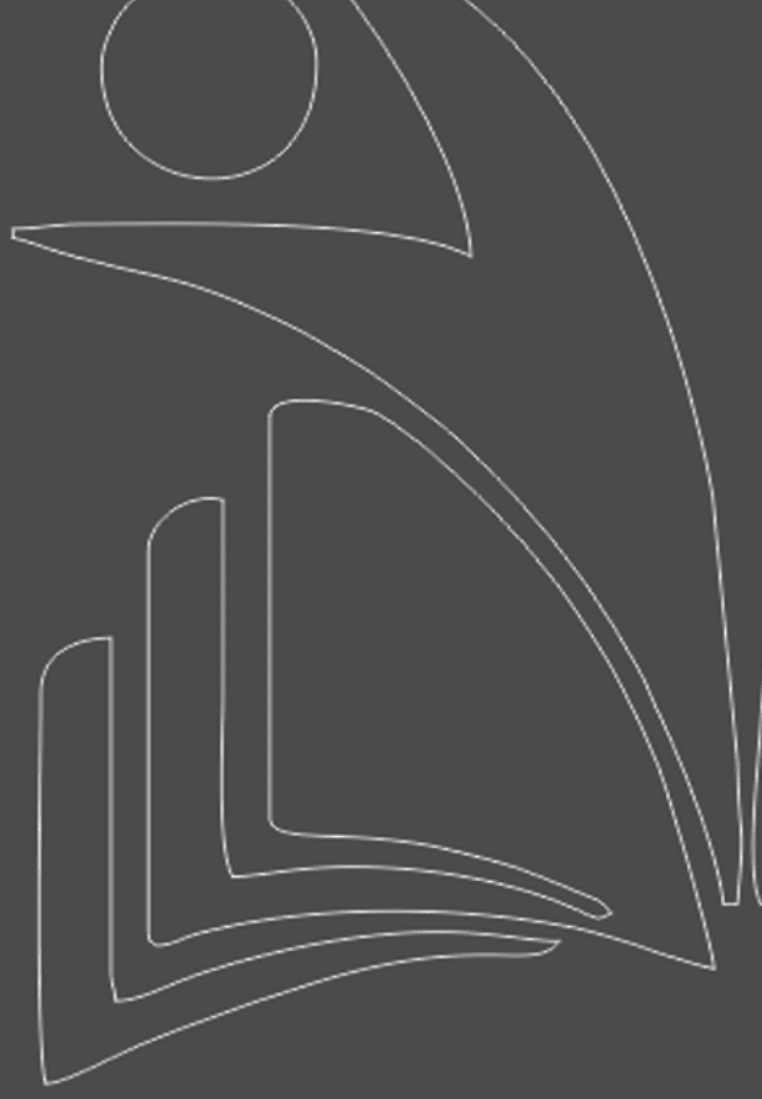

CENTRO UNIVERSITARIO DO SUL DE MINAS

CENTRO UNIVERSITARIO DO SUL DE MINAS

CENTRO UNIVERSITARIO DO SUL DE MINAS

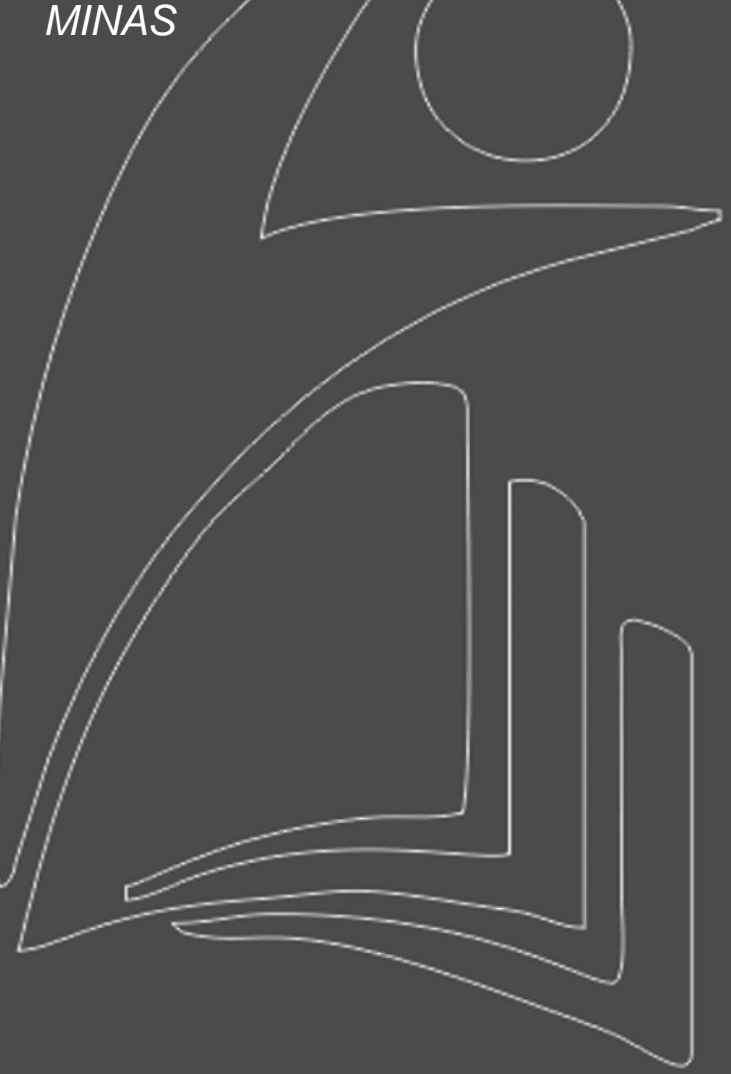


Resumo: A candidíase vulvovaginal (CVV) é a infecção da vulva e da vagina, que aflige milhares de mulheres pelo mundo, comumente causada pelo fungo do gênero cândida. O desconforto característico associado à venda livre de antifúngicos pode explicar o alto índice de automedicação, e tem causado preocupação aos profissionais de saúde devido ao crescente número de casos. Este trabalho analisa o grau de conhecimento em alunas de âmbito universitário sobre a candidíase vulvovaginal. Tal abordagem se faz necessária devido ao tratamento inadequado com automedicação e as consequências mais agravantes do quadro, assim como seus hábitos pessoais. O propósito foi obtido mediante questionário aplicado no Sul de Minas Gerais, a 122 alunas, via Google Forms. Das entrevistadas, evidenciou-se que o percentual de alunas que possuem conhecimento foi de $92,62 \%$ (113) com prevalência na faixa etária de 20 a 29 anos. A minoria relatou nunca ter tido algum episódio da infecção vulvoginal na vida e apenas $33(27,04 \%)$ voluntárias afirmaram não apresentarem a doença. O hábito não saudável é um dos maiores fatores contribuintes para o desencadeamento da CVV e se faz presente em 19,67\% (24). A sintomatologia regular das entrevistadas, desde corrimento vaginal a ocorrência de coceira e ardor, irritação, dor no ato sexual, dores ao urinar, dentre outros fatores visto que variaram de sintomas fortes e leves com predomínio nos intermediários representando $64,75 \%$ (79). Quanto às medidas tomadas para o tratamento, há uma diferença significativa entre as que afirmam tratamento com antifúngicos, sendo elas $81,53 \%$ (159). Subtotal de 195, frente aos resultados de métodos utilizados, visto que as mesmas utilizam mais de um método de tratamento, tratando-se de métodos caseiros com estimativa de 18,46\% (36).

Palavras-chave: Candidíase Vulvovaginal. Fatores de Riscos. Prevalência. 


\section{INTRODUÇÃO}

A candidíase vulvovaginal (CVV) é a infecção da vulva e vagina que afeta milhares de mulheres pelo mundo. É causada pelo crescimento excessivo de leveduras do gênero Cândida, microrganismos comensais que colonizam a mucosa vaginal, mas podem tornar-se patogênicos sob determinadas condições que alteram o ambiente vaginal. O gênero Cândida é composto por aproximadamente 200 espécies diferentes de leveduras colonizando inúmeros nichos corporais (YANO et al., 2019). A CVV é a segunda causa de vaginite mais comum (SASANI et al., 2021). É mais comumente causada pelo fungo Cândida albicans, responsável por $85 \%$ a $90 \%$ dos casos. Esse fungo é encontrado tradicionalmente na mucosa vaginal, gastrointestinal e oral. (LOPEZ, 2015; SOARES et al., 2019).

C. albicans é um fungo dimórfico, que se apresenta sob formas leveduriformes (blastoconídios) no estado saprofítico, estando associado à colonização assintomática; ou como formas filamentosas (pseudo-hifas e hifas verdadeiras), observadas em processos patogênicos. Além disso, sob condições de crescimento subótimas, nesse fungo pode ocorrer a formação de clamidósporos (esporos arredondados que possuem uma espessa parede celular). Dessa forma, o fungo tem a capacidade de se adaptar a diferentes nichos biológicos, podendo ser considerado, a rigor, um organismo pleomórfico (ALVARES et al., 2007).

Os principais sintomas são corrimento vaginal, coceira e ardor, irritação. No entanto, os sinais e sintomas podem variar desde lesões superficiais em pessoas saudáveis até infecções difusas em pacientes neutropênicos (com baixos níveis de neutrófilos) (ALVARES et al.,2007). Segundo o estudo de Carvalho e colaboradores (2020), a maioria das candidíases vulvovaginais não são complicadas e respondem a vários esquemas terapêuticos. Todavia, observa-se a instalação da forma recorrente do agravo em 5\% das mulheres (FISCHER, 2012). O agente etiológico pode ser transmitido por meio de contato com mucosas e secreções da pele de portadores ou infectados, contato sexual, água contaminada e transmissão vertical durante o parto normal (SOARES et al., 2019).

Os hábitos alimentares estão entre os fatores que interferem na imunidade do indivíduo e têm capacidade de facilitar ou inibir o crescimento do fungo. Por passar a maior parte do dia fora de casa, a praticidade acarreta o aumento do consumo de alimentos ultra processados, ricos em carboidratos simples e açúcares. Essa se predispõe como consequência da ausência de tempo para se dedicar a uma boa alimentação, provocando uma alteração no pH intestinal, o que facilita a proliferação dos fungos e o favorecimento a manifestação da candidíase (YANO et al., 2019; SILVA et al.,2020) 
Nas situações de candidíase vulvovaginal, as parcerias só precisam ser tratadas se apresentarem sintomas. Entretanto, é necessário enfatizar a importância do aconselhamento das parcerias sexuais. O diagnóstico de IST (Infecção Sexualmente Transmissível), diferentemente das infecções endógenas ou iatrogênicas, implica a necessidade de orientação e tratamento das parcerias sexuais. É importante avaliar a percepção da mulher quanto a existência de corrimento vaginal fisiológico e recomendar a investigação de outras IST (CARVALHO et al., 2020).

Para a manifestação da CVV recorrente, frequentemente é prescrito um tratamento antifúngico mais prolongado. No tratamento local, preconiza-se uso do clotrimazol (2 cápsulas de $100 \mathrm{mg}$ ), duas vezes por semana durante seis meses ou uso tópico de terconazol (0.8\%) com aplicação de $5 \mathrm{~g}$ durante sete dias. O tratamento oral engloba o uso de: cetoconazol (2 cápsulas de $200 \mathrm{mg}$ ) durante cinco dias após a menstruação, durante seis meses ou o uso de fluconazol (150 mg), administrados durante um mês ou ainda o uso de itraconazol $(200 \mathrm{mg}$ ) durante trinta dias. Após esse período, a terapia é descontinuada. Caso haja recidiva, reinicia-se o tratamento, com regime de supressão, seguido de manutenção por um ano (LEAL et al., 2016).

O tratamento da CVV tem por objetivo, melhorar a sintomatologia da paciente, podendo ser efetuado por via oral ou tópica. No tratamento oral, a paciente pode se beneficiar de agentes imidazólicos e triazólicos: Fluconazol 150 mg em dose única e Cetoconazol 200mg uma vez ao dia, por 14 dias. Já o tratamento tópico, deve ser via intravaginal com uso de Clotrimazol 1\% durante 7 dias, Terconazol 0.8\% aplicação de $5 \mathrm{~g}$ durante três dias e o ácido bórico (600 mg/supositório) duas vezes ao dia, por 14 dias. Não há consenso sobre a superioridade de um medicamento em relação ao outro, devido à escassez de publicações sobre as atividades dos antifúngicos mais utilizados. Porém, é relatada na literatura, a ocorrência de reações adversas com o uso de antifúngicos, principalmente naqueles de administração via oral, tais como: dor vaginal, infecção do trato urinário, insônia, ansiedade, desconforto gastrointestinal, disúria, dentre outros (LEAL et al., 2016).

No estudo de Furtado e colaboradores (2018), amostras de 144 pacientes foram coletadas no período de outubro de 2010 a maio de 2011 em São Luís do Maranhão. Dessas amostras, 90 mulheres (62,5\%) tiveram culturas positivas para leveduras do gênero Cândida, com maior prevalência das espécies $C$. parapsilosis (43,3\%), C. glabrata (16,7\%) e C. albicans (15,6\%). As demais espécies, C. tropicalis, C. famata, C. krusei, C. sake e C. globosa apresentaram frequência isolada inferior a $10 \%$ dos casos.

Apesar de a CVV representar um problema global de saúde pública, sua incidência real é desconhecida, pois não é considerada uma doença de notificação compulsória às autoridades de saúde. Além disso, 
o diagnóstico é realizado baseado nos sinais e sintomas, sem qualquer teste confirmatório e a prática da automedicação com medicamentos de venda livre, contribuem para dificultar ainda mais a determinação da incidência (SOARES et., 2019).

O estudo teve como objetivo aplicar e analisar um questionário em mulheres em ambiente universitário sobre a candidíase vulvovaginal, a fim de obter informações sobre o conhecimento das mulheres sobre a infecção e analisar a prevalência das manifestações e quais os métodos de tratamento utilizados.

(Graduada pelo Centro Universitário do Sul de Minas). milena-oliveira251@hotmail.com

\section{MATERIAIS E MÉTODOS}

Trata-se de um estudo de base populacional no qual foram entrevistadas 122 alunas universitárias via Google Forms acima de 17 anos, residentes de cidades localizadas na região sudeste do Brasil.

O questionário online (APÊNDICE A) foi composto por questões como o conhecimento sobre a candidíase e o fungo causador da infecção, a probabilidade de ser transmitida sexualmente (IST), idade, quantidade de episódios causados pela candidíase, sintomas, a intensidade dos sintomas, medidas de tratamento, se foram tratadas por ca partir de prescrição médica ou por conta própria, com antifúngicos ou métodos caseiros, hábitos alimentares, e o entendimento frente aos principais fatores de riscos para proliferação de fungos. O questionário elaborado na plataforma Google Forms e enviado à população através de redes sociais. Os dados foram organizados em planilhas no Excel para análise e confecção de gráficos.

\section{RESULTADOS}

Foram analisadas as informações de 122 universitárias de 17 a 49 anos com idade média de 25 anos. A prevalência de mulheres que possuem algum conhecimento sobre a infecção foi de 92,62\% (113), enquanto 7,37\% (9) não possuíam conhecimento. Destas 9,01\% (11) tem de 17 a 19 anos, 78,68\% (96) 20 a 29 anos, 6,55\% (8) 30 a 39 anos, 5,73\% (7) 40 a 49 anos. (Figura 1). O percentual de mulheres que compreendem que a candidíase vulvovaginal é causada por um fungo foi de 90,16\% (110), e 9,83 (12) não possuíam essa informação.

Das entrevistadas 86,06\% (105) se atentam que a candidíase vulvovaginal é comumente considerada uma das infecções genitais femininas mais comuns, afetando $75 \%$ das mulheres ao menos uma vez na vida, e 13,93\% (17) não sabiam. Os dados informam também que 90,16\% (110) mulheres consideram 
a candidíase uma infecção sexualmente transmissível (IST) e 9,83\% (12) afirmaram que não consideram. Em relação aos episódios de candidíase, 41,80\% (51) tiveram ao menos 1x em 12 meses, 12,29\% (15) tiveram ao menos 2x em 12 meses, 18,85\% (23) tiveram 3x ou mais em 12 meses, e 27,04\% (33) nunca tiveram candidíase. Houve prevalência em ao menos 1x em 12 meses com 41,80\% (51) dos casos. De acordo com os dados obtidos, nota-se que as participantes afirmaram terem tido mais de um sintoma. Sintomas dos quais se mostraram de fase intermediários com significância de 64,75\% (79). No presente estudo 50\% (61) possuem hábitos saudáveis, 19,67\% (24) não possuem, e 30,32\% (37) afirmaram que os hábitos são regulares.

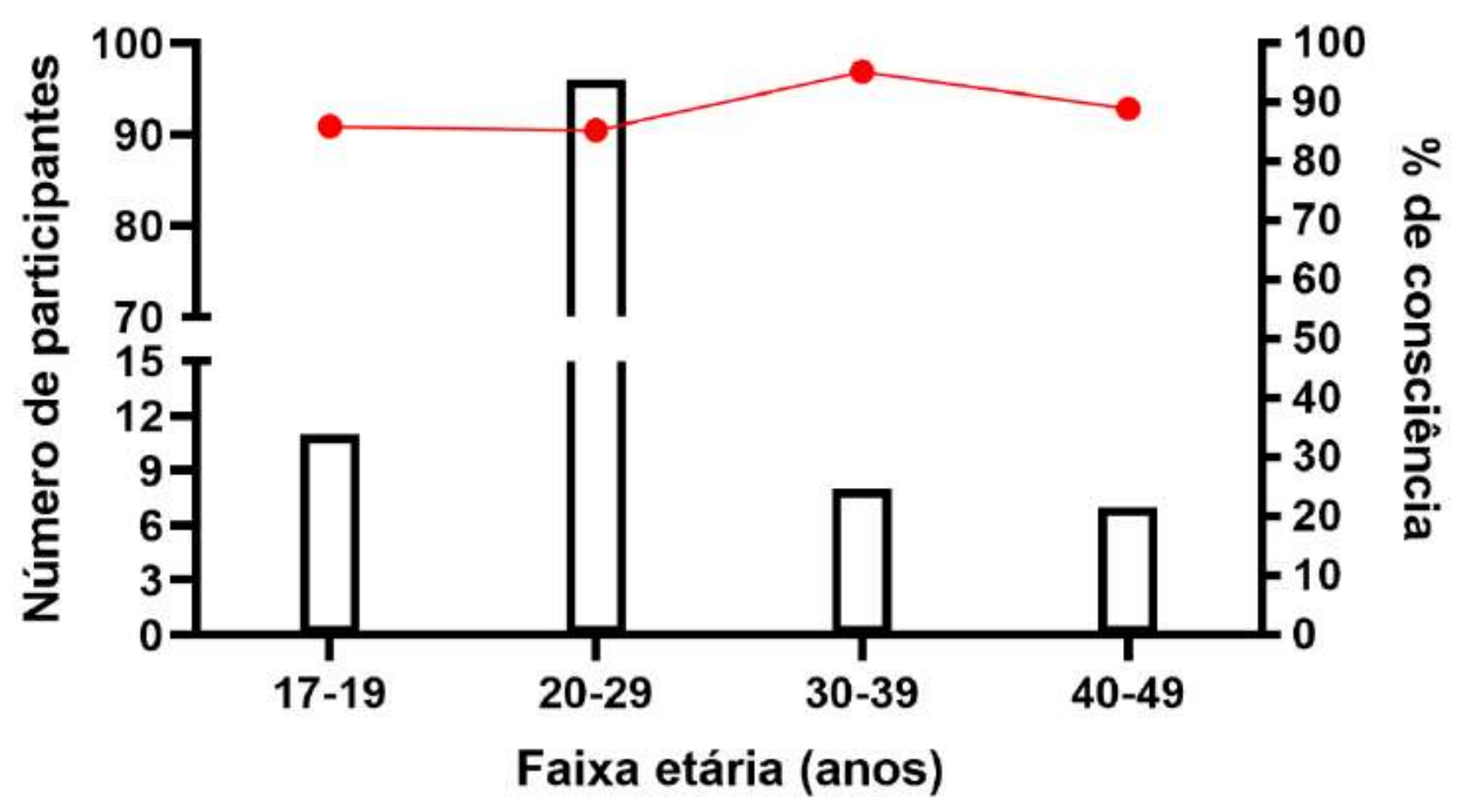

Figura 1- Resultado do conhecimento das mulheres entrevistadas de acordo com a faixa etária.

\section{Fonte: Os autores}

Com relação a todas as informações disponíveis acerca da relação de sintomatologia neste estudo notou-se que as manifestações clínicas mais citadas da candidíase vulvovaginal foram corrimento vaginal, 24,75\% (119), coceira e ardor, 22,86\% (110), irritação, 21,20\% (102) com queixas mais frequentes, seguidas de dor vulvovaginal, dor no ato sexual, dores ao urinar seguidas de um percentual total de $31,18 \%$ (150). A Figura 2 mostra o resultado da porcentagem de sinais e sintomas de acordo com a faixa etária. 
Faixa etária 17 à 19 anos

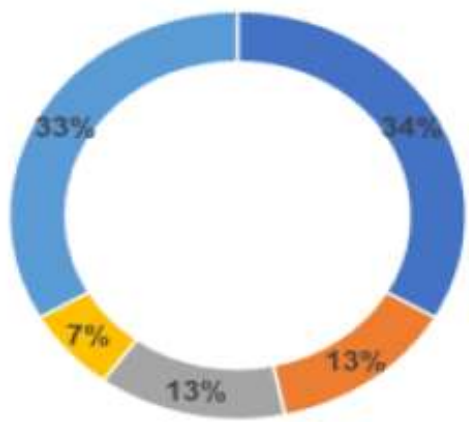

Faixa etária 30 à 39 anos

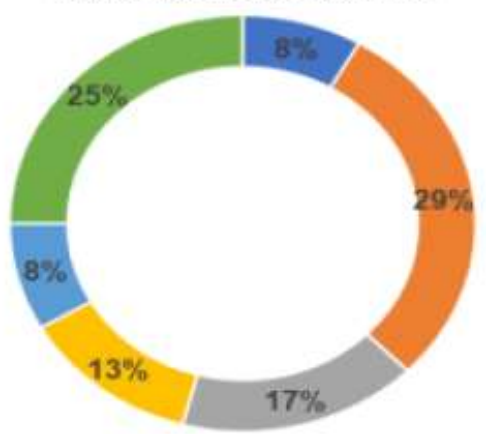

Faixa etária 20 à 29 anos

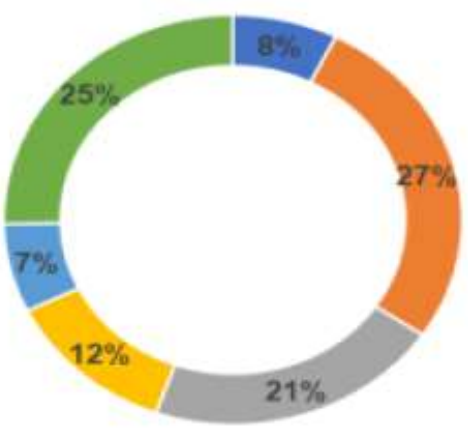

Faixa etária 40 à 49 anos

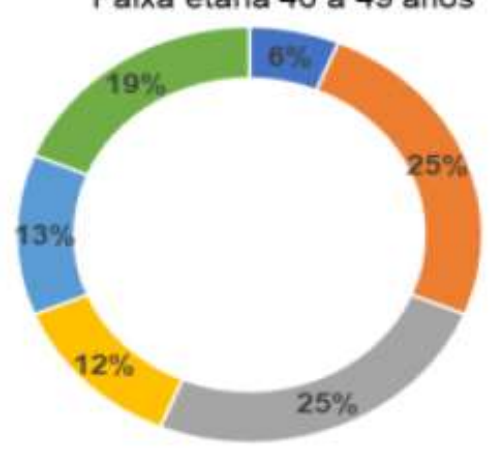

- Dor vulvovaginal

- Coceira e ardor

= Irritaçẵo

= Dor no ato sexual

- Dores ao urinar

- Corrimento vaginal

Figura 2- Sintomatologia das voluntarias de acordo com faixa etária. Fonte: Os autores.

Os métodos de tratamentos de maior prevalência foram com antifúngicos, visto que 53,17\% (109) consultaram o médico ginecologista, e $24,39 \%$ (50) sem consentimento do especialista, a automedicação com métodos caseiros esteve com índice de 17,56\% (36), e apenas 4,87\% (10) não realizaram tratamento. Com base nos resultados obtidos, pode-se observar que as entrevistadas utilizam ao menos duas formas de tratamento para a infecção fúngica. Foram citados alguns métodos caseiros, medicamentos orais ou injetáveis, os quais as participantes mostraram-se utilizarem mais de um deles, conforme mostrado na Tabela 1.

Tabela 1. Métodos mais utilizados para o tratamento. Fonte: Os autores. 


\section{Medicamentos orais e injetaveis}

\section{Fluconazol}

Secnidazol

Metronidazol

Gino Canesten

Nistatina

\section{Métodos caseiros}

Banho de assento com vinagre, camomila e bicarbonato

\section{Takil}

\section{Sabonete de barbatimão}

Ducha Higienica

\section{Oleo de coco}

\section{Yakut}

\section{DISCUSSÃO}

O presente estudo propôs analisar o grau de conhecimento em alunas de âmbito universitário sobre a candidíase vulvovaginal, a partir de um questionário que forneceu dados relevantes. A diferença quanto ao isolamento de Cândida spp. a partir da mucosa vaginal pode ser explicada por hábitos culturais de diferentes regiões, especialmente no que se refere às práticas de higiene, pois este fator está diretamente relacionado à autocontaminação, visto que a levedura pertence à microbiota normal do trato gastrointestinal (FURTADO et al., 2018).

Os dados encontrados na literatura referente à infecção da vulva e a vagina, causada pelo crescimento excessivo de leveduras é considerada a segunda causa mais comum de infecção genital em mulheres de idade reprodutiva (SOARES et al., 2019). Dessa forma, é necessário salientar que esta pesquisa 
atingiu universitárias com média de 25 anos, mas de predomínio com faixa etária entre os 20 à 29 anos, o que não difere da revisão de literatura com abordagem para Candida albicans.

Os estudos de Soares e colaboradores (2019) informam que o gênero Cândida constitui o principal grupo de leveduras que causam infecções oportunistas em seres humanos e compreende aproximadamente 200 diferentes espécies, sendo que cerca de 10\% são associadas a infecções, em indivíduos saudáveis. E nesse estudo foi possível observar que a maioria das mulheres - 105 (86,06\%) - obtém conhecimento de que cerca de $75 \%$ das mulheres apresentam, durante a sua vida, pelo menos um episódio de candidíase vulvovaginal.

Foi possível observar uma quantidade muito baixa de estudantes que nunca apresentaram nenhum episódio de candidíase, evidenciando dessa forma que a grande maioria das mulheres entrevistadas, apresentaram sintomas que são indícios de uma possível infecção, ao menos uma vez na vida. Muitas mulheres articulam a candidíase ao corrimento e sua espessura, e assim iniciam um tratamento inadequado, onde na realidade esses sintomas podem ser indicativos de outras infecções, portanto, há grande importância em fazer um acompanhamento periódico com um médico ginecologista especialista.

Com relação a todas as informações disponíveis acerca da relação de sintomatologia notou-se que as manifestações clínicas mais observadas da candidíase vulvovaginal nessa pesquisa foram significativas para fase intermediária. Os sintomas se intensificam no período pré-menstrual, quando a acidez vaginal aumenta.

A transmissão sexual também é aceita, o que torna a CVV uma doença sexualmente transmissível (IST). Tanto fatores locais como sistêmicos podem contribuir para a invasão tecidual por $C$. albicans e por leveduras não-C. albicans. Sua intensa multiplicação no canal vaginal é favorecida por uma série de fatores predisponentes. Do ponto de vista do hospedeiro, a colonização prévia por levedura e a posterior diminuição da capacidade de resposta imunológica observada em doenças imunossupressoras, diabetes millitus (DM), gestantes e usuárias crônicas de corticóides parecem favorecer a infecção. Ainda parecem contribuir o uso de antibióticos, estrogenoterapia, pequenos traumas como o ato sexual, hábito de usar roupas muito justas ou de fibras sintéticas, além da dieta alimentar muito ácida. A utilização de antibióticos pode incrementar tanto a colonização quanto a infecção por cândida (ÁLVARES et al., 2007).

Embora a percentagem de pacientes com os principais sinais e sintomas da candidíase vulvovaginal seja elevada, o diagnóstico clínico é apenas sugestivo, devendo ser confirmado por testes 
laboratoriais, pois manifestações similares podem ser causadas por outros agentes infecciosos ou por condições ligadas ao hospedeiro (BOATTO et al., 2007).

Para confirmação a relação entre o status de melhoramento da qualidade de vida das mulheres visto que a grande maioria possui hábitos alimentares saudáveis, com resultados significativos de $50 \%$ (61), acerca de hábitos regulares e não saudáveis temos a quantidade em conjunto de também 50\% (61) pode-se dizer que destas, a probabilidade de interferência em qualidade de vida das mulheres jovens, afeta sua saúde mental, física e sexual. É necessário para a clínica médica saber diferenciar a suspeita de candidíase vulvovaginal e a real infecção por Candida. A suspeita dá-se pelos sinais e sintomas da doença, que muitas vezes podem ser gerais de outras infecções vaginais, já a infecção por Cândida é confirmada pela cultura, que é considerada como o diagnóstico com maior sensibilidade e especificidade utilizado na prática clínica. Logo, não é indicado iniciar o tratamento a partir da suspeita médica, mas sim da confirmação, a fim de evitar o sobrediagnóstico ou o subdiagnóstico e o consequente tratamento errôneo da doença. Dessa forma, torna-se possível melhorar o prognóstico da doença, além de reduzir as chances de recorrência da mesma e, com isso, aumentar a qualidade de vida dos indivíduos acometidos (FUKAZAWA et al., 2019; ARAUJO, 2020).

De acordo com Fukazama (2018), qualidade de vida é uma noção particularmente humana, que no sentido mais objetivo, se relaciona com o grau de satisfação encontrado em ambientes familiares, sociais, vida amorosa e o que agrada ao indivíduo. Subentende-se a presença de todos os elementos que a determinada sociedade considera como seu padrão de conforto e bem-estar.

\section{CONSIDERAÇÕES FINAIS}

Levando-se em consideração os aspectos analisados com os resultados obtidos pela pesquisa, os dados foram satisfatórios tendo em vista que o conhecimento das mulheres é positivo, mas que não deixa de ser um problema. As afirmações acerca da literatura não diferem do presente projeto. Visto que as informações consideram a doença, que pode ser grave, interferentes na qualidade de vida de milhões de mulheres, sendo considerada um problema de saúde pública mundial.

Embora tais condições sejam tão relevantes, o público-alvo da atual pesquisa utiliza-se da automedicação sendo eles antifúngicos ou métodos caseiros sem prescrição médica, que podem agravam e promovem a persistência da infecção, assim como hábitos e comportamentos inadequados acerca de higiene e vestuários íntimos. 
Tais achados reforçam a necessidade de consulta médica ao especialista ginecologista que pode indicar um tratamento mais adequado, diminuindo a probabilidade de desenvolvimento de resistência a antifúngicos e evitando o agravamento da infecção. Além disso, é necessário um aprimoramento mais amplo e inovador que faça com que as mulheres mudem seus hábitos, para impedir a proliferação do agente causador. 


\section{REFERÊNCIAS}

ALVARES, Cassiana Aparecida et al. Candidíase vulvovaginal: Fatores predisponentes do hospedeiro e virulência das leveduras. Bras Patol Med Lab v. 43 n. 5 p. 319-327 outubro 2007. Disponível em: <https://www.scielo.br/j/jbpml/a/zv8qWLFBRYXNHykbx7QK3Yk/?format=pdf\&lang=pt> Acesso em: 18.ago.2021.

ARAUJO, Isabela Macêdo. Caracterização sistemática da resposta imune à infecção por Candida. Braz. J. Hea. Rev., Curitiba, v. 3, n. 2, p. 3788-3803 mar./apr. 2020. Disponível em: <https://www.brazilianjournals.com/index.php/BJHR/article/view/9325> Acesso em: 19.set.2021.

BOATTO, Humberto Fabio et al. Correlação entre os resultados laboratoriais e os sinais e sintomas clínicos das pacientes com candidíase vulvovaginal e relevância dos parceiros sexuais na manutenção da infecção em São Paulo, Brasil. Rev Bras Ginecol Obstet. 2007; 29(2). Disponível em: <https://www.scielo.br/j/rbgo/a/tSGKbyCCkpTLmvrcz77fkVx/?lang=pt > Aceso em: 25.ago.2021.

CARVALHO, Newton Sérgio et al. Protocolo Brasileiro para infeç̧ões sexualmente transmissíveis 2020: infecções que causam corrimento vaginal. Epidemiol. Serv. Saude, Brasília, 30(Esp.1):e2020593, 2021. Disponível em: <https://www.scielo.br/j/ress/a/X9WkLLZRBbcW3mFwbRYBHXD/?lang=pt> Acesso em: 18.ago.2021.

FISCHER, G. Chronic vulvovaginal candidiasis: What we know and what we have yet to learn. Australasian Journal of Dermatology, v. 53, n. 4, p. 247-254, 2012.

FUKAZAWA, E. I. et al. Influence of recurrent vulvovaginal candidiasis on quality of life issues. Archives of Gynecology and Obstetrics, n. 0123456789, p. 1-4, 2019.

FURTADO, Haryne Lizandrey Azevedo et al. Fatores predisponentes na prevalência da candidíase vulvovaginal. Rev. Investig, Bioméd. São Luís, 10(2): 190-197, 2018. Disponivel em: $<$ https://www.researchgate.net/profile/Thayomara-

Silva/publication/332459077_FATORES_PREDISPONENTES_NA_PREVALENCIA_DA_CANDIDIASE_VUL VOVAGINAL/links/603f9c614585154e8c74eee1/FATORES-PREDISPONENTES-NA-PREVALENCIA-DACANDIDIASE-VULVOVAGINAL.pdf> Acesso em: 25.ago.2021.

LOPEZ, J. E. M. Candidiasis vulvovaginal. Clinical Evidence, v. 03, n. 815, p. 1-23, 2015.

LEAL, Mariana Robatto Dantas et al. Tratamento da candidíase vulvovaginal e novas perspectivas terapêuticas: uma revisão narrativa. Revista Pesquisa em Fisioterapia. 2016 Nov;6. Disponível em: <https://www5.bahiana.edu.br/index.php/fisioterapia/article/view/1021> Acesso em: 19.set.2021.

SASANI, E. et al. Vulvovaginal candidiasis in Iran: A systematic review and meta-analysis on the epidemiology, clinical manifestations, demographic characteristics, risk factors, etiologic agents and laboratory diagnosis. Microbial Pathogenesis, v. 154, n. March, p. 104802, 2021.

SOARES, Dagmar Mercado et al. Candidíase vulvovaginal: Uma revisão de literatura com abordagem para candida albicans. V.25,n1,pp.28-34 (Dez 2018 - Fev 2019). Disponível em: <https://www.mastereditora.com.br/periodico/20181204_202650.pdf>

YANO, J. et al. Current patient perspectives of vulvovaginal candidiasis: Incidence, symptoms, management and post-treatment outcomes. BMC Women's Health, v. 19, n. 1, p. 1-9, 2019. 


\section{Capítulo 18}

\section{doi $10.37423 / 211104969$}

\section{CONHECIMENTO, EXPECTATIVAS E PREFERÊNCIAS DOS HOMENS SOBRE O CÂNCER DE PRÓSTATA E O TOQUE RETAL}

Geraldo de Azevedo Souza

Matheus de Azevedo Souza

José Fernandes Neto

Victor de Azevedo Souza

Lucas Praxedes Barreto

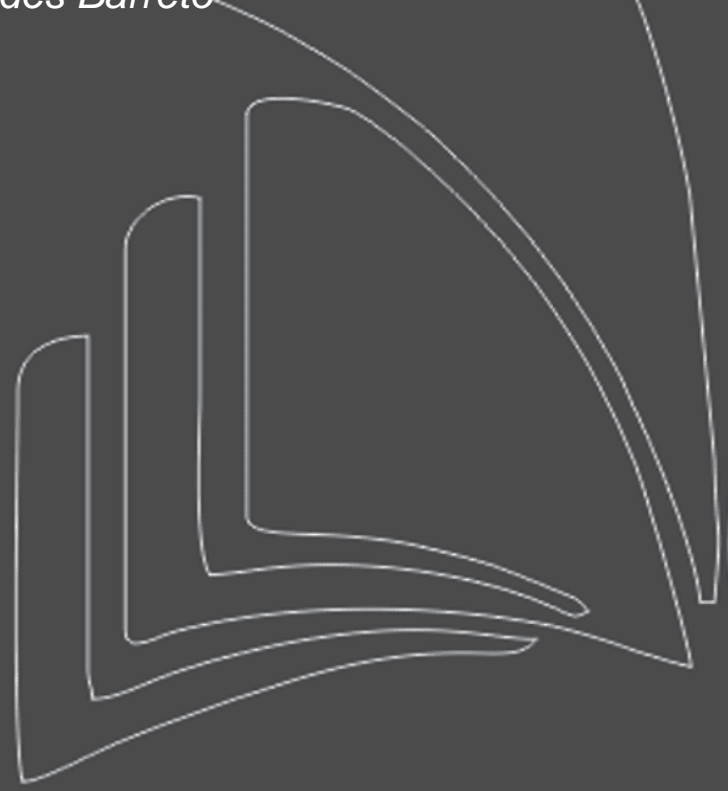

Centro Universitário Christus

Centro Universitário Christus

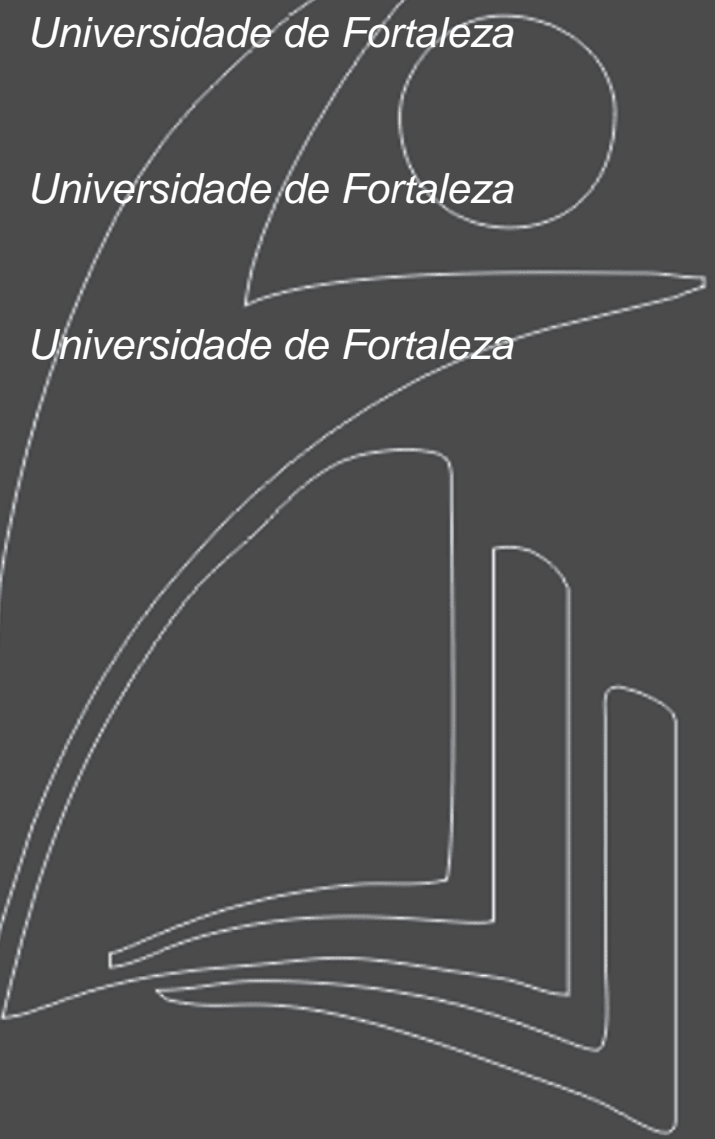




\section{INTRODUÇÃO:}

O Câncer de Próstata ( $\mathrm{CaP}$ ) é o tipo de câncer mais prevalente em homens, no Brasil, representando cerca de $33 \%$ de todos os novos tipos de neoplasias diagnosticadas. Ademais, configura a segunda causa de mortalidade oncológica. Desde modo, o rastreio e diagnóstico precoce para esta patologia se torna a única forma de redução da mortalidade. Entretanto, diversas circunstâncias interferem na adesão ou atrasam a realização do exame preventivo do CaP, principalmente atrelados ao toque retal, são exemplos: vergonha, constrangimento, desinformação, preconceito e desconhecimento sobre a doença e o exame. Em vista disso, a exclusão de tais estigmas é imprescindível, para que ocorra o diagnóstico precoce, objetivando melhores prognósticos.

\section{OBJETIVOS:}

Identificar as impressões pessoais a respeito do exame do toque retal, a posição preferível do paciente para a realização do toque retal e aferir o conhecimento dos pacientes em relação aos fatores de risco para o câncer de próstata.

\section{MÉTODOS:}

Trata-se de um estudo transversal realizado em um ambulatório de urologia, onde os pacientes do sexo masculino, responderam a um questionário preparado previamente. As perguntas contidas no questionário tratavam sobre a identificação do paciente, impressões iniciais sobre o exame de toque retal, conhecimento acerca de fatores de risco para o CaP, posição de toque retal mais aceita.

\section{RESULTADOS:}

O estudo obteve um amostra de 40 pacientes, entre 19 e 80 anos de idade. Os principais resultados foram: $75 \%$ dos pacientes possuíam impressões positivas em relação ao exame do toque retal, enquanto $15 \%$ possuíam impressões negativas. A posição do toque retal, em que os pacientes declaravam sem mais confortável foi a posição de Sims (45\%), seguida pela posição litotômica (25\%) e posição genu-peitoral (17,5\%). Por fim, $72,5 \%$ dos pacientes conheciam pelo menos um fator de risco para $\mathrm{CaP}$, sendo os mais reconhecidos: história familiar $(52,5 \%)$, idade $(47,5 \%)$ e tabagismo $(42,5 \%)$. 


\section{CONCLUSÃO:}

Os pacientes apresentaram certo conhecimento sobre os dois principais fatores de risco para o câncer de próstata. E se demonstraram complacentes com a realização da prevenção e do toque retal, caso seja necessário. Entretanto, a posição no qual o toque retal será realizada, deve ser perguntado previamente ao paciente. Convém ainda, permanecer com os programas de conscientização e, quiçá, elaborar novas estratégias no tocante a disseminação da prevenção do câncer de próstata e esclarecimentos sobre o toque retal, um exame tão estigmatizado. Em virtude do diagnóstico precoce do câncer de próstata, para reduzir a morbi-mortalidade relacionada.

Palavras-Chave: Neoplasias da Próstata; Urologia; Programas Nacionais de Saúde. 